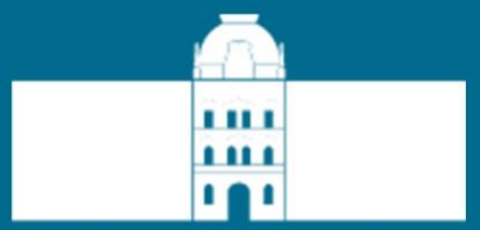

University of Maribor

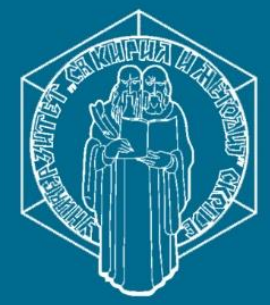

Advances in Production and Industrial Engineering

\author{
Editors: \\ dr. Franc Čuš \\ dr. Valentina Gecevska
}




\section{กิ1 \\ กิกิ \\ 101}

University of Maribor Press 


\section{University of Maribor Press}

All rights reserved. No part of this book may be reprinted or reproduced or utilized in any form or by any electronic, mechanical, or other means, now known or hereafter invented, including photocopying and recording, or in any information storage or retriveal system, without permission in writing from the publisher.

Title: $\quad$ Advances in Production and Industrial Engineering

Editors: $\quad$ prof. dr. Franc Čuš (University of Maribor, Faculty of Mechanical Engineering), prof. dr. Valentina Gecevska (Ss. Cyril and Methodius University in Skopje, Faculty of Mechanical Engineering)

Review: $\quad$ prof. dr. Ivo Pahole (University of Maribor, Faculty of Mechanical Engineering), prof. dr. Mirko Ficko (University of Maribor, Faculty of Mechanical Engineering)

Cover design: University of Maribor Press

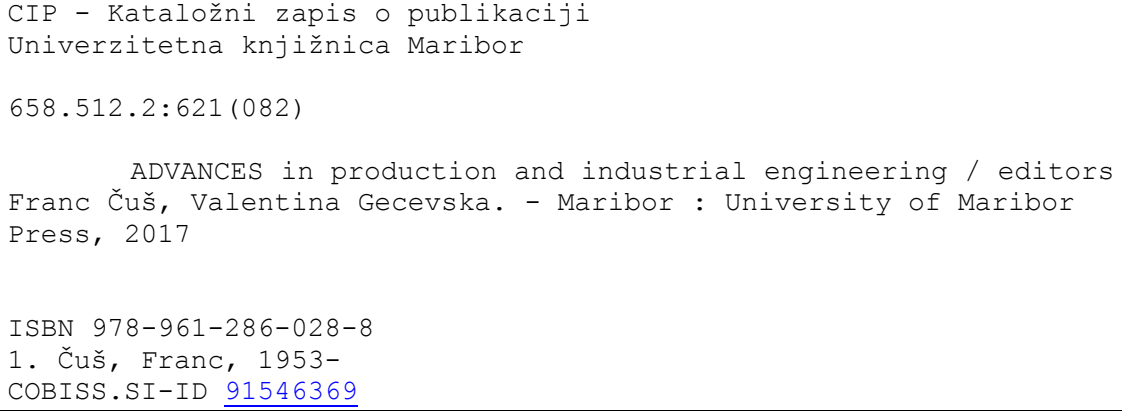

First published in 2017 by

University of Maribor Press

Slomškov trg 15, 2000 Maribor, Slovenia tel. +386225042 42, fax +38622523245

http://press.um.si, zalozba@um.si

\section{Co-published by}

University of Maribor, Faculty of Mechanical Engineering

Smetanova ulica 17, 2000 Maribor, Slovenia tel. +386222075 00, faks +38622207990

http://www.fs.um.si, fs@um.si

Price: free copy

\section{For publisher:}

prof. dr. Igor Tičar, rector (University of Maribor) 



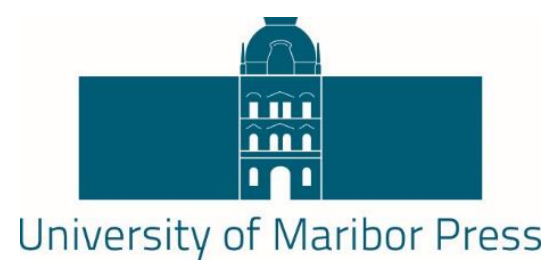

Advances in Production and Industrial Engineering

Editors:

dr. Franc Čuš

dr. Valentina Gecevska

April 2017 



\title{
Advances in Production and Industrial Engineering
}

\author{
FRANC ČUŠ \& VALENTINA GECEVSKA
}

\begin{abstract}
This publication, scientific monograph, offers comprehensive chapter series from scientific researchers conducted by regional authors, authorities in the fields and summarizes the principal scientific contributions. The chapters deal with range topics from optimization techniques in production development, quality in production processes, product and process development, technologies for business development and factors of social and economic development. Edited by two editors with contributions from chapters' authors, this scientific monograph presents advanced topics for students, educators and practitioners. The editors would like to thank all chapters' authors for devoting of the research results and expertise with the great enthusiasm. We encourage all of them to continue successful highly valuable cooperation, between Faculty of Mechanical Engineering at the University of Maribor and Faculty of Mechanical Engineering at the Ss. Cyril and Methodius University in Skopje.
\end{abstract}

Keywords: - production engineering - industrial engineering • product development $\bullet$ process control $\bullet$ business development $\bullet$

Correspondence Adress: Franc Čuš, Ph.D., Full Professor, University of Maribor, Faculty of Mechanical Engineering, Smetanova ulica 17, 2000 Maribor, Slovenia, e-mail: franc.cus@um.si. Valentina Gecevska, Ph.D., Full Professor, „Ss. Cyril and Methodius” University in Skopje, Faculty of Mechanical Engineering-Skopje, Rudger Boshkovikj bb, Skopje 1000, Republic of Macedonia, e-mail: valentina.gecevska@mf.edu.mk.

https://doi.org/10.18690/978-961-286-028-8 ISBN 978-961-286-028-8

(C) 2017 University of Maribor Press

Available at: http://press.um.si. 



\section{Table of Contents}

Part I - METHODS FOR INDUSTRIAL DEVELOPMENT 1

Chapter 1: Risk Evaluation in Project Planning 3

Bojan Ačko, Zvonko Kremljak \& Borut Buchmeister

Chapter 2: Analysis of Visual Methods for more Effective Simulation

Aleksandra Simonovska, Bojan D. Jovanoski, Robert Minovski \& Valentina Gecevska

Chapter 3: Advanced Methods for Job Shop Scheduling

Borut Buchmeister, Robert Ojsteršek \& Iztok Palčič

Part II - METHODS FOR PRODUCTION 51

DEVELOPMENT

Chapter 4: Visual Cutting Chips Size Monitoring in Milling

Processes

Marko Reibenschuh \& Uroš Župerl

Chapter 5: Mathematical Models with Feedback for Surface

Roughness Parameter Prediction in Longitudinal Turning

Mite Tomov, Mikolaj Kuzinovski \& Piotr Cichosz

Chapter 6: Tool Wear Compensation in End Milling Based on Cutting Force Measuring and Tool Visual Monitoring Franc Čuš, Tomaž Irgolič \& Uroš Župerl

Chapter 7: Comparative Mathematical Modelling of Cutting 107 Tool Wear and Cutting Tool Life Prediction for Two Milling Machines

Valentina Gecevska, Mikolaj Kuzinovski, Franc Čuš \& Mite Tomov

\section{Part III - TECHNIQUES IN PRODUCTION DEVELOPMENT}

Chapter 8: A Linguistic Model Based on if-then Rules for Cutting Force Predictions in End Milling Franc Čuš, Uroš Župerl, Tomaž Irgolič \& Zoran Pandilov 
Chapter 9: Design Guidelines in Developing a Prototype using Additive Manufacturing Methods

Ognen Tuteski \& Atanas Kochov

Chapter 10: Teaching-learning Based Optimization 147 Algorithm for Cutting Force Maximization in end Milling Processes

Uroš Župerl, Franc Čuš \& Tomaž Irgolič

Part IV - METHODS FOR SOCIAL AND ECONOMIC DEVELOPMENT

Chapter 11: Innovation Partners of Macedonian Companies 163

Bojan R. Jovanovski, Ivana Stankovska, Radmil Poleankovikj \& Ines Šuh

Chapter 12: Assessment of Alternatives for Natural Gas Supply in Macedonia versus Technical Indicators

Daniela Mladenovska \& Atanas Kochov

Chapter 13: Nursing in Support to Maintain the Health of 181 Machine Tool Operator

Petra Klanjšek \& Jadranka Stričević

Part V - EDUCATION IN SOCIAL AND ECONOMIC DEVELOPMENT

Chapter 14: The Educational Model for Occupational Safety 195 Expert

Jasmina Caloska \& Trajce Velkovski

Chapter 15: Status - quo of Macedonian Entrepreneurship 207

Education System in 2016

Liljana Polenakovikj \& Radmil Poleankovikj

Part VI - OTHER TECHNIQUES FOR INDUSTRY DEVELOPMENT

Chapter 16: Modeling of Liquid Nitrogen Thermal Influence of Inconel 718

Matija Hriberšek, Franci Pušavec \& Janez Kopač

Chapter 17: Optimization of Single Pass Welding of High Carbon Bainitic Steel

Peter Kirbiš, Tomaž Vuherer, Tomaž Irgolič \& Ivan Anžel 
Chapter 18: Microstructure and Properties of Kinetically Activated Bainite (KAB) Steels

Peter Kirbiš, Ivan Anžel, Tomaž Irgolič \& Mihael Brunčko

Editorial review 
iv $\mid$ Advances in Production ANd IndUstrial ENGINEERING 
ADVANCES IN PRODUCTION AND INDUSTRIAL ENGINEERING

F. Čuš \& V. Gecevska

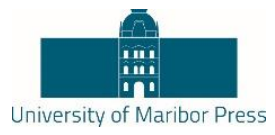

\section{Part I - METHODS FOR INDUSTRIAL DEVELOPMENT}





\title{
Chapter 1
}

\section{Risk Evaluation in Project Planning}

\author{
BOJAN AČKO, ZvONKO KREMLJAK \& BORUT BUCHMEISTER
}

\begin{abstract}
Risk management is one of the key project management processes performed in the initial project planning. The risk management process includes many steps, described in the chapter. Claims management is one of the most important challenges in large projects and linked with many financial losses. In the research, all frequent claims are identified in a piping project. Probabilistic claims are evaluated by questionnaire aimed at calculation of probability percentage and also probability of success. In order to determine reliability of questionnaire, statistical test of internal consistency coefficient was applied. Result of the present study is to quantify claims in implementation phase of piping projects and finally by analysing cost effects. Difference between probability of final project cost before and after application of claim indicates a more accurate estimation of project cost given portions of claims for project; impact of claim on project success rate in this project is 8 $\%$.
\end{abstract}

Keywords: • risk management • risk evaluation • project • claims • costs •

Correspondence Adress: Bojan Ačko, Ph.D., Full Professor, University of Maribor, Faculty of Mechanical Engineering, Smetanova ulica 17, 2000 Maribor, Slovenia, e-mail: bojan.acko@um.si, Zvonko Kremljak, Ph.D., Telekom Slovenije, d.d., Cigaletova 15, 1000 Ljubljana, Slovenia, Borut Buchmeister, Ph.D., Full Professor, University of Maribor, Faculty of Mechanical Engineering, Smetanova ulica 17, 2000 Maribor, Slovenia, e-mail: borut.buchmeister@um.si

https://doi.org/10.18690/978-961-286-028-8.1 ISBN 978-961-286-028-8

(C) 2017 University of Maribor Press

Available at: http://press.um.si. 
Risk evaluation is concerned with assessing probability and impact of individual risks, taking into account any interdependencies or other factors outside the immediate scope under investigation [1]:

- Probability is the evaluated likelihood of a particular outcome actually happening (including a consideration of the frequency with which the outcome may arise). For example, major damage to a building is relatively unlikely to happen, but would have enormous impact on business continuity. Conversely, occasional personal computer system failure is fairly likely to happen, but would not usually have a major impact on the business.

- Impact is the evaluated effect or result of a particular outcome actually happening. Impact should ideally be considered under the elements of:

$$
\begin{aligned}
& \text { - time, } \\
& \text { - quality, } \\
& \text { - benefit, } \\
& \text { - people/resource. }
\end{aligned}
$$

Risk management is the process of identifying, analysing, responding to, and controlling project risks. Risk management is a proactive project management process, since you are trying to deal with potential future events before they occur. Risk management is performed in the initial project planning.

The process includes the following steps [2]:

- create a Risk Management Plan (RMP),

- identify all potential risks,

- analyse the risks using qualitative techniques,

- utilize quantitative analysis for all high-level risks (optional),

- create a response plan for each high-level risk,

- move the activities associated with the risk response plans to the project schedule.

The remaining, follow-up steps are:

- monitor the risk response plan,

- periodically re-evaluate risks [2].

Risk management is not a one-time process. Project manager should always identify risks at the beginning of the project during the up-front planning process, but he should also periodically look at remaining work to identify any new risks. 
Since risks are generally perceived as bad, it makes sense that the first instinct of a project manager would be to eliminate them. Mitigation is a risk response that tries to minimize the probability of a risk occurring or to minimize the impact of the risk on your project. However, there are a number of other options for responding to a risk, including: leave it, monitor the risk, avoid the risk or move the risk [3]. None of these options include ignoring the risk. Even the option to leave the risk is the result of a conscious decision.

When identifying risks on the project, the first place to look is the inherent risks, which are based on the general characteristics of a project rather than the specific circumstances of the project. Since they are general in nature, they can be identified and placed in a checklist for all project managers to review (tight deadlines, project size, new vendors, new technologies etc.). This should be the starting point for the risk identification process. On the other hand, risks are future conditions or circumstances outside the control of the project team that will have an adverse impact on the project should they occur.

This chapter is focused to claims in construction industry as the potential problems related to risk and its control.

The management of claims is the greatest challenge facing with contractors in today's challenging business environments. Nowadays, construction projects become increasingly at risk due to a variety of factors which may cause to time extension and cost recovery [4].

Claim management is somehow similar to risk management procedure and consists of the following four processes: claim identification, claim quantification, claim prevention, claim resolution [5].

Reliable prediction of construction duration and consequently budget control is consolidated in decision making process and is an essential part of a successful management [6].

\section{Overview of theory}

\subsection{Risk managment}

The risk management loop according to Fig. 1 is a guideline for establishment of a risk management system. 


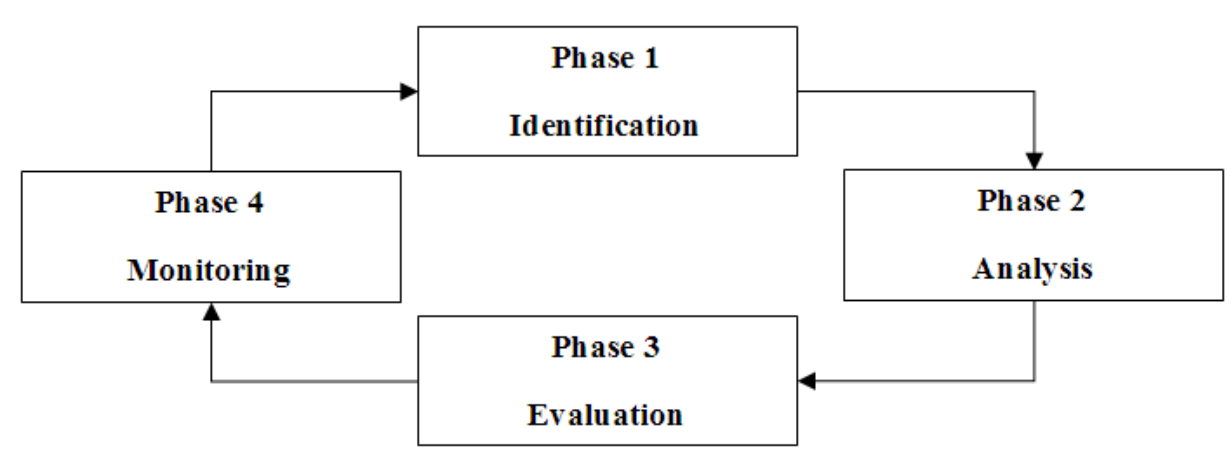

Figure 1. Schematic Risk Management Circle according to [7]

When risk identification and registration are completed, a probability of occurrence and consequence are assigned to each task. This assignment can be done through a quantitative assessment or a qualitative one or a combination of both [8].

\subsection{Claim management}

Claim was initially proposed in 1978 as a risk and probability and consequences of the various claims considered during a project life cycle [9].

While there is no a unique definition of this subject in the literature, a claim can be defined as "right given to the party who deserves a request for compensation and damages incurred by the other party" [10]. It may be also described as investigation of consideration or change by one of the parties involved in the project process. A claim happens when one party to the contract has suffered a detriment by the other party [11].

Claim management describes the processes required for elimination, prevention or reduction of construction claims when they are expected to occur [5].

\subsection{Construction claims}

No project can be considered isolated from a potential claim. Also much kind of claims can lead to financial damages [12]. Construction claims are observed by many participants as an unpleasant event in a project [13]. In general, claims are a common part in construction projects and may happen as a result of several reasons which can contribute delaying a project and/or increasing its relevant costs. On time accomplishing of a project is a difficult task to accomplish in the uncertain, complex, and dynamic environment of construction projects [11]. Claims may arise on a construction project due to number of reasons. Some well-known ones include as given below [14]:

- creep in scope of work (changes, extras and errors), 
- inadequate bid / tender information,

- faulty and/or lately supply of equipment and materials by owner,

- low quality of drawings and/or specifications,

- insufficient time through biding analysis,

- interruptions through proceeding of the operations due to lack of coordination, design information or equipment,

- blocked work,

- re-schedule of works ordered by owner, etc.

The most influencing factors of claims are unclear documentations, weak instructions, variations initiated by the employer/engineer, measurement related issues, weather conditions, change and time extension assessment [15].

\section{$3 \quad$ Claims of piping projects}

Deterministic claims are not in our research focus. Probabilistic claims in piping construction projects may include [16]: material control, organizational communications, documents and piping plans.

Main approach of this research is to identify and study potential claims which are discussed in piping construction projects and by prioritization and ranking of the claims in a specialized form.

Two factors entitled "probability" and "impact" had been evaluated by questionnaire and required data were collected. To find out the importance or magnitude of a cause from a set of causes for occurrence of claims, two factors entitled "probability of occurrence" and "chance of claim occurrence" were examined and evaluated the most probabilistic causes of claims.

Thus, a questionnaire including 15 questions related to probabilistic claims in piping construction were prepared.

According to 5-fold Likert scale (very low, low, moderate, high, very high) rate of each index for each claim was rolled up and scored [17]. The statistical population's size was selected based on comments made by project managers, piping managers, planning and project control managers, contract managers with high executive experiences. Selection of people was performed based on communications and their involvements in projects. About 25 answered questionnaires were collected for claim analysis and monitoring stage.

\subsection{Verification and validation}

In the present study, to check the validation for questions of questionnaires, surface and content of questionnaire were examined by independent interviews and finally by comparison among conditions of the present and past projects, 
potential claims of the projects were evaluated. The Cronbach's alpha coefficient for questions about probability was 0.77 and for questions was 0.71 which are acceptable measurements.

First stage in project planning is to include claim through deterministic planning.

In a project plan along with risk analysis, different outcomes and ways were examined for the given project and impacts of claim risks on the project success were determined.

\subsection{Risk analysis for cost and time of project}

Through running risk analysis, three optimistic (minimum), the most probabilistic, and pessimistic (maximum) scenarios have to be considered instead of incorporating a deterministic cost and time analysis. By applying project claim analysis, more realistic scheduling is obtained. Before a cost is allocated with a risk, a resource should be defined so that the cost could be allocated. Cost allocation to an activity is the best cost estimation approach for the activity definition. In piping construction projects, once resource for an activity is defined, planned cost for any activity is determined and then triangular distribution has been used to estimate minimum and maximum costs for any individual activity (90\% and $110 \%$ of the estimated cost), see an example in Fig. 2.

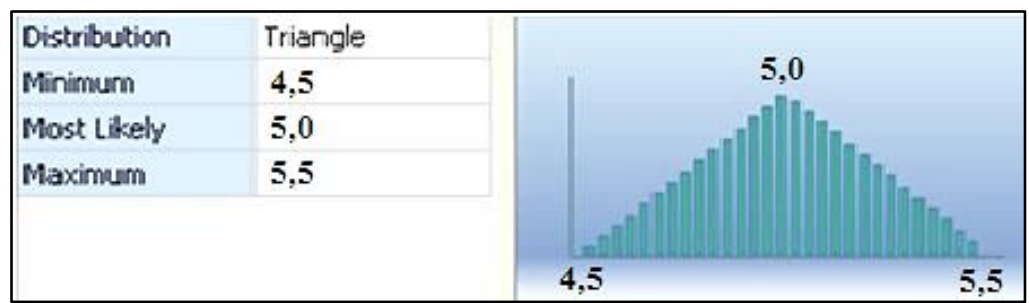

Figure 2. Triangular distribution of activity cost

All this imposes the need for radical changes of education structure, selection of study contents and learning methods as required by the Bologna reforms of the existing education system. Education, formal and informal, must serve the society as a tool for strengthening creativity, development and expansion of know-how and science; knowledge and teaching must be accessible to all.

\subsection{Claims identification and screening process}

A check-list of potential claims were prepared for running a comparison between identified potential claims in current and in the projects completed in the past. Outcome of this stage was a list of potential claims for the present project with a certain range of influencing factors. To find the most important claims, two factors "probability of occurrence" and "claim's chance of success" (intensity of claim) 
were examined and evaluated by the questionnaire. Variables used in scoring include:

- Claim's probability of occurrence (P),

- Claim's impact or chance of occurrence (I),

- Claim's degree of risk (C).

Table 1. Impact and probability scoring factors

\begin{tabular}{|l|c|}
\hline \multicolumn{1}{|c|}{ Description } & Numerical score \\
\hline Very low $(\mathrm{VL})$ & 1 \\
\hline Low $(\mathrm{L})$ & 3 \\
\hline Medium $(\mathrm{M})$ & 5 \\
\hline High $(\mathrm{H})$ & 7 \\
\hline Very high $(\mathrm{VH})$ & 9 \\
\hline
\end{tabular}

To rank and classify claim risks, once average probability and impact of claim's risk is calculated, by probability of occurrence (P) multiplied by impact (I), claim's degree of risk $(\mathrm{C})$ is obtained:

$$
C=P \times I
$$

According to prioritization of claims, 6 important claims that are likely to have the highest effect on the project were investigated.

According to the data entry of quantitative values for probability and impact of claims, those could be scored and finally ranked. Since it is possible that available resources in organization are not enough in order to deal with all claims presented in the project, ranking the risks based on the obtained scores could be very helpful to identify important claims of the project.

A risk could have positive or negative effects on the project [18]. If it has a positive effect on the project, it is called an opportunity and if it has a negative effect on the project, it is called a threat.

Claims could be mapped to an individual activity in the project to run an integrate analysis.

Once questionnaires collected, risk ranking matrix may specify position of each claim based on probability and its effect on Probability-Impact matrix (PI matrix), see Table 2. 
Table 2. Claims PI matrix

\begin{tabular}{|l|c|c|c|c|c|}
\cline { 2 - 6 } \multicolumn{1}{c|}{} & \multicolumn{5}{c|}{ Impact } \\
\hline Probability & Very low & Low & Medium & High & $\begin{array}{c}\text { Very } \\
\text { high }\end{array}$ \\
\hline Very high [\%] & 9 & 27 & 45 & 63 & 81 \\
\hline High [\%] & 7 & 21 & 35 & 49 & 63 \\
\hline Medium [\%] & 5 & 15 & 25 & 35 & 45 \\
\hline Low [\%] & 3 & 9 & 15 & 21 & 27 \\
\hline Very low [\%] & 1 & 3 & 5 & 7 & 9 \\
\hline
\end{tabular}

By ranking of associated risks, we could specify the most important and effective claims. Since scores of claims are determined in terms of probability and risk impact, the ranking indicates the importance of risks as compared to each other properly. The most important claims are given in Table 3 by preference.

Table 3. Most important piping construction claims

\begin{tabular}{|c|c|c|c|c|}
\hline \multirow{2}{*}{ Rank } & \multirow{2}{*}{ Claim event } & \multirow{2}{*}{ Factor } & \multirow{2}{*}{$\begin{array}{l}\text { Average } \\
\text { score }\end{array}$} & \multirow{2}{*}{$\frac{\text { Score }}{(P \times I) \times 100}$} \\
\hline & & & & \\
\hline \multirow[b]{2}{*}{1} & \multirow{2}{*}{$\begin{array}{l}\text { Contractors' claims, in case } \\
\text { of issuance of material issue } \\
\text { voucher (MIV) and delay in } \\
\text { delivery of material or Non- } \\
\text { Issue (NIS) }\end{array}$} & Probability & 7.6 & \multirow[b]{2}{*}{55.48} \\
\hline & & Impact & 7.3 & \\
\hline \multirow{2}{*}{2} & \multirow{2}{*}{$\begin{array}{l}\text { Requirements for piping } \\
\text { operations to be hold or not } \\
\text { met }\end{array}$} & Probability & 7.2 & \multirow{2}{*}{51.12} \\
\hline & & Impact & 7.1 & \\
\hline \multirow{2}{*}{3} & \multirow{2}{*}{$\begin{array}{l}\text { Client delays in delivering } \\
\text { isometric drawings }\end{array}$} & Probability & 6.6 & \multirow{2}{*}{42.90} \\
\hline & & Impact & 6.5 & \\
\hline \multirow{2}{*}{4} & \multirow{2}{*}{$\begin{array}{l}\text { Discrepancies and } \\
\text { shortcomings in contract } \\
\text { terms }\end{array}$} & Probability & 6.7 & \multirow{2}{*}{42.88} \\
\hline & & Impact & 6.4 & \\
\hline \multirow[b]{2}{*}{5} & \multirow{2}{*}{$\begin{array}{l}\text { TQ (Technical Query) due } \\
\text { to failure, inadequacy and } \\
\text { deficiencies information } \\
\text { plan }\end{array}$} & Probability & 6.2 & \multirow[b]{2}{*}{36.58} \\
\hline & & Impact & 5.9 & \\
\hline \multirow{2}{*}{6} & \multirow{2}{*}{$\begin{array}{l}\text { Delay in piping invoices } \\
\text { payment }\end{array}$} & Probability & 5.8 & \multirow{2}{*}{34.22} \\
\hline & & Impact & 5.9 & \\
\hline
\end{tabular}




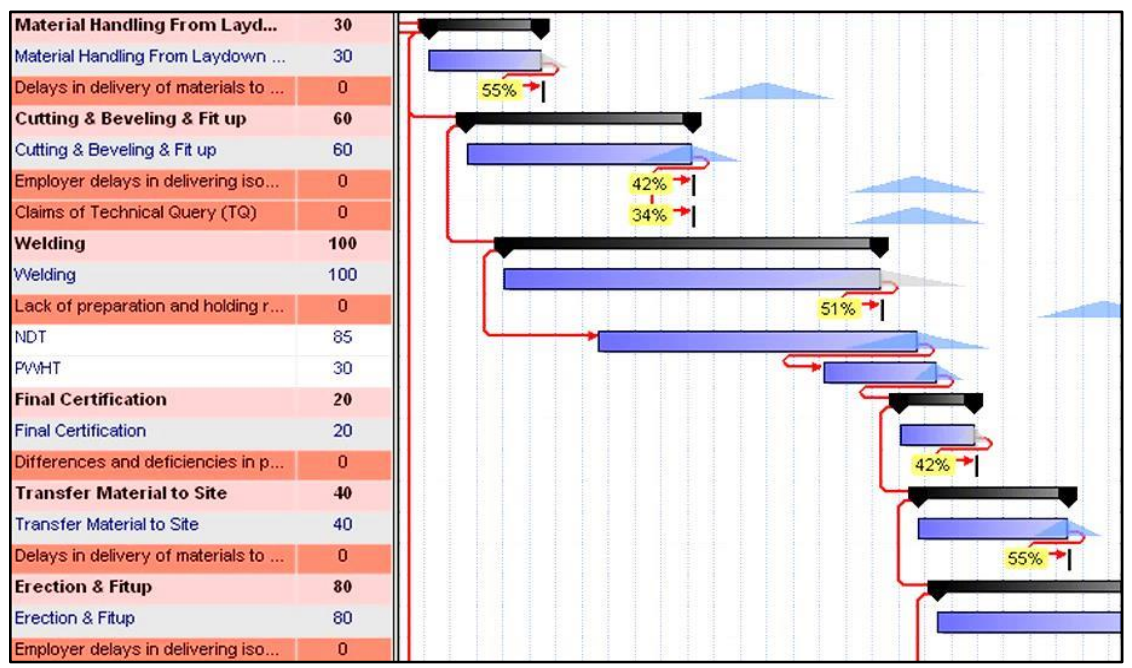

Figure 3. Project schedule with included claims (segment)

In this project triangular distribution is used to schedule activities (Fig. 3). Then triangular distribution is selected and applied for costs of resources. By doing risk analysis of graphs before applying claim, cost of the project can be registered.

\subsection{Cost distributions}

After completion of analysis, cost for any repetition (using random values from the triangular distributions) is displayed on a graph [19] which illustrates distribution of project cost (Fig. 4).

As can be seen from the Fig. 4, with a $90 \%$ confidence interval, total cost of piping construction project is $17,424,568$ USD (see the cumulative frequency) and the estimated probability for completing the estimated cost equals to $16,460,200$ USD is only $51 \%$.

Implementing claim risk analysis by application of claims after taking a preventive (post-mitigation) action, next distribution graph is registered.

As could be seen in Fig. 5, there is $43 \%$ probability the project is completed with the initial estimation 16,460,200 USD. Also, this figure shows with an $80 \%$ confidence the final cost of project could be considered 17,185,148 USD.

Handling claims efficiently and accurately is essential to keeping projects within acceptable time and cost limits and improving your overall performance. Decision management for claims enables the organization to combine predictive analytics with industry best practices and existing business processes. As a result, claims adjustors and others with in-depth project knowledge can quickly and easily define 
ADVANCES IN PRODUCTION AND INDUSTRIAL ENGINEERING

B. Ačko, Z. Kremljak \& B. Buchmeister: Chapter 1

Risk evaluation in project planning

how risk should be assessed and automate many routine decisions while retaining full control of the claims handling process.

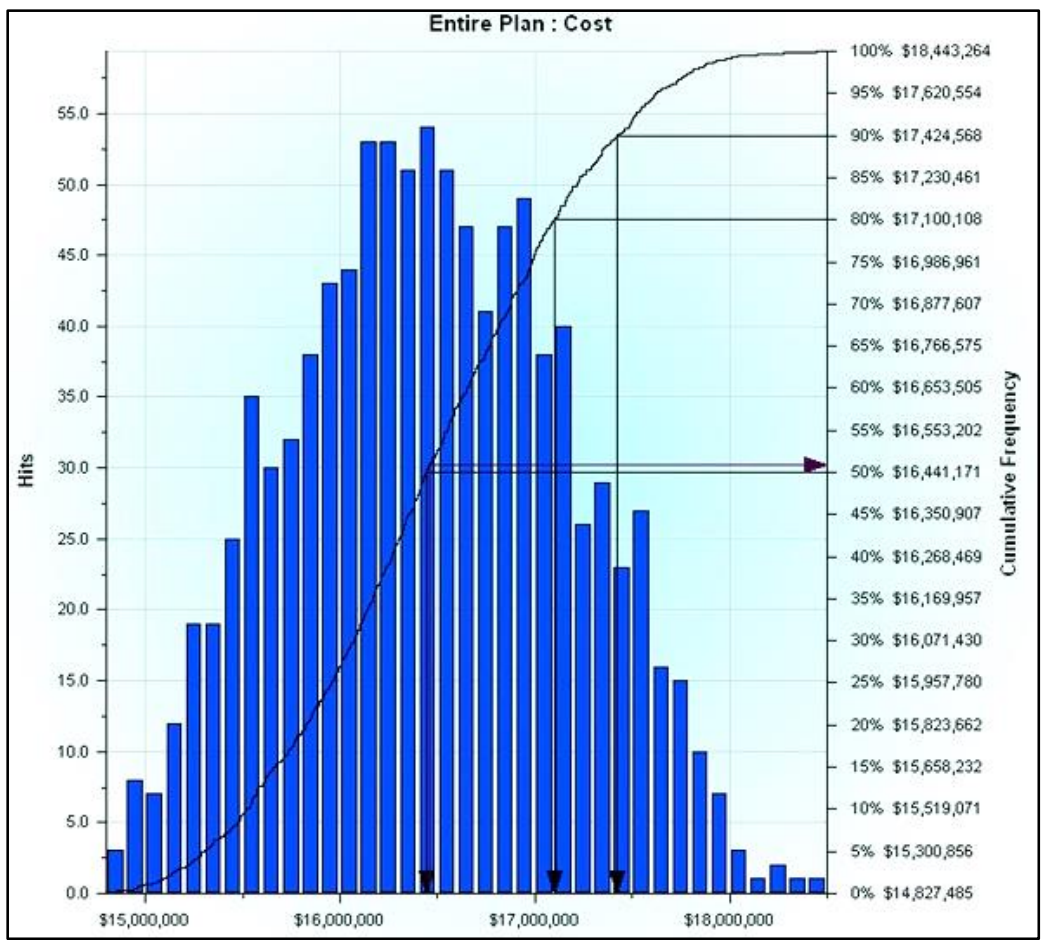

Figure 4. Cost distribution of piping construction project in uncertain conditions

Table 4 shows statistical values including minimum, maximum, mean, $90 \%$ confidence level, probability of occurrence, and project costs for both states before and after application of claims. 
Table 4. Comparison of costs before and after application of claims

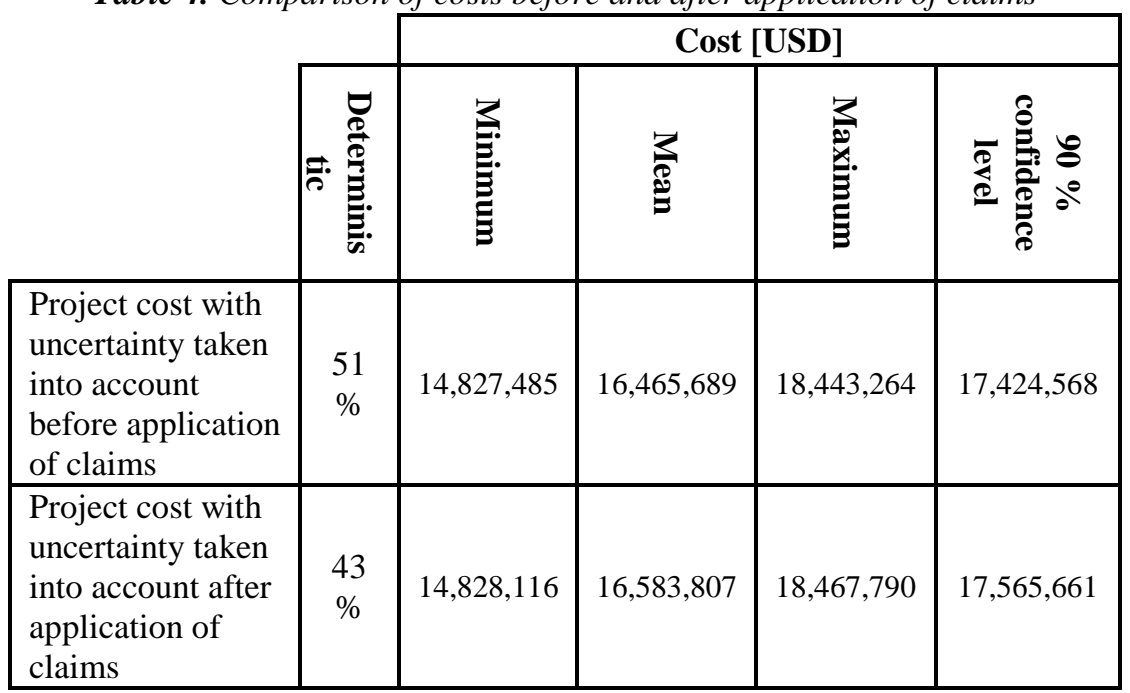

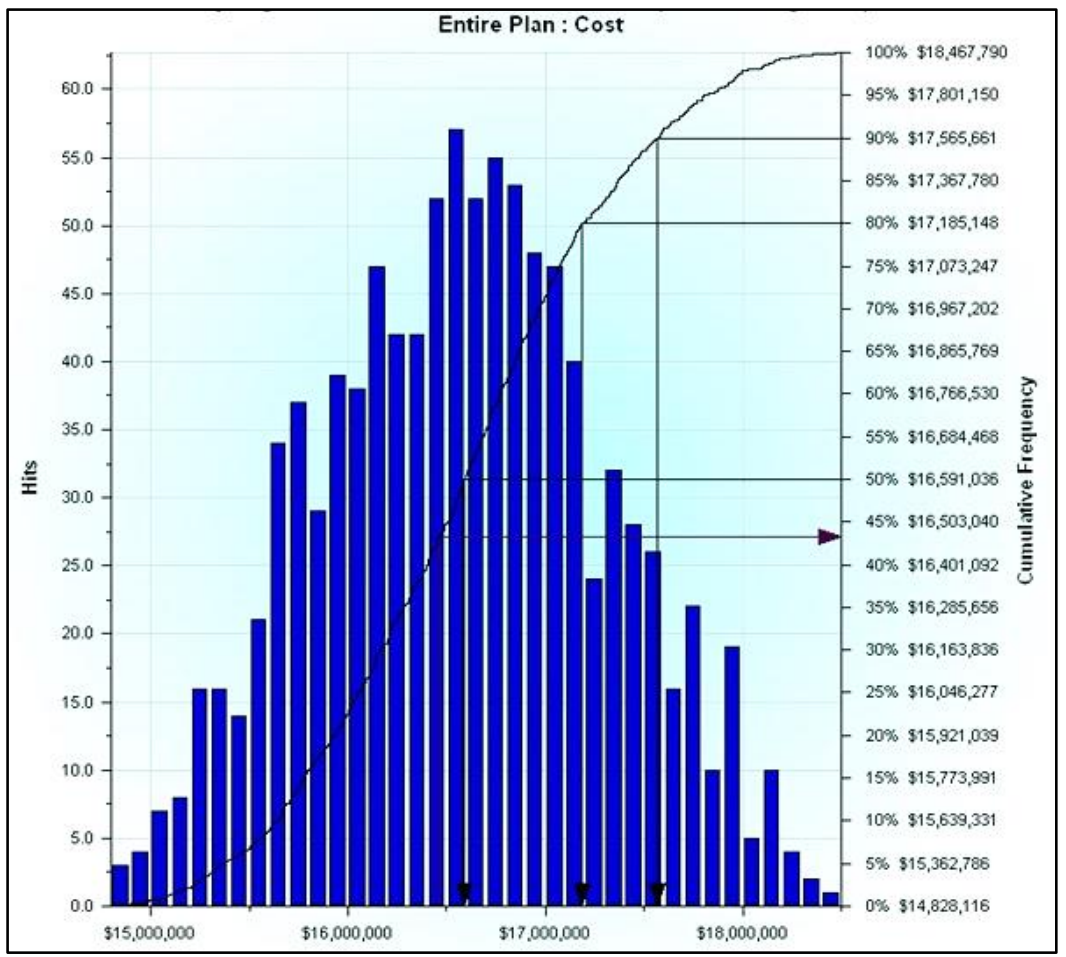

Figure 5. Cost distribution of piping construction project after application of claims 


\section{Conclusion}

Analyses of claim risks in projects are very important. This chapter, identifying common claims in piping construction contract was performed by questionnaire distributed among senior experienced managers and experts in this industry. Once the most important claims were determined by quantifying the claims project success rates before and after applying the claim were found and difference between the obtained values indicated impact percentage of claim risk in piping construction projects.

This study has important achievements for piping construction projects and the important results include:

1. Identification of actionable claims in piping construction projects and also ranking and prioritization of the most important claims.

2. Claims: impact on project success rate is $8 \%$ for project cost overrun.

3. Understanding cost sensitivity indicates impact of cost of an activity on the total cost.

Using this information, the project could be estimated and evaluated more accurately. Claims affecting aims of project are identified and documented according to expert judgments.

Project risk is one of those exciting topics that everyone (executives, functional managers, project managers or engineers) has an opinion about. Any good project has plenty of risk. The claim strategy depends on our answers to the questions about our relationship to the contractual partner, the policies of other involved units, project goals, business goals etc.

Future research work will be oriented to other types of industries too. It will include some improvements of the model, for example: more parameters for observation, related to specific branch, application of fuzzy modelling through project claim management, inclusion of decision support system, adopted methods of analysis etc.

\section{References}

[1] Abdullah, L. \& Azman, F. N. (2016). Circumcenter of centroid of fuzzy number for identifying risk factors of obesity: a qualitative evaluation, Quality \& Quantity, Vol. 50, No. 6, pp. 2433-2449, DOI:10.1007/s11135-015-0270-5

[2] Mochal, T. \& Mochal, J. (2011). Lessons in Project Management, 2nd edition, Apress, Springer-Verlag, New York

[3] Kremljak, Z. \& Kafol, C. (2014). Types of risk in a system engineering environment and software tools for fisk analysis, Proceedings of the 24th DAAAM International 
Symposium on Intelligent Manufacturing and Automation, Procedia Engineering, Vol. 69, pp. 177-183, DOI:10.1016/j.proeng.2014.02.218

[4] Kululanga, G.; Kuotcha, W.; McCaffer, R. \& Edum-Fotwe, F. (2001). Construction contractors' claim process framework, Journal of Construction Engineering and Management, Vol. 127, No. 4, pp. 309-314,

[5] PMI. (2013). A Guide to the Project Management Body of Knowledge (PMBOK® Guide), 5th edition, Project Management Institute, Newtown Square

[6] Al-Momani, A. H. (2000). Construction delay: a quantitative analysis, International Journal of Project Management, Vol. 18, No. 1, pp. 51-59, DOI: 10.1016/S02637863(98)00060-X

[7] Kremljak, Z. (2004). Decision making under risk, DAAAM Publishing series Management Science, DAAAM International, Vienna

[8] Smith, C. A. (2011). Integrated scenario-based methodology for project risk management, PhD Thesis, University of Maryland, College Park

[9] Bosch, R. V. (1978). Identifying construction claims, Transactions of the American Association of Cost Engineers, pp. 320-329

[10] Simon, M. S. (1979). Construction Contracts and Claims, McGraw-Hill, New York

[11] Kartam, S. (1999). Generic methodology for analyzing delay claims, Journal of Construction Engineering and Management, Vol. 125, No. 6, pp. 409-419,

[12] Enshassi, A.; Mohamed, S. \& El-Ghandour, S. (2009). Problems associated with the process of claim management in Palestine: Contractors' perspective, Engineering, Construction and Architectural Management, Vol. 16, No. 1, pp. 61-72,

[13] Ho, S. P. \& Liu, L. Y. (2004). Analytical model for analyzing construction claims and opportunistic bidding, Journal of Construction Engineering and Management, Vol. 130, No. 1, pp. 94-104, DOI:10.1061/ (ASCE)0733-9364(2004)130:1(94)

[14] Jergeas, G. F. \& Hartman, F. T. (1994). Contractors' construction-claims avoidance, Journal of Construction Engineering and Management, Vol. 120, No. 3, pp. 553-560, DOI:10.1061/(ASCE)0733-9364(1994) 120:3(553)

[15] Yogeswaran, K.; Kumaraswamy, M. M. \& Miller, D. R. A. (1998). Claims for extensions of time in civil engineering projects, Construction Management \& Economics, Vol. 16, No. 3, pp. 283-293, DOI: 10.1080/014461998372312

[16] Yi, H. Y. \& Guo, P. (2015). Modelling risk coordination of supply chains with put option contracts and selective return policies, International Journal of Simulation Modelling, Vol. 14, No. 3, pp. 551-562, DOI: 10.2507/IJSIMM14(3)CO15

[17] Hwang, C.-L. \& Yoon, K. (1981). Multiple Attribute Decision Making: Methods and Applications - A State-of-the-Art Survey, Springer-Verlag, Berlin

[18] Ocampo, L. A.; Clark, E. E.; Tanudtanud, K. V. G.; Ocampo, C. O. V.; Impas Sr., C. G.; Vergara, V. G.; Pastoril, J.; Tordillo, J. A. S. (2015). An integrated sustainable manufacturing strategy framework using fuzzy analytic network process, Advances in Production Engineering \& Management, Vol. 10, No. 3, pp. 125-139, DOI: 10.14743/apem2015.3.197

[19] Palisade Corp. (2013). @ RISK for Project (ver. 6), Palisade, Middlesex 
16 AdVANCES IN PROduction AND INDUSTRIAL ENGINEERING 


\title{
Chapter 2
}

\section{Analysis of Visual Methods for more Effective Simulation}

\author{
ALEKSANDRA SimONOVSKA, BOJAN D. JOVANOSKI, ROBERT MINOVSKI \& \\ VALENTINA GECEVSKA
}

\begin{abstract}
This chapter analizes many methods that are able to inspect the problems, crucial in the process of making a simulation model. Each method has its own features, ways of how it's made not every method satisfies the requirements for obtaining a better simulation model. This chapter analyses four methods: Flowchart Diagram, Process Chart, Cross-Functional Diagram and SADT. The case shown and analysed in this chapter with the mentioned methods is the process of making padlocks. The conceptual phase of the modelling process needs to be performed with a visual mapping of the analysed process. According to analized case, It is recommended that every modelar knows more than three different mapping methods in order to choose the best for the given situation.
\end{abstract}

Keywords: modelling - mapping - process - simulation model • padlocks

CORRESPONDENCE AdRESS: Aleksandra Simonovska, BSc, „Ss. Cyril and Methodius” University in Skopje, Faculty of Mechanical Engineering-Skopje, Rudger Boshkovikj bb, Skopje 1000, Republic of Macedonia, e-mail: aleksandra.simonovska@mk.pwc.com. Bojan D. Jovanoski, Ph.D., Assistant Professor, „Ss. Cyril and Methodius” University in Skopje, Faculty of Mechanical Engineering-Skopje, Rudger Boshkovikj bb, Skopje 1000, Republic of Macedonia, e-mail: bojan.jovanoski@mf.edu.mk. Robert Minovski, Ph.D., Full Professor, „Ss. Cyril and Methodius” University in Skopje, Faculty of Mechanical Engineering-Skopje, Rudger Boshkovikj bb, Skopje 1000, Republic of Macedonia, e-mail: robert.minovski@mf.edu.mk. Valentina Gecevska, Ph.D., Full Professor, ,Ss. Cyril and Methodius" University in Skopje, Faculty of Mechanical Engineering-Skopje, Rudger Boshkovikj bb, Skopje 1000, Republic of Macedonia, e-mail: valentina.gecevska@mf.edu.mk. 
The aim of the paper is to show the importance of proper mapping of the processes from the real world. The ultimate goal is to obtain better simulation models. There are many methods that are able to inspect the problems to be analysed, crucial in the process of making a simulation model. Each method has its own features, ways of how it's made and application areas. This means that not every method satisfies the requirements for obtaining a better simulation model. This paper analyses four methods: Flowchart Diagram, Process Chart, Cross-Functional Diagram and SADT.

Mapping the process is only one phase of the simulation methodology, according to the methodology used by [1]. In fact, it is only one part of the conceptual phase, along with the list of entities, list of assumptions and list of exclusions, [2].

The idea for this kind of research arose when trying to create the simulation model from the conceptual phase. There were always some parts missing in the conceptual model that needed to be redone and reanalysed in order for someone to create a final simulation model, [3]. By this we mean:

- Not enough details about the structure of the process;

- Not enough details about the operational part of the process (processing times, for example);

- Not a clear picture of the consequent sub-processes;

- Not a clear information about the quantities of parts entering an assembly activity.

That is why this paper analysis the four different methods if they are applied for a same case.

\section{The analysed case}

\subsection{Basic information about the case}

The case that will be shown in the next few pages and analysed with the methods is the process of making padlocks. First, the following text will explain the process from the beginning till the end, along with all the sub-processes. Second, the process of making padlocks will be presented through the four previous explained methods. This will give the reader a clear picture of the flow of the operations for the process of making padlocks.

One padlock contains 24 steel plates that are laminated together. A punch press cuts and shapes pieces of steel into caps that would be fixed on the padlock's body. This is shown in Figure 1. 


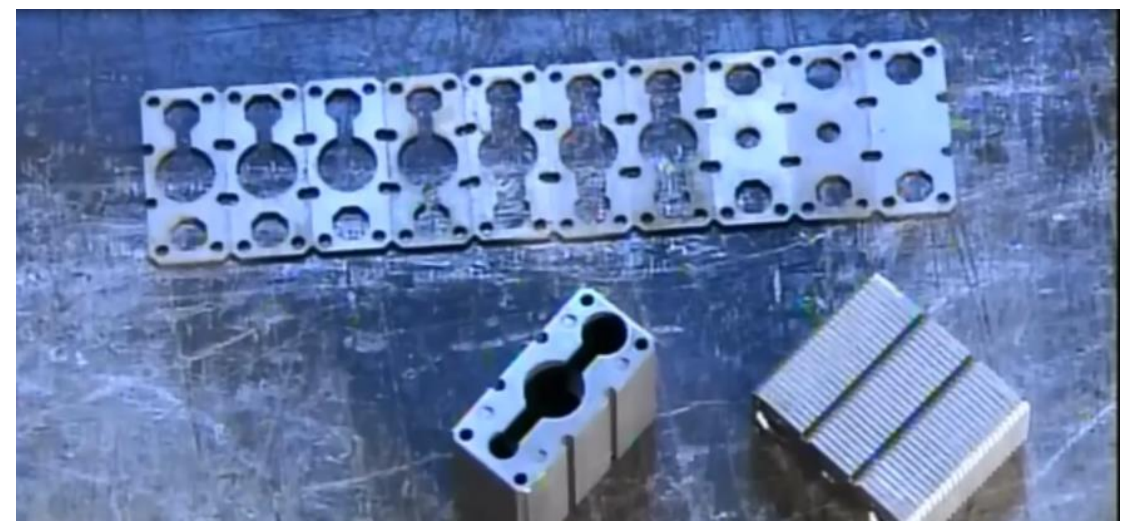

Figure 1. Components of 1 padlock

Meanwhile, cutters cut tore steel rods so they fit into the lock rods body hole, while lubricant keeps things cool. The finish rods are ready to be shaped on a form press which bends the steel into a $U$ form. Then the shackles roll into a furnes for tempering, a process that makes the steel even stronger. After a little more machining, the shackle is ready to be installed. The shackle will need to move up and down as the lock is opened and closed and that's where the ball bearings come in. Lubricant gel aids the process. A cylinder extension is inserted between the ball bearings and the protective casing.

The final assembly starts when a machine loads copper plated shells onto mandrels. Plugs, pins and spring are brought to the lock assembly station. A selected padlock is pushed into the lock cylinder. Then it's taped off with a retention play. A machine presses the bottom of the padlock and it secures the lock cylinder. A spring for the shackle is inserted and the bottom cap goes on next. Then the entire assembly is riveted together. Each key is tested to make sure it matches. A computerized system opens and closes a randomly selected padlock thousands of times to make sure it's up to the job. The lock also has to hold up to force. Weights are dropped to replicate a hammer hit on a padlock and test if it would withstands the strike.

If the padlock satisfies all of the previous mentioned controls the process of making padlocks is over.

\subsection{Elaboration of the process through the four methods}

After the detail description of the process for making padlocks, a couple of elements are crucial for finishing the process:

1. Determination of the sub-processes of the process for making padlocks,

2. Determination of the order how the sub-processes are conducted,

3. Exact times for each sub-process and

4. Entities (materials) needed for process. 
These information are used for representing the process with the previous explained methods (Flowchart, Process Chart, Cross-Functional Diagram and SADT). More information about the diagrams can be read in [4-7]

\subsubsection{Flowchart diagram}

First, the process will be shown with the flowchart diagram, (Figure 2). The diagram is very easy to develop, easy to read, but lacks a lot of other information (for example - times, entities for every sub-process), [8].

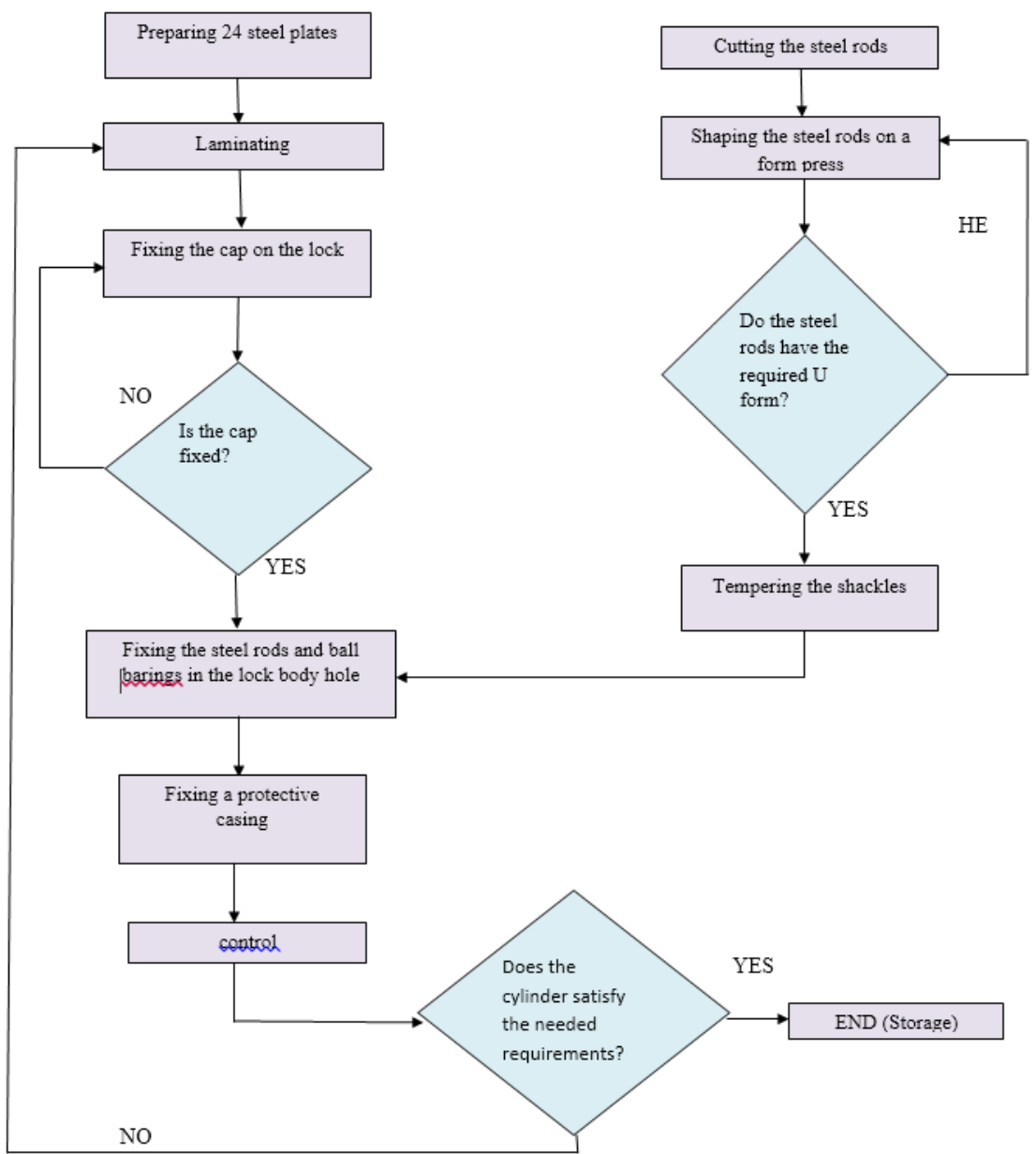

Figure 2. Flowchart Diagram 
A. Simonovska, B. D. Jovanoski, R. Minovski \& V. Gecevska: Chapter 2

Analysis of Visual Methods for more Effective Simulation

\subsubsection{Process Chart Diagram}

The process flow chart diagram is a more systematized option for describing the process. The Figure 3 shows that there are a lot of attributes that need to be filled in, thus giving a direction what needs to be analysed and what kind of information needs to be presented, [5].

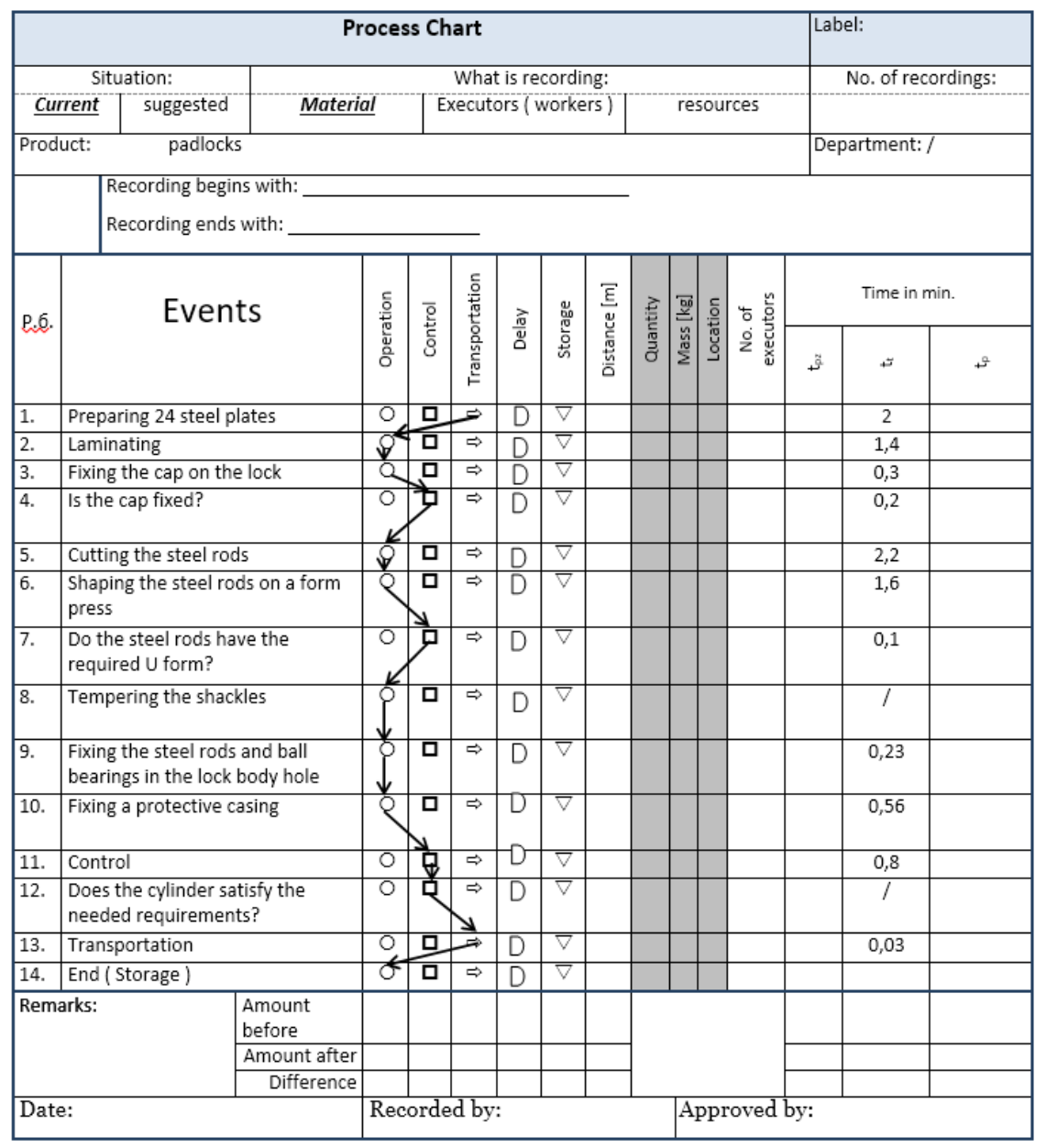

Figure 3. Flowchart Diagram

\subsubsection{Cross-functional Diagram}

The same process is presented with the Cross-functional diagram, more specifically with the Deployment Cross-Functional Diagram, [9]. The complete diagram is shown in Figure 4. 
A. Simonovska, B. D. Jovanoski, R. Minovski \& V. Gecevska: Chapter 2

Analysis of Visual Methods for more Effective Simulation

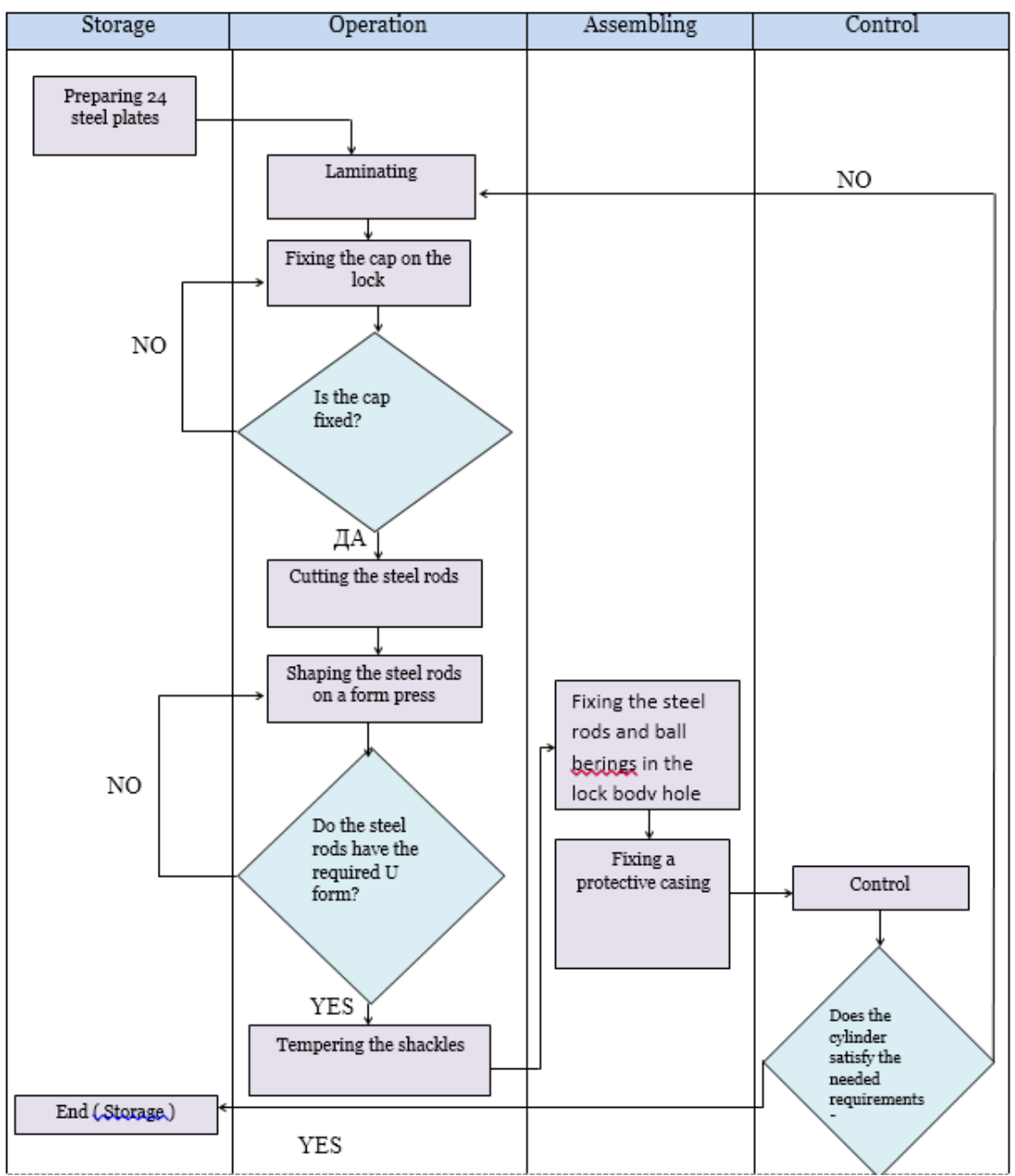

Figure 4. Deployment Cross-Functional Chart

This diagram is more visually appealing than the flowchart, but it requires a little bit more time and effort to complete it. However, even so, it does not give any added value, for this case, exactly. It is concluded that this diagram is more suitable for larger and more complex processes, those that have more than 20 sub-processes, where multiple functional areas are involved and details are not so important.

\subsubsection{SADT}

Before creating the diagram, first of all there are a couple of things that are needed to be done, [10]. The actual presenting of the process will be a bit different from 
the three previously presented methods. Four steps need to be followed in order for one to create the diagram:

1. Identification of entities;

2. Identification of all activities (Listing any resource and constraint requirements related to each activity);

3. Draw SADT branches for each activity;

4. Generate the complete activity diagram by combining all SADT branches.

The identified entities for the process of making padlocks are:

- $\quad$ Steel plates - E1

- Steel rods - E2

- Ball Bearings - E3

- Protective casing - E4

All activities included in the process are shown in Table 1. 
Table 1. Activities included in the process

\begin{tabular}{|c|c|c|c|c|c|}
\hline Activity & Label & Resource & Label & Control & Label \\
\hline $\begin{array}{lll}\begin{array}{l}\text { Preparing } \\
\text { plates }\end{array} & & \text { steel } \\
\end{array}$ & Sc (OP9) & $\begin{array}{l}\text { Transportation } \\
\text { vehicle }\end{array}$ & $\mathrm{T}_{1}$ & $\begin{array}{l}\text { Production } \\
\text { schedule }\end{array}$ & $\mathrm{C}_{1}$ \\
\hline Laminating & OP10 & Punch press & M1 & $\mathrm{n} / \mathrm{a}$ & \\
\hline $\begin{array}{l}\text { Fixing the cap on } \\
\text { the lock }\end{array}$ & OP20 & Punch press & $\mathrm{R} 1-2$ & $\mathrm{n} / \mathrm{a}$ & \\
\hline $\begin{array}{l}\text { Test area } 1-\text { is the } \\
\text { cap fixes }\end{array}$ & $\mathrm{T} 1$ & $\begin{array}{l}\text { Computerized } \\
\text { system }\end{array}$ & $\mathrm{M}_{1}$ & $\mathrm{n} / \mathrm{a}$ & \\
\hline Rework area 1 & RT1 & Punch press & $\mathrm{R}_{4}$ & $\mathrm{n} / \mathrm{a}$ & \\
\hline $\begin{array}{l}\text { Cutting the steel } \\
\text { rods }\end{array}$ & OP30 & Cutting machine & $\overline{\mathrm{M}_{1}}$ & $\mathrm{n} / \mathrm{a}$ & \\
\hline $\begin{array}{l}\text { Shaping the steel } \\
\text { rods on a form press }\end{array}$ & OP40 & Cutting machine & M1 & $\mathrm{n} / \mathrm{a}$ & \\
\hline $\begin{array}{l}\text { Test area } 2-\text { Do the } \\
\text { steel rods have the } \\
\text { required } U \text { form }\end{array}$ & $\mathrm{T} 2$ & $\begin{array}{l}\text { Computerized } \\
\text { system }\end{array}$ & M1 & $\mathrm{n} / \mathrm{a}$ & \\
\hline Rework area 2 & RT2 & Cutting machine & R5 & $\mathrm{n} / \mathrm{a}$ & \\
\hline $\begin{array}{l}\text { Tempering the } \\
\text { shackles }\end{array}$ & OP50 & $\begin{array}{ll}\text { Furnace } & \text { for } \\
\text { tempering } & \end{array}$ & M1 & $\mathrm{n} / \mathrm{a}$ & \\
\hline $\begin{array}{l}\text { Fixing the steel rods } \\
\text { and ball bearings in } \\
\text { the lock body hole }\end{array}$ & OP60 & Shift operator & $\mathrm{M}_{1}$ & $\mathrm{n} / \mathrm{a}$ & \\
\hline $\begin{array}{l}\text { Fixing a protective } \\
\text { casing }\end{array}$ & OP70 & Machine & M1 & $\mathrm{n} / \mathrm{a}$ & \\
\hline $\begin{array}{l}\text { Test area } 3-\text { does } \\
\text { the cylinder satisfy } \\
\text { the needed } \\
\text { requirements }\end{array}$ & $\mathrm{T} 3$ & $\begin{array}{l}\text { Computerized } \\
\text { system }\end{array}$ & M1 & $\mathrm{n} / \mathrm{a}$ & \\
\hline $\begin{array}{l}\text { End - transporting } \\
\text { the product to } \\
\text { storage }\end{array}$ & $\begin{array}{l}\text { Sk } \\
\text { (OP80) }\end{array}$ & $\begin{array}{l}\text { Transportation } \\
\text { vehicle }\end{array}$ & $\mathrm{T}_{2}$ & $\mathrm{n} / \mathrm{a}$ & \\
\hline
\end{tabular}


According to the table, all branches are developed as modular designs, Figure 5.
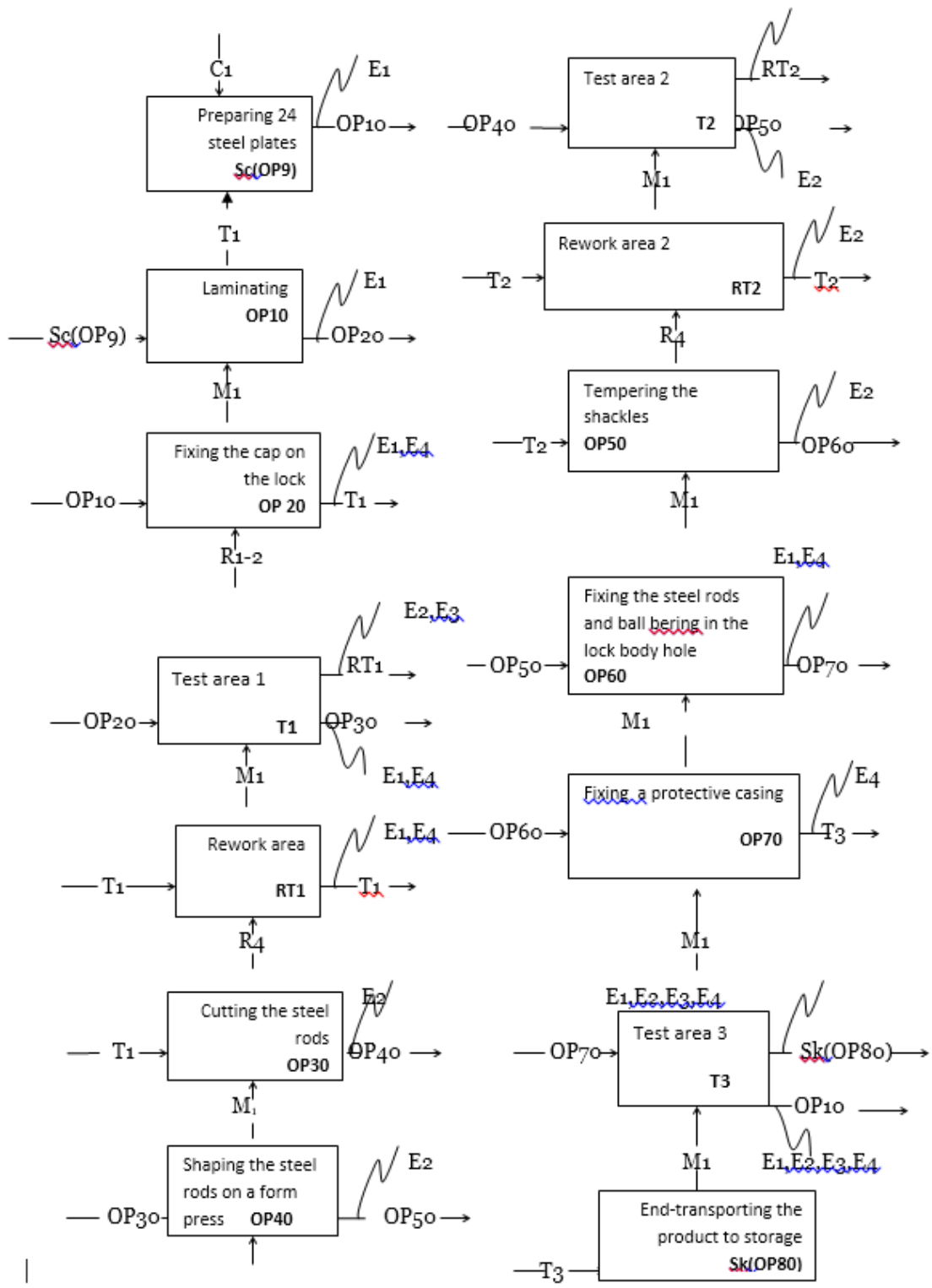

Figure 5. SADT CM branches

When the branches are assembled and connected to each other according the connection number, the final structure is presented like in Figure 6. 


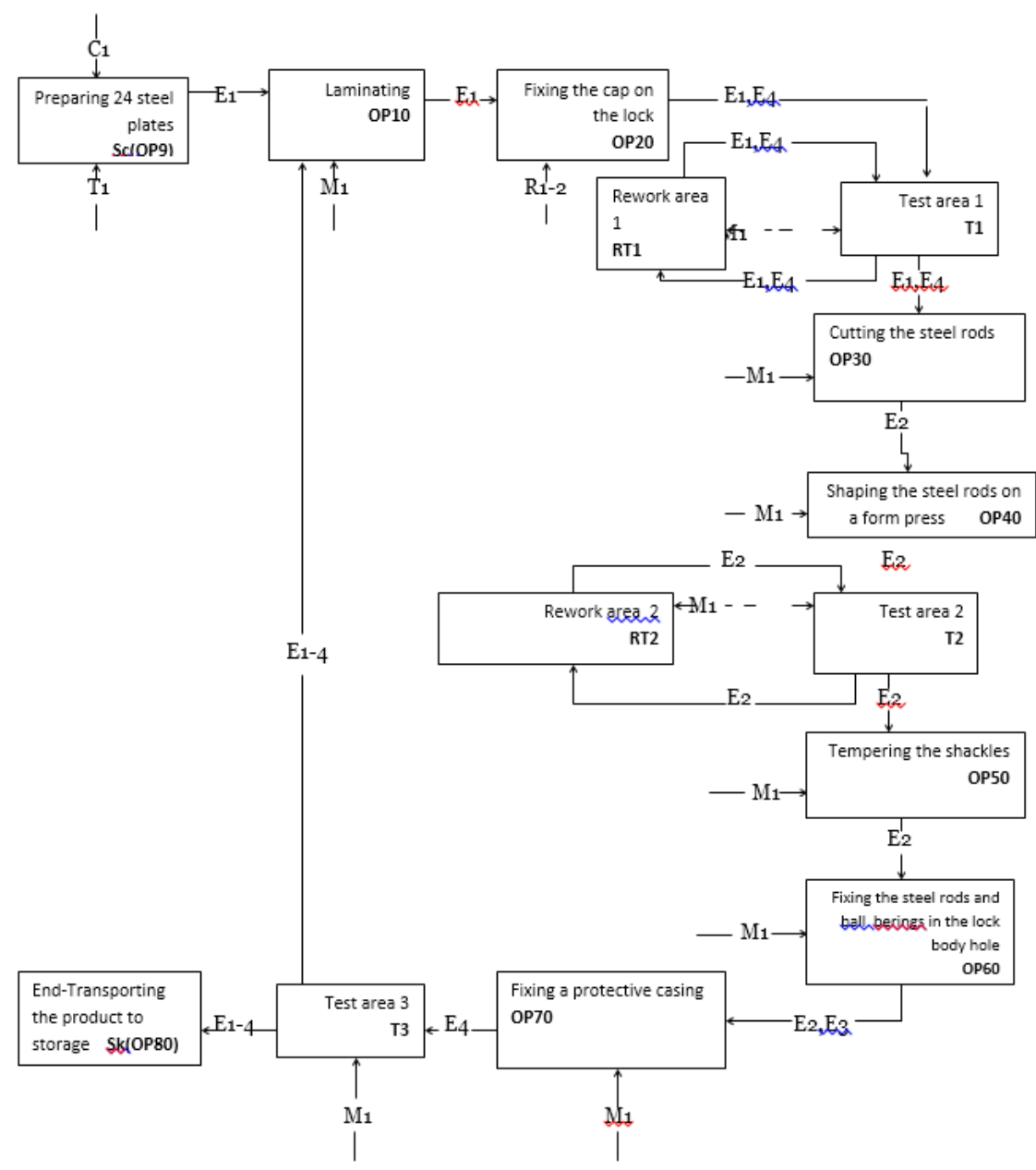

Figure 6. Complete SADT diagram

\section{$3 \quad$ Analysis for obtainig better simulation model}

The presented analysis is supposed to give the reader a clear picture which one of the methods is more helpful for obtaining a better simulation model. Firstly, what can be noticed is that one process - case (here the process of making padlocks) is presented differently, with four almost completely different methods. The only thing that is common between them is that all show the sequence of events exactly as they happen (operations, control, transportation, storage). What cannot be seen in the four methods together are the parallel operations that are happening in the same time, which is one of the most important factor for obtaining a better simulation model. The diagram that can partially visually show this feature are the Flowchart and 
Cross-Functional Diagram. One of the weaknesses of the Flowchart Diagram is that it does not show the required resources for running the process (they are shown as entities in the simulation model), nor the time. The only diagram that shows the resources is SADT. The Cross-Functional diagram is not a good choice when modelling simple processes.

The SADT defines all the components of the process (resources, entities, control), but the limitation of handling systems with a large number of activities and resources makes the method unfavourable for use. Third important factor when choosing better method for obtaining a better simulation model is the processing time of the operations. The only method that show the duration of the operations is the Process Chart. The chosen elements for the analysis are shown and presented in Table 2.

Table 2. Analysis of the methods

\begin{tabular}{|c|c|c|c|c|}
\hline $\begin{array}{c}\text { Element } \\
\text { for analysis }\end{array}$ & $\begin{array}{c}\text { Flowchart } \\
\text { Diagram }\end{array}$ & $\begin{array}{c}\text { Process } \\
\text { Chart }\end{array}$ & $\begin{array}{c}\text { Cross- } \\
\text { Functional } \\
\text { Diagram }\end{array}$ & SADT \\
\hline $\begin{array}{c}\text { Parallel } \\
\text { operations }\end{array}$ & Yes & No & Yes & No \\
\hline $\begin{array}{c}\text { Display of } \\
\text { resources }\end{array}$ & No/yes & No & No & Yes \\
\hline $\begin{array}{c}\text { Systems with } \\
\text { large number of } \\
\text { operations }\end{array}$ & Yes/no & No & Yes & No \\
\hline $\begin{array}{c}\text { Processing times } \\
\text { No }\end{array}$ & Yes & No & No \\
\hline
\end{tabular}

The conclusion of the analysis is that there is no straight answer when deciding which diagram to choose when doing the concept model of the simulation model. If one makes a simulation for a simple process, then a Flowchart is enough. When a more sophisticated process is analysed, with a lot of entities, different places of production etc., then a cross-functional diagram or SADT is recommended. Sometimes, a combination of two can be an ideal situation, [11], or even, modification of the already known diagrams (like adding processing times or entities in the Flow chart).

Based on the analysis performed with the diagrams, a simulation model was developed. It is shown in Figure 7. For this example, it was concluded that the 
combination of the Flow chart and the Process chart gives an optimal solution when developing the conceptual model.

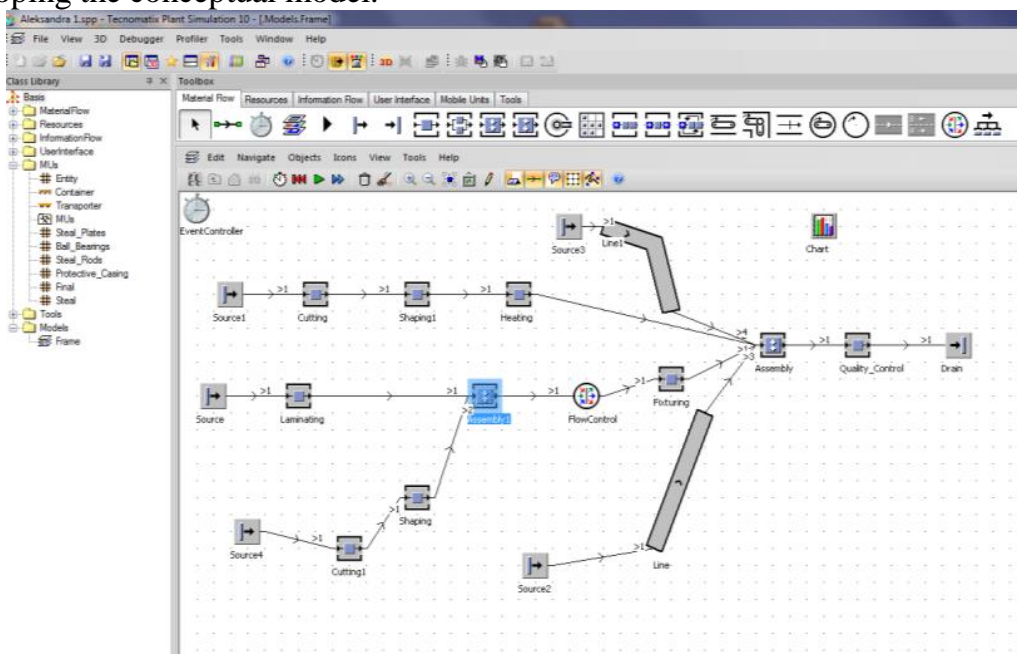

Figure 7. Simulation model for the process of making padlocks

\section{Conclusion}

The benefits of using simulation modelling in the decision making process are considerably big. In order to make the most out of the simulation model, it has to be developed with a systematic analysis of the real world. For that, the conceptual phase of the modelling process needs to be performed with a lot of care. The core of this phase is the visual mapping of the analysed process. Four different diagrams were analysed: Flowchart Diagram, Process Chart, Cross-Functional Diagram and SADT for one case.

Each diagram was used to model the process and positive/negative comments were given regarding the experience. It is concluded that one simple answer from this research cannot be given. None of the methods covered the desired output from the conceptual phase. That is why, a combination of Flowchart and Process chart was used. It is recommended that every modelar knows more than three different mapping methods in order to choose the best for the given situation.

\section{References}

1. Banks, J., Handbook of simulation. Handbook of simulation, ed. J. Banks. Vol. 32. 1998: Wiley Online Library. 849.

2. $\quad$ Robinson, S., Simulation: The Practice of Model Development and Use. Vol. 67. 2004: John Wiley\& Sons Ltd. 336-336.

3. Robinson, S., et al., eds. Conceptual Modeling for Discrete-Event Simulation. 2010, CRC Press. 
A. Simonovska, B. D. Jovanoski, R. Minovski \& V. Gecevska: Chapter 2

Analysis of Visual Methods for more Effective Simulation

4. Sharp, A. and P. McDermott, Workflow Modeling - Tools for Process Improvement and Applications Development. 2009: Artech House.

5. Aalst, W.c.d. and K.v. Hee, Workflow management: models, methods and systems. 2002: MIT.

6. Jacka, J.M. and P.J. Keller, Business process mapping : improving customer satisfacion. 2009: John Wiley \& Sons, Inc.

7. Crittenden, V.L. and A.G. Woodside, Mapping strategic decision-making in cross-functional contexts. Journal of Business Research, 2006. 59(3): p. 360-364.

8. Minovski, R., Management Information Systems. 2007, Skopje: UKIM.

9. Parry, G.C. and C.E. Turner, Application of lean visual process management tools. Production Planning and Control: The management of operations, 2006. 17(1): p. 77-86.

10. Ahmed, F., S. Robinson, and A.A. Tako, Using the structred analysis and design technique (SADT) in simulation conceptual modeling. 2014: p. 1038-1049.

11. Jovanoski, B., et al., Managing strategy and production through hybrid simulation. Industrial Management \& Data Systems, 2013. 113(8): p. 1110-1132. 
AdVANCES In PRoduction AND INDUSTRIAL ENGINEERING 


\title{
Chapter 3
}

\section{Advanced Methods for Job Shop Scheduling}

\author{
BORUT BUCHMEISTER, ROBERT OJSTERŠEK \& IZTOK PALČIČ
}

\begin{abstract}
Scheduling is a decision-making process used on a regular basis in many manufacturing and service industries. It plays an important role in shop floor planning. Job shop scheduling is a combinatorial optimization problem in which jobs are assigned to resources at particular times. Jobs represent activities and machines represent resources. Schedule is a timetable for both jobs and machines. Complex and mathematically involved scheduling methods require substantial and extensive knowledge. Since job shop scheduling problems fall mostly into the class of NP-hard problems, they are among the most difficult to formulate and solve. In the chapter, a selection of advanced job shop scheduling methods is represented: filtered beam search, constraint-guided heuristic search and genetic algorithms, all demonstrated with simple examples.
\end{abstract}

Keywords: - job shop - scheduling - filtered beam search • constraint-guided search $\bullet$ genetic algorithms

Correspondence Adress: Borut Buchmeister, Ph.D., Full Professor, University of Maribor, Faculty of Mechanical Engineering, Smetanova ulica 17, 2000 Maribor, Slovenia, e-mail: borut.buchmeister@um.si, Robert Ojsteršek, Young Researcher, University of Maribor, Faculty of Mechanical Engineering, Smetanova ulica 17, 2000 Maribor, Slovenia, e-mail: robert.ojstersek@um.si, Iztok Palčič, Ph.D., Associate Professor, University of Maribor, Faculty of Mechanical Engineering, Smetanova ulica 17, 2000 Maribor, Slovenia, e-mail: iztok.palcic@um.si

https://doi.org/10.18690/978-961-286-028-8.3 ISBN 978-961-286-028-8

(C) 2017 University of Maribor Press

Available at: http://press.um.si. 


\section{Introduction}

On the market, which is shaped by increasingly more demanding customers, the rising number of providers and the competitiveness between them, and right business and production strategy are the deciding factors of a company's success [1]. It is not enough only to keep up with the others. Today, success represents sustainability in introducing new standards and orientation toward the customer, to the quality and price of products, to flexibility, agility and promptness, to economising in resources and protection of the environment [2]. There are an increasing number of companies, which produce mostly with a job shop system for a known customer. With competitive cost calculation and appropriate product quality, time is becoming the most important factor of business success. This is especially noticeable in job shop production, where adaptability and shortening of flow times decide on the business success or failure of the company [3].

Scheduling is as old as humankind is. It is about time and some optimisation. It is an act of defining priority or arranging activities to meet certain requirements, constraints or objectives. Time is always a major constraint. People schedule their activities so that jobs could be accomplished within the available time. Time to get up, time to work, to play, to sleep ... Time is a limiting unrecoverable resource and we must schedule our activities to utilise this limited resource in an optimum manner. Recent studies indicate the need for scheduling tools that focus on the actual work routine, characteristics of the scheduling environment, and cognitive tasks of the schedulers [4].

As the industrialized world develops, more and more resources are becoming critical. Machines, workers and facilities are now thought of as resources in production or service activities. Scheduling these leads to increased efficiency, utilization and profitability for the company [5].

We have to think about time all the time. We trade time for money. Efficient use of time is namely one of the greatest indicators of competitiveness.

\section{Role and impact of scheduling}

Scheduling is a decision-making process used on a regular basis in many manufacturing and service industries. These forms of decision-making play an important role in procurement and production, in transportation and distribution, and in information processing and communication [6]. The scheduling functions in a company rely on mathematical techniques and heuristic methods to allocate limited resources to the activities that have to be done. This allocation of resources has to be done in such a way that the company optimizes its objectives and achieves its goals. Resources may be machines in a workshop, crews at a construction site, or processing units in a computing environment. Activities may be operations in a workshop, stages in a construction project, or computer programs that have to be executed. Each activity may have a priority level, an 
earliest possible starting time and a due date. Objectives can take many different forms, such as minimizing the time to complete all activities, minimizing the number of activities that are completed after the committed due dates, and so on [7].

Within scheduling in manufacturing in the chapter, a generic manufacturing environment and the role of its scheduling function will be described. Orders that are released in a manufacturing setting have to be translated into jobs with associated due dates. These jobs often have to be processed on the machines in a work-station in a given order or sequence. The processing of jobs may sometimes be delayed if certain machines are busy. Preemptions may occur when high priority jobs are released which have to be processed at once. Unexpected events on the shop-floor, such as machine breakdowns or longer-than-expected processing times, also have to be taken into account, since they may have a major impact on the schedules. Developing, in such an environment, a detailed schedule of the jobs to be performed helps maintain efficiency and control of operations [8].

Production scheduling is an important tool in helping the company provide accurate, real-time schedules, decision support and available-to-promise date and quantities. It is a manufacturing planning tool that is used to represent what the company plans to produce expressed in specific configurations, quantities and dates. It takes into account the forecast, the production plan, and other important considerations such as backlog, availability of material, availability of capacity, and management policies and goals.

The scheduling process also interacts with the production planning process, which handles medium-term to long-term planning for the entire organization. This process intends to optimize the firm's overall product mix and long-term resource allocation based on inventory levels, demand forecasts and resource requirements [9]. Decisions made at this higher planning level may impact the more detailed scheduling process directly. Fig. 1 shows the information flow in a manufacturing system. 


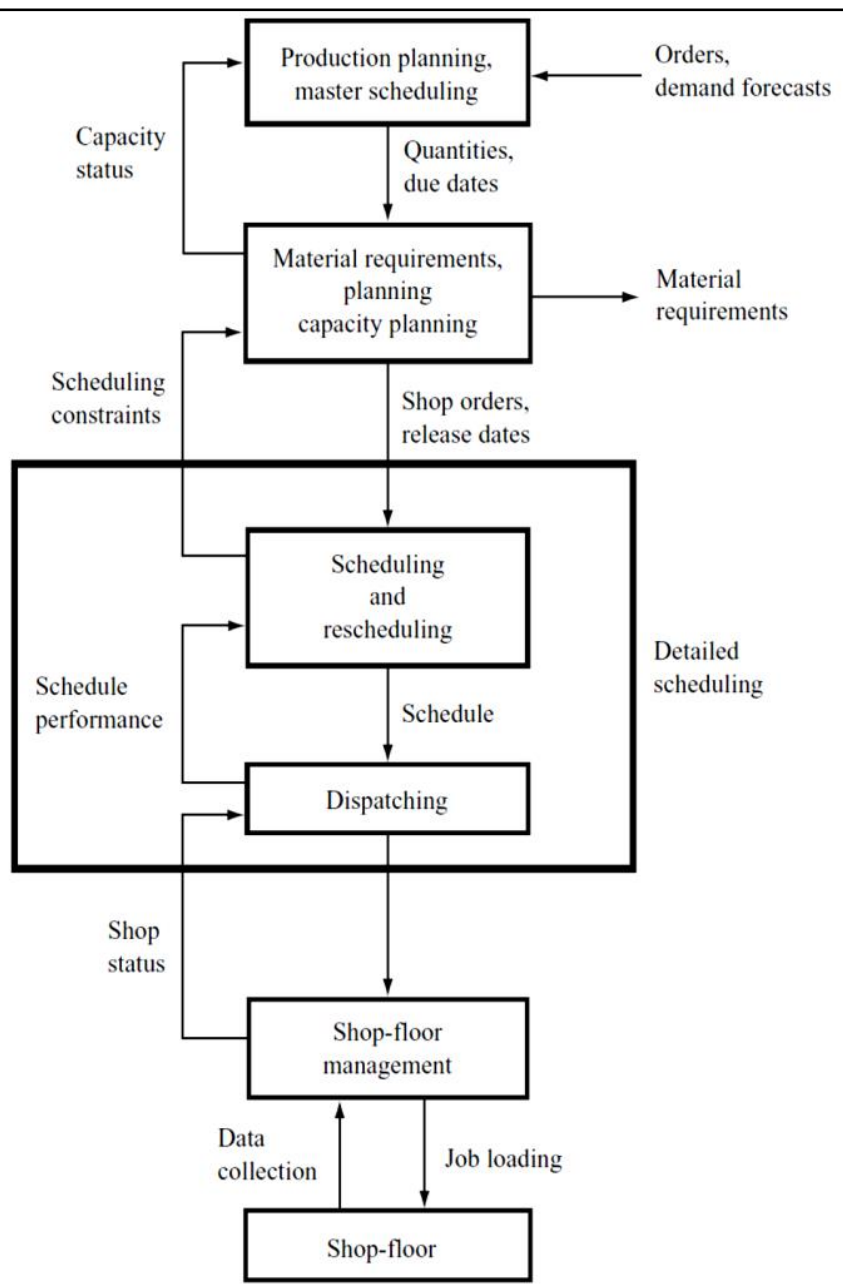

Figure 1. Information flow diagram in a manufacturing system [10]

\subsection{Filtered Beam Search}

This method is based on the ideas of branch and bound. Enumerative branch and bound methods are currently the most widely used methods for obtaining optimal solutions to "NP-hard" scheduling problems. The main disadvantage of branch and bound is that it is usually extremely time consuming, because the number of nodes one must consider is very large (Fig. 2). 


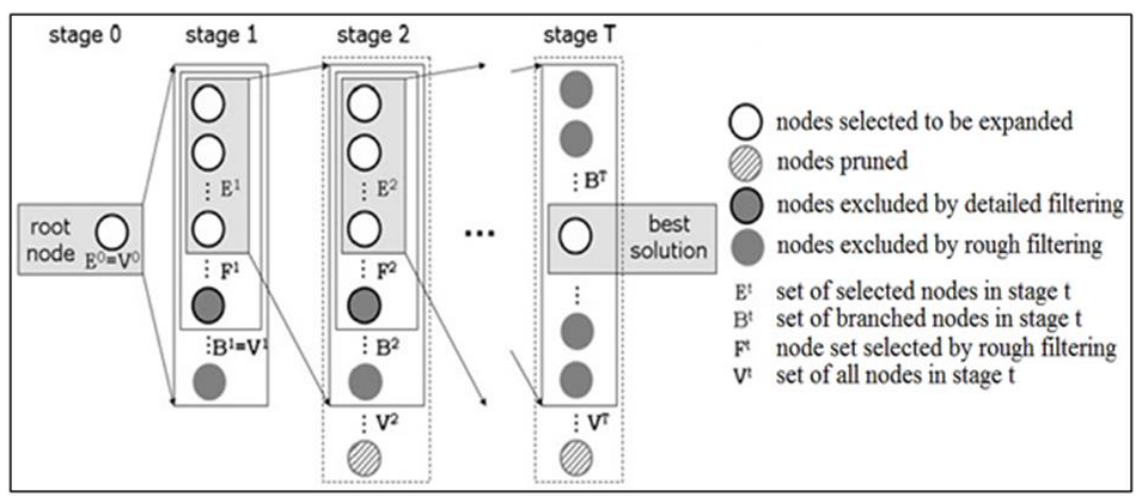

Figure 2. Schematic representation of Filtered Beam Search

Consider, for example, a single machine problem with $n$ jobs. Assume that for each node at level $k$, jobs have been selected for the first $k$ positions. There is a single node at level 0 , with $n$ branches emanating from it to $n$ nodes at level 1 . Each node at level 1 branches out into $n-1$ nodes at level 2, resulting in a total of $n$. $(n-1)$ nodes at level 2. At level $k$, there are $n ! /(n-k)$ ! nodes. At the bottom level, level $n$, there are $n$ ! nodes. Branch and bound method attempts to eliminate a node by determining a lower bound on the objective for all partial schedules that sprout out of that node. If the lower bound is higher than the value of the objective under a known schedule, then the node may be eliminated and its offspring disregarded. If one could obtain a reasonably good schedule through some clever heuristic before going through the branch and bound procedure, then it might be possible to eliminate many nodes. Even after these eliminations, there are usually still too many nodes to be evaluated. The main advantage of branch and bound is that, after evaluating all nodes, the final solution is known with certainty to be optimal [11].

Filtered beam search is an adaptation of branch and bound in which not all nodes at any given level are evaluated. Only the most promising nodes at level $k$ are selected as nodes to branch from. The remaining nodes at that level are discarded permanently. The number of nodes retained is called the beam width of the search. The evaluation process that determines which nodes are the promising ones is a crucial component of this method. Evaluating each node carefully, to obtain an estimate for the potential of its offspring, is time consuming. There is a trade-off here: a crude prediction is quick but may lead to discarding good solutions, whereas a more thorough evaluation may be prohibitively time consuming. Here is where the filter comes in. For all the nodes generated at level k, a crude prediction is done. Based on the outcome of these crude predictions, a number of nodes are selected for a thorough evaluation, and the remaining nodes are discarded permanently. The number of nodes selected for a thorough evaluation is referred to as the filter width. Based on the outcome of the careful evaluation of all nodes that pass the filter, a subset of these nodes (the number being equal to 
the beam width, which, therefore, cannot be greater than the filter width) is selected, from which further branches will be generated.

Example 1: Consider the instance of 1||$\sum w_{\mathrm{j}} T_{\mathrm{j}}$ (using notation $\alpha|\beta| \gamma$ ). The objective is to minimize the sum of the weighted tardinesses. Table 1 contains the basic data (all jobs are available at time zero; due dates are extremely low to expose the objective function).

Table 1. Data for four jobs and notation

\begin{tabular}{|c|c|c|c|c|l|}
\hline Job $j$ & 1 & 2 & 3 & 4 & $j-$ job number \\
\hline$p_{j}$ & 10 & 10 & 13 & 4 & $p_{j}$ - processing time of job \\
\hline$d_{j}$ & 4 & 2 & 1 & 12 & $d_{j}$-due date of job \\
\hline$w_{j}$ & 14 & 12 & 1 & 12 & $w_{j}-$ weight of job \\
\hline
\end{tabular}

Because the number of jobs is rather small, only one type of prediction is made for the nodes at any particular level. No filtering mechanism is used. The beam width is chosen to be 2 , which implies that at each level only two nodes are retained. The prediction at a node is made by scheduling the unscheduled jobs according to the ATC (Apparent Tardiness Cost) rule. With the due-date range factor:

$$
R=\frac{d_{\max }-d_{\min }}{\hat{C}_{\max }}
$$

$R=11 / 37$ and the due-date tightness factor:

$$
\tau=1-\frac{\bar{d}}{\hat{C}_{\max }}
$$

$\tau \approx 32 / 37$, the look-ahead parameter $k$, estimated by the following equations:

$$
\begin{array}{ll}
k=4.5+R, & R<0.5 \\
k=6-2 \cdot R, & R \geq 0.5
\end{array}
$$

is chosen to be 5 . 


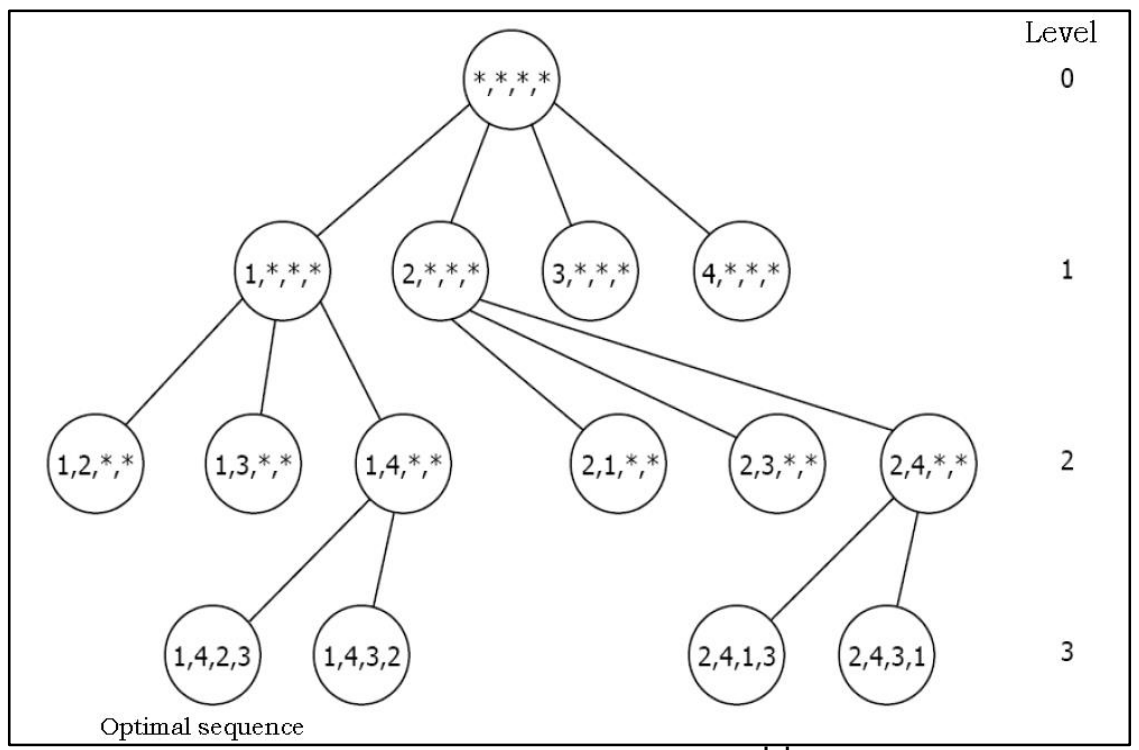

\section{Figure 3. Beam search applied to 1$\rceil \sum w_{j} T j$}

A branch and bound tree is constructed with the assumption that the sequence is developed, starting from $\mathrm{t}=0$. So, at the jth level of the tree jobs are put into the jth position. At the level 1 of the tree, there are four nodes: $(1, * * * *),(2, *, * *)$, $(3, *, *, *)$ and $(4, *, * *)$, see Fig. 3 . Using the ATC rule to the remaining jobs at each one of four nodes results in four sequences: $(1,4,2,3),(2,4,1,3),(3,4,1,2)$ and $(4,1,2,3)$ with objective values $408,436,814$ and 440 . Because the beam width is 2 , only the first two nodes are retained.

Each of these two nodes leads to three nodes at level 2. Node $(1, *, *, *)$ leads to nodes $(1,2, *, *),(1,3, *, *)$ and $(1,4, *, *)$, and node $(2, *, * *)$ leads to nodes $(2,1, *, *)$, $\left(2,3, *{ }^{*}\right)$ and $\left(2,4,{ }^{*}, *\right)$. Applying the ATC rule to the remaining two jobs in each one of the six nodes at level 2 results in nodes $(1,4, *, *)$ and $\left(2,4,{ }^{*}, *\right)$ being retained and the remaining four being discarded.

Two nodes at level 2 lead to four nodes at level 3 (the last level), $(1,4,3,2)$, $(1,4,2,3),(2,4,1,3)$ and $(2,4,3,1)$. Of these four sequences, sequence $(1,4,2,3)$ is the best with a total weighted tardiness equal to 408 . This sequence is optimal.

\subsection{Constraint-Guided Heuristic Search}

In many real-world situations, there is not really an objective. Rather it is required only to generate a feasible schedule that satisfies various constraints and rules. One approach for generating schedules in these situations is referred to in the literature [9] as constraint-guided search. This approach has been very popular among computer scientists and artificial intelligence experts. 
Constraint-guided search may be described best through an example. Consider a number of not necessarily identical machines in parallel. A job has to be processed only on the one of the machines; for each job there may be a feasible set of machines $M_{\mathrm{j}}$ to choose from. Job $j$ requires a processing time $p_{\mathrm{j}}=1, j=1, \ldots, n$ and has release date $r_{\mathrm{j}}$ and the due date $d_{\mathrm{j}}$. The goal is to find a feasible schedule in which all jobs are processed within their respective time windows. In this case the optimal schedule has an objective of value 0 (perfect feasibility).

Constraint-guided search may operate according to the following rules. Jobs are scheduled one at a time. When a job is scheduled, it is assigned to a specific time slot on a specific machine, which is still free. At the each iteration, an unassigned job is selected according to a set of job rules that have been arranged in some priority. The job rules specify whether the particular job actually can be processed on a given machine.

The jobs can be ordered according to their criticality or flexibility; the job with the least flexibility is the most critical and has the highest priority. The flexibility of a job can be measured in several ways (flexibility in time - slack time, flexibility with regard to the number of appropriate machines, etc.).

The machines also can be ordered in such a way that the machine with the least flexibility has the highest priority (the flexibility of a machine, measured by the number of jobs that can be processed on the machine).

An important concept in constraint-guided search is constraint propagation. The assignment of a particular job to a given time slot on a given machine has implications with regard to the assignment of other jobs on the given machine and on other machines. These implications may point to the violation of hard constraints and may indicate that the associated part of the search space can be disregarded.

Example 2: Consider the problem $P 3\left|r_{\mathrm{j}}, p_{\mathrm{j}}=1, M_{\mathrm{j}}\right| \sum U_{\mathrm{j} .} U_{\mathrm{j}}=1$, if $C_{\mathrm{j}}>d_{\mathrm{j}}$, otherwise

$U_{\mathrm{j}}=0$. We have three machines and nine jobs. The processing times, release dates, and due dates of the job are presented in Table 2. If the processing time of a job on a machine is infinity $(\infty)$, then the job cannot be processed on that machine. The goal is to find a feasible schedule with all jobs completed on time $\left(\Sigma U_{\mathrm{j}}=0\right)$. 
Table 2. Data for nine jobs

\begin{tabular}{|c|c|c|c|c|c|c|c|c|c|}
\hline Job $j$ & 1 & 2 & 3 & 4 & 5 & 6 & 7 & 8 & 9 \\
\hline$p_{1 j}$ & $\infty$ & 1 & 1 & $\infty$ & 1 & $\infty$ & $\infty$ & 1 & 1 \\
\hline$p_{2 j}$ & 1 & 1 & $\infty$ & 1 & 1 & 1 & $\infty$ & 1 & 1 \\
\hline$p_{3 j}$ & 1 & 1 & $\infty$ & 1 & 1 & $\infty$ & 1 & $\infty$ & 1 \\
\hline$r_{j}$ & 1 & 1 & 0 & 0 & 0 & 0 & 1 & 1 & 2 \\
\hline$d_{j}$ & 3 & 2 & 1 & 2 & 1 & 1 & 3 & 3 & 3 \\
\hline
\end{tabular}

There are nine timeslots and three on each machine. Each job has its own time window, which represents a set of constraints. For each job, a flexibility factor $\Phi \mathrm{j}$ can be calculated. In this example: $\Phi_{\mathrm{j}}$ is the number of timeslots to which a job may be assigned on various machines. The flexibility factor $\Phi_{\mathrm{j}}$ of job $j$ is presented in Table 3.

Instead of the flexibility of a machine, the flexibility of a timeslot on a machine is determined. It is defined as the number of jobs that can be processed during the timeslot. The flexibility factor $\Phi_{(\mathrm{i}, 1)}$ of job timeslot $(i, l)$ is presented in Table 4 .

Table 3. Flexibility factor of nine jobs

\begin{tabular}{|c|c|c|c|c|c|c|c|c|c|}
\hline Job $j$ & 1 & 2 & 3 & 4 & 5 & 6 & 7 & 8 & 9 \\
\hline$\Phi_{j}$ & 4 & 3 & 1 & 4 & 3 & 1 & 2 & 4 & 3 \\
\hline
\end{tabular}

Table 4. Flexibility factor of job timeslot

\begin{tabular}{|c|c|c|c|c|c|c|c|c|c|}
\hline Machine & 1 & 1 & 1 & 2 & 2 & 2 & 3 & 3 & 3 \\
\hline Timeslot & $(1,1)$ & $(1,2)$ & $(1,3)$ & $(2,1)$ & $(2,2)$ & $(2,3)$ & $(3,1)$ & $(3,2)$ & $(3,3)$ \\
\hline$\Phi_{(i, l)}$ & 2 & 2 & 2 & 3 & 4 & 3 & 2 & 4 & 3 \\
\hline
\end{tabular}

Sequence of jobs in increasing flexibility results in: $3,6,7,2,5,9,1,8$, 4. Priorities of the timeslots may result in the sequence $(1,3),(3,1),(1,1),(1,2),(2,1),(2,3)$, $(3,3),(3,2),(2,2)$.

Job 3 is selected first. It is checked to determine whether it is allowed to be processed in the timeslot $(1,3)$. It is not (too late). The next timeslot is tried $(3,1)$ - not on 3rd machine, and so on, until a timeslot is found during which it is allowed to be processed. Job 3 is then assigned to slot $(1,1)$. Job 6 is considered in the same manner and assigned to slot $(2,1)$. Continuing in this manner results in the following assignment - see Table 5 . All the constraints are fulfilled. 
Table 5. Assignment of jobs to timeslots

\begin{tabular}{|c|c|c|c|c|c|c|c|c|c|}
\hline Timeslot & $(1,1)$ & $(1,2)$ & $(1,3)$ & $(2,1)$ & $(2,2)$ & $(2,3)$ & $(3,1)$ & $(3,2)$ & $(3,3)$ \\
\hline Job & 3 & 2 & 9 & 6 & 8 & 1 & 5 & 4 & 7 \\
\hline
\end{tabular}

After a job has been assigned, the flexibility factors of the remaining jobs to be assigned and the remaining timeslots available may change. It would have been possible to reorder the remaining jobs, as well as the remaining timeslots, based on the new flexibility factors. In the example above this was not done.

Constraint-guided search does not always yield a feasible solution after the first pass. It may occur that when the last job has to be assigned, no feasible assignment is possible. In this case, the method has to rely on a post-processing procedure, which, through pairwise interchanges, attempts to construct a feasible solution.

\subsection{Genetic Algorithms}

Genetic algorithms (GA) are an optimization methodology based on a direct analogy to Darwinian natural selection and mutations in biological reproduction. In principle, genetic algorithms encode a parallel search through concept space, with each process attempting coarse-grain hill climbing. Instances of a concept correspond to individuals of a species. Induced changes and recombinations of these concepts are tested against an evaluation function to see which ones will survive to the next generation [12]. The use of genetic algorithms (Fig. 4) requires five components:

1. A way of encoding solutions to the problem - fixed length string of symbols.

2. An evaluation function that returns a rating for each solution.

3. A way of initializing the population of solutions.

4. Operators that may be applied to parents when they reproduce to alter their genetic composition such as crossover (i.e., exchanging a randomly selected segment between parents), mutation (i.e., gene modification), and other domain specific operators.

5. Parameter setting for the algorithm, the operators, and so forth. 


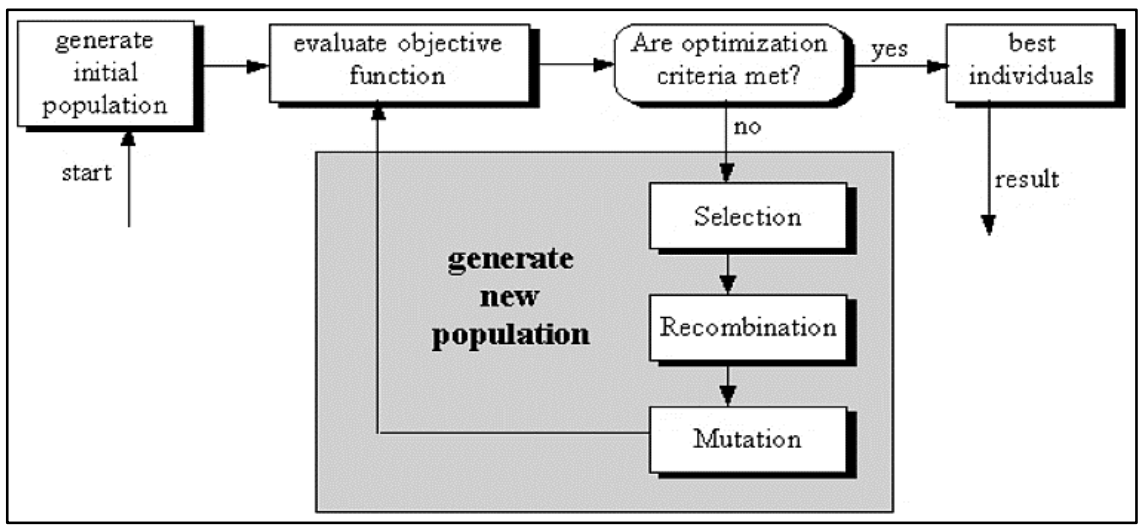

Figure 4. Structure of a simple genetic algorithm

Two basic encoding approaches, direct and indirect, are applicable. The direct approach encodes a job shop schedule as a chromosome and the genetic operators are used to evolve these chromosomes into better schedules. In the indirect approach, a sequence of decision preferences is encoded into the chromosome, for example scheduling rules for job assignments, and the genetic operators are applied to improve the ordering of the various preferences. A job shop schedule is then generated from the sequence of preferences [13].

A number of approaches have been utilized in the application of genetic algorithms (GA) to scheduling problems:

1. Genetic algorithms with blind recombination operators have been utilized in job shop scheduling. Their emphasis on relative ordering schema, absolute ordering schema, cycles, and edges in the offsprings will arise differences in such blind recombination operators.

2. Sequencing problems have been also addressed by the mapping of their constraints to a Boolean satisfiability problem using partial payoff schemes. This scheme has produced good results for very simple problems.

3. Heuristic genetic algorithms have been applied to job shop scheduling. In these genetic schemes, problem specific heuristics are incorporated in the recombination operators (such as optimization operators based).

Example 3: A simple genetic algorithm is used to treat the job shop problem. This algorithm was developed independently, without regard for the work of other researchers [14]. The intention was to make a simple algorithm, which will try to find the schedule with the smallest makespan. Only genetic operations are used in order to achieve this. It is possible to schedule a various number of jobs, but neither release times nor due dates are considered. Only selection and permutation are used as genetic operations. The algorithm uses random moves to search for the 
optimal schedule in the solution space, which means that the solution is obtained without the help of heuristic methods.

How to encode solutions to chromosomes to ensure feasible solutions is a key issue for genetic algorithms. In our algorithm, the preference list-based representation is used. In this encoding method, the operations are arranged in a certain order. It depends on this order, how the operations will be processed on the machines. It is very important, that the precedence constrains of operations of individual jobs are considered. This means, that the sequence of operations of a job must stay intact also in the encoded solution. How the encoding works is shown on a simple example. Table 6 shows a $3 \times 3$ instance; 3 jobs ( 9 operations) must be scheduled on 3 machines (M1, M2, M3) to achieve the smallest possible makespan.

Table 6. Data for a $3 \times 3$ instance

\begin{tabular}{|c|c|c|c|c|c|c|}
\hline \multirow{2}{*}{ Jobs } & \multicolumn{3}{|c|}{ Processing times } & \multicolumn{3}{c|}{ Processing order } \\
\cline { 2 - 7 } & \multicolumn{3}{|c|}{ Operations } & \multicolumn{3}{c|}{ Operations } \\
\cline { 2 - 7 } & 1 & 2 & 3 & 1 & 2 & 3 \\
\hline J1 & 29 & 78 & 9 & machine M1 & machine M2 & machine M3 \\
\hline J2 & 43 & 90 & 28 & machine M1 & machine M3 & machine M2 \\
\hline J3 & 91 & 85 & 74 & machine M2 & machine M1 & machine M3 \\
\hline
\end{tabular}

From the Table 6 it is possible to write the operation sequence for each job:

$$
\begin{aligned}
& \text { J1 (J1 M1 29) (J1 M2 78) (J1 M3 9) } \\
& \text { J2 (J2 M1 43) (J2 M3 90) (J2 M2 28) } \\
& \text { J3 (J3 M2 91) (J3 M1 85) (J3 M3 74) }
\end{aligned}
$$

Job J1 must first be processed on machine M1 for 29 time units. After that on machine M2 for 78 units and the last is machine M3 for 9 units. Similar goes for the other two jobs. The schedule for this instance is encoded into a string, where the position of the operation in the string plays an important role. Operations are ordered with the help of a randomizer. Therefore, it is important to use a reliable randomizer. String making in our case looks like this:

a) A list of first operations of all jobs has been made.

$$
\text { ((J1 M1 29) (J2 M1 43) (J3 M2 91)) }
$$

b) From the list of first operations, one operation is chosen randomly; let's say (J2 M1 43). This operation is the first operation in the string. The operation is taken from the corresponding job and inserted into the string. 


\section{String:}

c) Again, a list of first operations of all the jobs is made and an operation is randomly selected from the list; let's say (J1 M1 29). This operation is taken from the corresponding job and inserted as second operation in the string.

$$
\begin{aligned}
& \text { J1 (J1 M2 78) (J1 M3 9) } \\
& \text { J2 (J2 M3 90) (J2 M2 28) } \\
& \text { J3 (J3 M2 91) (J3 M1 85) (J3 M3 74) }
\end{aligned}
$$

String:

$$
\text { ((J2 M1 43) (J1 M1 29)) }
$$

d) The procedure is repeated until all the operations from the jobs are transferred into the string.

If the procedure, described above, would be continued until the end, the string could look like this:

$$
\begin{aligned}
& \text { ((J2 M1 43) (J1 M1 29) (J1 M2 78) (J3 M2 91) (J2 M3 90) } \\
& \text { (J3 M1 85) (J2 M2 28) (J1 M3 9) (J3 M3 74)) }
\end{aligned}
$$

This string will be used later on for demonstrations. A closer look at the string reveals that the precedence constrains have been considered during the making of the string. Job operations in the string still have the same processing order, but now they are mixed together. Why this is so important is explained below.

Because the string making is left to coincidence, it is possible to make many versatile strings (organisms) which are necessary for the initial population.

Only feasible strings represent a solution to our problem and therefore it is very important that feasibility is maintained throughout the searching process. Because in our case the goal lies in the time optimization of schedules, we are interested in the makespan. Besides the makespan, we are interested also in the processing order on the machines. The Gantt chart (string evaluation) is done step by step with adding operations one after another. In our case, the operations are added directly from the string, from the left side to the right side. The operations, which are at the beginning of the string, have a higher processing priority than those at the end. This means, that the Gantt chart and the makespan depend only upon the order in the string. That is why it is so important, that the operation order in the string is 
according to the precedence constrains. Otherwise, the evaluation would give a false value. The Gantt chart for our string is shown in Fig. 5.

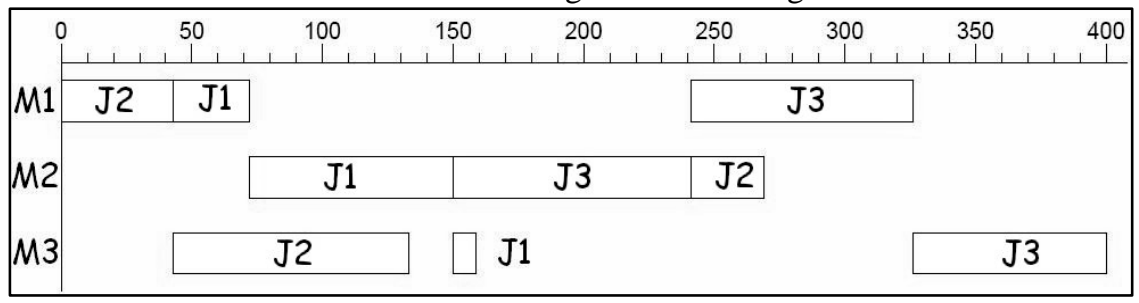

Figure 5. Gantt chart for the $3 \times 3$ instance

String:

$$
\begin{aligned}
& \text { ((J2 M1 43) (J1 M1 29) (J1 M2 78) (J3 M2 91) (J2 M3 90) } \\
& \text { (J3 M1 85) (J2 M2 28) (J1 M3 9) (J3 M3 74)) }
\end{aligned}
$$

Because the use of graphic Gantt charts in programming would be annoying, Gantt charts in numerical form are used. These charts are not as synoptic as graphical, but it is possible to comprehend all the important data from them. The Gantt chart in Fig. 4 looks in numerical form like this:

$$
\begin{aligned}
& \text { M1 (0 J2 43) (43 J1 72) (241 J3 326) } \\
& \text { M2 (72 J1 150) (150 J3 241) (241 J2 269) } \\
& \text { M3 (43 J2 133) (150 J1 159) (326 J3 400) }
\end{aligned}
$$

Genetic operations are the driving force in genetic algorithms. Which operations are reasonable to use for solving a certain problem depends on the encoding method. The only genetic operation, which is independent from encoding, is selection. Selection is the most simple of all genetic operations. In our algorithm, the tournament selection is used. Its purpose is to maintain the core of good solutions intact. This is done with transferring good solutions from one generation to the next one. Because selection does not change the organism (string), we have no problem with maintaining feasibility, which is not the case in all other genetic operations. The use of the crossover operation can be problematical in some cases. The crossover operation often produces infeasible offspring, which are difficult to repair.

The only genetic operation besides selection, which is used in our algorithm, is permutation. The permutation is based on switching operations inside the organism. The organism, which will be permutated, is chosen with the selection. When executing the permutation it is necessary to consider the precedence constrains. The permutation procedure is described and shown on our string from Table 6:

a) A random operation is chosen from the string; let's say (J2 M1 43). 
String:

((J2 M1 43) (J1 M1 29) (J1 M2 78) (J3 M2 91) (J2 M3 90)

(J3 M1 85) (J2 M2 28) (J1 M3 9) (J3 M3 74))

b) The left and the right border for the chosen operation have to be defined. Because the chosen operation belongs to job J2, it is necessary to search for the first operation, left and right of the chosen operation, which belongs to job J2. If the operation does not exist, the border is represented by the end or the beginning of the string. In our case, the right border is represented by the operation (J2 M3 90) and the left border is presented by the beginning of the string. In the string, the space between the borders is marked with square brackets.

String:

([(J2 M1 43) (J1 M1 29) (J1 M2 78) (J3 M2 91)] (J2 M3 90)

(J3 M1 85) (J2 M2 28) (J1 M3 9) (J3 M3 74))

c) A random position between the brackets is chosen where the operation (J2 M1 43) is inserted; let us say in front of (J1 M2 78).

String:

((J1 M1 29) (J2 M1 43) (J1 M2 78) (J3 M2 91) (J2 M3 90)

(J3 M1 85) (J2 M2 28) (J1 M3 9) (J3 M3 74))

This procedure randomly changes the chosen organism, which also changes the solution, which the organism represents. Because there is often necessary to switch more than one operation in the organism, it is possible to repeat the whole procedure over and over.

Evolution parameters are parameters, which influence the searching procedure of the genetic algorithm. If we want to obtain good solutions, the parameters have to be set wisely. These parameters are:

- selection pressure,

- population size,

- amount of change, made by genetic operation,

- share of individual genetic operations in the next generation,

- number of generations (stopping criterion),

- number of independent civilizations.

The selection pressure defines what kind of solutions will be used in genetic operations. If the selection pressure is high, then only the best solutions will get the chance. If it is low, then also worse solutions are used. The higher the selection 
pressure, the higher the possibility that the search will end up in a local optimum. If it is too low, the search procedure examines insignificant solutions, which protracts the whole search.

When an organism is being modified, it is necessary to specify how much the genetic operation will change the organism. It is recommended that small and large changes are made to the organisms. This assures versatility in the population.

Each genetic operation must make a certain amount of organisms for the next generation. At least $10 \%$ of the next population has to be made with selection [15], so that the core of good solutions is maintained. All the other organisms are created with other genetic operations.

If the number of generations is multiplied with the size of the population, we get the number of organisms, which have been examined during the search. When solving complex problems, the number of organisms is greater than in easier cases. The question is, should the search be executed with a small population and a lot of generations or opposite. In most cases, a compromise is the best choice.

Because the search with genetic algorithms bases on random events, it is not necessary that good solutions are obtained in every civilization. In most cases, the search stops in a local optimum. That is why it is necessary to execute multiple searches for a given problem.

The algorithm was tested on the benchmark $10 \times 10$ instance (see the results in Table 7 for the data in Table 8), which was proposed by Fisher and Thompson [16].

Rows contain the order of the operations for each job Ji: each entry $(\mathrm{Mj}, \mathrm{p})$ contains the code of machine $\mathrm{Mj}$ and the processing time pij on it.

Table 7. Evolution parameters and results for the $10 \times 10$ instance

\begin{tabular}{|l|c|}
\hline Parameter & $\mathbf{1 0} \times \mathbf{1 0}$ \\
\hline Population size & 200 \\
\hline Number of generations & 500 \\
\hline Number of independent populations & 100 \\
\hline Optimal solution & 930 \\
\hline Best solution obtained & 941 \\
\hline
\end{tabular}


Table 8. The 10 job 10 machine instance [16]

\begin{tabular}{|c|c|c|c|c|c|c|c|c|c|c|}
\hline \multirow{2}{*}{ Jobs } & \multicolumn{10}{|c|}{ Operation sequence } \\
\cline { 2 - 11 } & 1. & 2. & 3. & 4. & 5. & 6. & 7. & 8. & 9. & 10. \\
\hline J1 & M1 29 & M2 78 & M3 9 & M4 36 & M5 49 & M6 11 & M7 62 & M8 56 & M9 44 & M10 21 \\
\hline J2 & M1 43 & M3 90 & M5 75 & M10 11 & M4 69 & M2 28 & M7 46 & M6 46 & M8 72 & M9 30 \\
\hline J3 & M2 91 & M1 85 & M4 39 & M3 74 & M9 90 & M6 10 & M8 12 & M7 89 & M10 45 & M5 33 \\
\hline J4 & M2 81 & M3 95 & M1 71 & M5 99 & M7 9 & M9 52 & M8 85 & M4 98 & M10 22 & M6 43 \\
\hline J5 & M3 14 & M1 6 & M2 22 & M6 61 & M4 26 & M5 69 & M9 21 & M8 49 & M10 72 & M7 53 \\
\hline J6 & M3 84 & M2 2 & M6 52 & M4 95 & M9 48 & M10 72 & M1 47 & M7 65 & M5 6 & M8 25 \\
\hline J7 & M2 46 & M1 37 & M4 61 & M3 13 & M7 32 & M6 21 & M10 32 & M9 89 & M8 30 & M5 55 \\
\hline J8 & M3 31 & M1 86 & M2 46 & M6 74 & M5 32 & M7 88 & M9 19 & M10 48 & M8 36 & M4 79 \\
\hline J9 & M1 76 & M2 69 & M4 76 & M6 51 & M3 85 & M10 11 & M7 40 & M8 89 & M5 26 & M9 74 \\
\hline J10 & M2 85 & M1 13 & M3 61 & M7 7 & M9 64 & M10 76 & M6 47 & M4 52 & M5 90 & M8 45 \\
\hline
\end{tabular}

As it can be seen from Table 7, the algorithm did not manage to find the optimal solution for the problem, but due its simplicity, the algorithm was able to obtain good solutions.

The number of possible schedules $S$ (solutions) can be calculated with eq. (4), where $m$ represents the number of machines and $n$ represents the number of jobs.

$$
S=(n !)^{m}
$$

So, for our case we get: $S_{10 \times 10} \approx 4 \times 10^{65}$ possible schedules. Because the algorithm is written in the LISP programming language, the search procedure took relatively long time. The best obtained solution deviates $1.2 \%$ from the optimal solution. The best result was obtained in only 1 run out of 100 runs.

The search procedure often falls in a local optimum. When this happens, it is very unlikely that the search will proceed to a better solution, because a memory function is not present. This means that the quality of the final solution depends on the initial population and pure chance. So, the search procedure must be repeated several times for a specific problem [17].

\section{$4 \quad$ Conclusion}

Scheduling is the allocation of shared resources over time to competing activities. Scheduling in praxis means knowing:

- The status and priority of each order on the shop floor.

- Which machines and other resources (e.g. sub components, materials, tooling and operators) are required for each order. 
- When these resources are required and when they will be available. When do we expect the resources to arrive or be available?

Scheduling balances due dates, machine capacity, tooling and labour to develop a realistic plan of action to move orders through various operation steps [18].

Advanced scheduling methods are potential tools for making (near) optimal and feasible schedules [19]. For the applications in praxis, it is important to understand how the resulting schedule is generated, unless the schedule will not be used. It is hard to understand why operations are prioritised in a certain sequence for the operators that only see a dispatch list. The resulting sequence of operations has to take into account all capacity, inventory, material availability and delivery time constraints and, at the same time, it should increase throughput and minimize the operational costs [20].

Some classes of manufacturing models, which already have been considered in the literature, may in the future be generalized and extended in new directions. Models considered in the literature often focus on a single objective. In practice, it may very well be the case that several objectives have to be considered at the same time and that the user would like to see a parametric analysis in order to evaluate the trade-offs.

\section{References}

[1] Baesler, F.; Gatica, J. \& Correa, R. (2015). Simulation optimisation for operating room scheduling. International Journal of Simulation Modelling, Vol. 14, No. 2, pp. 215-226, DOI: 10.2507/IJSIMM14(2)3.287

[2] Huang, R. (2010). Multi-objective job-shop scheduling with lot-splitting production. International Journal of Production Economics, Vol. 124, No. 1, pp. 206-213

[3] Buchmeister, B.; Kremljak, Z.; Pandza, K. \& Polajnar, A. (2004). Simulation study on the performance analysis of various sequencing rules. International Journal of Simulation Modelling, Vol. 3, No. 2-3, pp. 80-89

[4] De Man, J. C.; Nehzati, T.; Arica, E.; Kiil, K. (2015). Automating scheduling tasks; experience of a real case. In: Proceedings of the 2015 IEEE International Conference on Industrial Engineering and Engineering Management, pp. 1447-1451, Singapore

[5] Yagmahan, B. \& Yenisey, M. M. (2009). Scheduling practice and recent developments in flow shop and job shop scheduling. In: Computational Intelligence in Flow Shop and Job Shop Scheduling, Chakraborty, U. K. (Ed.), pp. 261-300, Springer-Verlag, Berlin

[6] Blazewicz, J.; Ecker, K. H.; Pesch, E.; Schmidt, G. \& Weglarz, J. (2007). Handbook on scheduling. Springer-Verlag, Berlin

[7] Singh, A. (2014). Resource constrained multi-project scheduling with priority rules \& analytic hierarchy process. Procedia Engineering, Vol. 69 (24th DAAAM International Symposium), pp. 725-734

[8] Kaban, A. K.; Othman, Z. \& Rohmah, D. S. (2012). Comparison of dispatching rules in job-shop scheduling problem using simulation: a case study. International Journal 
of Simulation Modelling, Vol. 11, No. 3, pp. 129-140, DOI: 10.2507/IJSIMM11(3)2.201

[9] Velaga, P. (Optisol) (2013). Production Scheduling for Job Shops, Available from: http://www.optisol.biz/job_shop_scheduling.html, accessed on 25-11-2013

[10] Pinedo, M. L. (2005). Planning and scheduling in manufacturing and services. Springer Science+Business Media, New York

[11] Tasic, T.; Buchmeister, B. \& Acko, B. (2007). The development of advanced methods for scheduling production processes. Strojniski vestnik - Journal of Mechanical Engineering, Vol. 53, No. 12, pp. 844-857

[12] Gao, J.; Gen, M.; Sun, L. \& Zhao, X. (2007). A hybrid of genetic algorithm and bottleneck shifting for multiobjective flexible job-shop scheduling problems. Computers \& Industrial Engineering, Vol. 53, No. 1, pp. 149-162

[13] Nagano, M. S.; Ruiz, R. \& Lorena, L. A. N. (2008). A constructive genetic algorithm for permutation flowshop scheduling. Computers \& Industrial Engineering, Vol. 55, No. 1, pp. 195-207

[14] Lestan, Z.; Brezocnik, M.; Buchmeister, B.; Brezovnik, S. \& Balic, J. (2009). Solving the job-shop scheduling problem with a simple genetic algorithm. International Journal of Simulation Modelling, Vol. 8, No. 4, pp. 197-205

[15] Brezocnik, M. (2000). The use of genetic programming in intelligent manufacturing systems (in Slovene). Faculty of Mechanical Engineering, University of Maribor, Maribor

[16] Fisher, H. \& Thompson, G. L. (1963). Probabilistic learning combinations of local jobshop scheduling rules. In: Industrial Scheduling, Muth, J. F.; Thompson, G. L. (Eds.), pp. 225-251, Prentice Hall, Englewood Cliffs

[17] Tay, J. C. \& Ho, N. B. (2008). Evolving dispatching rules using genetic programming for solving multi-objective flexible job-shop problems. Computers \& Industrial Engineering, Vol. 54, No. 3, pp. 453-473

[18] Saravanan, M.; Haq, A. N.; Vivekraj, A. R. \& Prasad, T. (2008). Performance evaluation of the scatter search method for permutation flowshop sequencing problems. International Journal of Advanced Manufacturing Technology, Vol. 37, No. 11-12, pp. 1200-1208

[19] Jarboui, B.; Ibrahim, S.; Siarry, P. \& Rebai, A. (2008). A combinatorial particle swarm optimization for solving permutation flowshop problems. Computers \& Industrial Engineering, Vol. 54, No. 3, pp. 526-538

[20] Lei, D. (2008). A Pareto archive particle swarm optimization for multi-objective jobshop scheduling. Computers \& Industrial Engineering, Vol. 54, No. 4, pp. 960-971 
AdVANCES In PRoduction AND INDUSTRIAL ENGINEERING 
AdVANCES IN PRODUCTION AND INDUSTRIAL ENGINEERING

F. Čuš \& V. Gecevska

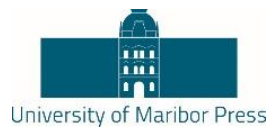

\section{Part II - METHODS FOR PRODUCTION DEVELOPMENT}





\title{
Chapter 4
}

\section{Visual Cutting Chips Size Monitoring in Milling Processes}

\author{
MARKO REIBENSCHUH \& UROŠ ŽUPERL
}

\begin{abstract}
In this research a reliable monitoring using the combination of high speed camera and software development system for milling processes is established. It enables the detection of different features such as chip size and surface roughness, which are directly linked to current cutting conditions and consequently to the quality of the whole machining process. Software for cutting chip size measurements is developed, tested and presented.
\end{abstract}

KEYWORDS: • milling • visual monitoring $・$ chip size $・$ surface roughens $\bullet$ high speed camera

CoRRESPONDENCE AdREss: Marko Reibenschuh, Ph.D., University of Maribor, Faculty of Mechanical Engineering, Smetanova ulica 17, 2000 Maribor, Slovenia, e-mail: marko.reibenschuh@um.si, Uroš Župerl, Ph.D., Associate Professor, University of Maribor, Faculty of Mechanical Engineering, Smetanova ulica 17, 2000 Maribor, Slovenia, e-mail: uros.zuperl@um.si 
On-line [4,5] optimization algorithms run in slow or medium speed applica-tions, where the systems has enough time to gather, evaluate, compute and present the results. Researchers [1,2,3] apply different artificial intelligent methods [6,7] and special programs to achieve improvements in speed of on-line machining optimization algorithms. The methods try to improve the quality of machined surface and increase the tool life. Usually only one of the above mentioned properties can be improved at the same time. The reason is the correlation between different factors. The end quality of the work piece is correlated to feed rate. Feed rate is correlated to cutting forces and this again to tool life. The relations are proven by many researchers and their papers $[6,8]$. Furthermore almost every researcher goes his own way of defining the correlations and setting the rules for optimization. In such a spirit the new system was developed to increases the monitoring speed of machining process.

In our research we concentrate on researching the cutting conditions during end milling and plain milling. The quality of end finishing is not satisfying; therefore there is a lot of space for further research and improvements.

Reviewing up to date research $[9,10,11]$, a decision was made to implement a visual monitoring of cutting quantities.

The developed visual monitoring system is adapted to milling and special programs were developed to monitor chip geometry. The chip formation is at high feed rates very distinctive for a certain type of material and it is quite easy to be visual detected.

\section{$2 \quad$ Visual monitoring system}

The programs to run the devices and form the visual monitoring system were designed in LabVIEW. The software part (feature recognition program) of the whole system was also developed in LabVIEW. LabVIEW enables lot of options and combinations for using the $1772 \mathrm{C}$. In the first settings, the program was set to detect the wear of the cutting tool and a change in the proximity of the cutting tool - chip formation. Next the surface quality recognising is ensured.

The whole system is set up as follows in Fig. 1.

The dashed bracket in Fig. 1 presents a closed loop which is started as soon as the system detects first chips. Once started the closed loop continues until termination. It can be terminated by the operator or the systems itself. On behalf of the inspection results, the interface reports the inspection status to the operator via network variables. If the inspected values are within predefined values, the process runs without interruption. 
On the other hand, if the system detects a measurements deviation or error, a warning is issued for the operator to react. Different options are proposed to the operator. If he does not react in a predefined time, the system automatically changes the parameters.

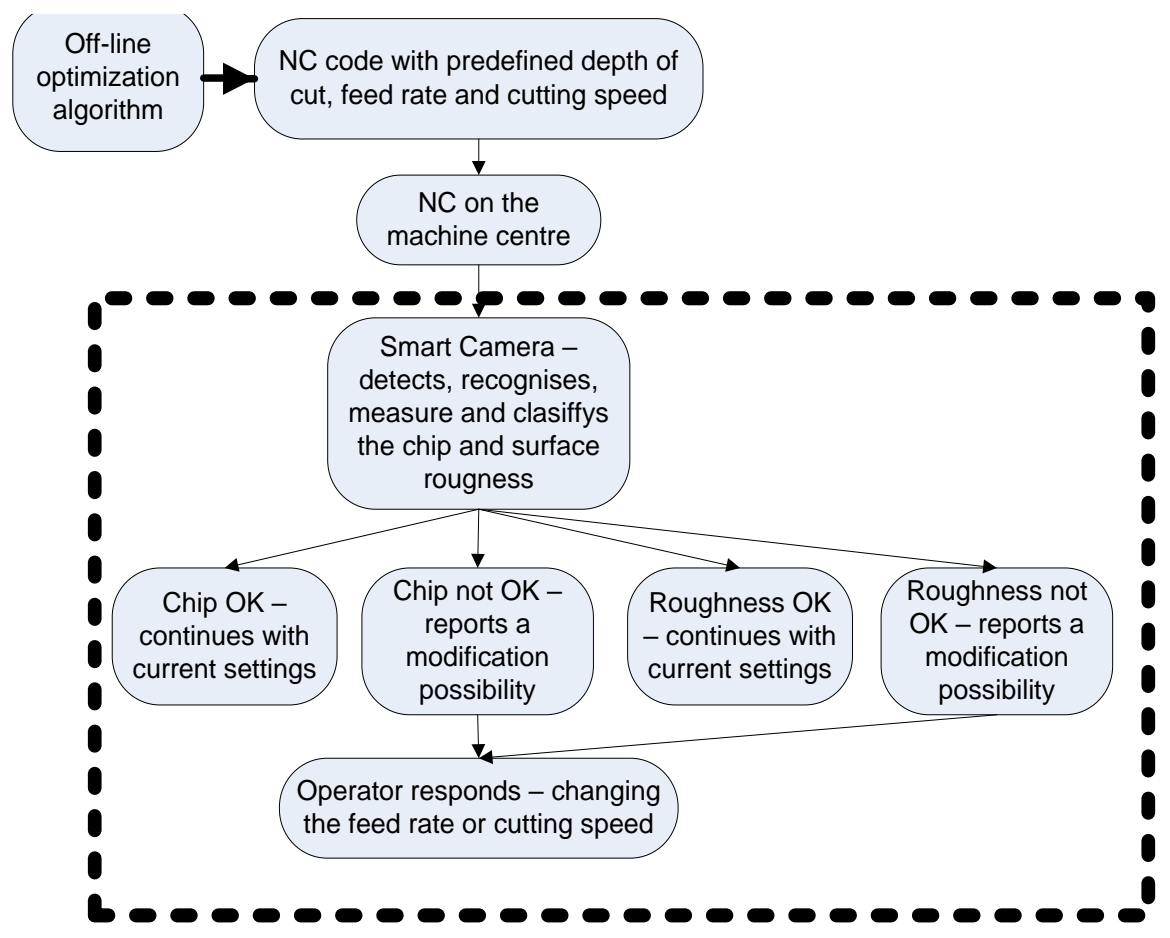

Figure 1.Visual monitoring system architecture

Development and programming for chip and roughness detection was conducted in LabVIEW and Vision Builder (VB) NI.

The main difficulty was the connection between the smart camera and the computer. Namely the smart camera can only be called once from LabVIEW once the connection is established, other programs can't access the camera. This fact had to be taken into account.

\section{$3 \quad$ Experimental set-up}

The experimental setup is shown in Fig. 2. The system consists of a high speed smart camera for online monitoring and special developed software. The smart camera was chosen to visually detect, recognise and measure the chip, surface roughness and tool wear. The used smart Camera 1772C (1772C) is a product of 
National Instrument. The maximum output is 64,995 frames per second (fps). Additional Basler acA640 camera was also used. Its maximum output is $110 \mathrm{fps}$. The $1772 \mathrm{C}$ has all the connectors to connect it to a PC, external lightning, external monitor whereas the acA640 lack these connections. Over the external connection it is possible to connect a LED light source to the 1772C. The options in light settings were set to strobe mode. This mode enables that the light turns on just in the right moment as the camera takes the frame. The intensity of the light is also higher because higher amperage can be set. On continuous light, the maximum can be set at $500 \mathrm{~mA}$, at strobe mode, this value can be set to $1 \mathrm{~A}$. The light is not a single LED diode, but it is an assembled ring light consisting of 24 separate LED's.

The main difference between cameras is in it adjustments possibilities. The $1772 \mathrm{C}$ has a lot of options including the most useful ones: setting the light conditions driver for external light, setting the colour of the gathered frames - RGB or monochrome.

The Basler camera does not support such settings, furthermore it's speed requires a very capable computer with fast processing abilities. Namely the speed of the frame acquisition is for normal computers too fast. Special adaptations are needed for the computer to save and process all the data. SATA 2 ports are physically too slow. It is not the size of the gathered frames that presents a problem but the size respectively the number of frames per second. All the data must be transferred to the PC via Giga Ethernet cable. The 110 files need to be saved. Because every second another 110 frames arrive, the buffer of the computer fills up and consequently the camera slows down - the frame rate begins to fluctuate. A focus on one specific point is not possible.

The $1772 \mathrm{C}$ also possesses its own buffer and so enables to store all gathered frames without a delay in observation. It also has a built in processor. The $1772 \mathrm{C}$ can be used autonomously or connected to a PC via Ethernet port.

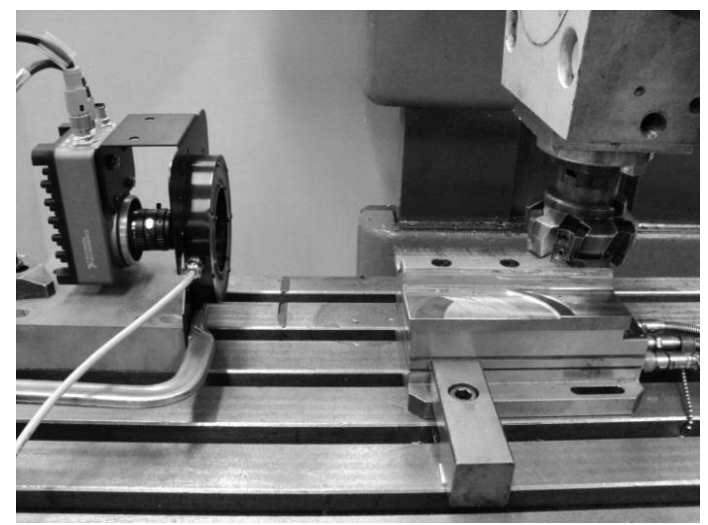

Figure 2. Experimental setup 
For workpiece material a special hard steel alloy was chosen. The hardness of the material ranged from 60 to 64 HRC. Dry cutting conditions were chosen. Cutting fluid is not suitable for vision applications because the camera need a clear side of view - the cutting fluid blurs the view.

The cutting parameters were set to a medium value for a certain type of milling tool (Table 1).

Table 1: Cutting parameters and tool data

\begin{tabular}{|l|c|}
\hline Diameter of the cutting tool & $100 \mathrm{~mm}$ \\
\hline Number of Inserts & 5 \\
\hline Maximum cutting speed & $6500 \mathrm{rpm}$ \\
\hline Medium cutting speed & $3250 \mathrm{rpm}$ \\
\hline
\end{tabular}

Considering the cutting speed of $3250 \mathrm{rpm}$, the tool rotates 54.17 times in a second. To match this value, the value for exposure time and gain was adapted so that the camera captures the same amount of frames - a frame was captured every 0.0185 s. These settings were set in the program Measurement \& Automation Explorer. The values on the machine were set to $3250 \mathrm{rpm}$ and a feed rate was chosen according to the tool.

Various lighting conditions were tested before the right one was chosen. Also some modifications were needed to the whole setup of tool, work piece and equipment, to prevent light reflection and figure distortion.

For an accuracy of $0.1 \mathrm{~mm}$ there are some area limitations. The observed area is $640 \times 480$ pixels which is equivalent to $21.3 \times 16 \mathrm{~mm}$.

For higher or lower values, a new calculation must be made and other settings need to be adjusted. In this case, for insert and chip monitoring, the observed area is just right.

During the testing some issues were raised about the focus of the camera. Because the camera has no auto focus, this must be set manually.

For further testing a holder is being developed, which enables a constant distance to the cutting tool and in doing so, enable sharp frames during the whole testing.

\section{$4 \quad$ Results}

Initial results gathered during the first cut, were used to assess the situation in the cutting zone and to develop a feature recognizing software. The frames acquired during the test are shown in Fig. 3. The detected chips on separate frame are indicated with circles and cross hairs. 
The circular white spots represent the light reflection of the external lightning (led diodes assembled in the ring). White rectangle represents the workpiece. Cutting tool is on the right side of each frame.

To detect the presence of the insert, the size and the shape of it, some additional programs are needed. All of the programming was conducted in LabVIEW 2011.

Figure 4 shows how the program works - detection of insert and taking action (recognition, measurements, classification...). In this step, the insert was recognized and measured.

A green rectangle is displayed on the detected insert. The measured flank tool wear is displayed. The four circular white spots represent the light reflection of the external lightning.

Figure 5 and 6 show the chip detection measurement process. The bigger circle on Figure 6 represents the area of interest - the area where the camera respectively the program searches for a change or familiar shape. When such a change is detected, a smaller circle and square appear on the detected chip (see Figure 6). Now the program classifies the chip according to preset values.

It is also capable of measuring the chip and on behalf of those measurements makes a conclusion on current cutting conditions.

The measured chips are framed with the red squares. The program is similar to the one for insert detection but it has some additional filters and filter settings, logic calculators etc. which allows the detection of different shapes and sizes. 
M. Reibenschuh \& U. Župerl: Chapter 4

Visual Cutting Chips Size Monitoring in Milling Processes

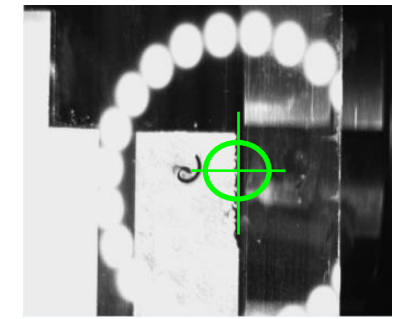

Frame 1

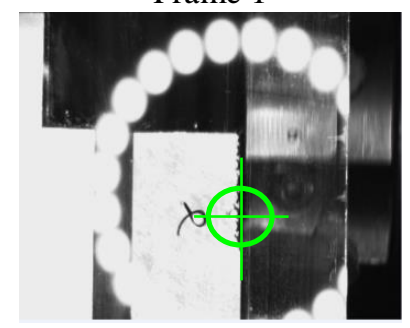

Frame 3

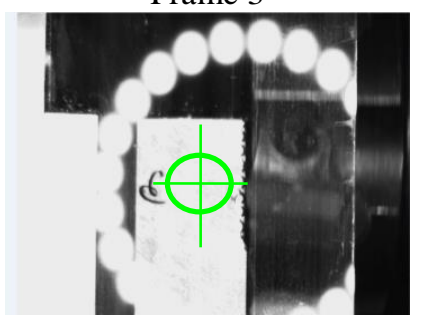

Frame 5

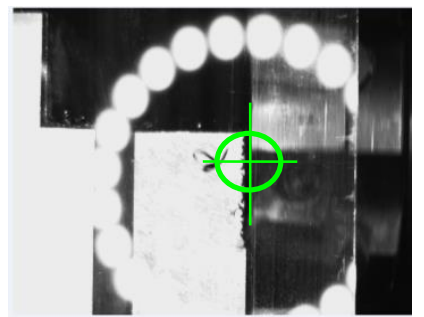

Frame 2

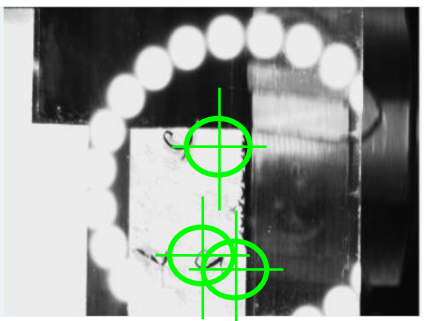

Frame 4

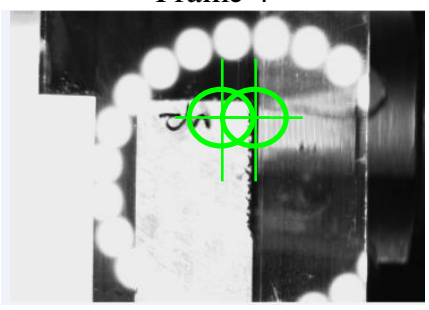

Frame 6

Figure 3. Gathered frames for developing a program

Figure 6 shows how a chip is detected and measured during its flight from the shear zone. A mesh appears and the whole broken off chip is measured.

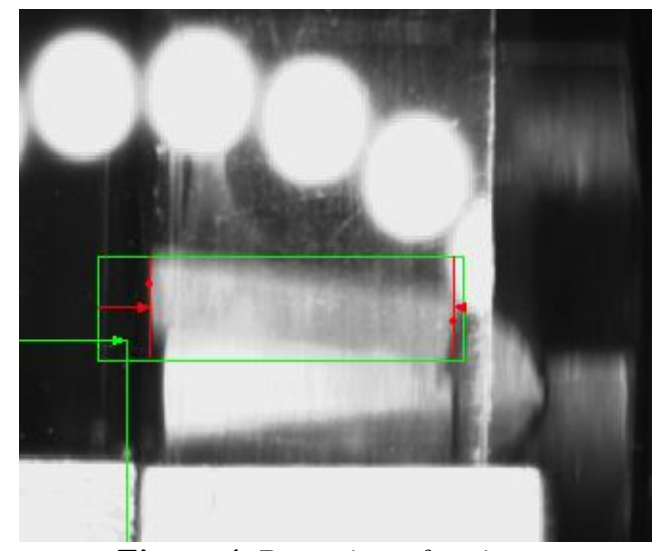

Figure 4. Detection of an insert 
Visual Cutting Chips Size Monitoring in Milling Processes

If the chip is too small, then the cutting parameters are not suitable for cutting such a material. Also visible are the already broken off chips which are not removed from the area of interest.

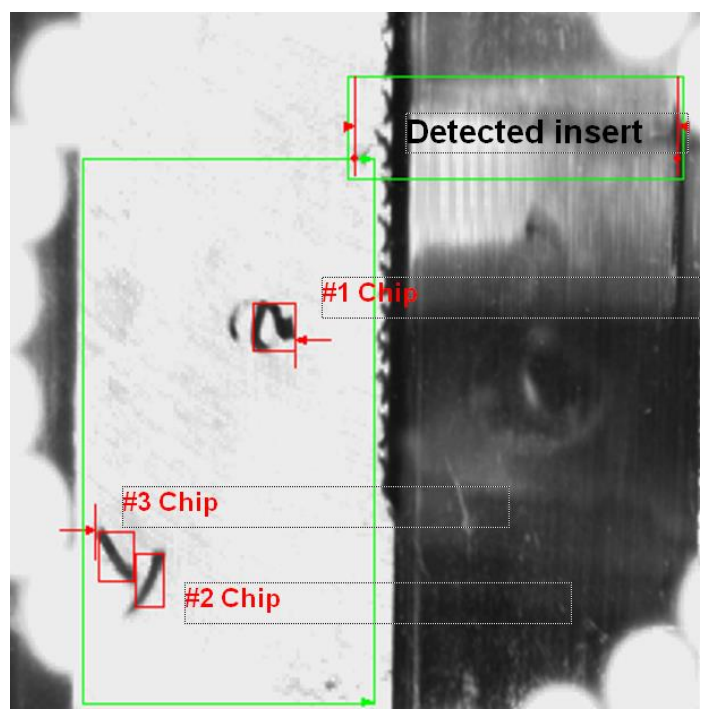

Figure 5. Chip detection

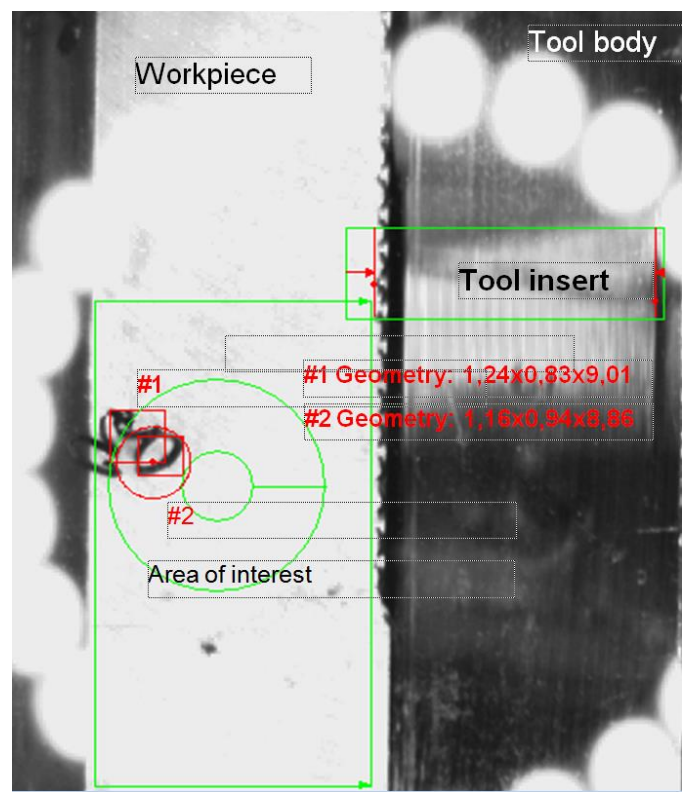

Figure 6. Chip geometry measurement 


\section{Conclusion}

Control of cutting conditions parameters and the influence of them can be performed with modern monitoring systems. In this paper the development and application of a new monitoring system, based on visual detection of cutting chips, is described. The used equipment and software is outlined. Software for chip measurements is developed, tested and presented.

Because of the systems relative low demands for computer power, different applications can be run on a single computer. But for more complex observations, monitoring and data processing in real time a more capable computer is needed.

For further work additional upgrades (tool temperature measurements, tool inspection,...) will be conducted to evaluate the usability of such a monitoring approach. The use of additional cameras is being also evaluated.

\section{References}

[1] Cus, F., Balic, J., Optimization of cutting process by GA approach, Robot. Comput. Integr. Manuf. 19 (2005), pp. 113-121.

[2] Zuperl, U., Cus, F., Gecevska, V., Optimization of the characteristic parameters in milling using the PSO evolution technique, Stroj. vestn. 653 (2007), pp. 354-368.

[3] Zuperl, U., Cus, F., Optimization of cutting conditions during cutting by using neural networks. Robot. Comput.-Integr. Manuf. 19 (2004), pp. 189-199.

[4] Jee, S., Koren, Y., Adaptive fuzzy logic controller for feed drives of a CNC machine tool, Mechatronics 143 (2004), pp. 299-326.

[5] Tsourveloudis, N., Ioannidis, S., Valavanis, K., Fuzzy surplus based distributed control of manufacturing systems. Advances in production engineering \& management 1 (2006), pp. 5-12.

[6] Zuperl, U., Cus, F., Balic, J., Neural Network Based Control Algorithm in Robotised Unmanned Flexible Manufacturing System, Annals of DAAAM for 2010 \& Proceedings of the 21st International DAAAM Symposium, 20-23rd October 2010, Croatia, Katalinic, B. (Ed.), pp. 0305-0306.

[7] Mulc, T., Udiljak, T., Ciglar, D., Brezak, D., Staroveski, T., Application of NonParametric Methods for Monitoring of Tool Chipping. Annals of DAAAM for 2010 \& Proceedings of the 21st International DAAAM Symposium, 20-23rd October 2010, Zadar, Croatia, Katalinic, B. (Ed.), (2010), pp. 0297-0298, Published by DAAAM International Vienna, Vienna.

[8] Xu C., Chen, H., Liu, Z., Cheng, Z., Condition monitoring of milling tool wear based on fractal dimension of vibration signals. Strojniški vestnik - Journal of Mechanical Engineering 55 (2009), 1, pp. 15-25.

[9] Adamczak, S., Janecki, D., Stępień, K., Qualitative and quantitative evaluation of the accuracy of the V-block method of cylindricity measurement. Precision Engineering,. 34/3 (2010), pp. 619-626.

[10] Grigorescu, C., Moraru, S.A., Badea, M., Smart Data Acquisition Software Used in Industrial Monitoring Systems, Annals of DAAAM for 2010 \& Proceedings of the 21st International DAAAM Symposium, 20-23rd October 2010, Croatia, Katalinic, B. (Ed.), pp. 0103-0104. 
[11] Sysel, M., Remote Control and Monitoring in the Simulink. Annals of DAAAM for 2010 \& Proceedings of the 21st International DAAAM Symposium, 20-23rd October 2010, Zadar, Croatia, ISSN 1726-9679, ISBN 978-3-901509-73-5, Katalinic, B. (Ed.), pp. 0205-0206. 


\title{
Chapter 5
}

\section{Mathematical Models with Feedback for Surface Roughness Parameter Prediction in Longitudinal Turning}

\author{
Mite Tomov, MiKolaj KuZINOvsKi \& PIORT CiCHOSZ
}

\begin{abstract}
This chapter presents mathematical models for predicting and roughness parameters based on the kinematical-geometrical copying of the cutting tool onto the machined surface. The feed, the radius and the angles have been used as input parameters in mathematical models. In order to increase the mathematical models' accuracy, as well as their practical applicability, this chapter proposes connecting the R-parameter prediction models with the condition of the surface roughness formation process. The parameter of statistic equality of sampling lengths in surface roughness measurement ( ) has been used for this purpose. The proposed mathematical models were verified using two different CNC lathes, working pieces made of the material 42CrMo (EN), using finishing inserts. The chapter provides the theoretically calculated values, the measured values and the percentage differences between them for the considered R-parameters.
\end{abstract}

Keywords: Surface roughness - R-parameters - Mathematical models $\bullet$ Surface roughness predication. $\bullet$ kinematical-geometrical copying

Correspondence Adress: Mite Tomov, Ph.D., Assistant Professor, ,Ss. Cyril and Methodius" University in Skopje, Faculty of Mechanical Engineering-Skopje, Rudger Boshkovikj bb, Skopje 1000, Republic of Macedonia, e-mail: mite.tomov@mf.edu.mk. Mikolaj Kuzinovski, Ph.D., Full Professor, „Ss. Cyril and Methodius” University in Skopje, Faculty of Mechanical Engineering-Skopje, Rudger Boshkovikj bb, Skopje 1000, Republic of Macedonia, e-mail: mikolaj.kuzinovski@mf.edu.mk. Piotr Cichosz, Ph.D., Full Professor, Wroclaw University of Technology, Faculty of Mechanical Engineering, 5 Łukasiewicza st., 50-371 Wrocław, Poland, e-mail: piotr.cichosz@pwr.edu.pl.

https://doi.org/10.18690/978-961-286-028-8.5 ISBN 978-961-286-028-8

(C) 2017 University of Maribor Press

Available at: http://press.um.si. 
Mathematical Models with Feedback for Surface Roughness Parameter

Prediction in Longitudinal Turning

\section{Introduction}

Surface texture increasingly becomes a dominant factor in the successful operation of mechanical parts. Hence, surface texture or surface roughness becomes the most frequently used parts quality index. Therefore, a great deal of research [1-12] geared towards the development of various optimization methods for surface roughness prediction even in the parts formation stages becomes an increasingly current topic. Generally, the already developed surface roughness prediction methods can be systematized in three groups.

The first group contains the experimental methods for surface roughness prediction, based on and developed by the design of experiments [1-3]. This type of research typically ends with a specific mathematical model for surface roughness prediction with a nonlinear shape or a linear shape (regression shape) after the application of logarithmic transformations. The mathematical models developed in such a way contain a certain constant and exponents of independent input values that apply exclusively to the experimental equipment used to perform the experiments. It is precisely this limitation that can be considered the greatest deficiency of this group of models. Another limitation relates to the fact that the input independent values are being considered (change) in a specific hyperspace (framework), and therefore the obtained models pertain only to the researched hyperspace and not beyond it.

The second group [4-10] includes the experimental surface roughness prediction methods again based on and developed by the design of experiments, but augmented and expanded using another mathematical method (technique). The most commonly used mathematical methods in this regard include response surface methodology $[4,5]$, regression and neural networks [6-8], expert systems $[9,10]$ etc. These mathematical methods enable the model to include a larger number of impact factors with a view of predicting surface roughness as accurately as possible. Still, the limitations for the first group apply here as well.

The third group [11,12] of surface roughness prediction methods rely on the kinematical-geometrical copying of the cutting tool onto the processed surface. Usually, these surface roughness predictions can be found in the catalogues of cutting tools manufacturers. These methods do not have limitations with respect to a particular experimental equipment or hyperspace, but have serious accuracy deficiencies when predicting roughness in specific processing conditions, i.e. cutting regime values. The reason for this is that the analytical formulations for calculating the roughness parameters do not take into consideration the key values, such as the cutting speed $V$ and the cutting depth $a_{p}$, vital for the proper implementation of the process of transformation of the removed material into a chip. Another deficiency may also relate to the fact that the research focuses, primarily, on the two parameters $R_{a}$ and $R_{t}$, which cannot uniquely define the roughness profile. 
The research in this paper firstly aims at developing mathematical models for a specific number of roughness parameters, based on the kinematical-geometrical copying of the cutting tool onto the processed surface, taking into account the impact of as many input values (in addition to $f$ and $r_{\varepsilon}$ ) as possible, and secondly at linking these models to parameters that provide information on the stability of the process. This objective agrees with the essential reason for the metrology discipline which states that surface metrology must enable full control of surface constitution and provide an understanding of the functionally important surface characteristics.

\section{Mathematical models for prediction of the primary profile or roughness profile parameters?}

The surface roughness prediction models presented in [1-12] refer to the roughness profile. According to international ISO standards, as well as other national standards (ANSI, JIS etc.), like the procedure for obtaining the primary profile, the roughness and waviness profiles presented in [13], the roughness profile is a derived value obtained from the total or the primary profile using the $\lambda_{\mathrm{c}}$ and $\lambda_{\mathrm{s}}$ profile filters. Many existing researches aim mainly at obtaining accurate roughness profiles and they refer to software filtration and the types of the $\lambda_{c}$ profile filter [14, 15], mechanical filtration [16-18] etc. Certain errors in obtaining the roughness profile and the roughness parameters can contribute to serious inaccuracies in the surface roughness prediction models.

On the other hand, the contact phenomena (wear, lubrication, friction) occur of the real surface that integrally contains all kinds of first to sixth order deviations according to [13]. Hence the dilemma: Whether mathematical prediction models for primary parameter (P-parameter), based on the principle of kinematicalgeometrical copying, can be developed?

To solve this dilemma we will use Fig. 1 which shows the location of the roughness of the surface from the aspect of the constitution of the surface and its measurement. According to [19], the real surface simultaneously and integrally contains all types of deviations from first to sixth order. Third to fifth order deviations together form the roughness of the surface. If we look at the explanation of the causes of the third to fifth order deviations, Fig. 1, we will conclude that we can only predict the causes for the third order deviations (cutting tool geometry, feed, cutting depth etc.). The causes of the fourth and fifth order deviations are unpredictable and different for different processes and some of them also depend on the causes for the third order deviations.

From the surface roughness measurement point of view, roughness is a derived value, as shown in Fig. 1. The primary profile consists of deviations between the first and second order deviations, Fig. 1. The causes of the first and second order 
deviations also cannot be completely predicted and directly depend on numerous factors such as the condition of the machine, cutting tool and parameters etc. This suggests that the development of mathematical models for predicting the primary profile parameters (P-parameter), based on the principle of kinematicalgeometrical copying of the cutting tool onto the processed surface is unjustified. We can only develop mathematical models that predict the roughness profile parameters (R-parameter) based on the principle of kinematical-geometrical copying.

\section{$3 \quad$ Mathematical model postulates}

We will develop mathematical models for the $R_{z}, R_{p}, R_{v}, R_{a}, R S_{m}$ and $R_{m r(c)} R$ parameters, as a function of the feed $f$, the radius $r_{\varepsilon}$ and the angles $\lambda_{s}, \gamma_{0}, \kappa_{r}$. The angles $\lambda_{s}, \gamma_{0}$ determine whether a circular part (if both of them equal zero) or an ellipse will be copying onto the processed surface. The angle $\kappa_{r}$ additionally determines the position of the ellipse relative to the processed surface. The angles $\lambda_{s}, \gamma_{0}$ directly impact the process of chip formation. All considered $R$-parameters, given above, will apply within the sampling length.

As we mentioned previously, the mathematical formulations for calculating roughness parameters, based on kinematical-geometrical copying of the cutting tool onto the processed surface, do not take into account processing parameters vital to the correct realization of the process of transformation of the removed material into a chip. 


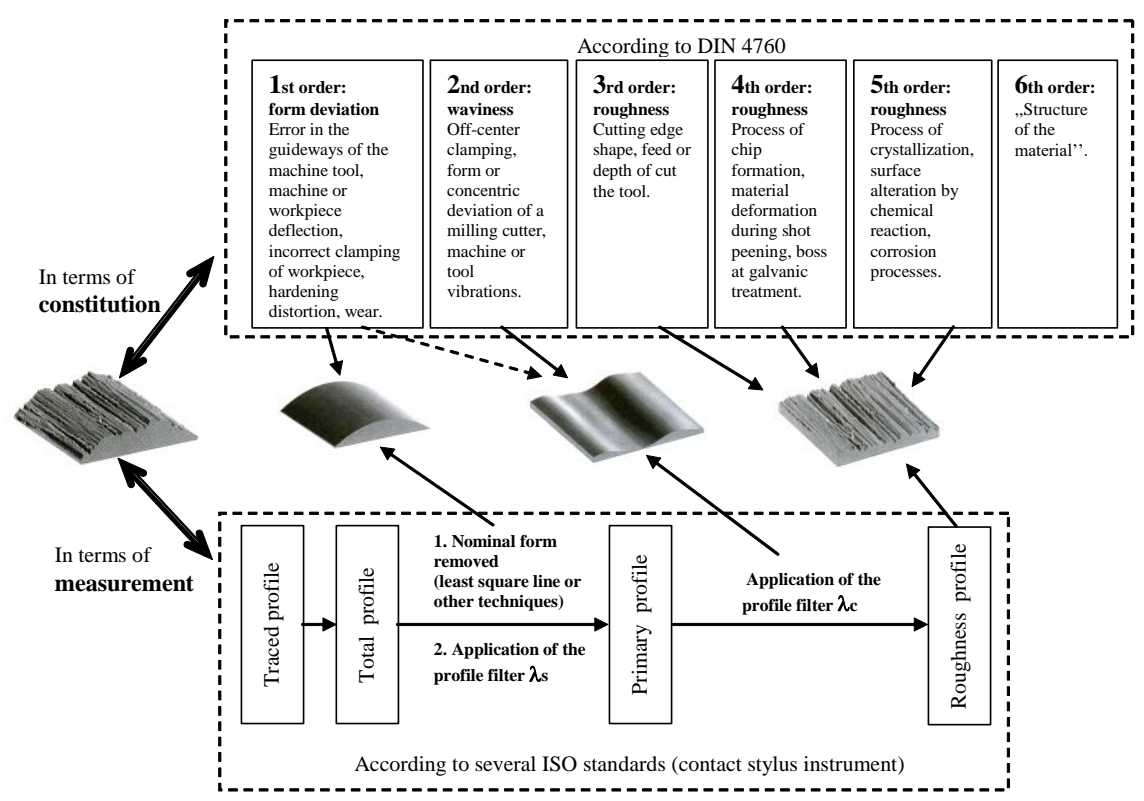

Figure 1. Location of the roughness from the aspect of surface constitution and measurement.

These include the cutting speed $V$ and the cutting depth $a_{p}$. The formation of the surface, or more specifically the surface texture depends not only on the cutting parameters $f, V, a_{p}$ etc. Impact on the texture of the surface, and hence the roughness, have the work piece, with its mechanical properties and thermic preparation, the material of the inserts especially the coatings, the positioning of the tool, the working condition of the machine, the cutting force, the cutting temperatures, the tool wear, the vibrations of the work piece, and especially of the tool etc.

The question is how to take into account all of these influential factors when predicting the surface roughness, when most of them depend on one or more other factors. In order to simplify the impacts of all these factors, this research accepts that the roughness profile comprises the roughness profile obtained by kinematical-geometrical copying of the cutting tool with the addition of (distorted by) the profile formed as a result of the other influential factors, i.e. expressed as:

$$
R=R_{\text {kinem.-geomet. }}+R_{\text {distorting }}
$$

The value of the parameters that describe the $R_{\text {kinem.geomet. }}$ profile will be determined by the suggested mathematical models, while the influence of $R_{\text {distorting }}$ 
will be taken into account using the parameter of statistic equality of sampling lengths in surface roughness measurement (SE) [14].

Basically we will attempt to use the $S E$ parameter to feed back to the models for predicting the roughness parameters depending on the stability and the condition of the surface roughness formation process. According to [14], the $S E$ parameter is calculated as follows:

$$
S E=\frac{K_{s m}}{K_{S}}
$$

where $K_{s m}$ and $K_{s}$ are coefficients obtained as follows:

$$
K_{s m}=\frac{s_{\max }^{2}-s_{\min }^{2}}{s_{\max }^{2}}
$$

where $s_{\max }$ is the value of the maximal standard deviation calculated within the sampling lengths, while $s_{\min }$ is the value of the minimal standard deviation calculated within the sampling lengths.

$$
K_{s}=\frac{s^{-2}}{s_{R}^{2}}
$$

where $\bar{s}$ is the standard deviation calculated as the mean value of the individual standard deviations within the sampling length, while $\mathrm{s}_{\mathrm{R}}$ is the standard deviation calculated for evaluation length of the roughness profile.

Equation (1) expresses not only the simple sum of $R_{\text {kinem.geomet. }}$ and $R_{\text {distorting }}$ but an interaction between $R_{\text {kinem-geomet. }}$ and $R_{\text {distorting }}$, in particular the impact of $R_{\text {distorting }}$ on $R_{\text {kinem.geomet. }}$ The $R$-parameters for which mathematical models will be developed, will be expressed as $R_{z k-g}, R_{p k-g,} R_{v k-g .} R_{a k-g,} R S_{m k-g}$ and $R_{m r(c) k-g}$.

\section{Derivation of the matematical models fort he r-parameters}

\subsection{Kinematical-geometrical copying of the cutting tool}

Planes in the tool-in-hand system [20] and tool angles (turning tool) [20] represent a basis for the setup and the derivation of mathematical models for different geometries (positive, negative and combined) of the cutting tool. The angles $\kappa_{r}, \lambda_{s}$ and $\gamma_{0}$ define the spatial position of the plane $A C D$, Fig. 2, containing the tool corner radius, approximated with point $D$. 
Fig. 2 shows different positions of the $A C D$ plane relative to the tool reference plane $\mathrm{P}_{\mathrm{r}}$. These positions form the basis for the derivation of the mathematical models. Fig. 2a shows the case with positive $\lambda_{s}$ and $\gamma_{0}$ (greater than zero), Fig. 2b shows the case with negative $\lambda_{s}$ and $\gamma_{0}$, Fig. $2 \mathrm{c}$ shows the case with $\lambda_{s}$ positive and $\gamma_{0}$ negative and Fig. $2 \mathrm{~d}$ shows the case with $\lambda_{s}$ negative and $\gamma_{0}$ positive.

The $\overline{A B}, \overline{B C}$ and $\overline{B D}$ axes are mutually perpendicular. The planes $P_{r}{ }^{\prime}$ and $P_{r}{ }^{\prime \prime}$ are parallel to the tool reference plane $P_{r}$ and the position of the $A C D$ plane, i.e. the angles $\lambda_{s}$ and $\gamma_{0}$ is determined relative to them.

The angles $\omega$ and $\sigma$ are additional angles which define the spatial orientation of the plane $A C D$ in relation to the tool reference plane and these angles are used in the mathematical models. The $\overline{A C}$ (i.e. $\overline{A C}$ or $\overline{A^{\prime} C}$ ) axis is the pivotal axis for the $A C D$ ( $A C^{\prime} D ; A^{\prime} C D$ ) plane. The angle $\omega$ shows the rotation of the $A C D$ plane, relative to the reference plane, around the $\overline{A C}$ (i.e. $\overline{A C}$ or $\overline{A^{\prime} C}$ ) axis.

The angles $\omega$ and $\sigma$ as a function of $\lambda_{s}$ and $\gamma_{0}$ are expressed by:

$$
\begin{aligned}
& \sigma=\arctan \left(\frac{\tan \lambda_{s}}{\tan \gamma_{0}}\right) \\
& \omega=\arctan \left(\frac{\tan \gamma_{0}}{\cos \sigma}\right)
\end{aligned}
$$

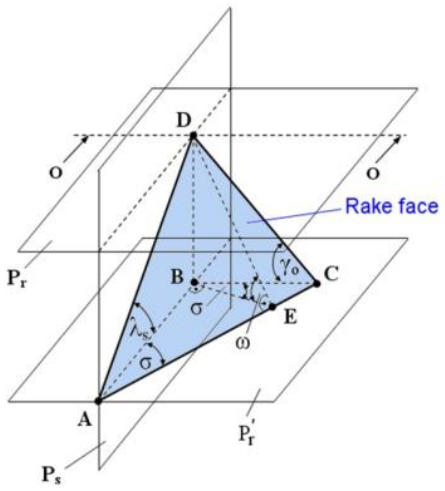

a) $\lambda_{s}$ and $\gamma_{0}$ are positive;

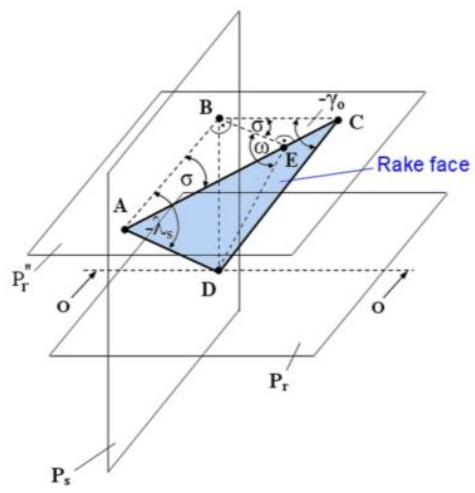

b) $\lambda_{s}$ and $\gamma_{0}$ are negative; 
Mathematical Models with Feedback for Surface Roughness Parameter

Prediction in Longitudinal Turning

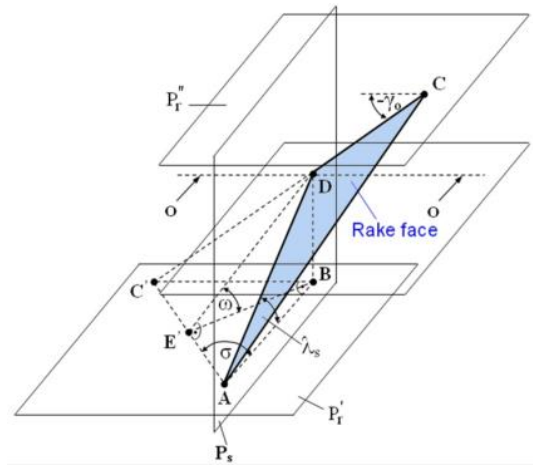

c) $\lambda_{s}$ is positive, $\gamma_{0}$ is negative;

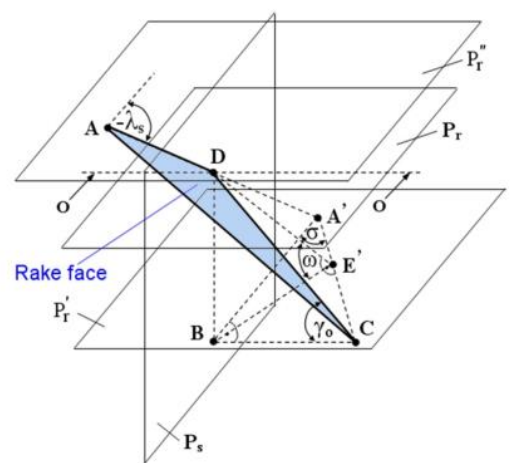

d) $\lambda_{s}$ is negative, $\gamma_{0}$ is positive;

Figure 2. Different positions of the ACD plane relative to the tool reference plane $\left(P_{r}\right)$

The expressions (5) and (6) apply to all cases shown in Fig. 2.

The angle $\varphi$ is used to determine the position of the $\overline{A C}$ axis relative to the rotation axis of the machined part, Fig. 3. Fig. 3 shows that $\kappa_{r}=\sigma+\varphi$, i.e.:

$$
\varphi=\kappa_{r}-\sigma
$$

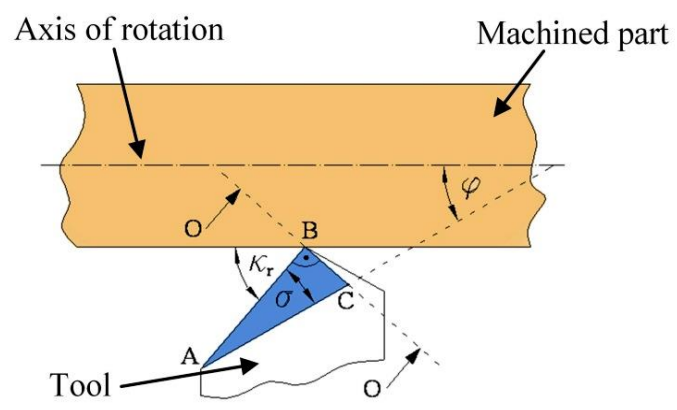

Figure 3. Determining the angle $\varphi$

When the angles $\lambda_{s}$ and $\gamma_{0}$ are different than zero or if only one of the angles is different than zero, the projection of the radius $r_{\varepsilon}$ onto the reference plane will an ellipse. 


\subsection{Mathematical models}

In order to obtain the mathematical models for determining the $R$-parameters as a function of $f, r_{\varepsilon}, \lambda_{s}, \gamma_{0}$ and $\kappa_{r}$ we will consider a segment of the deterministic profile, Fig. 4. Angle $\kappa_{r}$ serves solely to determine the angle $\varphi$ i.e. the position of the axis around which the $A C D$ plane rotates relative to the work piece axis. Because the nose radius of the cutting tool lies on the $A C D$ plane, the angle $\varphi$ determines the position of the ellipse axes around which it rotates.

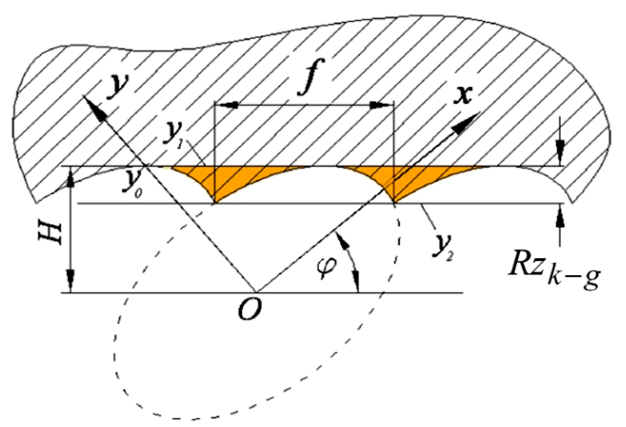

Figure 4. Roughness profile segment

The Cartesian coordinate system is centered in the center of the ellipse and rotated by an angle $\varphi$ relative to the rotation axis of the work piece.

Because the rake face always rotates around the $x$ axis, the ellipse semi-major axis equals of the insert nose radius $r_{\varepsilon}$, while the semi-minor axis equals $r_{\varepsilon} \cos \omega$. To calculate the $H$ value, which will help us determine the $R_{z k-g}$ parameter, we need to determine the equation for the straight line $\mathrm{y}_{1}$. We know only the direction of the straight line $y_{1}$. The location of the line $y_{1}=-x \cdot \tan \varphi+y_{0}$ will be determined from the relation of tangency with the ellipse $\frac{x^{2}}{r_{\varepsilon}^{2}}+\frac{y^{2}}{r_{\varepsilon}^{2} \cos ^{2} \omega}=1$.

In the ellipse equation $\frac{x^{2}}{r_{\varepsilon}^{2}}+\frac{y^{2}}{r_{\varepsilon}^{2} \cos ^{2} \omega}=1$, if we substitute the line equation $y=y_{1}=-x \tan \varphi+y_{0}$ we obtain:

$$
x^{2}\left(\cos ^{2} \omega+\tan ^{2} \varphi\right)-x 2 y_{0} \tan \varphi+y_{0}^{2}-r_{\varepsilon}^{2} \cos ^{2} \omega=0
$$


Mathematical Models with Feedback for Surface Roughness Parameter

Prediction in Longitudinal Turning

$$
X_{1 / 2}=\frac{2 y_{0} \tan \varphi \pm \sqrt{4 y_{0}^{2} \tan ^{2} \varphi-4\left(\tan ^{2} \varphi+\cos ^{2} \omega\right)\left(y_{0}^{2}-r_{\varepsilon}^{2} \cos ^{2} \omega\right)}}{2\left(\tan ^{2} \varphi+\cos ^{2} \omega\right)} \text { or }
$$

since we have one touching (intersection) point we need:

$$
4 y_{0}^{2} \tan ^{2} \varphi-4\left(\tan ^{2} \varphi+\cos ^{2} \omega\right)\left(y_{0}^{2}-r_{\varepsilon}^{2} \cos ^{2} \omega\right)=0
$$

After the reducing the equation we see that: $y_{0}=r_{\varepsilon} \sqrt{\tan ^{2} \varphi+\cos ^{2} \omega}$.

Now we can write that:

$$
H=\cos \varphi \cdot y_{0}=r_{\varepsilon} \sqrt{\sin ^{2} \varphi+\cos ^{2} \varphi \cos ^{2} \omega}=r_{\varepsilon} \sqrt{1-\cos ^{2} \varphi \sin ^{2} \omega}
$$

From the intersection of the ellipse $\frac{x^{2}}{r_{\varepsilon}^{2}}+\frac{y^{2}}{r_{\varepsilon}^{2} \cos ^{2} \omega}=1$ with the line $y_{2}=-x \tan \varphi+\frac{H-R z_{k-g}}{\cos \varphi}$ we get two intersection points with $\mathrm{x}$-axis coordinates:

$$
x_{1 / 2}=\frac{2\left(\frac{H-R z_{k-g}}{\cos \varphi}\right) \tan \varphi \pm \sqrt{4\left(\frac{H-R z_{k-g}}{\cos \varphi}\right)^{2} \tan ^{2} \varphi-4\left(\tan ^{2} \varphi+\cos ^{2} \omega\right)\left(\left(\frac{H-R z_{k-g}}{\cos \varphi}\right)^{2}-r_{\varepsilon}^{2} \cos ^{2} \omega\right)}}{2\left(\operatorname{tg}^{2} \varphi+\cos ^{2} \omega\right)}
$$

Using the equation $X_{1}-X_{2}=f \cdot \cos \varphi$ we obtain:

$$
\frac{\sqrt{4\left(\frac{H-R z_{k-g}}{\cos \varphi}\right)^{2} \tan ^{2} \varphi-4\left(\tan ^{2} \varphi+\cos ^{2} \omega\right)\left(\left(\frac{H-R z_{k-g}}{\cos \varphi}\right)^{2}-r_{\varepsilon}^{2} \cos ^{2} \omega\right)}}{\tan ^{2} \varphi+\cos ^{2} \omega}=X_{1}-X_{2}=f \cdot \cos \varphi
$$

Hence, after reducing the equation we can express $R_{z k-g}$ as follows:

$$
R z_{k-g}=r_{\varepsilon} \sqrt{1-\cos ^{2} \varphi \cdot \sin ^{2} \omega}-\sqrt{r_{\varepsilon}^{2}\left(1-\cos ^{2} \varphi \cdot \sin ^{2} \omega\right)-\frac{f^{2}}{4 \cos ^{2} \omega}\left(1-\cos ^{2} \varphi \cdot \sin ^{2} \omega\right)^{2}}
$$


In order to further reduce the expression, we introduce the following replacement $t=1-\cos ^{2} \varphi \cdot \sin ^{2} \omega$. The reduced expression for $R_{z k-g}$ will be as follows:

$R z_{k-g}=r_{\varepsilon} \sqrt{t}-\sqrt{r_{\varepsilon}^{2} t-\frac{f^{2}}{4 \cos ^{2} \omega} t^{2}}$

If $\gamma_{0}=0 \quad$ and $\quad \lambda_{s}=0$, we obtain $\omega=\arctan \left(\frac{\tan \gamma_{0}}{\cos \sigma}\right)=0 \quad$ and $t=1-\cos ^{2} \varphi \sin ^{2} \omega=1$, and therefore $R_{z k-g}$ will be as follows:

$$
R z_{k-g}=r_{\varepsilon} \sqrt{t}-\sqrt{r_{\varepsilon}^{2} t-\frac{f^{2}}{4 \cos ^{2} \omega} t^{2}}=r_{\varepsilon}-\sqrt{r_{\varepsilon}^{2}-\frac{f^{2}}{4}} \approx \frac{f^{2}}{8 r_{\varepsilon}}
$$

Equation (11) is extensively used in the catalogues of cutting tool manufacturers, but also in a great deal of research in the past.

In order to find the coordinates of the intersection points we need to go back to the calculated $R_{z-g}$ :

$$
x_{1 / 2}=\frac{2\left(\frac{H-R z_{k-g}}{\cos \varphi}\right) \tan \varphi \pm \sqrt{4\left(\frac{H-R z_{k-g}}{\cos \varphi}\right)^{2} \tan ^{2} \varphi-4\left(\tan ^{2} \varphi+\cos ^{2} \omega\right)\left(\left(\frac{H-R z_{k-g}}{\cos \varphi}\right)^{2}-r_{\varepsilon}^{2} \cos ^{2} \omega\right)}}{2\left(\tan ^{2} \varphi+\cos ^{2} \omega\right)}
$$

And we obtain:

$$
X_{1 / 2}=\sin \varphi \sqrt{\frac{r_{\varepsilon}^{2}}{t}-\frac{f^{2}}{4 \cos ^{2} \omega}} \pm \frac{f \cos \varphi}{2} ; Y_{1 / 2}=\frac{H-R z_{k-g}}{\cos \varphi}-\tan \varphi \cdot X_{1 / 2}
$$

The determination of the models of the other R-parameters requires the determination of the mean line of the roughness profile. We will determine the mean line of the roughness profile using the equation $\frac{1}{b-a} \int_{a}^{b} f(x) d x$. Indeed $\int^{b} f(x) d x$ presents the surface area bound by the function $f(x)$, the $x$-axis and the a 
Mathematical Models with Feedback for Surface Roughness Parameter

limits $a$ and $b$. In the considered case $b-a=f$ and $\int_{a}^{b} f(x) d x=P_{\text {segment }}$. Therefore we need to find the surface area $\mathrm{P}_{\text {segment, }}$ Fig. 5 . We will determine the surface area $\mathrm{P}_{\text {segment }}$ by determining the surface area of the sector $\left(\mathrm{P}_{\text {sector }}\right)$ between the points $\left(\mathrm{X}_{1}, \mathrm{Y}_{1}\right)$ and $\left(\mathrm{X}_{2}, \mathrm{Y}_{2}\right)$ minus the surface area of the triangle $\left(\mathrm{P}_{\Delta}\right)$ formed between the coordinate system center and the points $\left(\mathrm{X}_{1}, \mathrm{Y}_{1}\right)$ and $\left(\mathrm{X}_{2}, \mathrm{Y}_{2}\right)$. This means:

$$
P_{\text {segment }}=P_{\text {sector }}-P_{\Delta}
$$

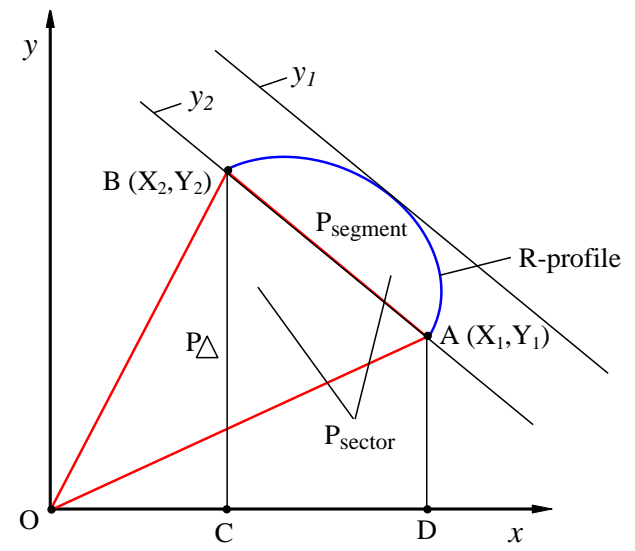

Figure 5. Surface area of the ellipse segment

First we determine $\mathrm{P}_{\text {sector. }}$ In order to simplify the calculation we will use polar coordinates, i.e. $x=r \cos \rho, y=r \sin \rho$, where $r=r(\rho)$ and by substituting in $\frac{x^{2}}{r_{\varepsilon}^{2}}+\frac{y^{2}}{r_{\varepsilon}^{2} \cos ^{2} \omega}=1$ we obtain $r(\rho)=\frac{r_{\varepsilon} \cos \omega}{\sqrt{1-\cos ^{2} \rho \sin ^{2} \omega}}$. The angular change $\rho$ is bound by the angle of the point $\left(\mathrm{X}_{1}, \mathrm{Y}_{1}\right)$ to the angle of the point $\left(\mathrm{X}_{2}, \mathrm{Y}_{2}\right)$.

For the surface area we obtain:

$$
P_{\text {sector }}=\frac{1}{2} \int_{\rho_{1}}^{\rho_{2}} r^{2}(\rho) d \rho=\frac{1}{2} \int_{\rho_{1}}^{\rho_{2}} \frac{r_{\varepsilon}^{2} \cos ^{2} \omega}{1-\cos ^{2} \rho \sin ^{2} \omega} d \rho
$$

We substitute $t=\tan \rho ; \cos ^{2} \rho=\frac{1}{1+t^{2}} ; d \rho=\frac{d t}{1+t^{2}}$ and for the limits of $\rho_{1}$ we get $t_{1}=\operatorname{tg} \rho_{1}$ and for $\rho_{2}$ we get $t_{2}=\operatorname{tg} \rho_{2}$. 


$$
\begin{aligned}
& P_{\text {sector }}=\frac{1}{2} r_{\varepsilon}^{2} \cos ^{2} \omega \int_{t_{1}}^{t_{2}} \frac{1}{1-\frac{1}{1+t^{2}} \sin ^{2} \omega} \frac{d t}{1+t^{2}}=\frac{1}{2} r_{\varepsilon}^{2} \cos ^{2} \omega \int_{t_{1}}^{t_{2}} \frac{d t}{1+t^{2}-\sin ^{2} \omega} \\
& P_{\text {sector }}=\frac{1}{2} r_{\varepsilon}^{2} \cos ^{2} \omega \int_{t_{1}}^{t_{2}} \frac{d t}{t^{2}+\cos ^{2} \omega}=\frac{1}{2} r_{\varepsilon}^{2} \cos ^{2} \omega\left[\frac{1}{\cos \omega} \operatorname{arctg} \frac{t}{\cos \omega}\right]_{t_{1}}^{t_{2}} \\
& P_{\text {sector }}=\frac{1}{2} r_{\varepsilon}^{2} \cos ^{2} \omega\left[\frac{1}{\cos \omega} \arctan \frac{\tan \rho_{2}}{\cos \omega}-\frac{1}{\cos \omega} \arctan \frac{\tan \rho_{1}}{\cos \omega}\right]
\end{aligned}
$$

If the limits are reversed then we will obtain a negative value, and therefore we write:

$$
P_{\text {sector }}=\left|\frac{1}{2} r_{\varepsilon}^{2} \cos \omega\left[\arctan \frac{\tan \rho_{2}}{\cos \omega}-\arctan \frac{\tan \rho_{1}}{\cos \omega}\right]\right|
$$

At the same time we know that $\tan \rho_{1}=\frac{Y_{1}}{X_{1}}$ and $\tan \rho_{2}=\frac{Y_{2}}{X_{2}}$ and the formula will be transformed into:

$$
P_{\text {sector }}=\mid \frac{1}{2} r_{\varepsilon}^{2} \cos \omega\left[\arctan \left(\frac{Y_{2}}{X_{2} \cos \omega}\right)-\arctan \left(\frac{Y_{1}}{X_{1} \cos \omega}\right)\right]
$$

If the change of the function $\arctan (x)$ is between $-90^{\circ}$ and $90^{\circ}$, in order to capture all points we need to make the following corrections.

If $X_{i} \geq 0 \Rightarrow K_{i}=\arctan \left(\frac{Y_{i}}{X_{i} \cos \omega}\right) \ldots(\mathrm{rad})$

If $X_{i}<0 \Rightarrow K_{i}=\pi+\arctan \left(\frac{Y_{i}}{X_{i} \cos \omega}\right) \ldots .(\mathrm{rad})$

Therefore we get:

$$
P_{\text {sector }}=\left|\frac{1}{2} r_{\varepsilon}^{2} \cos \omega\left(K_{2}-K_{1}\right)\right|
$$


Mathematical Models with Feedback for Surface Roughness Parameter Prediction in Longitudinal Turning

We need to determine the surface area of the $\triangle O A B$, Fig. 5 .

$$
\begin{aligned}
& P_{\triangle O A B}=P_{\triangle}=P_{\triangle O B C}+P_{A B C D}-P_{\triangle O A D} \\
& P_{\triangle O B C}=\frac{X_{2} Y_{2}}{2} \\
& P_{A B C D}=\frac{\left(X_{1}-X_{2}\right)\left(Y_{1}+Y_{2}\right)}{2} \\
& P_{\triangle O A D}=\frac{X_{1} Y_{1}}{2} \\
& P_{\triangle O A B}=P_{\Delta}=P_{\triangle O B C}+P_{A B C D}-P_{\triangle O A D}=\frac{X_{1} Y_{2}-X_{2} Y_{1}}{2}
\end{aligned}
$$

If we reverse these coordinates then we get a negative value, therefore we write:

$$
P_{\Delta}=\left|\frac{X_{1} Y_{2}-X_{2} Y_{1}}{2}\right|
$$

The formula is correct for any position of the points with coordinates $\left(\mathrm{X}_{1}, \mathrm{Y}_{1}\right)$ and $\left(\mathrm{X}_{2}, \mathrm{Y}_{2}\right)$ in then coordinate system.

Now we can determine the surface area of the segment:

$$
P_{\text {segment }}=P_{\text {sector }}-P_{\Delta}=\left|\frac{r_{\varepsilon}^{2} \cos \omega}{2}\left(K_{2}-K_{1}\right)\right|-\left|\frac{X_{1} Y_{2}-X_{2} Y_{1}}{2}\right|
$$

We will determine the maximal height of the roughness profile $R_{p k-g}$, using the formula:

$$
R p_{k-g}=\frac{P_{\text {segment }}}{f}=\left|\frac{r_{\varepsilon}^{2} \cos \omega}{2 f}\left(K_{2}-K_{1}\right)\right|-\left|\frac{X_{1} Y_{2}-X_{2} Y_{1}}{2 f}\right|
$$

We will determine the maximum valley depth of the roughness profile $R_{v}$ using the formula:

$$
R v_{k-g}=R z_{k-g}-R p_{k-g}
$$


Similarly, we need to determine the surface area above the mean line. This, in fact, is equal to the one below the mean line. This will help us find the entire surface area, at a distance of the feed $f$ above and below the mean line. Thus we can calculate the value for $R a_{k-g}=\frac{1}{l} \int_{0}^{l}|f(x)| d x$ where, in the considered case, $l=f$.

In order to achieve this objective we need to find the new points intersecting the middle line:

$$
X_{3 / 4}=\frac{\left(H-R z_{k-g}+R p_{k-g}\right) \sin \varphi \pm \cos \varphi \cdot \cos \omega \sqrt{r_{\varepsilon}^{2} t-\left(H-R z_{k-g}+R p_{k-g}\right)^{2}}}{t}
$$

$$
Y_{3 / 4}=\frac{H-R z_{k-g}+R p_{k-g}}{\cos \varphi}-\tan \varphi \cdot X_{3 / 4}
$$

The formulation of $R_{a k-g}$ will be the same as for $R_{p k-g}$, the only difference being the coordinates $\left(\mathrm{X}_{3}, \mathrm{Y}_{3}\right)$ and $\left(\mathrm{X}_{4}, \mathrm{Y}_{4}\right)$ and we will have two such surface areas. Therefore the mathematical formulation for $R_{a k-g}$ will be as follows:

$$
R a_{k-g}=\left|\frac{r_{\varepsilon}^{2} \cos \omega}{f}\left(K_{4}-K_{3}\right)\right|-\left|\frac{X_{3} Y_{4}-X_{4} Y_{3}}{f}\right|
$$

Since the theoretic roughness profile obtained from longitudinal turning is deterministically and periodically replicable, the mean width of the profile elements $R S_{m k-g}$ is adopted to be approximately equal to the feed:

$$
R S m_{k-g} \approx f
$$

If we take a random straight line parallel to $\mathrm{y}_{1}$ and $\mathrm{y}_{2}$ located between them at a distance $c$ relative to $\mathrm{y}_{2}$, then the $x$-axis coordinates intersecting the ellipse can be expressed as:

$$
X_{i / i+1}=\frac{2\left(H-R z_{k-g}+c\right) \sin \varphi \pm \cos \varphi \cos \omega \sqrt{r_{\varepsilon}^{2} t-\left(H-R z_{k-g}+c\right)^{2}}}{t}
$$


Mathematical Models with Feedback for Surface Roughness Parameter Prediction in Longitudinal Turning

The distance between this two points is:

$$
\frac{X_{i}-X_{i+1}}{\cos \varphi}=\frac{2 \cos \omega \sqrt{r_{\varepsilon}^{2} t-\left(H-R z_{k-g}+c\right)^{2}}}{t}
$$

Hence we can determine the material ratio of roughness profile by:

$$
\operatorname{Rmr}(c)_{k-g}=\left(1-\frac{2 \cos \omega \sqrt{r_{\varepsilon}^{2} t-\left(\sqrt{r_{\varepsilon}^{2} t-\frac{f^{2}}{4 \cos ^{2} \omega} t^{2}}+c\right)^{2}}}{f \cdot t}\right) \cdot 100 \%
$$

If $\gamma_{0}=0$ and $\lambda_{s}=0$, we get that $\omega=\arctan \left(\frac{\tan \gamma_{0}}{\cos \sigma}\right)=0 \quad$ and $t=1-\cos ^{2} \varphi \sin ^{2} \omega=1$ and for $R_{m r(c) k-g}$ we get:

$$
\operatorname{Rmr}(c)_{k-g}=\left(1-\frac{2 \sqrt{r_{\varepsilon}^{2}-\left(\sqrt{r_{\varepsilon}^{2}-\frac{f^{2}}{4}}+c\right)^{2}}}{f}\right) \cdot 100 \%
$$

Because the mathematical expressions of the considered $R$-parameters are interdependent, we derived them using a systematically consecutive.

\subsubsection{Constraints of the mathematical models}

When $\gamma_{0}=0$, equation (5) becomes undefined ( $\arctan \pm \infty$ ), and therefore when using equations to calculate $R$-parameters when $\gamma_{0}=0$, the calculations for $\gamma_{0}$ should consider an angle close to zero (for example $0.001^{\circ}$ ).

Also, when the tool cutting edge angle $\kappa_{r}=45^{0}$, the angles $\gamma_{0}$ and $\lambda_{s}$ cannot have equal values with opposite signs (like $\gamma_{0}=8 ; \lambda_{s}=-8$ ), because then $\mathrm{Y}_{1}$ and $\mathrm{Y}_{2}$ in 
equation (12) become zero. In such a case it is recommended to take slightly different values for $\gamma_{0}$ and $\lambda_{s}$.

We have deliberately deviated from the definition of the material ratio of the roughness profile $R_{\operatorname{mr}(c)}\left(R_{\operatorname{mr}(c) k-g}\right)$ provided in [21]. The difference is that the parameter $R_{\operatorname{mr}(c)}$, according to [21] is calculated within the evaluation length, while here it is calculated within the sampling length. Therefore we replaced $R_{t}$ with $R_{z}$. This deviation is inevitable because the mathematical formulation (19) directly depends on the other mathematical formulations used to derive the other parameters, derived from the sampling length.

All previously mentioned mathematical models apply only when using cutting tools that have a nose radius of the cutting insert $\left(r_{\varepsilon} \neq 0\right)$, and only when the corner nose radius of the insert copying onto the processed surface (not major cutting edge or minor cutting edge).

\subsection{Mathematical models including $S E$}

As previously mentioned, in these investigation propose the use of the $S E$ parameter as an indicator of the stability and the conditions of the surface roughness formation process. The authors propose to calculate the roughness $R$ parameters as follows:

$R z=R z_{k-g} \cdot e^{3 S E}$

where the parameter $R z_{k-g}$ is calculated using the formula (10).

$$
R p=R p_{k-g} \cdot e^{2 S E}
$$

where the parameter $R p_{k-g}$ is calculated using the formula (13).

$$
R v=R v_{k-g} \cdot e^{3 S E}
$$

where the parameter $R v_{k-g}$ is calculated using the formula (14).

$$
R a=R a_{k-g} \cdot e^{S E}
$$


where the parameter $R a_{k-g}$ is calculated using the formula (17).

$$
\begin{aligned}
& R S m=R S m_{k-g}, \text { or } \\
& R S m=R S m_{k-g} \cdot e^{S E}
\end{aligned}
$$

where the parameter $R S m_{k-g}$ is calculated using the formula (18).

$$
\operatorname{Rmr}(c)=\frac{R m r(c)_{k-g}}{e^{S E}}
$$

where the parameter $R m r(c)_{k-g}$ is calculated using the formula (19).

As equations (21-27) show, here the paper proposes to express the $S E$ parameter using the exponential function $f(S E)=e^{S E}$ because of the following:

- According to $[1,4,6]$ the use of exponential models to model surface roughness has been generally accepted,

- The exponential expression $e^{S E}$ in equations (21-27) also preserves the "natural principle" of the roughness modeling process, i.e. in the event of a stable surface roughness formation process then we expect that $S E \rightarrow 0$. When $S E \rightarrow 0$, the expression $e^{S E} \rightarrow 1$, i.e. approaches the theoretically calculated roughness parameter values.

In realistic processing conditions, the height parameters $R_{z}, R_{p}, R_{v}$, and $R_{a}$ are expected to have higher values than the theoretically calculated values due to the "distorting" of the roughness profile and therefore the theoretically calculated value are multiplied with the expression $e^{S E}$. The coefficient in front of $S E$ is different for the considered height parameters because the directly measured parameters are more sensitive to the "distorting" of the profile than the average $R_{a}$ parameter.

In realistic conditions, due to "distorting, the $\mathrm{R}_{\operatorname{mr}(\mathrm{c})}$ parameter is expected to have smaller values than the theoretically calculated values and therefore the expression $e^{S E}$ is in the denominator in order to reduce the theoretically calculated values. 
The $R S_{m}$ parameter is expected to be the least sensitive to "distorting" of the roughness profile, to a certain extent of "distorting". Therefore we propose two formulations (25 and 26) to calculate this parameter. The experimental verification will show the extent of "distorting" of the roughness profile, which represents the key element in calculating $R S_{m}$ according to the first or the second formulation (equation).

\section{Experimental verification}

\subsection{Experimental plan}

For the experimental verification of the obtained mathematical modules we adopted a planning principle identical to two-level full factorial experimental design. The input parameters are cutting speed $(V)$, feed $(f)$, tool nose radius $\left(\mathrm{r}_{\varepsilon}\right)$ and depth of cut $\left(a_{p}\right)$. Although they do not participate in the mathematical models, the reason for inclusion of $V$ and $a_{p}$ was elaborated in item 3 . Therefore the number of experiments that will be implemented is $2^{4}=16$, as well as four experiments as a repetition of the input values in the central point, or in total $2^{4}=16+4=20$ experiments. Table 1 provides the values of the input variables. The input parameter values are in accordance with the recommendations of the insert manufacturer, but we also paid attention to obtain roughness profiles with as large a parameter value span as possible (for example from $R_{a}=0.2$ to $R_{a}=7.5 \mu \mathrm{m}$ ). Table 2 shows the detailed experiment plan.

Table 1. Input parameters and their levels

\begin{tabular}{|l|l|c|c|c|}
\hline Sr. no. & Parameters & Level 1 & $\begin{array}{c}\text { Central } \\
\text { point }\end{array}$ & Level 2 \\
\hline 1 & Cutting speed $(V), \mathrm{m} / \mathrm{min}$ & 150 & 185.7 & 230 \\
\hline 2 & Feed $(f), \mathrm{mm} / \mathrm{rev}$ & 0.1 & 0.173 & 0.3 \\
\hline 3 & Tool nose radius $\left(\mathrm{r}_{\varepsilon}\right), \mathrm{mm}$ & 0.4 & 0.8 & 1.6 \\
\hline 4 & Depth of cut $\left(\mathrm{a}_{\mathrm{p}}\right), \mathrm{mm}$ & 0.4 & 0.69 & 1.2 \\
\hline
\end{tabular}


Mathematical Models with Feedback for Surface Roughness Parameter

Prediction in Longitudinal Turning

Table 2. Experimental plan

\begin{tabular}{|c|c|c|c|c|c|c|}
\hline No. & Piece & $\begin{array}{l}\text { Segments } \\
\text { markings }\end{array}$ & $\begin{array}{c}\boldsymbol{V} \\
(\mathbf{m} / \mathbf{m i n})\end{array}$ & $\underset{(\mathrm{mm} / \mathrm{rev})}{f}$ & $\begin{array}{c}\mathbf{r}_{\varepsilon} \\
(\mathbf{m m})\end{array}$ & $\begin{array}{c}\mathbf{a p}_{\mathbf{p}} \\
(\mathbf{m m})\end{array}$ \\
\hline 1 & \multirow{5}{*}{1} & 1.1 & 150 & 0.1 & 0.4 & 0.4 \\
\hline 2 & & 1.2 & 230 & 0.1 & 0.4 & 0.4 \\
\hline 3 & & 1.3 & 150 & 0.3 & 0.4 & 0.4 \\
\hline 4 & & 1.4 & 230 & 0.3 & 0.4 & 0.4 \\
\hline 5 & & 1.5 & 150 & 0.1 & 1.6 & 0.4 \\
\hline 6 & \multirow{5}{*}{2} & 2.1 & 230 & 0.1 & 1.6 & 0.4 \\
\hline 7 & & 2.2 & 150 & 0.3 & 1.6 & 0.4 \\
\hline 8 & & 2.3 & 230 & 0.3 & 1.6 & 0.4 \\
\hline 9 & & 2.4 & 150 & 0.1 & 0.4 & 1.2 \\
\hline 10 & & 2.5 & 230 & 0.1 & 0.4 & 1.2 \\
\hline 11 & \multirow{5}{*}{3} & 3.1 & 150 & 0.3 & 0.4 & 1.2 \\
\hline 12 & & 3.2 & 230 & 0.3 & 0.4 & 1.2 \\
\hline 13 & & 3.3 & 150 & 0.1 & 1.6 & 1.2 \\
\hline 14 & & 3.4 & 230 & 0.1 & 1.6 & 1.2 \\
\hline 15 & & 3.5 & 150 & 0.3 & 1.6 & 1.2 \\
\hline 16 & \multirow{5}{*}{4} & 4.1 & 230 & 0.3 & 1.6 & 1.2 \\
\hline 17 & & 4.2 & 185.7 & 0.173 & 0.8 & 0.69 \\
\hline 18 & & 4.3 & 185.7 & 0.173 & 0.8 & 0.69 \\
\hline 19 & & 4.4 & 185.7 & 0.173 & 0.8 & 0.69 \\
\hline 20 & & 4.5 & 185.7 & 0.173 & 0.8 & 0.69 \\
\hline
\end{tabular}

\subsection{Work piece material}

The work pieces used in this research are made of steel $42 \mathrm{CrMo}$ (EN), or AISI 4140 (USA). The hardness of all piece segments along the entire length ranges from 32 to 34 HRC. The pieces have a special design, Fig. 6, each featuring five segments for processing and one segment for clamping to chuck. The segments for processing are appropriately marked as shown in Table 2 . 


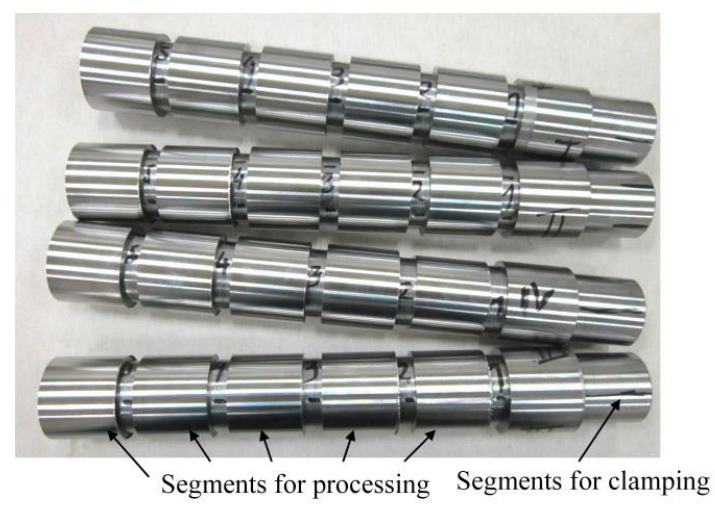

Figure 6. The work piece

\subsection{Machine and cutting tool}

The work pieces are processed using two different CNC lathes. The lathe shown on Fig. 7, model OKUMA LB 15-II (C-1S) has variable spindle speed of 38-3800 $\mathrm{rpm}$, feed rate $0.001-1000 \mathrm{~mm} / \mathrm{rev}$ and $15 \mathrm{~kW}$ spindle drive motor, and will be indicated as Lathe 1 hereinafter in the text. The lathe shown on Fig. 8, model MORI SEIKI SL-3H has a variable spindle speed 37-4000 rpm, feed rate 0.0001$500 \mathrm{~mm} / \mathrm{rev}$ and $15 \mathrm{~kW}$ spindle drive motor, will be indicated as Lathe 2 hereinafter in the text. The research involves two different $\mathrm{CNC}$ lathes in order to increase the reliability of the practical verification, i.e. to get two processing systems with different $\mathrm{R}_{\text {distorting. }}$.

The four work pieces are positioned identically in both lathes. From one side the work pieces are clamped in the chuck, while, on the other side, they lean on the tailstock, Fig. 7 and Fig. 8. Before processing starts in accordance with the experimental plan, the pieces were processed in order to remove the circular run out from the clamping of the pieces. A coolant was applied during the machining of the pieces.

The pieces were processed using a holder designated PSSNR/L 2020-12K (PAFANA), with $\kappa_{r}=45^{\circ}, \gamma_{0}=-8^{0}, \lambda_{s}=0^{0}$ and cutting finishing inserts designated SNMG 120404-MF, SNMG 120408-MF and SNMG 120416-MF from the Sandvik Coromant.

Every workpiece segment is processed using a new cutting edge of the insert, in order to eliminate the effect from the wear of the inserts. 
ADVANCES IN PRODUCTION AND INDUSTRIAL ENGINEERING

M. Tomov, M. Kuzinovski \& P. Cichosz: Chapter 5

Mathematical Models with Feedback for Surface Roughness Parameter

Prediction in Longitudinal Turning

\subsection{Measurement equipment and conditions}

The roughness of the processed segments was measured using Surf test model No. SJ-410 (Mitutoyo make), Fig. 9.

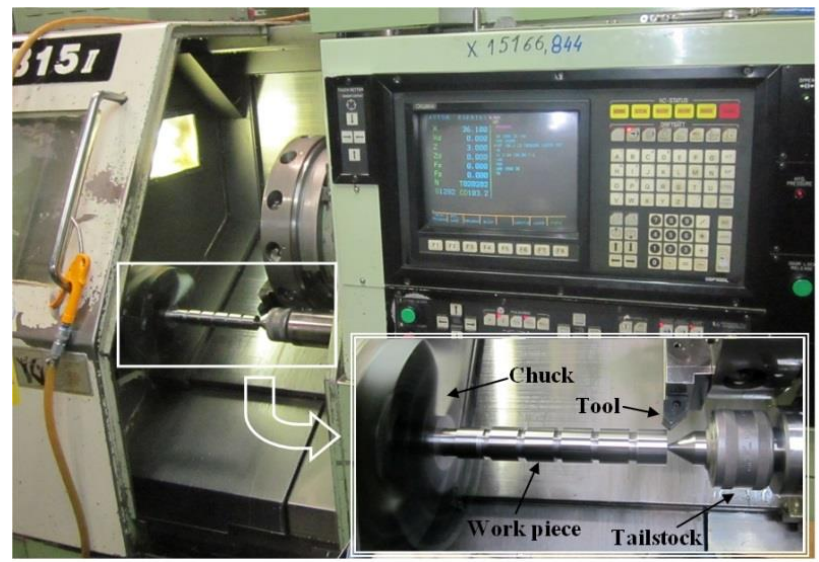

Figure 7. CNC lathe model OKUMA LB 15-II (C-1S)

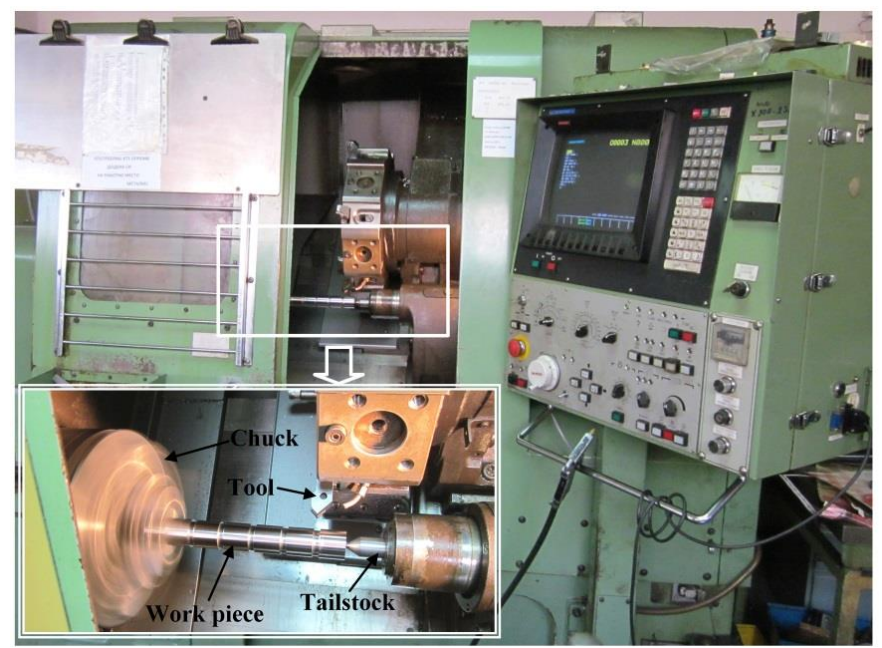

Figure 8. CNC lathe model MORI SEIKI SL-3H

The surface roughness was measured at five equally spaced locations around the circumference of the work pieces to obtain the statistically significant data for the test. 
The measured roughness parameters shown in Table 3 and 4 are average values from five measurements. The roughness parameters were measured and calculated in accordance with the ISO standard recommendations, i.e. in accordance with the procedure for obtaining the primary profile, the roughness profile and waviness profile presented in [13]. A Gaussian filter of appropriate size equal to the sampling length was used as a $\lambda_{c}$ profile filter. We used two sampling lengths of $0.25 \mathrm{~mm}$ and $0.8 \mathrm{~mm}$ depending on the value of the $\mathrm{RS}_{\mathrm{m}}$.

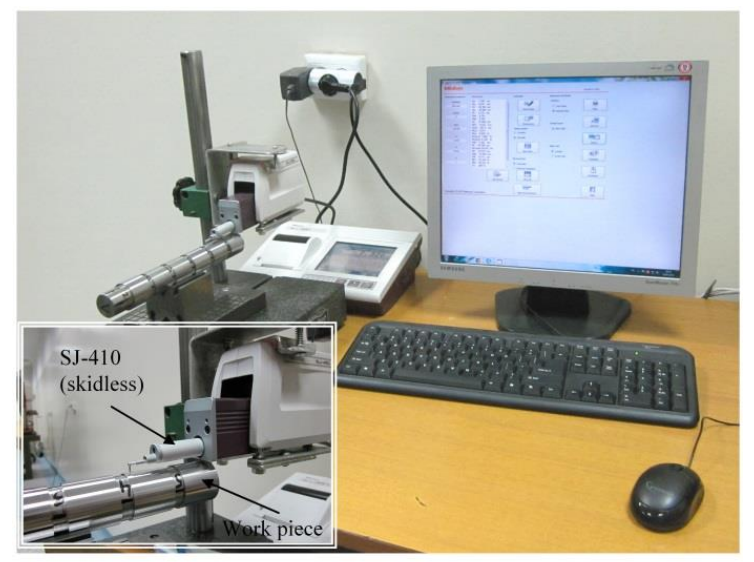

Figure 9. Surf test model No. SJ-410 (Mitutoyo make)

The $R_{m r(c)}$ parameter was calculated at a level of $30 \%$ of $\mathrm{R}_{\mathrm{z}}\left(30 \mathrm{R}_{\mathrm{z}}\right)$ from the highest peak of the roughness profile, i.e. $c=30 \%$ of $\mathrm{R}_{\mathrm{z}} \mu \mathrm{m}$, for all considered roughness profile. A pick-up stylus used had a top angle of 60 degrees and a top radius of 2 $\mu \mathrm{m}$. A skidless pick-up was used. During the measurements, the instrument was mechanically levelled with respect to the measured surface. The measuring system was calibrated using a type $C$ etalon with $\mathrm{R}_{\mathrm{a}}=2.97 \mu \mathrm{m}$, and was verified using a type $C$ etalon with $\mathrm{R}_{\mathrm{a}}=6 \mu \mathrm{m}$. The used calibration etalons have a measuring uncertainty of $5 \%$.

The parameter $S E$ was calculated for a roughness evaluation length $\left(l_{n}\right)$ greater than $\left(l_{n}\right)$ for which the roughness parameters were measured, i.e. the next largest $\left(l_{n}\right)$ recommended by ISO 4288:1996 [22]. The $S E$ value provided in Tables 3 и 4 is an mean value of the five measurements around the circumference of each segment.

\subsection{Result and discussion}

Tables 3 and 4 systematize the values for the considered roughness parameters calculated in accordance with equation (10), (13), (14), (17), (18) and (19), and the measured values (averages from five measurement) of the processed segments 
AdVANCES IN PRODUCTION AND INDUSTRIAL ENGINEERING

M. Tomov, M. Kuzinovski \& P. Cichosz: Chapter 5

Mathematical Models with Feedback for Surface Roughness Parameter

Prediction in Longitudinal Turning

for Lathe 1 and Lathe 2 . The roughness parameters obtained by measuring the processed segments will be expressed as $R z_{m}, R p_{m}, R_{m}, R a_{m}, R S m_{m}$ and $R m r(c)_{m}$.

Table 3. Roughness parameters - calculated and obtained by measurement of the segments and SE, for Lathe 1.

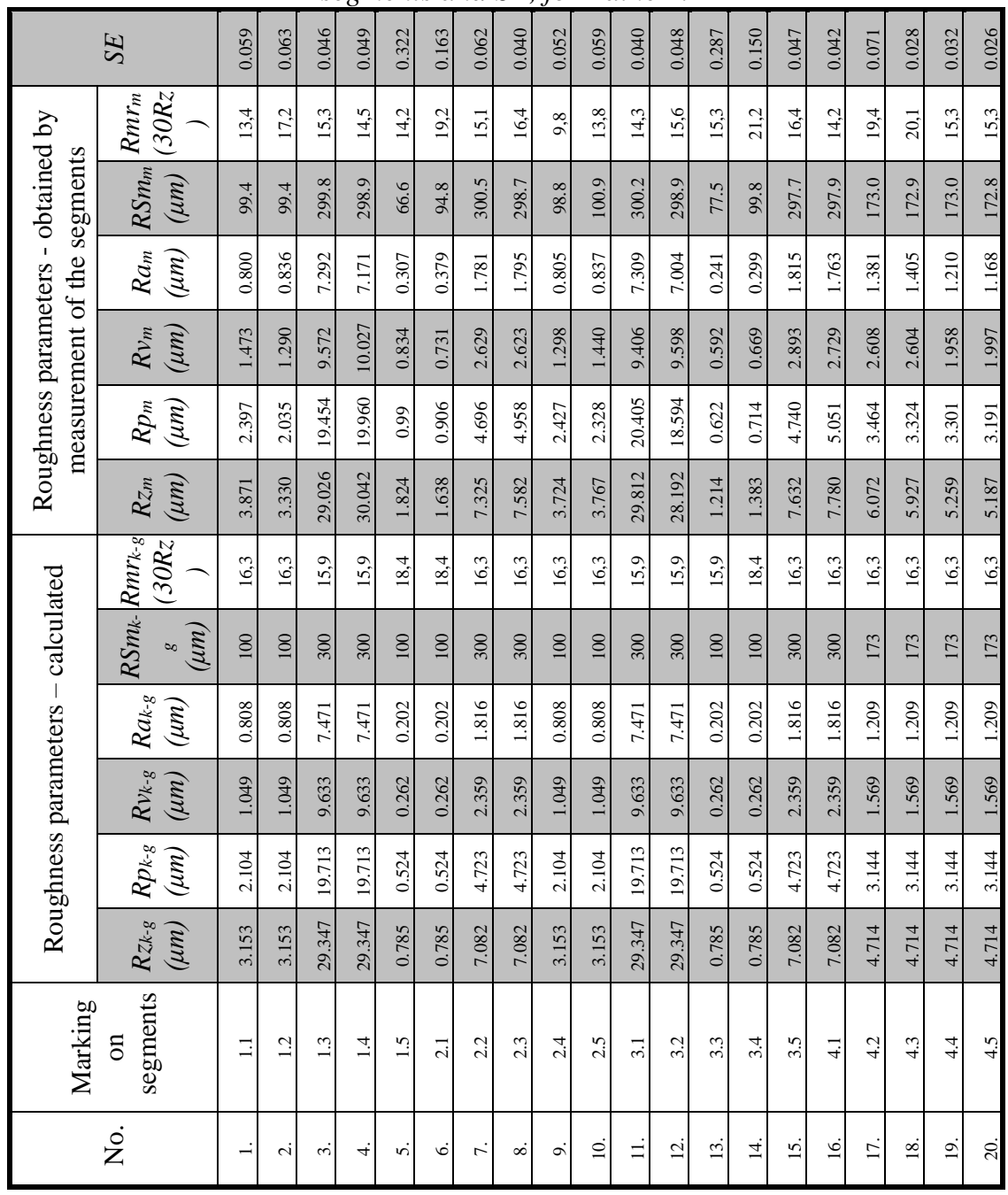

In order to obtain information about distortion of the measured $R$-parameter values, Table 5 provides the differences between the highest and the lowest measured value from five $R$-parameter measurements expressed in as percentages $(\%)$. 
Mathematical Models with Feedback for Surface Roughness Parameter

Prediction in Longitudinal Turning

Table 6 provides the percentage differences between the theoretically calculated values for the parameters as $R_{z k-g}, R_{p k-g,} R_{v k-g .} R_{a k-g}, R S_{m k-g}$ and $R_{m r(c) k-g}$ and the measures values for the roughness parameters, as well as the percentage differences between the theoretical values calculated for the parameters $R_{z}, R_{p}, R_{v}$, $\mathrm{R}_{\mathrm{a}}, \mathrm{RS}_{\mathrm{m}}, \mathrm{R}_{\mathrm{mr}(\mathrm{c})}$ and the measured values of the roughness parameters for both CNC lathes. The minus sign in front of the percentage differences indicates a measured value greater than the theoretically calculated value.

Table 4. Roughness parameters - calculated and obtained by measuring the segments and SE for Lathe 2.

\begin{tabular}{|c|c|c|c|c|c|c|c|c|c|c|c|c|c|c|c|c|c|c|c|c|c|}
\hline \multicolumn{2}{|r|}{$\frac{1}{5}$} & อี & o. & $\begin{array}{l}0 \\
\vdots \\
0 \\
0\end{array}$ & $\stackrel{\tilde{0}}{0}$ & ถู่ & तై & $\stackrel{d}{0}$ & 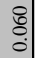 & $\stackrel{9}{0}$ & సे| & 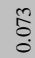 & 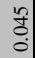 & $\stackrel{n}{a}$ & 告 & 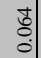 & 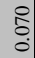 & $\begin{array}{l}\vec{d} \\
\stackrel{0}{0}\end{array}$ & 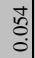 & 章 & \\
\hline \multirow{6}{*}{ 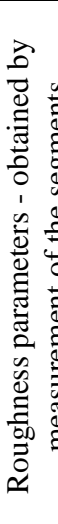 } & 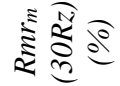 & $\stackrel{\infty}{=}$ & $\stackrel{2}{=}$ & $\overline{ \pm}$ & $\stackrel{m}{m}$ & $\stackrel{\dot{m}}{\mathrm{~g}}$ & : & $\stackrel{\infty}{=}$ & : & $\stackrel{2}{=}$ & $\stackrel{0}{i}$ & $\stackrel{\circ}{=}$ & $\stackrel{0}{=}$ & 2 & $\dot{\infty}_{\infty}^{+}$ & $\stackrel{m}{=}$ & ถి & $\stackrel{?}{2}$ & $\stackrel{0}{=}$ & తొ & \\
\hline & हิ ई & 8 & $\begin{array}{l}\text { : } \\
\stackrel{0}{0}\end{array}$ & $\hat{\stackrel{0}{0}}$ & $\stackrel{\infty}{\stackrel{\alpha}{े}}$ & กิ่ & 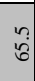 & 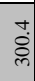 & : & ฉั & ๕̊: & $\stackrel{\vec{d}}{\vec{d}}$ & 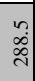 & :̊̊. & $\stackrel{0}{\circ}$ & ลे. & ลें & $\stackrel{n}{=}$ & $\vec{\Xi}$ & ì & \\
\hline & है & oี & $\begin{array}{l}0 \\
\infty \\
\infty \\
0\end{array}$ & 号 & $\stackrel{2}{7}$ & $\begin{array}{l}\bar{d} \\
\text { d }\end{array}$ & ?ొ & 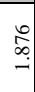 & 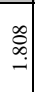 & 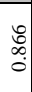 & $\begin{array}{l}n \\
0 \\
0 \\
0\end{array}$ & 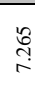 & 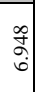 & مे & 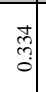 & 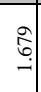 & : & $\stackrel{\bar{T}}{-}$ & त् & $\stackrel{\Xi}{\vec{f}}$ & \\
\hline & 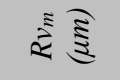 & $\stackrel{\infty}{\stackrel{\infty}{n}}$ & $\stackrel{7}{-}$ & 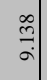 & ڤે & ڤે & $\begin{array}{l}\bar{\sigma} \\
0 \\
0\end{array}$ & $\begin{array}{l}0 \\
\stackrel{0}{\infty} \\
i\end{array}$ & $\vec{n}$ & סี้ & $\stackrel{\text { ले}}{-}$ & $\begin{array}{l}\infty \\
\stackrel{0}{0} \\
\stackrel{?}{=}\end{array}$ & $\stackrel{0}{a}$ & $\stackrel{\infty}{-\infty}$ & $\begin{array}{l}0 \\
0 \\
0 \\
0\end{array}$ & ț & $\begin{array}{l}\text { ลี } \\
\text { הิ }\end{array}$ & $\begin{array}{l}\text { पे } \\
\text { in }\end{array}$ & $\begin{array}{l}\frac{ \pm}{m} \\
i\end{array}$ & $\begin{array}{l}\text { nิ } \\
\text { הิ }\end{array}$ & \\
\hline & & $\frac{\pi}{4}$ & 孛 & $\begin{array}{l}n \\
n \\
\vdots \\
\vdots \\
\vdots\end{array}$ & $\begin{array}{l}\text { f̀ } \\
\text { g. }\end{array}$ & : & on & $\begin{array}{l}\stackrel{a}{b} \\
\stackrel{+}{+}\end{array}$ & $\begin{array}{l}\mathfrak{a} \\
\rightarrow \\
\rightarrow\end{array}$ & 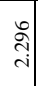 & ఫे & ڤิ & \begin{tabular}{ll|l} 
& 0 \\
$\vdots$ \\
9 \\
9
\end{tabular} & : & ఏి & 总 & 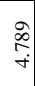 & $\stackrel{\vec{s}}{\dot{m}}$ & 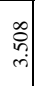 & $\begin{array}{l}m \\
0 \\
\dot{f}\end{array}$ & \\
\hline & 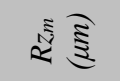 & 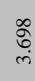 & $\begin{array}{l}\stackrel{0}{0} \\
\stackrel{\infty}{\infty}\end{array}$ & 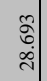 & $\begin{array}{l}0 \\
\infty \\
0 \\
d \\
d\end{array}$ & 원 & $\stackrel{5}{\stackrel{5}{ت}}$ & $\stackrel{i}{i}$ & $\begin{array}{l}8 \\
0 \\
\infty\end{array}$ & $\stackrel{\infty}{\stackrel{\infty}{c}}$ & 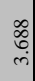 & $\stackrel{\leftrightarrow}{\circ}$ & 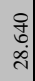 & $\begin{array}{l}\text { ô. } \\
\text { d. } \\
\text { in }\end{array}$ & 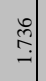 & $\stackrel{\bar{\sigma}}{+}$ & $\stackrel{\vec{i}}{i}$ & $\begin{array}{l}\overline{0} \\
i\end{array}$ & $\begin{array}{l}0 \\
f \\
0 \\
i n \mid\end{array}$ & 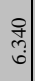 & \\
\hline \multirow{6}{*}{ 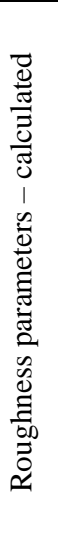 } & 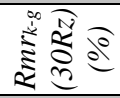 & $\stackrel{3}{0}$ & $\hat{=}$ & is & s) & 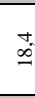 & $\stackrel{+t}{0}$ & ف․ & on. & $\stackrel{?}{0}$ & ?. & $\stackrel{a}{\imath}$ & s. & 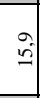 & 声 & 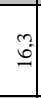 & ?.? & $\stackrel{?}{0}$ & 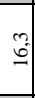 & $=$ & \\
\hline & हई & 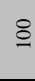 & 의 & : & \&్ల & 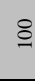 & 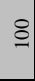 & \& & \&्లి & 의 & 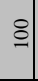 & \&్ల & \&్లి & 의 & 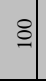 & ః्ల. & \&్లి & $\stackrel{\cong}{\simeq}$ & $\cong$ & $\cong$ & โ \\
\hline & $\frac{\sqrt{2}}{3}$ & $\begin{array}{l}0 \\
\infty \\
\infty \\
0 \\
0\end{array}$ & $\begin{array}{l}0 \\
0 \\
0 \\
0\end{array}$ & 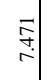 & 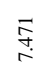 & ธิँ & ธิ่ี & $\stackrel{\substack{0 \\
-\infty}}{-}$ & $\stackrel{\substack{0 \\
-\infty}}{-1}$ & $\begin{array}{l}\infty \\
\stackrel{0}{0} \\
0 \\
0\end{array}$ & $\begin{array}{l}\infty \\
0 \\
0 \\
0 \\
0\end{array}$ & $\underset{7}{\stackrel{7}{i}}$ & 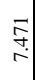 & ธิ๋ & 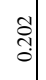 & $\stackrel{\substack{\infty \\
\hdashline}}{\rightarrow}$ & $\stackrel{\substack{\infty \\
-\infty}}{-}$ & त्ञ & స્తి & व્ণ্= & \\
\hline & है & $\stackrel{0}{0}$ & $\stackrel{q}{+}$ & & త్రి & ్ํㅇ & ปั. & के & 仓े & dot. & tot & హే & హీ: & đ̊ำ & 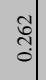 & ले & फे & . & 总 & | & \\
\hline & है & $\stackrel{t}{\stackrel{4}{\mathrm{i}}}$ & 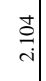 & $\stackrel{m}{\stackrel{9}{a}}$ & $\stackrel{m}{\stackrel{2}{9}}$ & 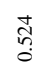 & ֻี & 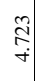 & 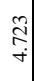 & $\stackrel{+}{\stackrel{\Delta}{\mathrm{i}}}$ & $\underset{⿱ 亠}{\stackrel{\Delta}{c}}$ & $\stackrel{m}{\stackrel{2}{2}}$ & $\stackrel{m}{\stackrel{2}{a}}$ & 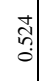 & ڤึ. & $\underset{\substack{f \\
+}}{ }$ & 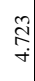 & $\frac{J}{\dot{m}}$ & $\frac{⿱}{ \pm}$ & $\frac{\forall}{m}$ & \\
\hline & 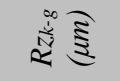 & $\frac{\tilde{n}}{m}$ & $\stackrel{m}{m}$ & $\begin{array}{l}\text { के } \\
\text { ते }\end{array}$ & 告 & 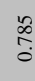 & $\begin{array}{l}\infty \\
\stackrel{0}{0}\end{array}$ & 足 & 品 & $\frac{n}{m}$ & $\stackrel{n}{m}$ & ले & సे & $\begin{array}{l}\mathscr{0} \\
\stackrel{0}{0}\end{array}$ & $\begin{array}{l}\infty \\
\stackrel{0}{0} \\
\stackrel{0}{0}\end{array}$ & م. & مٌ & $\underset{f}{\stackrel{f}{f}}$ & $\underset{f}{\stackrel{t}{f}}$ & $\stackrel{ \pm}{+}$ & \\
\hline \multicolumn{2}{|c|}{ 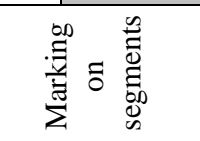 } & $\exists$ & $\stackrel{?}{=}$ & $\stackrel{m}{=}$ & $\stackrel{ \pm}{ \pm}$ & 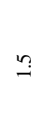 & $\vec{i}$ & त) & $\vec{i}$ & $\stackrel{+}{i}$ & $i$ & $\bar{m}$ & ले & $\stackrel{m}{m}$ & $\stackrel{+}{\oplus}$ & $m$ & $\bar{f}$ & $\stackrel{\mathscr{f}}{\rightarrow}$ & $\stackrel{m}{\rightarrow}$ & $\stackrel{+}{+}$ & $" s$ \\
\hline \multicolumn{2}{|r|}{$\dot{0}$} & & il & $\dot{m}$ & $\dot{+}$ & in & 0 & $\therefore$ & $\infty$ & $\sigma^{\circ}$ & $\stackrel{-}{0}$ & $\dot{\Xi}$ & I & 9 & \pm & $\stackrel{n}{2}$ & $\stackrel{\varphi}{0}$ & 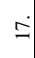 & ? & 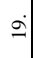 & \\
\hline
\end{tabular}


Mathematical Models with Feedback for Surface Roughness Parameter

Prediction in Longitudinal Turning

Table 5. Differences between the highest and the lowest measured value from five measurements of parameters expressed as percentages (\%).

\begin{tabular}{|c|c|c|c|c|c|c|c|c|c|c|c|c|c|}
\hline \multirow[b]{2}{*}{ No. } & \multirow[b]{2}{*}{ 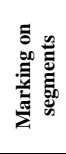 } & \multicolumn{6}{|c|}{ Lathe 1} & \multicolumn{6}{|c|}{ Lathe 2} \\
\hline & & $\begin{array}{l}R z_{m} \\
(\%)\end{array}$ & $\begin{array}{l}\boldsymbol{R} \boldsymbol{p}_{m} \\
(\%)\end{array}$ & $\begin{array}{l}R v_{m} \\
(\%)\end{array}$ & $\begin{array}{l}R a_{m} \\
(\%)\end{array}$ & $\begin{array}{c}R S m \\
m \\
(\%)\end{array}$ & $\begin{array}{c}R m r_{m} \\
(30 R z \\
) \\
(\%)\end{array}$ & $\begin{array}{c}R z_{m} \\
(\% \\
)\end{array}$ & $\begin{array}{l}R p_{m} \\
(\%)\end{array}$ & $\begin{array}{l}R v_{m} \\
(\%)\end{array}$ & $\begin{array}{l}R a_{m} \\
(\%)\end{array}$ & $\begin{array}{c}\boldsymbol{R S S m _ { m }} \\
(\%)\end{array}$ & $\begin{array}{c}R m r_{m} \\
(30 R z) \\
(\%)\end{array}$ \\
\hline 1 & 1.1 & 2.1 & 3.9 & 3.3 & 1.9 & 3.6 & 14.6 & 3.1 & 6.1 & 5.1 & 0.4 & 2.1 & 32.0 \\
\hline 2 & 1.2 & 3.8 & 3.9 & 4.2 & 1.2 & 2.6 & 11.0 & 3.3 & 8.0 & $\begin{array}{c}10 . \\
6\end{array}$ & 2.9 & 3.9 & 13.8 \\
\hline 3 & 1.3 & 3.3 & 3.7 & 2.3 & 2.5 & 0.9 & 3.2 & 1.0 & 1.5 & 2.3 & 2.1 & 33.5 & 9.0 \\
\hline 4 & 1.4 & 1.1 & 1.3 & 4.7 & 1.5 & 1.5 & 9.9 & 2.5 & 3.9 & 3.2 & 2.2 & 1.5 & 7.1 \\
\hline 5 & 1.5 & $\begin{array}{c}13 . \\
8\end{array}$ & 10.3 & $\begin{array}{c}21 . \\
9\end{array}$ & 8.7 & 23.0 & 35.5 & $\begin{array}{c}14 . \\
6\end{array}$ & $\begin{array}{c}15 . \\
5\end{array}$ & $\begin{array}{c}17 . \\
8\end{array}$ & $\begin{array}{c}21 . \\
1\end{array}$ & 44.6 & 33.5 \\
\hline 6 & 2.1 & 9.4 & 12.1 & 5.8 & 1.8 & 8.9 & 25.3 & $\begin{array}{c}15 . \\
7\end{array}$ & $\begin{array}{c}12 . \\
9\end{array}$ & $\begin{array}{c}18 . \\
9\end{array}$ & 3.6 & 30.1 & 28.1 \\
\hline 7 & 2.2 & 4.5 & 3.0 & 7.6 & 1.6 & 1.0 & 9.4 & 1.3 & 1.6 & 3.7 & 2.2 & 0.8 & 9.2 \\
\hline 8 & 2.3 & 1.7 & 1.0 & 3.8 & 1.8 & 0.7 & 7.0 & 1.5 & 2.1 & 1.9 & 1.5 & 0.9 & 3.0 \\
\hline 9 & 2.4 & 2.9 & 6.1 & 6.8 & 1.8 & 2.1 & 30.2 & 2.7 & 3.2 & 5.2 & 4.3 & 1.1 & 21.5 \\
\hline 10 & 2.5 & 2.3 & 1.7 & 6.4 & 1.3 & 2.8 & 14.3 & 5.5 & 6.3 & 9.3 & 2.2 & 4.6 & 37.1 \\
\hline 11 & 3.1 & 1.7 & 1.6 & 2.7 & 1.2 & 1.2 & 5.5 & 2.7 & 3.9 & 1.3 & 1.2 & 2.1 & 25.2 \\
\hline 12 & 3.2 & 1.1 & 2.3 & 3.7 & 1.8 & 0.7 & 7.3 & 1.7 & 2.1 & 3.5 & 2.4 & 1.5 & 11.9 \\
\hline 13 & 3.3 & 3.3 & 3.7 & 2.3 & 2.5 & 0.9 & 3.2 & 1.0 & 1.5 & 2.3 & 2.1 & 33.5 & 48.2 \\
\hline 14 & 3.4 & $\begin{array}{c}20 . \\
4\end{array}$ & 22.5 & $\begin{array}{c}31 . \\
3\end{array}$ & 3.9 & 1.4 & 27.0 & $\begin{array}{c}13 . \\
8\end{array}$ & $\begin{array}{c}17 . \\
8\end{array}$ & $\begin{array}{c}12 . \\
7\end{array}$ & $\begin{array}{c}10 . \\
4\end{array}$ & 21.3 & 48.2 \\
\hline 15 & 3.5 & 3.0 & 3.4 & 4.1 & 1.1 & 1.5 & 8.8 & 4.6 & 3.8 & 6.7 & 0.8 & 1.4 & 9.4 \\
\hline 16 & 4.1 & 3.4 & 3.3 & 4.5 & 1.9 & 1.2 & 10.5 & 4.6 & 4.4 & 4.9 & 3.3 & 5.1 & 4.9 \\
\hline 17 & 4.2 & 1.4 & 2.3 & 3.6 & 0.9 & 0.9 & 3.0 & 3.4 & 2.2 & 9.6 & 1.1 & 0.5 & 9.4 \\
\hline 18 & 4.3 & 3.2 & 2.4 & 5.1 & 1.2 & 0.4 & 8.7 & 2.3 & 2.5 & 8.0 & 2.0 & 1.0 & 31.2 \\
\hline 19 & 4.4 & 3.5 & 2.1 & 6.2 & 0.8 & 0.6 & 4.5 & 2.2 & 1.2 & 5.9 & 1.8 & 0.8 & 11.3 \\
\hline 20 & 4.5 & 3.7 & 3.5 & 5.0 & 0.9 & 0.7 & 16.0 & 5.5 & 5.5 & $\begin{array}{c}11 . \\
5\end{array}$ & 1.8 & 1.4 & 11.0 \\
\hline
\end{tabular}

The experiments show that the $S E$ parameter can successfully be used as an indicator of the condition of the process referring to the formation of the surface roughness, i.e. an indicator of the roughness profile condition. For example, this can be seen on Fig. 10, 11 and 12. Fig. 10 shows a roughness profile with $S E=0.26$, obtained from measuring the segment marked 1.5 from the first work piece. Fig. 11 shows a roughness profile with $S E=0.09$, obtained from measuring the segment marked 2.5 from the second work piece and Fig. 12 shows a roughness profile $S E=0.04$, obtained from measuring the segment marked 3.2 from the third work piece. This does not mean that thee roughness profile shown on Fig. 10 was obtained from an unstable machining process. The main reason for the "distortion" of the shape and the deviation from the strictly deterministic shape relates to the ratio between the values of $f$ and $r_{\varepsilon}$. The radius of the insert $r_{\varepsilon}\left(r_{\varepsilon}=1.6 \mathrm{~mm}\right)$ is multiple times greater than the feed $f(f=0,1 \mathrm{~mm} / \mathrm{rev})$, and therefore the kinematical-geometrical copying of the cutting tool onto the processed surface is much less apparent than the process of transforming the material into a chip. 
M. Tomov, M. Kuzinovski \& P. Cichosz: Chapter 5

Mathematical Models with Feedback for Surface Roughness Parameter

Prediction in Longitudinal Turning

Table 6. Percentage difference between theoretical value and measured average values.

\begin{tabular}{|c|c|c|c|c|c|c|c|c|c|c|c|c|c|}
\hline \multirow{3}{*}{ No. } & \multirow{3}{*}{ 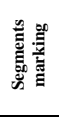 } & \multicolumn{4}{|c|}{$R z$} & \multicolumn{4}{|c|}{$R p$} & \multicolumn{4}{|c|}{$R v$} \\
\hline & & \multicolumn{2}{|c|}{ Lathe 1} & \multicolumn{2}{|c|}{ Lathe 2} & \multicolumn{2}{|c|}{ Lathe 1} & \multicolumn{2}{|c|}{ Lathe 2} & \multicolumn{2}{|c|}{ Lathe 1} & \multicolumn{2}{|c|}{ Lathe 2} \\
\hline & & $\begin{array}{c}A \\
(\%)\end{array}$ & $\begin{array}{c}\mathbf{B} \\
(\%) \\
\end{array}$ & $\begin{array}{c}A \\
(\%)\end{array}$ & $\begin{array}{c}\text { B } \\
(\%) \\
\end{array}$ & $\begin{array}{c}\mathrm{C} \\
(\%) \\
\end{array}$ & $\begin{array}{c}\text { D } \\
(\%) \\
\end{array}$ & $\begin{array}{c}\mathrm{C} \\
(\%) \\
\end{array}$ & $\begin{array}{c}\text { D } \\
(\%)\end{array}$ & $\begin{array}{c}E \\
(\%) \\
\end{array}$ & $\begin{array}{c}\mathbf{F} \\
(\%)\end{array}$ & $\begin{array}{c}\mathrm{E} \\
(\%)\end{array}$ & $\begin{array}{c}\mathbf{F} \\
(\%)\end{array}$ \\
\hline 1 & 1.1 & -22.8 & -2.9 & -17.3 & 0.1 & $\begin{array}{c}- \\
13.9 \\
\end{array}$ & -1.3 & -0.9 & 9.4 & -40.4 & 17.7 & -50.8 & -28.4 \\
\hline 2 & 1.2 & -5.6 & 12.7 & -20.0 & 10.3 & 3.3 & 14.8 & $\overline{11.2}$ & 8.3 & -23.0 & -1.7 & -37.3 & -2.7 \\
\hline 3 & 1.3 & 1.1 & 13.8 & 2.2 & 13.4 & 1.3 & 10.0 & 0.8 & 8.5 & 0.6 & 13.4 & 5.1 & 16.0 \\
\hline 4 & 1.4 & -2.4 & 11.7 & 1.8 & 16.2 & -1.3 & 8.2 & 1.3 & 11.3 & -4.1 & 10.2 & 2.9 & 17.2 \\
\hline 5 & 1.5 & -132.4 & 11.6 & -96.2 & 59.5 & $\begin{array}{c}- \\
89.0\end{array}$ & 0.7 & 45.1 & 49.3 & $\begin{array}{c}- \\
218.2\end{array}$ & $\overline{21.1}$ & -197.5 & 38.6 \\
\hline 6 & 2.1 & -108.7 & $\begin{array}{c}- \\
28.1 \\
\end{array}$ & 125.0 & $\begin{array}{c}- \\
10.0 \\
\end{array}$ & $\begin{array}{c}- \\
73.0 \\
\end{array}$ & $\begin{array}{c}- \\
24.9 \\
\end{array}$ & 82.2 & $\begin{array}{c}- \\
13.1 \\
\end{array}$ & 179.2 & 71.3 & -209.7 & -51.4 \\
\hline 7 & 2.2 & -3.4 & 14.1 & -5.3 & 8.9 & 0.6 & 12.2 & 1.4 & 10.5 & -11.4 & 7.5 & -19.1 & -3.0 \\
\hline 8 & 2.3 & -7.1 & 5.2 & -13.0 & 5.7 & -5.0 & 3.2 & -1.4 & 10.1 & -11.2 & 1.5 & -36.2 & -13.7 \\
\hline 9 & 2.4 & -18.1 & -1.0 & -20.5 & 15.8 & 15.3 & -3.9 & -9.1 & 14.0 & -23.7 & -5.8 & -43.2 & -0.2 \\
\hline 10 & 2.5 & -19.5 & -0.2 & -17.0 & 20.6 & 10.6 & 1.6 & -9.3 & 15.6 & -37.3 & 15.1 & -32.6 & 9.9 \\
\hline 11 & 3.1 & -1.6 & 10.0 & -5.9 & 14.9 & -3.5 & 4.5 & -4.3 & 9.8 & 2.4 & 13.4 & -9.1 & 12.3 \\
\hline 12 & 3.2 & 3.9 & 16.8 & 2.4 & 14.8 & 5.7 & 14.3 & 1.3 & 9.8 & 0.4 & 13.7 & 4.8 & 16.9 \\
\hline 13 & 3.3 & -54.6 & 34.7 & -90.3 & 45.2 & $\begin{array}{c}- \\
18.7 \\
\end{array}$ & 33.2 & $\begin{array}{c}- \\
40.8 \\
\end{array}$ & 38.6 & $\begin{array}{c}- \\
125.9 \\
\end{array}$ & 4.6 & -188.3 & 17.0 \\
\hline 14 & 3.4 & -76.2 & 12.3 & 121.1 & 43.6 & $\begin{array}{c}- \\
36.3 \\
\end{array}$ & -0.9 & $\begin{array}{c}- \\
77.4 \\
\end{array}$ & 28.7 & 155.4 & 62.8 & -207.8 & 21.5 \\
\hline 15 & 3.5 & -7.8 & 6.3 & -4.5 & 13.6 & -0.4 & 8.6 & -0.8 & 11.3 & -22.6 & -6.6 & -12.0 & 7.5 \\
\hline 16 & 4.1 & -9.9 & 3.0 & -8.9 & 11.8 & -7.0 & 1.6 & -1.4 & 11.9 & -15.7 & -2.1 & -23.8 & -0.3 \\
\hline 17 & 4.2 & -28.8 & -4.2 & -12.5 & 0.4 & 10.2 & 4.3 & 3.0 & 10.5 & -66.2 & 34.5 & -43.4 & -26.9 \\
\hline 18 & 4.3 & -25.7 & 15.5 & -24.0 & -5.4 & -5.7 & 0.1 & $\begin{array}{r}- \\
11.6 \\
\end{array}$ & -0.1 & -65.9 & 52.4 & -47.5 & -25.4 \\
\hline 19 & 4.4 & -11.6 & -1.5 & -34.5 & $\begin{array}{c}- \\
19.0 \\
\end{array}$ & -5.0 & 1.4 & 29.9 & $\begin{array}{c}- \\
19.7 \\
\end{array}$ & -24.8 & $\begin{array}{c}- \\
13.5 \\
\end{array}$ & -43.9 & -27.3 \\
\hline 20 & 4.5 & -10.0 & -1.8 & -25.8 & -3.6 & -1.5 & 3.6 & 16.8 & -2.6 & -27.3 & 17.8 & -43.9 & -18.5 \\
\hline $\begin{array}{l}\text { A-P } \\
\text { B- } P \\
\text { C- } P \\
\text { D- } P \\
\text { E- } P \\
\text { F- } P\end{array}$ & $\begin{array}{l}\text { ntage } \\
\text { ntage } \\
\text { ntage }\end{array}$ & $\begin{array}{l}\text { fference } \\
\text { fference } \\
\text { fference } \\
\text { fference }\end{array}$ & $\begin{array}{l}\text { etween } \\
\text { etween } \\
\text { etween } \\
\text { tween }\end{array}$ & $\begin{array}{l}\text { oretical } \\
\text { eoretical } \\
\text { eoretical } \\
\text { eoretica } \\
\text { eoretical } \\
\text { eoretical }\end{array}$ & $\begin{array}{l}\text { Ines } \mathrm{ca} \\
\text { lues } \mathrm{c} \\
\text { lues } \mathrm{ca} \\
\text { lues } \mathrm{ca}\end{array}$ & $\begin{array}{l}\text { ulated } \\
\text { ulated } \\
\text { ulated } \\
\text { ulated }\end{array}$ & $\begin{array}{l}\text { cording } \\
\text { cordins } \\
\text { cording } \\
\text { cording }\end{array}$ & $\begin{array}{l}\text { equ } \\
\text { equ }\end{array}$ & $\begin{array}{l}n(21) \\
\text { n (13) } \\
\text { n (22) } \\
\text { n(14) } \\
\text { (23) }\end{array}$ & $\begin{array}{l}\text { measu } \\
\text { d meast } \\
d \text { meas } \\
\text { d meas } \\
\text { d meas } \\
\text { d meast }\end{array}$ & $\begin{array}{l}\text { averag } \\
\text { lavera } \\
\text { lavera } \\
\text { I avera } \\
\text { avera } \\
\text { avera }\end{array}$ & $\begin{array}{l}\text { lues } \\
\text { values } \\
\text { values } \\
\text { values } \\
\text { values } \\
\text { values }\end{array}$ & \\
\hline
\end{tabular}

The results show that increasing the value of the $S E$ parameter leads to greater percentage differences between the highest and lowest measured value out of the five measurements for each segment (Table 5), as well as greater percentage differences between the theoretically calculated values and the measured values (Table 6).

The experiments showed that the inclusion of the input variables $V$ and $\mathrm{a}_{\mathrm{p}}$ is justified, although they do not participate in the theoretical calculations for the $R$ parameters. 
ADVANCES IN PRODUCTION AND INDUSTRIAL ENGINEERING

M. Tomov, M. Kuzinovski \& P. Cichosz: Chapter 5

Mathematical Models with Feedback for Surface Roughness Parameter

Prediction in Longitudinal Turning

Table 6. Percentage difference between theoretical value and measured average values (Continuation).

\begin{tabular}{|c|c|c|c|c|c|c|c|c|c|c|c|c|c|}
\hline \multirow{3}{*}{ No. } & \multirow{3}{*}{ 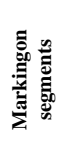 } & \multicolumn{4}{|c|}{$R a$} & \multicolumn{4}{|c|}{$R S m$} & \multicolumn{4}{|c|}{$\operatorname{Rrm}(30 R z)$} \\
\hline & & \multicolumn{2}{|c|}{ Lathe 1} & \multicolumn{2}{|c|}{ Lathe 2} & \multicolumn{2}{|c|}{ Lathe 1} & \multicolumn{2}{|c|}{ Lathe 2} & \multicolumn{2}{|c|}{ Lathe 1} & \multicolumn{2}{|c|}{ Lathe 2} \\
\hline & & $\begin{array}{c}\mathbf{G} \\
(\%)\end{array}$ & $\underset{(\%)}{\mathbf{H}}$ & $\underset{(\%)}{\mathbf{G}}$ & $\underset{(\%)}{\mathbf{H}}$ & $\underset{(\%)}{I}$ & $\underset{(\%)}{\mathbf{J}}$ & $\underset{(\%)}{I}$ & $\underset{(\%)}{\mathbf{J}}$ & $\underset{(\%)}{\mathbf{K}}$ & $\underset{(\%)}{\mathbf{L}}$ & $\underset{(\%)}{\mathbf{K}}$ & $\underset{(\%)}{\mathbf{L}}$ \\
\hline 1 & 1.1 & 1.0 & 6.7 & $\begin{array}{c}- \\
14.6 \\
\end{array}$ & -8.6 & 0.6 & -5.4 & 0.0 & -5.5 & 17.8 & 12.9 & -9.4 & 15.4 \\
\hline 2 & 1.2 & -3.4 & 2.9 & -8.4 & 1.6 & 0.6 & -5.9 & -0.6 & 10.8 & -5.9 & -12.8 & 6.2 & -3.4 \\
\hline 3 & 1.3 & 2.4 & 6.8 & 5.4 & 9.1 & 0.1 & -4.6 & 6.4 & 2.6 & 3.2 & -1.3 & 10.9 & 7.3 \\
\hline 4 & 1.4 & 4.0 & 8.6 & 4.8 & 9.7 & 0.4 & -4.6 & 0.1 & -5.4 & 8.8 & 4.2 & 14.6 & 10.0 \\
\hline 5 & 1.5 & -52.2 & -10.3 & 29.0 & 23.8 & 33.4 & 8.1 & 47.0 & 10.3 & 22.7 & -6.6 & 27.2 & $\begin{array}{c}- \\
23.1 \\
\end{array}$ \\
\hline 6 & 2.1 & -87.6 & -59.4 & $\begin{array}{c}- \\
76.2 \\
\end{array}$ & $\begin{array}{c}- \\
38.8 \\
\end{array}$ & 5.2 & 11.6 & 34.5 & 16.8 & -4.0 & -22.4 & 13.3 & $\begin{array}{c}- \\
10.0 \\
\end{array}$ \\
\hline 7 & 2.2 & 1.9 & 7.8 & -3.3 & 1.6 & -0.2 & -6.6 & -0.1 & -5.1 & 7.3 & 1.4 & -9.4 & 14.8 \\
\hline 8 & 2.3 & 1.2 & 5.1 & 0.5 & 6.3 & 0.4 & -3.7 & -0.2 & -6.4 & -0.8 & -5.0 & 0.1 & -6.1 \\
\hline 9 & 2.4 & 0.4 & 5.4 & -7.2 & 4.9 & 1.2 & -4.1 & 0.8 & 11.7 & 39.7 & 36.5 & 6.3 & -5.6 \\
\hline 10 & 2.5 & -3.6 & 2.3 & -2.2 & 10.2 & -0.9 & -7.0 & -0.2 & $\overline{14.0}$ & 15.4 & 10.3 & 22.8 & 12.2 \\
\hline 11 & 3.1 & 2.2 & 6.0 & 2.8 & 9.6 & -0.1 & -4.2 & 3.4 & -3.9 & 10.1 & 6.4 & 26.7 & 21.1 \\
\hline 12 & 3.2 & 6.2 & 10.6 & 7.0 & 11.1 & 0.4 & -4.5 & 3.8 & -0.6 & 1.5 & -3.4 & 14.1 & 10.1 \\
\hline 13 & 3.3 & -19.1 & 10.6 & 33.3 & 12.0 & 22.5 & -3.2 & 32.7 & -1.9 & 23.7 & -1.7 & 46.2 & 18.5 \\
\hline 14 & 3.4 & -48.2 & -27.5 & $\begin{array}{c}- \\
65.5 \\
\end{array}$ & -5.0 & 0.2 & $\begin{array}{c}- \\
16.0 \\
\end{array}$ & -6.7 & $\begin{array}{c}- \\
68.3 \\
\end{array}$ & -15.2 & -33.9 & 54.6 & 28.4 \\
\hline 15 & 3.5 & 0.1 & 4.6 & 7.5 & 13.2 & 0.8 & -4.0 & 0.7 & -5.8 & -0.8 & -5.6 & 18.6 & 13.2 \\
\hline 16 & 4.1 & 2.9 & 6.9 & 9.0 & 15.2 & 0.7 & -3.5 & 1.2 & -5.9 & 13.1 & 9.4 & 2.4 & -4.7 \\
\hline 17 & 4.2 & -14.2 & -6.4 & -0.1 & 3.9 & 0.0 & -7.3 & -0.3 & -4.4 & -19.3 & -28.0 & 17.9 & $\begin{array}{c}- \\
22.8 \\
\end{array}$ \\
\hline 18 & 4.3 & -16.2 & -12.9 & -2.5 & 2.9 & 0.0 & -2.8 & 0.0 & -5.6 & -23.6 & -27.1 & 16.4 & 11.8 \\
\hline 19 & 4.4 & -0.1 & 3.0 & 16.9 & 12.2 & 0.0 & -3.2 & 0.2 & -4.0 & 6.2 & 3.2 & 18.9 & 15.5 \\
\hline 20 & 4.5 & 3.4 & 5.9 & $\overline{11.7}$ & -4.7 & 0.1 & -2.5 & -0.5 & -7.2 & 6.2 & 3.8 & 3.9 & -2.5 \\
\hline $\begin{array}{l}\text { G- } \\
\text { H- } \\
\text { I- Pe } \\
\text { J- Pe } \\
\text { K- } P \\
\text { L- P }\end{array}$ & $\begin{array}{l}\text { ntage d } \\
\text { ntage } \\
\text { entage } \\
\text { ntage }\end{array}$ & $\begin{array}{l}\text { rence } \\
\text { erence } \\
\text { erence } \\
\text { erence }\end{array}$ & $\begin{array}{l}\text { ween } t \\
\text { ween } t \\
\text { ween } \\
\text { ween }\end{array}$ & $\begin{array}{l}\text { retical } \\
\text { retical } \\
\text { oretica } \\
\text { retica }\end{array}$ & $\begin{array}{l}\text { lues c } \\
\text { lues c } \\
\text { alues } \\
\text { alues }\end{array}$ & $\begin{array}{l}\text { ulated } \\
\text { ulated } \\
\text { culatec } \\
\text { culated }\end{array}$ & $\begin{array}{l}\text { cordin } \\
\text { cordir } \\
\text { ccordi } \\
\text { ccordi }\end{array}$ & $\begin{array}{l}\text { equa } \\
\text { o equi } \\
\text { to equ } \\
\text { o equ }\end{array}$ & $\begin{array}{l}\text { on }(24) \\
\text { in (18) } \\
\text { in (26) } \\
\text { on (19) } \\
\text { on (27) }\end{array}$ & $\begin{array}{l}\text { meas } \\
\text { meas mea } \\
\text { d mea }\end{array}$ & $\begin{array}{l}\text { averag } \\
\text { averag } \\
\text { d avera } \\
\text { d averag }\end{array}$ & $\begin{array}{l}\text { values } \\
\text { values } \\
\text { alues } \\
\text { alues } \\
\text { values } \\
\text { alues }\end{array}$ & \\
\hline
\end{tabular}

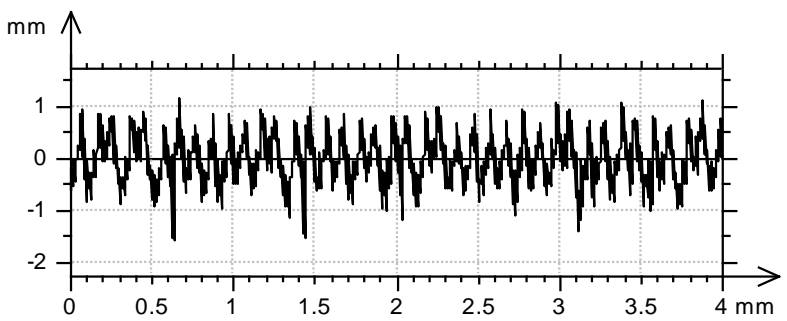

Figure 10. Roughness profile with $S E=0.26$ and $R_{a}=0,32 \mu \mathrm{m}$. 


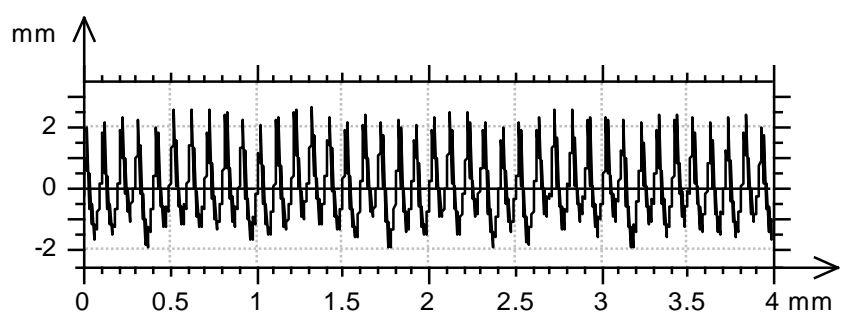

Figure 11. Roughness profile with $S E=0.09$ and $R_{a}=0,84 \mu \mathrm{m}$.

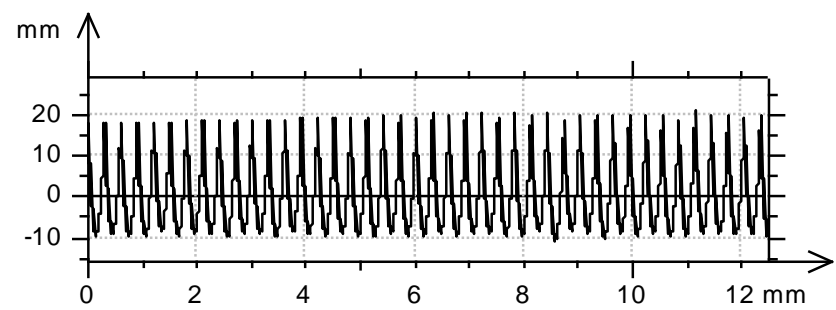

Figure 12. Roughness profile with $S E=0.04$ and $R_{a}=7,09 \mu \mathrm{m}$.

The percentage differences shown in Table 6 suggest that the inclusion of $S E$ in the $R$-parameter calculation models is quite justified. Perhaps if one considers the percentage differences between the theoretically calculated and the measured values in both cases separately, one may find examples where the theoretical values that do not take into account the $S E$ parameter provide smaller percentage differences. However, if we look at the entire hyperspace of input variables, we can clearly and visibly see the tendencies of obtaining smaller differences between the theoretically calculated values that the take the $S E$ parameter into account, and the measured values, for both lathes. Another positive effect is the change of the sign in front of the percentage differences from "-_" to "+" in some cases, which suggests that the theoretically calculated value is greater than the measured value which is particularly important when applying the "max-rule" to indication the roughness parameters in technical product documentation.

This confirms the expectation that the $R S_{m}$ parameter least sensitive to the "distortion" of the roughness profile. When $S E$ is less than 0.1, then the theoretical calculation of the value of $R S_{m}$ should not include the impact of the "distortion" of the profile, or $S E$. When $S E$ is greater than 0.1, then the inclusion of $S E$ in the theoretical calculation of the value for $R S_{m}$ is justified.

The different approach to the theoretical calculations and measurements also impact the percentage differences of the parameter $R_{\operatorname{mr}(\mathrm{c})}$. The theoretic calculation 
ADVANCES IN PRODUCTION AND INDUSTRIAL ENGINEERING

M. Tomov, M. Kuzinovski \& P. Cichosz: Chapter 5

Mathematical Models with Feedback for Surface Roughness Parameter

Prediction in Longitudinal Turning

of $\mathrm{R}_{\mathrm{mr}(\mathrm{c})}$ considers the sampling length while the measurements consider the evaluation length.

\subsubsection{Partical applicability of the research}

Based on the obtained results and the discussion above, and in order to make this research applicable, Fig. 13 below proposes an algorithm of steps for predicting and realizing the considered roughness parameters for industrial purposes.

From a practical standpoint, the existence of a "test processing" step may be considered a shortcoming of the algorithm. However this step is unavoidable because it indicates the condition of the process for a specific machine, i.e. SE. In the future, perhaps we should investigate the possibility of modelling (for example through Design of Experiment (DOE) of $S E$ and instead of having a "test processing" step, obtain the values for $S E$ from the $S E$ model.

\section{Conclusion}

The research presented in this paper further develops the models for predicting surface roughness by directly linking the theoretically developed models to the real machining process condition, different for different processing systems (machines). This approach facilitates a radical expansion of the area of practical applicability of the developed models. Here the research focuses on the development of mathematical models based on the principle of kinematicalgeometrical copying of the cutting tool onto the processed surface. Nevertheless, in the future we need to investigate whether and how this idea can expand to the other methods for predicting roughness parameters.

The authors think that the scientific contribution of this research is reflected in the fact that it sets the models for predicting the $R_{p}, R_{v}$ and $R_{m r(c)}$ parameters, something rarely seen in the research on this topic. Usually, the researchers focus on finding prediction models for the $\mathrm{R}_{\mathrm{a}}$ and $\mathrm{R}_{\mathrm{z}}\left(\mathrm{R}_{\mathrm{t}}\right)$ parameters.

Parameter of statistic equality of sampling lengths in surface roughness measurement $(S E)$ has proven here to be a successful index that provides information about the condition of the process with respect to surface roughness formation, i.e. an indicator of the roughness profile condition that can be successfully implemented in surface roughness prediction models.

We should point out that the obtained percentage differences between the theoretically calculated values for the $R$-parameters and the measured values do not express only the difference between them, but they also include the errors that occurred during the measurement of the $R$-parameters. The used type $\mathrm{C}$ measurement equipment calibration etalons have a calibration certificate that 
M. Tomov, M. Kuzinovski \& P. Cichosz: Chapter 5

Mathematical Models with Feedback for Surface Roughness Parameter

Prediction in Longitudinal Turning

certifies that they have an uncertainty level of the $\mathrm{R}_{\mathrm{a}}$-parameter of $5 \%$. In addition, the measuring device (Surf test SJ-410) can have a specific error (uncertainty). Therefore when the percentage differences between the theoretically measured values are small, we cannot ascertain that they reflect only the differences between the theoretical and the measured values.

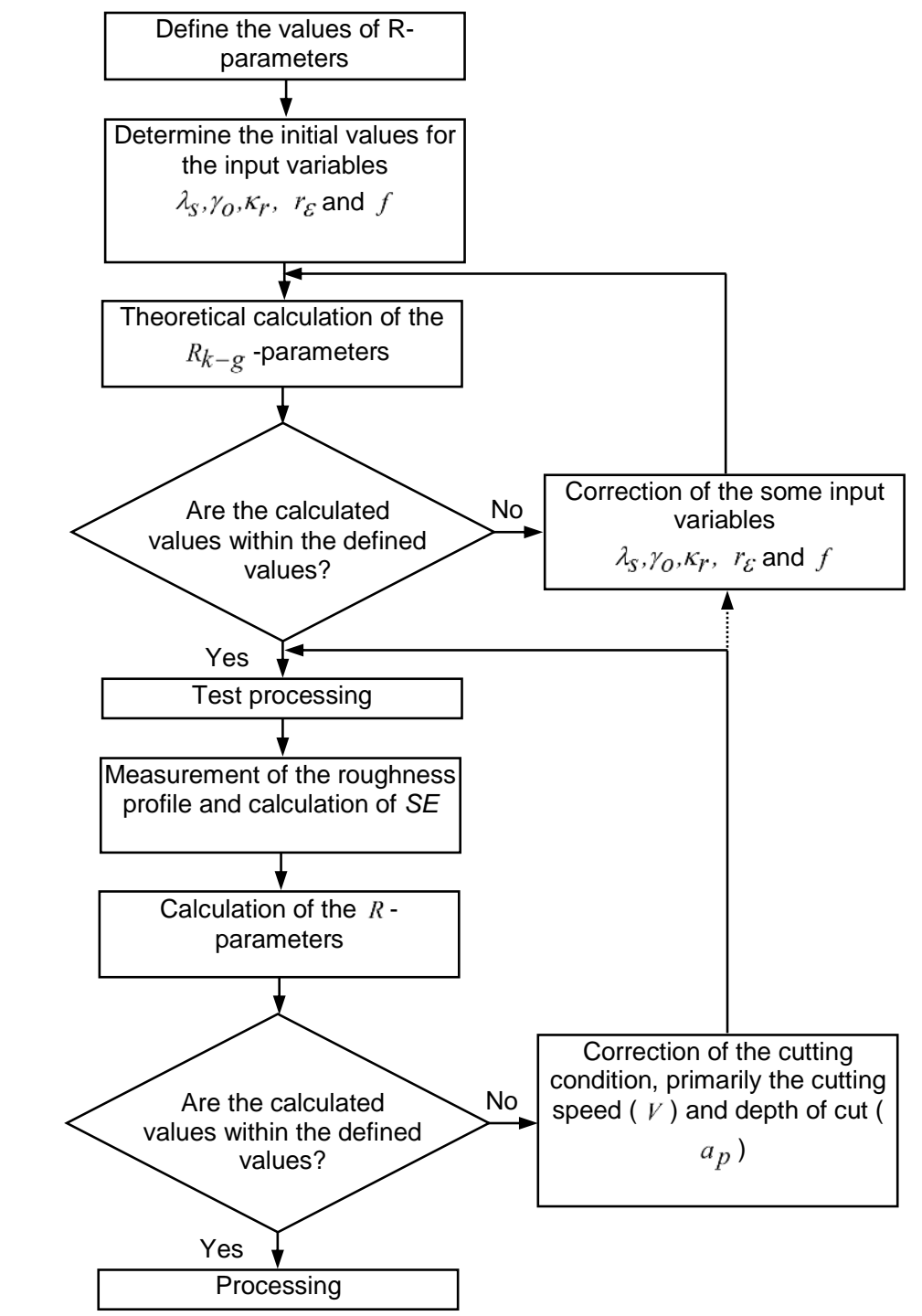

Figure 13. Algorithm of steps for predicting and realizing the considered roughness parameters for industrial purposes. 
Mathematical Models with Feedback for Surface Roughness Parameter

Prediction in Longitudinal Turning

In addition, we have to emphasize the impact of the selection of a large hyperspace for the input variables, especially $f$ and $r_{\varepsilon}$, on the occurrence of large percentage differences between the theoretically calculated values for the $R$-parameters and the measured values in some cases. During the practical verification, if the authors focused on a carefully selected smaller hyperspace for the input variables, then they could expect to obtain smaller differences between the calculated and the measured values.

\section{References}

[1] (Jack) Feng C.X., Wang X. (2002). Development of empirical models for surface roughness prediction in finish turning. International Journal of Advanced Manufacturing Technology. vol. 20, p. 348-356.

[2] Sundaram R.M., Lambert B.K. (1981). Mathematical models to predict surface finish in fine turning of steel, Part 1. International Journal of Production Research, vol. 19, no. 5 , p. 547-556.

[3] Choudhury, I.A., El-Baradie M.A. (1997). Surface roughness prediction in the turning of high-strength steel by factorial design of experiments. Journal of Materials Processing Technology. Vol. 67, p. 55-61.

[4] Makadia A. J., Nanavati J.I.(2013). Optimisation of machining parameters for turning operations based on response surface methodology. Measurement, vol. 46, p.1521-1529.

[5] Kahraman F. (2009).The use of response surface methodology for prediction and analysis of surface roughness of AISI 4140 steel. Materials and technology, vol. 43 no. 5, p. 267-270

[6] Ozel T., Karpat Y. (2005). Predictive modeling of surface roughness and tool wear in hard turning using regression and neural networks. International Journal of Machine Tools \& Manufacture, vol. 45, p. 467-479.

[7] Feng, C.X., Wang X.F. (2003). Surface roughness predictive modeling: neural networks versus regression. IIE Transactions, vol. 35.p. 11-27.

[8] Lee S.S., Chen J.C. (2003). On-line surface roughness recognition system using artificial neural networks system in turning operations. International Journal of Advanced Manufacturing Technology, vol. 22, no. 7/8, p. 498-509.

[9] Liao Y.G., Hu S.J. (2001). An integrated model of a fixture-workpiece system for surface quality prediction. International Journal of Advanced Manufacturing Technology. vol. 17, p. 810-818.

[10] Rosen B-G., Ohlsson R., Westberg J. (1995). Interactive surface modelling, an implementation of an expert system for specification of surface roughness and topography. International Journal of Machine Tools \& Manufacture, vol. 35, p. 317 324.

[11] Kuzinovski M., Stamboliska Z., Cichosz P.(2004). Engineering of surface layer in material removal machining. Journal of Materials Processing Technology, vol. 155156, p. 1451-1458.

[12] Miko E., Nowakowski Ł. (2012). Analysis and verification of surface roughness constitution model after machining process. Procedia Engineering, vol.39, p. 395404. 
[13] Tomov M., Kuzinovski M., Cichosz P.(2013). A new parameter of statistic equality of sampling lengths in surface roughness measurement. Strojniški vestnik - Journal of Mechanical Engineering, vol. 59, no.5, p.339-348.

[14] Raja J., Muralikrishnan B., Fu Shengyu. (2002). Recent advances in separation of roughness, waviness and form. Journal of the International Societies for Precision Engineering and Nanotechnology, vol. 26, p. 222-235.

[15] Raja J., Radhakrishnan V. (1979). Digital filtering of surface profiles. Wear, vol. 57, p.147-15.

[16] Pawlus P.(2004). Mechanical filtration of surface profiles. Measurements, vol. 35, p. 325-341.

[17] Whitehead S.A., Shearer A.C., Watts D.C., Wilson N.H.(1999) .Comparison of two stylus methods for measuring surface texture. Dental materials, vol. 15, p. 79-86.

[18] Pawlus P., Śmieszek M. (2005). The influence of stylus flight on change of surface topography parameters. Precision Engineering, vol. 29, no. 3, p. 272-280.

[19] DIN 4760. Gestaltabweichungen. Begriffe. Ordungssustem. Juni, 1982.

[20] ISO 3002/1-1982 (E): Basic quantities in cutting and grinding - Part 1 : Geometry of the active part of cutting tools - General terms, reference systems, tool and working angles, chip breakers.

[21] ISO 4287:1997. Geometrical Product Specifications (GPS) - Surface texture: Profile method - Terms, definitions and surface texture parameters.

[22] ISO 4288:1996. Geometrical Product Specifications (GPS) - Surface texture: Profile method - Rules and procedures for the assessment of surface texture. 
AdVANCES In PRoduction AND INDUSTRIAL ENGINEERING 


\title{
Chapter 6
}

\section{Tool Wear Compensation in End Milling Based on Cutting Force Measuring and Tool Visual Monitoring}

\author{
FRANC ČUŠ, TOMAŽ IRGOLIČ \& UROŠ ŽUPERL
}

\begin{abstract}
The aim of this study was to develop an accurate and reliable tool wear compensation system in end milling operations. This paper discusses the advantages of a vision system as an observation technique of tool condition during end milling. By integration of machine vision with indirect toll wear measurement technique an automatic tool wear compensation system is developed. The indirect technique is based on cutting force measurements and neuro-fuzzy algorithm which is trained to predict the amount of tool wear. The machine vision system signals and the output of an in-process tool wear model error are applied to a decision system for tool wear compensation.
\end{abstract}

Keywords: • tool wear $\cdot$ compensation $\cdot$ computer vision $\bullet$ wear model $\bullet$ cutting force

Correspondence Adress: Franc Čuš, Ph.D., Full Professor, University of Maribor, Faculty of Mechanical Engineering, Smetanova ulica 17, 2000 Maribor, Slovenia, e-mail: franc.cus@um.si, Tomaž Irgolič, Ph.D., Researcher, University of Maribor, Faculty of Mechanical Engineering, Smetanova ulica 17, 2000 Maribor, Slovenia, e-mail: tomaz.irgolic@um.si, Uroš Župerl, Ph.D., Associate Professor, University of Maribor, Faculty of Mechanical Engineering, Smetanova ulica 17, 2000 Maribor, Slovenia, e-mail: uros.zuperl@um.si

https://doi.org/10.18690/978-961-286-028-8.6 ISBN 978-961-286-028-8

(C) 2017 University of Maribor Press

Available at: http://press.um.si. 
With regard to the monitoring of cutting tool states, two main factors are tool wear and tool failure. Tool failure has become more important recently since hard tools are frequently used in the cutting process. Many studies have been conducted on the monitoring of malfunctions and abnormal cutting states of machine tools [1]. There are two techniques for tool condition sensing: direct and indirect. Generally, direct techniques are avoided because of the difficulty with online measurements. Haber [2] has measured the flank wear of the cutting tool using computer vision. He has proved the feasibility of this technique, however he also exposed problems with the integration of such system on the machine tool.

The indirect technique includes the measuring of cutting forces, torque, vibration, acoustic emission (stress wave energy), sound, temperature variation of the cutting tool, power or current consumption of spindles or feed motors, and roughness of the machined surface $[3,4]$.

The recent trend in TCM is the combination of direct and indirect techniques [5]. This paper discusses the advantages of integration of machine vision into the popular indirect technique for tool condition sensing which is based on cutting force measurements.

\section{$2 \quad$ Architecture of monitoring system}

Figure 1 shows the basic architecture of the proposed TCM system. The proposed system consists of five main parts. First part is ANFIS model of tool wear. It is developed from a set of data obtained during actual machining tests performed on a Heller milling machine using a Kistler force sensor. The signal processing module analyses the machining signals for extracting features sensitive to tool wear. The trained ANFIS model of tool wear is then merged subsequently with an optical vision system for assessing tool wear condition (good, broken). Tool deflection that occurs during machining and especially when flexible tools such as end mills are used, can result in dimensional errors on workpieces. Therefore, the fourth part, the error compensation module is developed. This part of TCM modifies the cutting conditions, compensates for the machining errors due to tool deflection and tool wear, without degrading the production performance and the machined accuracy. The compensation strategy allows the on-line optimization of feed rates or the tool path trajectory in order to achieve a specified tolerance. The output of error compensation module were applied to a decision system (part five) which can guide machine tool control system or operator in tool change decisions making. 


\section{$3 \quad$ Vision system}

The developed vision system is adapted to end milling and special programs were developed to monitor tool wear. The system consists of a high speed smart camera for online monitoring and special developed software. The smart camera was chosen to visually detect tool breakage. The used smart Camera $1772 \mathrm{C}$ is a product of National Instruments. The maximum output is 64.995 frames per second (fps). Additional Basler acA640 camera was also used. Its maximum output is $110 \mathrm{fps}$. The measured tool wear explains us the adequacy of cutting conditions during a specific time in machining and which parameters need to be adjusted to improve the surface roughness and decrease further tool wear. Testings are subordinated to determine the limits of the applied camera and what possibilities it offers for other applications. The programs to operate the vision system were designed in LabVIEW. In the first settings, the program was set to detect the wear of the cutting tool and a change in the proximity of the cutting tool - chip formation. Next the tool breakage detection is ensured.

On behalf of the observation results, the user interface reports the monitoring status of the tool to the operator via network variables. 
100 Advances in PROdUCtion AND INDUSTRIAL ENGINEERING F. Čuš, T. Irgolič \& U. Župerl: Chapter 6

Tool Wear Compensation in End Milling Based on Cutting Force Measuring and Tool Visual Monitoring

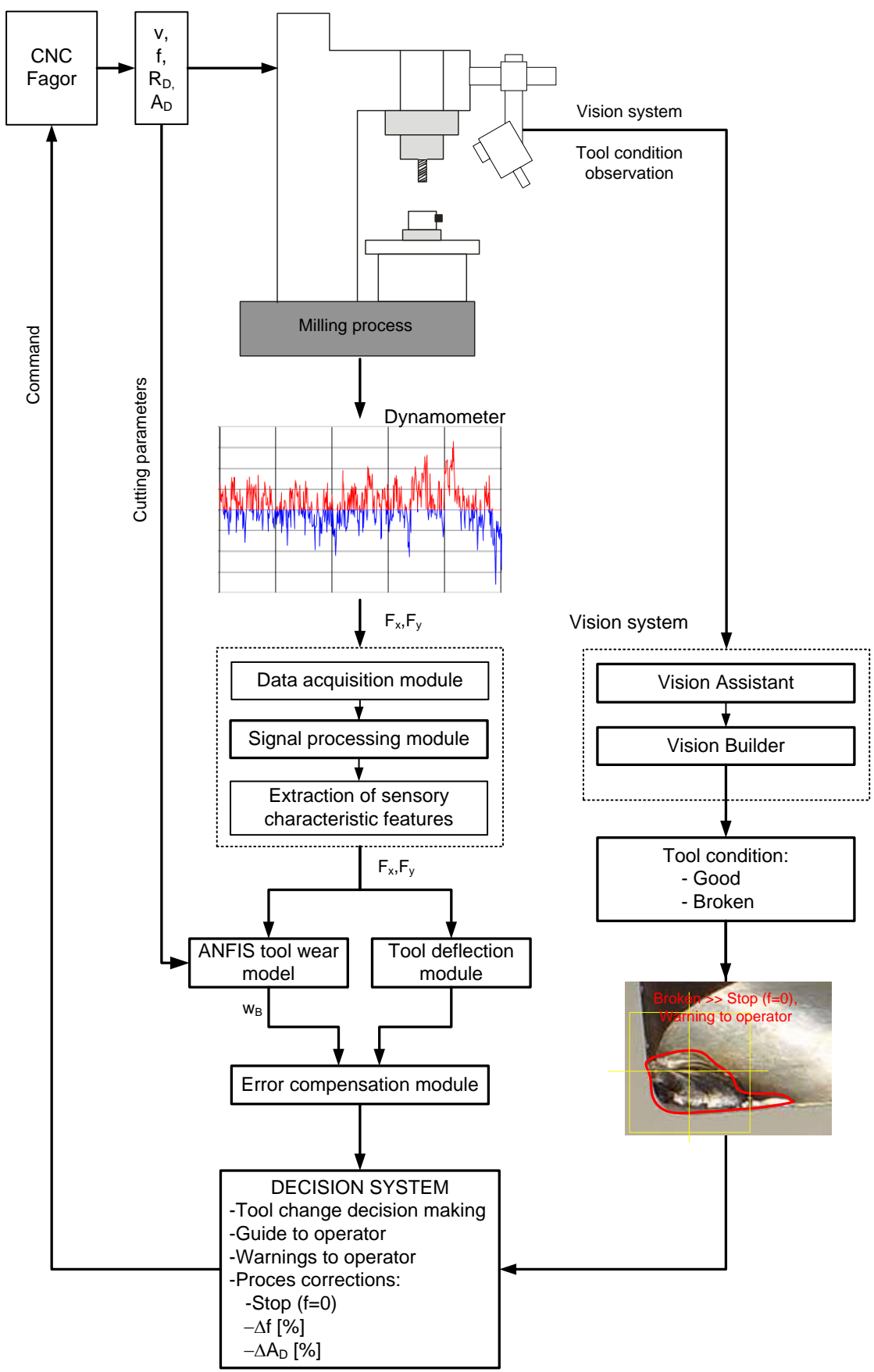

Figure 1. Architecture of tool condition monitoring system 
Tool Wear Compensation in End Milling Based on Cutting Force

Measuring and Tool Visual Monitoring

\section{$4 \quad$ Tool wear model}

The relationship between the machining parameters/sensor signals and flank wear is first captured via a network and is subsequently reflected in linguistic form with the help of a fuzzy logic based algorithm.

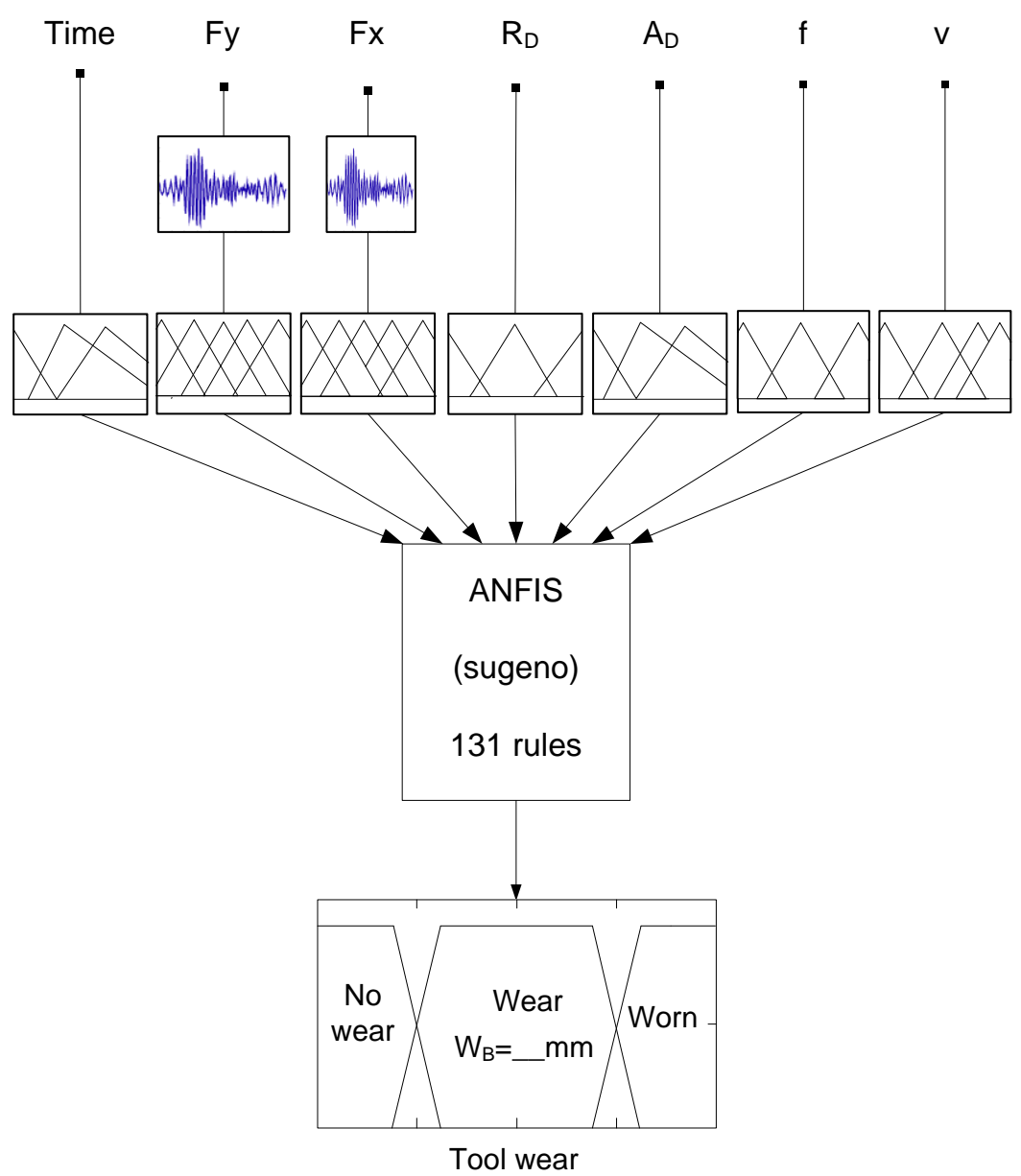

Figure 2. Structure of ANFIS tool wear model

The estimation design process consists of a linguistic rule construction, the partition of fuzzy subsets and the definition of the membership function shapes. It uses training examples as input and constructs the fuzzy if-then rules and the membership functions (MF) of the fuzzy sets involved in these rules as output. 
This process is called a training phase. Figure 2 shows the fuzzy rule architecture of ANFIS when the triangular membership function is adopted [6].

The fuzzy inference system under consideration has 7 inputs and one output $w_{\mathrm{B}}$. The process variables are force sensor readings $\left(F_{\mathrm{x}} F_{\mathrm{y}}\right)$, cutting speed $(v)$, feed rate $(f)$, depth of cutting $\left(\mathrm{A}_{\mathrm{D}} / \mathrm{R}_{\mathrm{D}}\right)$, machining time and flank wear $\left(w_{\mathrm{B}}\right)$. The domain of definition of these variables is normalized in the range $(0,1)$, where 1 corresponds to the maximal value of that variable.

\section{$5 \quad$ Tool deflection module}

The main objective of the deflection module is to determine the deflection of end mills under milling forces. For the deflection analysis of end mills, the tool holder is assumed to be rigid and the cantilever beam model is used. However, the holder and the clamping stiffness can also be included in the analysis if they are known. End mill deflections can be approximated by using the beam model.

Modelling can be unpractical and time consuming for each tool configuration in a virtual machining environment. Therefore, simplified equations are generated to predict deflections of tools for given geometric parameters (mill diameter, shank diameter, flute length, overall length), point load and density.

\section{$6 \quad$ Experimental set-up}

Experiments were performed on a CNC machining platform Heller with FAGOR CNC controller.

A vision system consisting of a high speed smart camera NI 1772C was used to detect tool breakage without dismounting the tool from the tool holder. The maximum output is 64,995 frames per second (fps).

Additional Basler acA640 camera was also used. Its maximum output is $110 \mathrm{fps}$. Proper lighting condition is assured with the use of a LED ring light, which provides a constant illumination of the observed area. The ring light is set to constant mode - this provides illumination without the flashing effect of the stroboscope settings.

The $1772 \mathrm{C}$ has a lot of options including: setting the light conditions - driver for external light, setting the colour of the gathered frame.

The Basler camera does not support such settings, furthermore its speed requires a very capable computer with fast processing abilities. 
Tool Wear Compensation in End Milling Based on Cutting Force

Measuring and Tool Visual Monitoring

Namely the speed of the frame acquisition is for normal computers too fast. Special adaptations are needed for the computer to save and process all the data.

All the data are transferred to the PC via Giga Ethernet cable. The $1772 \mathrm{C}$ also possesses its own buffer and so enables to store all gathered frames without a delay in observation.

The monitoring involved in end milling process of steel parts using two end mill tools: a normal tool and a tool with a broken tooth. The cutting tool used in the machining test was a solid end milling cutter with two cutting edges. The tool diameter was $16 \mathrm{~mm}$. Its helix angle was $10^{\circ}$. Figure 3 shows a worn tool using the vision system.

The corner radius of the cutter was $4 \mathrm{~mm}$. The workpiece material used in the machining test was $\mathrm{Ck} 45$ and $\mathrm{Ck} 45$ (XM) with improved machining properties. The workpiece was mounted in a 3 component piezoelectric dynamometer (Kistler 9255) to monitor the cutting forces in the $\mathrm{X}$ and $\mathrm{Y}$ directions. It was calibrated using a $10 \mu \mathrm{m}$ resolution.

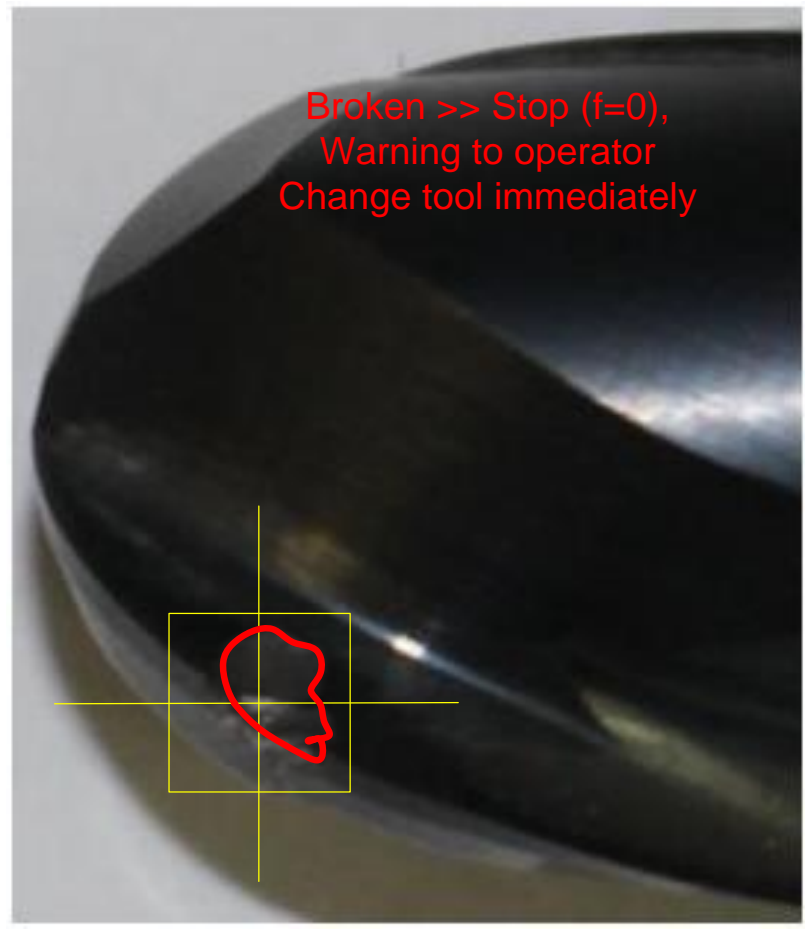

Figure 3. Detected broken tool by vision system 
Dynamometer was mounted on the machining table and connected to a 3-channel charge amplifier.

The signals were monitored by using a fast data acquisition card (National Instruments NI 9215 A) and software written with the National Instruments CVI programming package.

The flank wear after each cutting test was discontinuously measured with a tool microscope of $0.01 \mathrm{~mm}$ accuracy. The experiments were carried out for all combinations of the chosen cutting parameters and tool wear [7].

In the experiments the cutting parameters were set as: four levels of feed rate $\left(f_{1}=\right.$ $0.05, f_{2}=0.25, f_{3}=0.35, f_{4}=0.45 \mathrm{~mm} /$ tooth), four levels of cutting speed. A $\left(v_{1}=200, v_{2}=360, v_{3}=340\right.$ and $\left.v_{4}=480 \mathrm{~min}-1\right)$ and three levels of radial/axial depth of cut $\left(R_{\mathrm{D} 1}=1 \mathrm{~d}, R_{\mathrm{D} 2}=0.5 \mathrm{~d}, R_{\mathrm{D} 3}=0.25 \mathrm{~d} ; A_{\mathrm{D} 1}=2, A_{\mathrm{D} 2}=4, A_{\mathrm{D} 3}=8 \mathrm{~mm} ; d=16 \mathrm{~mm}\right.$-cutting parameter). The parameters such as tool diameter, rake angle, etc. were kept constant.

\section{$7 \quad$ Results and discussion}

The first results of visual system testing were used to optimize the computer program, which recognizes specific features, in our case the breakage of the tool cutting edge. The minimum capability of the system in the terms of accuracy is $7.4 \mu \mathrm{m}$.

Vision system compares all gathered frames of cutting tooth with a template frame (ideal tool tooth) - the differences are returned. With the gathered data (frames) 11 different settings were tested to determine which combination of steps and settings enables the best recognition capability for a certain feature.

In the end, an inspection status can be set up to determine if the frame passed the pre-set requirements. In any case, a rule can be applied that takes actions at specified results and makes changes.

If the acquired frame does not match the template, the program sends the information to decision system.

Tool condition observations were very sensitive to the lighting of the vision system.

\section{$8 \quad$ Conclusions}

The aim of this study is to develop a reliable tool wear compensation system for cutting end milling. Optical visual system is used to observe the actual tool 
Tool Wear Compensation in End Milling Based on Cutting Force

Measuring and Tool Visual Monitoring

condition during the machining. The sensor signals are then sent to decision system which is trained to communicate with CNC controller. The trained adaptive neuro-inference system (ANFIS), is also used to predict tool wear from measured cutting force signals. By developed monitoring system the machining process can be on-line monitored and stopped for tool change based on a pre-set tool-wear limit.

\section{References}

[1] Fu, P., Hope, A.D., Intelligent Classification of Cutting Tool Wear States, Advances in Neural Networks 39 (2008), pp. 1611-3349.

[2] Haber, R.E., Alique, A., Intelligent process supervision for predicting tool wear in machining processes, Mechatronics 13 (2013), pp. 825-849.

[3] Achiche, S., Balazinski, M., Baron, L., Tool wear monitoring using geneticallygenerated fuzzy knowledge bases, Engineering Applications of Artificial Intelligence 15 (2008), pp. 303-314.

[4] Kuo, R.J., Multi-sensor integration for on-line tool wear estimation through artificial neural net-works and fuzzy neural network, Engineering Applications of Artificial Intelligence 3 (2011), pp. 49-261.

[5] Mulc, T., Udiljak, T., Cus, F., Milfelner, M., Monitoring cutting- tool wear using signals from the control system, Strojniški vestnik - Journal of Mechanical Engineering50, (2011) 12, pp. 568-579.

[6] Zuperl, U., Cus, F., Kiker, E., Adaptive network based inference system for estimation of flank wear in end-milling, Journal of Materials Processing Technology, 209, 3, 1 (2009), pp. 1504-1511.

[7] Cus, F., Balic, J., Selection of Cutting Conditions and Tool Flow in Flexible Manufacturing System, The International Journal for Manufacturing Science \& Technology, (2000), pp. 101-106. 


\title{
Chapter 7
}

\section{Comparative Mathematical Modelling of Cutting Tool Wear and Cutting Tool Life Prediction for Two Milling Machines}

\author{
Valentina Gecevska, Mikolaj KuZInovski, Franc ČuŠ, \& Mite Tomov
}

\begin{abstract}
Cutting tool wear prediction has an important role in obtaining higher productivity and high quality products in industry. Flank wear of cutting tools is often selected as the tool life criterion since it determines the accuracy of machining, its machinability and reliability. In this chapter, a summary of the work performed in the area of cutting tool wear modelling for metal cutting process is presented. The main goal of this research is to establish an empirical model for cutting tool wear prediction for face milling dependance on the cutting speed, the cutting feed, the cutting depth and the time of machining. The modelling approach is based on the analytical model of the cutting tool wear, through experimental research with obtained experimental data and its mathematical solution for empirical model determination, adequate for specific experimental conditions.
\end{abstract}

Keywords: • cutting tool wear $\bullet$ prediction $\bullet$ modelling $\bullet$ milling • industry

Correspondence Adress: Valentina Gecevska, Ph.D., Full Professor, „Ss. Cyril and Methodius" University in Skopje, Faculty of Mechanical Engineering-Skopje, Rudger Boshkovikj bb, Skopje 1000, Republic of Macedonia, e-mail: valentina.gecevska@mf.edu.mk. Mikloaj Kuzinovski,, Ph.D., Full Professor, ,Ss. Cyril and Methodius" University in Skopje, Faculty of Mechanical Engineering-Skopje, Rudger Boshkovikj bb, Skopje 1000, Republic of Macedonia, e-mail: mikolaj.kuzinovski $@$ mf.edu.mk. Franc Čuš, Ph.D., Full Professor, University of Maribor, Faculty of Mechanical Engineering, Smetanova ulica 17, 2000 Maribor, Slovenia, e-mail: franc.cus@um.si. Mite Tomov, Ph.D., Assistant Professor, „Ss. Cyril and Methodius” University in Skopje, Faculty of Mechanical Engineering-Skopje, Rudger Boshkovikj bb, Skopje 1000, Republic of Macedonia, e-mail: mite.tomov@mf.edu.mk. 
Cutting tool wear prediction has an important role in obtaining higher productivity and high quality products in industry. Flank wear of cutting tools is often selected as the tool life criterion since it determines the accuracy of machining, its machinability, and reliability. Tool wear becomes one of the key factors in the machining processes. If a tool wear is not identified on time, significant degradation of the workpiece quality can occur. Therefore, research in this area is of significant interest for metal removal processes.

A great deal of laboratory and production research explores the problem of selecting the optimal machining conditions, developing good machinability data and obtaining productivity for machining centres. The selection of the applicable machining method depends on the required geometry, dimensional accuracy, and surface quality of the part. The cutting tools in any machining process are subjected to changes of their geometry and changes of the respective material properties where tribological processes [1] leading to tool wear occur at wear of flank face of the cutting tool, as losing of the cutting edge.

Several methods have been proposed for monitoring tool wear, which mainly clasify in the categories of direct and indirect methods. With direct methods it is possible to measure tool wear directly using some optical instrument which requires cutting operations to be interrupted periodically. A large number of research articles have been published on the subject of indirect methods for tool condition monitoring (TCM) by modelling the correlation between the tool wear and the data of the cutting force, torque, power, vibration, and other parameters of machining processes $[2,3,4]$. Researchers have attempted to model the features together with the applied cutting parameters, machining time, workpiece and tool materials in order to find correlation with tool wear.

Jozic at al.[5] have investigated the relationship between the milling flank wear prediction, the cutting parameters, and the force signals, by using functional data analysis methodology. Kwon and Fischer [6] have developed the tool wear and the tool life model, analysing the wear surface areas and the tool material loss by means of microoptics and image processing analysis, according to criteria of productivity improvement and reduction of manufacturing cost. Özel et al. [7] have investigated the influence of cutting parameters on the tool flank wear and surface roughness in finish turning of hard steel, observed by scanning electron microscopy (SEM). Richetti at al. [8] investigated the effect of the number of tools used in fase milling operations and related it to the tool life under specified cutting conditions. Wang et al. [9] proposed Gaussian mixture regression to realise robust prediction of the tool wear. Choudhury and Rath [10] have shown that tool wear can be well correlated with cutting parameters and cutting force coefficient with maximum deviation between experimental and calculated results. 


\section{$2 \quad$ Optimization of cutting parameters}

Maximization of the technological and the economic effects in manufacturing is usually done by optimizing the numerical controlled machining processes, performed at the machining centres. The authors of those papers [11,12] have conducted a large amount of research on increasing efficiency and the productivity of the machining processes, and have proposed a methodology for determining the optimal cutting parameters in milling. This optimization method defines: (1) the mathematical model for objective function in order to describe machining process and cutting conditions, (2) the mathematical modelling of constraints in order to explain restrictions for cutting parameters as boundaries, represented with linear or nonlinear mathematical functions, and (3) the criteria for optimization, as a result of the economical or technological effects of machining process, such as minimal machining times, minimal costs of production, or maximal productivity.

Constraint functions are determined to use analytical relations between cutting parameters into machining process, and they are usually formulated by empirical modelling from: cutting tools characteristics and tool wear, cutting tool life in different machining conditions, quality and accuracy of the machining, properties of tool and workpiece materials, geometry of the machining workpiece, etc. According to the theory of the machining, general mathematical model of the machining process has been modelled for different cutting conditions by determination of the influence from real machining parameters through mathematical modeling of influence factors. Depending on the constraints, different machining parameters, such as: the cutting tool life, the tool wear of the cutting edges (defined by width of flank wears), the engaged power, the cutting force can be analyzed through real machining conditions.

\subsection{Cutting tool wear prediction}

This chapter presents the research that has been done in order to determine the cutting tool wear $\left(\mathrm{VB}_{\mathrm{b}}\right)$ of cutting edge and to predict the tool life $(\mathrm{T})$ in correlation with the mathematical models of constraints, as highly influented by the machining processes, and the obtained experimental results.

The main goal of this research is to estabish an empirical model for cutting tool wear prediction for face milling depending on the cutting speed ( $V$ $[\mathrm{m} / \mathrm{min}])$, the cutting feed $(f[\mathrm{~mm} / \mathrm{t}])$, the cutting depth $(a[\mathrm{~mm}])$ and the time of machining $(t[\mathrm{~min}])$. The adequacy of the empirical model was checked by applying Fisher test at $\alpha=0.05$ level of significance. The accuracy of the mathematical models is defined with $95 \%$ confidence interval. From the obtained empirical model, Taylor equation for cutting tool life is solved. After mathematical modelling, simulation of the results is made. Simulations with graphical representations of the empirical model and tool wear curves are generated for different cutting data. In order to determine the influence of the manufacturing 
machine on the parameters in the empirical model, experiments are done for identical conditions at two different machining centres.

\section{Experimental verification}

\subsection{Mathematical functions for modelling}

Experimental verification is conducted for determination of the mathematical functions based on empirical data:

1. Empirical model of cutting tool wear prediction for face milling, as a function of cutting parameters (cutting speed, cutting feed, depth of cut) and cutting time; 2. Taylor's equation for cutting tool life, as a function of cutting parameters and cutting tool wear of cutting edge.

The cutting tool life is directly dependent on the tool wear of the cutting edge, as a result of tribological processes through metal removal machining. So, the tool life, as a cutting time with the same cutting tool, is inversely proportional to the tool wear. The tool wear is verified by the width of flank wear $\left(V B_{b}[\mathrm{~mm}]\right)$ of cutting edge (Fig.1).

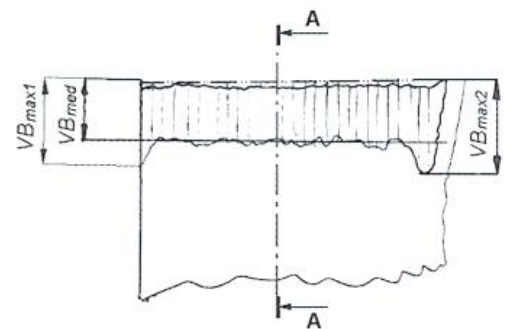

Fig.1. Geometrical presentation of tool wear $\left(V B_{b}\right)$ of cutting edge

The flank wear is caused by the friction between the flank face of the cutting tool and the machined workpiece surface, and leads to loss of the cutting edge. The flank wear affects the dimensional accuracy and the surface finish quality.

In practice, the flank wear is generally used as the cutting tool wear criterion. In this research, measuring the width of the flank wear to the rear surface of the cutting insert are made in the middle part of the length to the flank wear and its marking is done by $V B_{b}[\mathrm{~mm}]$.

According to the theory, there are more methods for determination of exponents in the equation for cutting tool life, based on fundamental and empirical research.

\section{Approximate method}


One of them is the approximate method for determination of tool wear value of cutting edge by check of $V B_{b}$ as a function of cutting time, ignoring the initial wear. This method is used in optimization methodology applied in research $[3,9,10]$, for analyzing the milling machining process.

\section{Empirical based method}

The other method is based on empirical determining of the equation, valid for specific experimental conditions, using Design of Experiment (DoE) approach, as is applied in the research $[8,12]$. In order to achieve the goal of this research, the method of plan of experiment is used for determining the empirical model of cutting tool wear and estimating of cutting tool life for milling conditions.

\subsection{Machine tool}

The face milling experimental investigation is carried out to two different vertical machining centres. Vertical machining centre, type MAZAK VQC-20/50 with $n$ $=3500[\mathrm{rpm}]$ and power $\mathrm{P}=10[\mathrm{~kW}]$, Figure 2, hereinafter referred to as Machine 1 and vertical machining centre type Matsuura MC-760VX, equipped with $n=10000$ [rpm], power $P=20[\mathrm{~kW}]$, Figure 3, hereinafter named Machine 2.

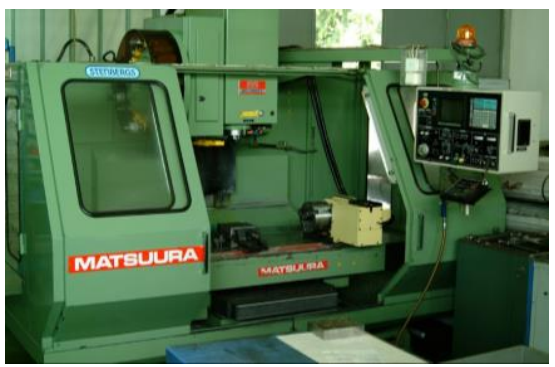

Fig.2. Vertical machining center Matsuura MC-760VX

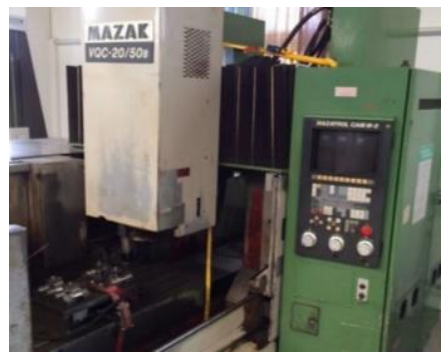

Fig.3. Vertical machining center MAZAK VQC-20/50

\subsection{Work piece}

Workpiece was made of steel DIN St70-2, with chemical and mechanical characteristics, given in the Table 1, prepared for milling operations in the form $200[\mathrm{~mm}] \times 100[\mathrm{~mm}] \times 100[\mathrm{~mm}]$ blocks and adapted according to the experimental needs.

Table 1. Chemical and mechanical characteristics of the steel DIN St70-2

\begin{tabular}{|c|c|c|c|c|c|c|c|}
\hline \multirow{2}{*}{$\begin{array}{c}\text { St70-2 } \\
\text { (DIN) }\end{array}$} & \multicolumn{7}{|c|}{ Chemical characteristics (in \%) } \\
\cline { 2 - 8 } & 0.17 & 0.30 & 1.36 & 0.017 & 0.013 & 0.038 & 0.007 \\
\hline
\end{tabular}




\begin{tabular}{|c|c|c|c|c|c|}
\hline \multirow{2}{*}{$\begin{array}{c}\text { Fe 690-2 } \\
\text { (ISO) }\end{array}$} & \multicolumn{4}{|c|}{ Mechanical characteristics } \\
\cline { 2 - 5 } & $R_{e}\left(N / \mathrm{mm}^{2} \mathrm{~min}\right)$ & \multirow{2}{*}{$\sigma_{\mathrm{m}}\left(\mathrm{N} / \mathrm{mm}^{2}\right)$} & \multicolumn{2}{|c|}{$K V$} & \multirow{2}{*}{$H B$} \\
\cline { 2 - 5 } & 379 & 733 & 100 & 0 & 190 \\
\hline
\end{tabular}

\subsection{Cutting tool}

A face-milling cutter, type RG 62.2-050M-10 with three inserts, produced by CORUN HOLDING was used as a cutting tool. The inserts were from hard metal P30, type TPKN 1603PRR PM30. The cutting tool specification is shown in Table 2. The experiments are conducted with coolant. Each experiment has been made with new cutting edges of the three inserts at milling cutter. It was an important condition in order to achieve consistency and to determine the influence of the machining parameters to the cutting tool wear through measuring of the tool flank wear.

Table 2. Characteristics of the face-milling cutter with carbide inserts

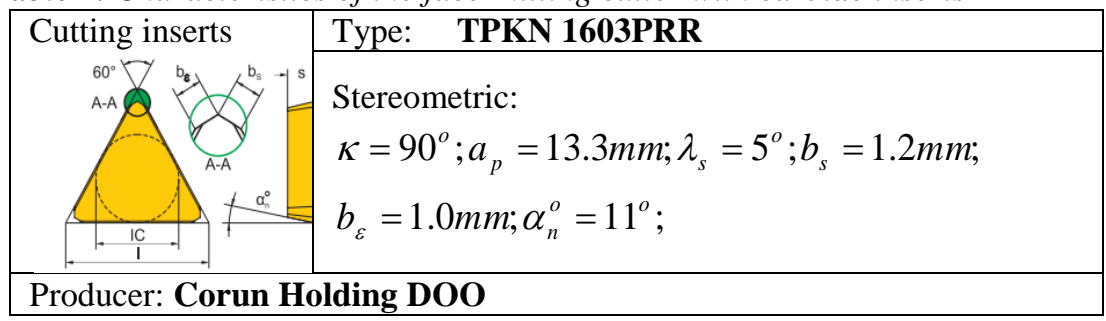

\subsection{Plan of Experiment}

Milling, as a metal cutting process with chip removal, has been carried out by changing the machining parameters: the cutting speed $(V)$, the cutting feed $(f)$, the depth of cut $(a)$ and the cutting time $(t)$, at the two levels (Table 3 ) by four-factor plan experiment $\left(2^{4}+4\right)$. Using DoE method, the coding plan-matrix has been defined with combinations of machining parameters for each single experiment that has been done.

Table 3. Plan of Design of Experiment

\begin{tabular}{|c|c|c|c|c|c|}
\hline \multicolumn{6}{|c|}{ Characteristics of independently variable } \\
\hline No. & Type & Level-code & $\begin{array}{c}\text { Maximal } \\
1\end{array}$ & $\begin{array}{c}\text { Middle } \\
0\end{array}$ & $\begin{array}{c}\text { Minimal } \\
-1\end{array}$ \\
\hline 1. & $V[\mathrm{~m} / \mathrm{min}]$ & $\mathrm{x} 1$ & 230 & 151.657 & 100 \\
\hline 2. & $f[\mathrm{~mm} / \mathrm{t}]$ & $\mathrm{x} 2$ & 0.4 & 0.200 & 0.1 \\
\hline 3. & $a[\mathrm{~mm}]$ & x 3 & 1.8 & 1.273 & 0.9 \\
\hline 4. & $t[\min ]$ & $\mathrm{x} 4$ & 6.0 & 2.449 & 1.0 \\
\hline
\end{tabular}


Introducing the time, as an independent variable parameter, enables to decide on:

- Empirical model for determination of the cutting tool wear $\left(V B_{b}\right)(1)$, as a function of machining parameters $(V, f, a)$ and cutting time $(t)$ :

$$
V B_{b}=C \cdot V^{x} \cdot f^{y} \cdot a^{z} \cdot t^{q}
$$

$C$ - a constant which depends on the machining material, the cutting materials, and the machining conditions.

$x, y, z, q-$ constants that are to be derived through DOE, as empirical factors that represent the impact from machining parameters $(V, f, a)$ and the cutting time $(t)$ to the tool wear $\left(V B_{b}\right)$.

- Empirical model of Taylor's equation (2) for cutting tool life for milling $\left(\mathrm{T}=\mathrm{f}\left(V, f, a, V B_{b}\right)\right)$, according to ${ }^{11}$, as a function of cutting speed, the cutting feed and the depth of cut, for criterion $V B_{b}$.

$$
T=\frac{\left(\frac{1}{C}\right)^{\frac{1}{q}} \cdot\left(V B_{b}\right)^{\frac{1}{q}}}{(V)^{\frac{x}{q}} \cdot(f)^{\frac{y}{q}} \cdot(a)^{\frac{z}{q}}}
$$

A series of experiments were conducted to establish the relationship between flank wear and cutting parameters, such as cutting speed, feed per tooth, depth of cut and cutting time. In order to be able to predict the flank wear, an empirical model has been determined for the experimental conditions by using data analysis methodology.

\section{$4 \quad$ Results and discussions}

In order to determine the constants in the empirical model (1) which are valid for real milling machining conditions, experiments for Machine 1 (shown in Table 4) and Machine 2 (shown in Table 5) have been conducted according to a defined plan of experiments. 
AdVANCES IN PRoduction ANd Industrial ENGineERING

V. Gecevska, M. Kuzinovski, F. Čuš \& M. Tomov: Chapter 7

Comparative Mathematical Modelling of Cutting Tool Wear and Cutting Tool Life Prediction for Two Milling Machines

Table 4. Data set of input factors and output results from plan of experiments for Machine 1

\begin{tabular}{|c|c|c|c|c|c|c|c|c|c|c|}
\hline \multirow[b]{2}{*}{$\begin{array}{c}\text { No } \\
\text {. }\end{array}$} & \multicolumn{4}{|c|}{ Input factors } & \multicolumn{4}{|c|}{ Output results } & \multirow{2}{*}{$\begin{array}{l}\text { Model } \\
V B_{b-M} \\
{[\mathrm{~mm}]}\end{array}$} & \multirow{2}{*}{$\begin{array}{c}\text { Difference } \\
V B_{b} / \\
V B_{b-M} \\
(\%) \\
\end{array}$} \\
\hline & $\begin{array}{c}V \\
{[\mathrm{~m} / \mathrm{min}]}\end{array}$ & $\begin{array}{c}f \\
{[\mathbf{m m} / \mathbf{t}]}\end{array}$ & $\begin{array}{c}a \\
{[\mathrm{~mm}} \\
]\end{array}$ & $\begin{array}{c}t \\
{[\mathrm{~min}} \\
]\end{array}$ & $\begin{array}{c}V B_{b-1} \\
{[\mathbf{m m}} \\
]\end{array}$ & $\begin{array}{c}V B_{b-2} \\
{[\mathrm{~mm}} \\
]\end{array}$ & $\begin{array}{c}V B_{b-3} \\
{[\mathbf{m m}} \\
]\end{array}$ & $\begin{array}{c}V_{B_{b-}} \\
\text { average } \\
{[\mathrm{mm}]}\end{array}$ & & \\
\hline 1 & 100 & 0.1 & 0.9 & 1 & 0.080 & 0.085 & 0.069 & 0.078 & 0.082 & -5.1 \\
\hline 2 & 230 & 0.1 & 0.9 & 1 & 0.124 & 0.117 & 0.122 & 0.121 & 0.124 & -2.3 \\
\hline 3 & 100 & 0.4 & 0.9 & 1 & 0.089 & 0.097 & 0.093 & 0.093 & 0.095 & -2.1 \\
\hline 4 & 230 & 0.4 & 0.9 & 1 & 0.129 & 0.149 & 0.151 & 0.143 & 0.143 & -0.3 \\
\hline 5 & 100 & 0.1 & 1.8 & 1 & 0.084 & 0.097 & 0.089 & 0.090 & 0.088 & 2.6 \\
\hline 6 & 230 & 0.1 & 1.8 & 1 & 0.131 & 0.148 & 0.136 & 0.138 & 0.132 & 4.3 \\
\hline 7 & 100 & 0.4 & 1.8 & 1 & 0.092 & 0.108 & 0.097 & 0.099 & 0.102 & -2.6 \\
\hline 8 & 230 & 0.4 & 1.8 & 1 & 0.170 & 0.155 & 0.149 & 0.158 & 0.153 & 2.9 \\
\hline 9 & 100 & 0.1 & 0.9 & 6 & 0.165 & 0.183 & 0.179 & 0.176 & 0.168 & 4.4 \\
\hline 10 & 230 & 0.1 & 0.9 & 6 & 0.255 & 0.241 & 0.246 & 0.247 & 0.254 & -2.5 \\
\hline 11 & 100 & 0.4 & 0.9 & 6 & 0.197 & 0.199 & 0.218 & 0.205 & 0.194 & 5.0 \\
\hline 12 & 230 & 0.4 & 0.9 & 6 & 0.297 & 0.303 & 0.284 & 0.295 & 0.294 & 0.3 \\
\hline 13 & 100 & 0.1 & 1.8 & 6 & 0.171 & 0.185 & 0.191 & 0.182 & 0.180 & 1.5 \\
\hline 14 & 230 & 0.1 & 1.8 & 6 & 0.251 & 0.267 & 0.255 & 0.258 & 0.271 & -5.3 \\
\hline 15 & 100 & 0.4 & 1.8 & 6 & 0.188 & 0.207 & 0.191 & 0.195 & 0.208 & -6.5 \\
\hline 16 & 230 & 0.4 & 1.8 & 6 & 0.308 & 0.328 & 0.312 & 0.316 & 0.314 & 0.6 \\
\hline 17 & 151.657 & 0.200 & 1.273 & 2.449 & 0.141 & 0.157 & 0.145 & 0.148 & 0.160 & -8.7 \\
\hline 18 & 151.657 & 0.200 & 1.273 & 2.449 & 0.164 & 0.181 & 0.171 & 0.172 & 0.160 & 6.7 \\
\hline 19 & 151.657 & 0.200 & 1.273 & 2.449 & 0.158 & 0.177 & 0.165 & 0.167 & 0.160 & 3.7 \\
\hline 20 & 151.657 & 0.200 & 1.273 & 2.449 & 0.144 & 0.168 & 0.166 & 0.159 & 0.160 & -0.7 \\
\hline
\end{tabular}

Each level of experiment with defined experimental conditions gave three results for width of flank wears $\left(V B_{b}\right)$, one for each cutting edge at each triangular insert of the milling cuter with three teeth, used in proper experiment. 
V. Gecevska, M. Kuzinovski, F. Čuš \& M. Tomov: Chapter 7

Comparative Mathematical Modelling of Cutting Tool Wear and Cutting

Tool Life Prediction for Two Milling Machines

Table 5. Data set of input factors and output results from plan of experiments for Machine 2

\begin{tabular}{|c|c|c|c|c|c|c|c|c|c|c|}
\hline \multirow[b]{2}{*}{ No. } & \multicolumn{4}{|c|}{ Input factors } & \multicolumn{4}{|c|}{ Output results } & \multirow{2}{*}{$\begin{array}{l}\text { Mode } \\
1 \\
\\
V B_{b-M} \\
{[\mathrm{~mm}]} \\
\end{array}$} & \multirow[b]{2}{*}{$\begin{array}{c}\text { Difference } \\
\boldsymbol{V B}_{b} / \\
\boldsymbol{V} \boldsymbol{B}_{b-M} \\
(\%) \\
\end{array}$} \\
\hline & $\begin{array}{c}V \\
{[\mathrm{~m} / \mathrm{min}} \\
]\end{array}$ & $\begin{array}{c}f \\
{[\mathbf{m m} / \mathbf{t}} \\
]\end{array}$ & $\begin{array}{c}a \\
{[\mathrm{~mm}} \\
]\end{array}$ & $\begin{array}{c}t \\
{[\mathrm{~min}} \\
]\end{array}$ & $\begin{array}{c}\boldsymbol{V} \boldsymbol{B}_{b-1} \\
{[\mathrm{~mm}} \\
]\end{array}$ & $\begin{array}{c}\boldsymbol{V} \boldsymbol{B}_{b-2} \\
{[\mathrm{~mm}} \\
]\end{array}$ & $\begin{array}{c}V B_{b-3} \\
{[\mathbf{m m}} \\
] \\
\end{array}$ & $\begin{array}{c}\boldsymbol{V} \boldsymbol{B}_{b-} \\
\text { average } \\
{[\mathbf{m m}} \\
]\end{array}$ & & \\
\hline 1 & 100 & 0.1 & 0.9 & 1 & 0.081 & 0.090 & 0.085 & 0.085 & 0.088 & -3.6 \\
\hline 2 & 230 & 0.1 & 0.9 & 1 & 0.133 & 0.143 & 0.138 & 0.138 & 0.135 & 2.5 \\
\hline 3 & 100 & 0.4 & 0.9 & 1 & 0.103 & 0.098 & 0.093 & 0.098 & 0.101 & -3.0 \\
\hline 4 & 230 & 0.4 & 0.9 & 1 & 0.150 & 0.161 & 0.157 & 0.156 & 0.154 & 1.5 \\
\hline 5 & 100 & 0.1 & 1.8 & 1 & 0.091 & 0.095 & 0.089 & 0.092 & 0.090 & 1.9 \\
\hline 6 & 230 & 0.1 & 1.8 & 1 & 0.130 & 0.140 & 0.133 & 0.134 & 0.137 & -1.9 \\
\hline 7 & 100 & 0.4 & 1.8 & 1 & 0.092 & 0.099 & 0.095 & 0.095 & 0.103 & -7.7 \\
\hline 8 & 230 & 0.4 & 1.8 & 1 & 0.160 & 0.172 & 0.169 & 0.167 & 0.156 & 6.3 \\
\hline 9 & 100 & 0.1 & 0.9 & 6 & 0.184 & 0.187 & 0.179 & 0.183 & 0.175 & 4.6 \\
\hline 10 & 230 & 0.1 & 0.9 & 6 & 0.248 & 0.256 & 0.262 & 0.255 & 0.266 & -4.3 \\
\hline 11 & 100 & 0.4 & 0.9 & 6 & 0.203 & 0.218 & 0.210 & 0.210 & 0.200 & 5.0 \\
\hline 12 & 230 & 0.4 & 0.9 & 6 & 0.279 & 0.289 & 0.286 & 0.285 & 0.304 & -6.9 \\
\hline 13 & 100 & 0.1 & 1.8 & 6 & 0.168 & 0.185 & 0.176 & 0.176 & 0.178 & -0.9 \\
\hline 14 & 230 & 0.1 & 1.8 & 6 & 0.260 & 0.274 & 0.263 & 0.266 & 0.271 & -2.0 \\
\hline 15 & 100 & 0.4 & 1.8 & 6 & 0.198 & 0.208 & 0.204 & 0.203 & 0.203 & 0.0 \\
\hline 16 & 230 & 0.4 & 1.8 & 6 & 0.300 & 0.319 & 0.310 & 0.310 & 0.310 & 0.0 \\
\hline 17 & 151.657 & 0.200 & 1.273 & 2.449 & 0.160 & 0.167 & 0.163 & 0.163 & 0.165 & -1.3 \\
\hline 18 & 151.657 & 0.200 & 1.273 & 2.449 & 0.177 & 0.185 & 0.175 & 0.179 & 0.165 & 7.6 \\
\hline 19 & 151.657 & 0.200 & 1.273 & 2.449 & 0.152 & 0.168 & 0.158 & 0.159 & 0.165 & -3.8 \\
\hline 20 & 151.657 & 0.200 & 1.273 & 2.449 & 0.174 & 0.177 & 0.169 & 0.173 & 0.165 & 4.6 \\
\hline
\end{tabular}

The values given in Table 4 and Table 5 , for $V B_{b-1}, V B_{b-2}$ and $V B_{b-3}$, have carried out the width of flank wears of each cutting edge to the three triangular cutting inserts at each cuter tooth, used in proper experiment. $V B_{\text {b-average }}$ is the middle value of $V B_{b-1}, V B_{b-2}$ and $V B_{b-3} . V B_{b-M}$ is the value for width of flank wears counted by the empirical models, Equations 3 and 4.

The dimensions of the width of flanks wear are measured by scanning by electronic microscope, type NICON with accuracy $0.001[\mathrm{~mm}]$, property of the Laboratory for metrology of geometrical characteristics and quality research at the Faculty of Mechanical Engineering in Skopje. The processing of the numerical and statistical experimental data has been made using methodology for adequate mathematical model selection, applied by CADEX [14] (Computer Aided Design and analysis of EXperiment) software. With CADEX software, mathematical deriving of constants in the empirical model has been carried out with transferring 
into linear model by logarithm transformation and its solving based on regression analysis.

As a result of the statistical analysis of the experimental data, starting from general empirical models, their specific forms valid for real machining conditions at two experimental machines, here defined as experimental conditions, are determined.

The empirical model for representation of cutting tool wears in our experimental machining conditions is given below as Equation (3) for Machine 1 and (4) for Machine 2, where constants are derived by CADEX software.

- Cutting tool wears of cutting edge for Machine 1,

$$
V B_{b}=0.01082 \cdot V^{0.495} \cdot f^{0.106} \cdot a^{0.097} \cdot t^{0.400}
$$

- Cutting tool wears of cutting edge for Machine 2,

$$
V B_{b}=0.01080 \cdot V^{0.505} \cdot f^{0.096} \cdot a^{0.025} \cdot t^{0.381}
$$

Taylor's equation for cutting tool life for face milling, for Machine 1, is given below, as Equation (5) and Equation (6) for Machine 2.

- Taylor's equation for cutting tool life for Machine 1,

$$
T=\frac{82122 \cdot V B_{b}^{2.500}}{V^{1.238} \cdot f^{0.265} \cdot a^{0.243}}
$$

- Taylor's equation for cutting tool life for Machine 2,

$$
T=\frac{145096 \cdot V B_{b}^{2.625}}{V^{1.325} \cdot f^{0.252} \cdot a^{0.638}}
$$

From the results shown in the Tables 4 and 5, the received empirical models and the Equation, given by $3,4,5,6$, it has been concluded that manufacturing machine with working conditions has influence to the constants $(C, x, y z$ and $q)$ from the empirical models for tool wear and tool life prediction. The measurements of the tool wear have shown that lower breaking up of the measured values is visible for Machine 2 comparing to Machine 1. The influence from the manufacturing machine is shown in the Table 6. $V B_{b}$ is taken as a comparison criterion. Time $T$ for receiving the $V B_{b}$ value is calculated with Equations 5 and 6, for identical 
cutting conditions, working material and workpiece positioning to the machining work table. It is evident that for equal $\mathrm{VB}_{\mathrm{b}}$, the maximum difference between machining time is about $0.4(\mathrm{~min})$.

Table 6. Comparison of cutting times for the same $V B_{b}$, for Machine 1 and Machine 2

\begin{tabular}{|c|c|c|}
\hline $\begin{array}{c}\boldsymbol{V} \boldsymbol{B}_{\boldsymbol{b}} \\
{[\mathbf{m m}]}\end{array}$ & $\begin{array}{c}\boldsymbol{T} \text {-Machine } \\
\mathbf{1} \\
{[\mathbf{m i n}]}\end{array}$ & $\begin{array}{c}\boldsymbol{T} \text {-Machine } \\
\mathbf{2} \\
{[\mathbf{m i n}]}\end{array}$ \\
\hline 0.05 & 0.1 & 0.1 \\
\hline 0.1 & 0.6 & 0.5 \\
\hline 0.2 & 3.3 & 3.0 \\
\hline 0.3 & 9.1 & 8.7 \\
\hline 0.4 & 18.7 & 18.6 \\
\hline
\end{tabular}

Graphical interpretation of the computed values for the cutting wears of the cutting edges, through applying the determined empirical model (3), is shown on Fig.4, where the mathematical dependences of cutting wear- $V B_{b}$ from cutting time- $t$, in correlation with the machining conditions, for Machine 1, are presented.

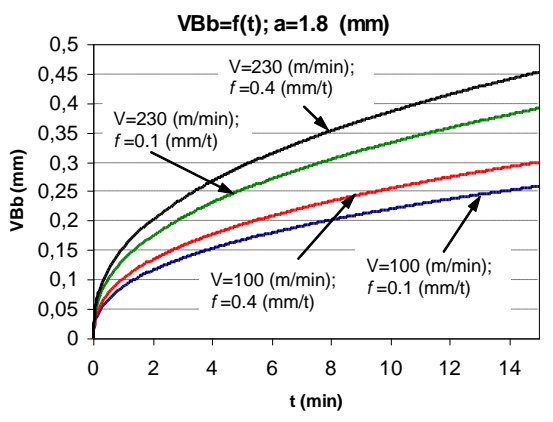

a)

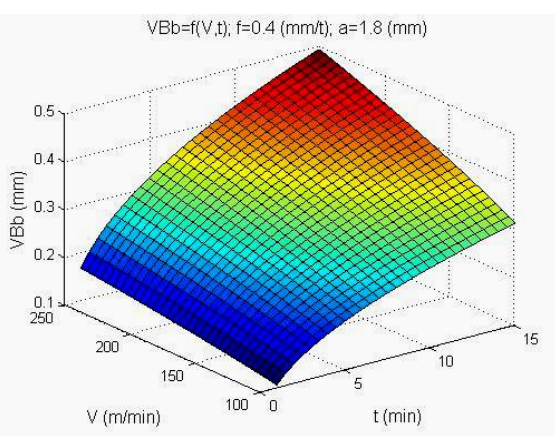

b)

Fig.4. a) Graphical presentation of empirical model for $V B_{b}$. a) the variable parameter is cutting time $t$ [min],

b) the variable parameters are cutting speed $V[\mathrm{~m} / \mathrm{min}$ ] and cutting time $t$ [min].

Graphical presentation of the computed values for the cutting tool life to the cutting edges for generated empirical model (5), for machining at Machine 1, is given on: (1) Fig. 5, where the cutting tool life as a function of the cutting speed and the tool wear $T=\mathrm{f}\left(V, V B_{b}\right)$ are presented, and (2) Fig. 6, as a function of the cutting speed and the cutting feed $T=\mathrm{f}(V, f)$. 
Comparative Mathematical Modelling of Cutting Tool Wear and Cutting Tool

Life Prediction for Two Milling Machines

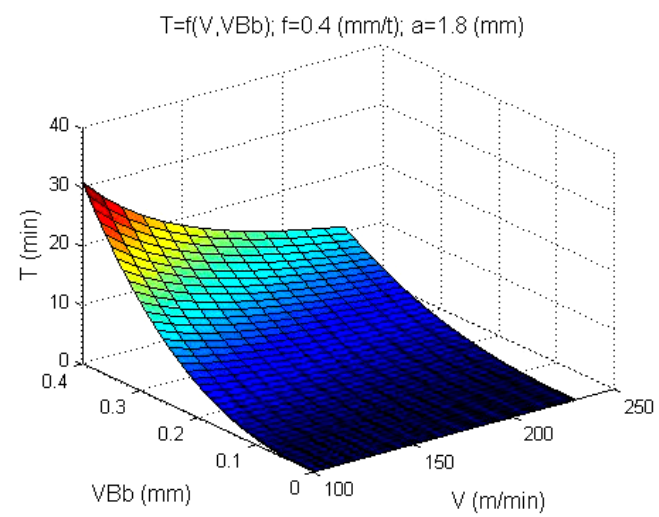

Fig.5. Graphical interpretation of mathematical model for cutting tool life $T$ [min] as a function of cutting speed $V$ [m/min] and cutting tool wear $V B_{b}[\mathrm{~mm}]$

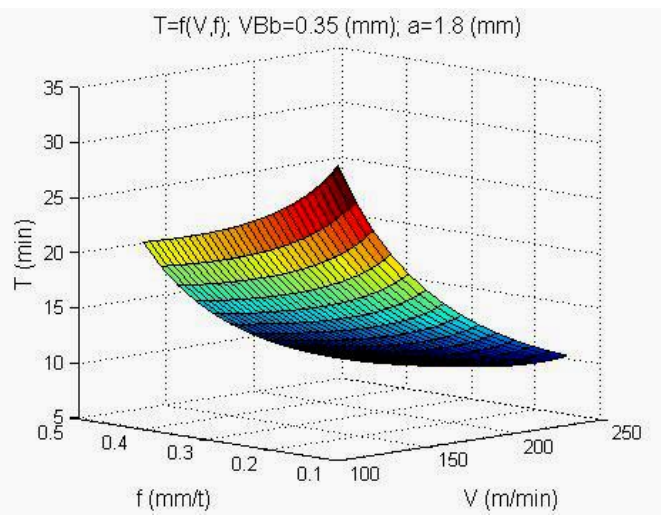

Fig.6. Graphical interpretation of mathematical model for cutting tool life $T$ [min] as a function of cutting speed $V[\mathrm{~m} / \mathrm{min}]$ and feed per tooth $\mathrm{f}[\mathrm{mm} / \mathrm{t}]$.

\section{Conclusion}

This analysis of the cutting condition has been made in order to design empirical models for flank wear estimation and cutting tool life prediction. The empirical models of the relationship between the wear level and the cutting conditions were found to be more appropriate in estimating the cutting tool life. The mathematical modelling and the derived empirical models have given the relations of influences between the tool life and the cutting conditions, such as the cutting speed, the cutting feed, the depth of cut, and the cutting time. The flank wear is found to be a good criterion for tool life modelling. 
The research has shown that manufacturing machine with working conditions has influence on the constants $(C, x, y, z$ and $q)$ from the empirical models for tool wear and tool life prediction. But, on the other hand, there is evidence that those (different machines) are not the dominant influences, which means that certain empirical models for tool wear and tool life prediction determined for one machine can be applied to other machine in the certain machining conditions.

\section{References}

[1] J. Frene, O. Bonneau, H. Zaidi, M. Arghir: Wear Damage in Tribology. Historical Aspects and Present Knowledge, J Balk Tribol Assoc, 14 (3), 331 (2008).

[2] S. Oraby, D. Hayhurst: Development of models for tool wear force relationships in metal cutting, Int. J Mechanical Science, 33 (2), 125 (1991).

[3] P. Palanisamy, I. Rajendran: Prediction of tool wear using regression and ANN models in end-milling operations, Int. J Advanced Manuf Tech, 37, 29 (2008).

[4] D. Bajic, L. Celent, S. Jozic: Modeling of the Influence of Cutting Parameters on the Surface Roughness, Tool Wear and Cutting Force in Face Milling in Off-Line Process Control, J. of Mechanical Engineering, 58 (11), 673 (2012).

[5] S. Jozic, B. Lela, D. Bajic: A New Mathematical Model for Flank Wear Prediction Using Functional Data Analysis Methodology, Advances in Mat. Sci. and Eng, 5 (1), ID138168 (2014).

[6] Y. Kwon, G. Fischer: A novel approach to quantifying tool wear and tool life measurements for optimal tool management, Int. J Mach Tools and Manufacture, 43 (4), 359 (2003).

[7] T. Ozel, Y. Karpat, L. Figueira, J. P. Davim: Modeling of surface finish and tool wear in hard turning of AISI D2 steel using ceramics wiper inserts, J Materials Processing Tech, 209, 5448 (2009).

[8] Richetti, A. Machado, M. Silva: Influence of the Number of Inserts for tool life evaluation in face milling of steels, Int J Mach Tools and Manufacture, 40 (7-8), 697 (2004).

[9] G. Wang, L. Qian, Z. Guo: Continuous tool wear prediction based on Gaussian mixture regression model, Int J Advanced Manuf Tech, 66 (9-12), 1921 (2013).

[10] S. K. Choudhury, S. Rath: In-process tool wear estimation in milling using cutting force model, J Materials Processing Tech, 99, 113 (2000).

[11] V. Gecevska: Research of significant factors on optimization of cutting parameters for NC machining of non-rotational parts, Doctoral dissertation, University Ss. Cyril and Methodius, Republic of Macedonia, 2002.

[12] M. Kuzinovski: Research of physical phenomena and techno-economical effects during the turning with increased cutting speeds, Doctoral dissertation, University Ss. Cyril and Methodius, Republic of Macedonia, 1991.

[13] V.Gecevska, M. Kuzinovski, F. Cus, U. Zuperl: Experimental and mathematical modeling of cutting tool wear in milling conditions, Journal Advanced Manufacturing Systems and Technology, 438, 451 (2005).

[14] M. Kuzinovski, V. Pavlovski, H. Zebrovski: Automation of experimental research in science and technics, Proc. Fac. Of MEch. Eng. , 12, 5 (1992). 
120 Advances in Production ANd INDUSTRIAL ENGINEERING 
AdVANCES IN PRODUCTION AND INDUSTRIAL ENGINEERING

F. Čuš \& V. Gecevska

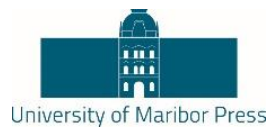

\section{Part III - TECHNIQUES IN PRODUCTION DEVELOPMENT}





\title{
Chapter 8
}

\section{A Linguistic Model Based on if-then Rules for Cutting Force Predictions in End Milling}

\author{
FRANC ČUŠ, UROŠ ŽUPERL, TOMAŽ IRGOLIČ \& ZORAN PANDILOV
}

\begin{abstract}
This chapter presents a new in-process cutting force $(\mathrm{F})$ prediction model of ball end-milling. An adaptive neuro-fuzzy inference system (ANFIS) was employed to evolve an efficient model of hardened die steel with carbide end mill. A set of most significant input milling parameters that have a major impact on the cutting forces was chosen to represent the machining conditions. A Kistler dynamometer was used to measure the actual cutting force, which was compared with the estimated one obtained via suggested procedure. The predicted cutting force values determined by ANFIS were compared with experimental measurements. The comparison indicates that the performance of this method turned out to be satisfactory for evaluating $\mathrm{F}$, within a $1.8 \%$ mean percentage error and $98 \%$ accuracy rate.
\end{abstract}

Keywords: • prediction $\bullet$ cutting force $\bullet$ ball-end milling $\bullet$ ANFIS • Kistler dynamometer

Correspondence Adress: Franc Čuš, Ph.D., Full Professor, University of Maribor, Faculty of Mechanical Engineering, Smetanova ulica 17, 2000 Maribor, Slovenia, e-mail: franc.cus@um.si. Uroš Župerl, Ph.D., Associate Professor, University of Maribor, Faculty of Mechanical Engineering, Smetanova ulica 17, 2000 Maribor, Slovenia, e-mail: uros.zuperl@um.si. Tomaž Irgolič, Ph.D., Researcher, University of Maribor, Faculty of Mechanical Engineering, Smetanova ulica 17, 2000 Maribor, Slovenia, e-mail: tomaz.irgolic@um.si. Zoran Pandilov, Full Professor, „Ss. Cyril and Methodius” University in Skopje, Faculty of Mechanical Engineering-Skopje, Rudger Boshkovikj bb, Skopje 1000, Republic of Macedonia, e-mail: panzo@mf.edu.mk.

https://doi.org/10.18690/978-961-286-028-8.8 ISBN 978-961-286-028-8

(C) 2017 University of Maribor Press

Available at: http://press.um.si. 
A Linguistic Model Based on if-then Rules for Cutting Force Predictions in End Milling

Many parameters influence cutting forces in end-milling. Feed rate, cutting speed, cutting depth and tool geometry are controllable parameters, while tool wear, vibrations and workpiece/tool variability are uncontrollable. In manufacturing the relationship between process characteristics and cutting forces is difficult to capture. This is due to the complexity of the relationship between cutting forces and process characteristics. In workshops, inspection of cutting forces is accomplished by on-line measurements. This approach is uneconomical. Therefore, an in-process method based on prediction model is required. Several models have been proposed to estimate the cutting forces. These include classical statistical approaches as well as fuzzy systems and neural networks.

Analytical cutting force modelling is difficult due to the large number of interrelated machining parameters.

The researchers have been trying to develop mathematical models that would predict the cutting forces based on the geometry and physical characteristics of the process. However, due to its complexity, the milling process still represents a challenge to the modeling and simulation research effort.

In fact, most of the research work reported in this regard, which is based on either analytical or semi-empirical approaches, has in general shown only limited levels of accuracy and generality.

For instance researchers $[1,2,3]$ developed an approach based on the least-squares regression for estimating cutting forces in machining while [4] have, respectively, used genetic programming for estimating cutting forces over a limited range of cutting conditions.

The capacity of artificial neural networks to capture nonlinear relationships in a relatively efficient manner has motivated a number of researchers to pursue the use of these networks in developing cutting force prediction models [5]. Compared to traditional computing methods, the artificial neural networks (ANNs) are robust and global But in such models, the nonlinear relationship between sensor readings and cutting forces embedded in a neural network remains hidden and inaccessible to the user [6].

In this research we attempt to solve this situation by using the ANFIS system to predict the cutting forces. This model offers ability to estimate cutting forces as its neural network based counterpart but provides an additional level of transparency that neural networks fails to provide [7]. We try to investigate the possibility and effectiveness of predicting cutting forces with ANFIS method. It uses training examples as input and constructs the fuzzy if-then rules and the membership 
functions of the fuzzy sets involved in these rules as output. Four milling parameters have been selected. Specifically the relationship between the sensor signals and cutting conditions is first captured via a neural network and is subsequently reflected in linguistic form with the help of a fuzzy logic based algorithm. In this model, we adopted two different types of membership functions for analysis in ANFIS training and compared their differences regarding the accuracy rate of the cutting force prediction. After training the estimator, its performance was tested under various cutting conditions. Test data sets collected from a wide range of cutting conditions in end milling were applied to the estimator for evaluating the $\mathrm{F}$.

The obtained result for predicting cutting force has a highly correct rate. The results also indicate that the triangular MF rather than the trapezoidal MF has a higher correct rate of prediction.

\section{AMFIS cutting force model}

The aim of this study is to develop an accurate and reliable model for predicting cutting forces during end milling process. The cutting force prediction model is built according to the ANFIS method. The ANFIS method seeks to provide a linguistic model for the prediction of cutting forces from the knowledge embedded in the trained neural network. By given input/output data set, the ANFIS method constructs a fuzzy inference system (FIS) whose membership function parameters are tuned (adjusted) using a backpropagation algorithm. This allows fuzzy systems to learn from the data they are modelling. FIS Structure is a network-type structure similar to that of a neural network, which maps inputs through input membership functions and associated parameters, and then through output membership functions and associated parameters to outputs. Figure 1 shows the basic flow chart for predicting the cutting forces via ANFIS. 
A Linguistic Model Based on if-then Rules for Cutting Force Predictions in End Milling

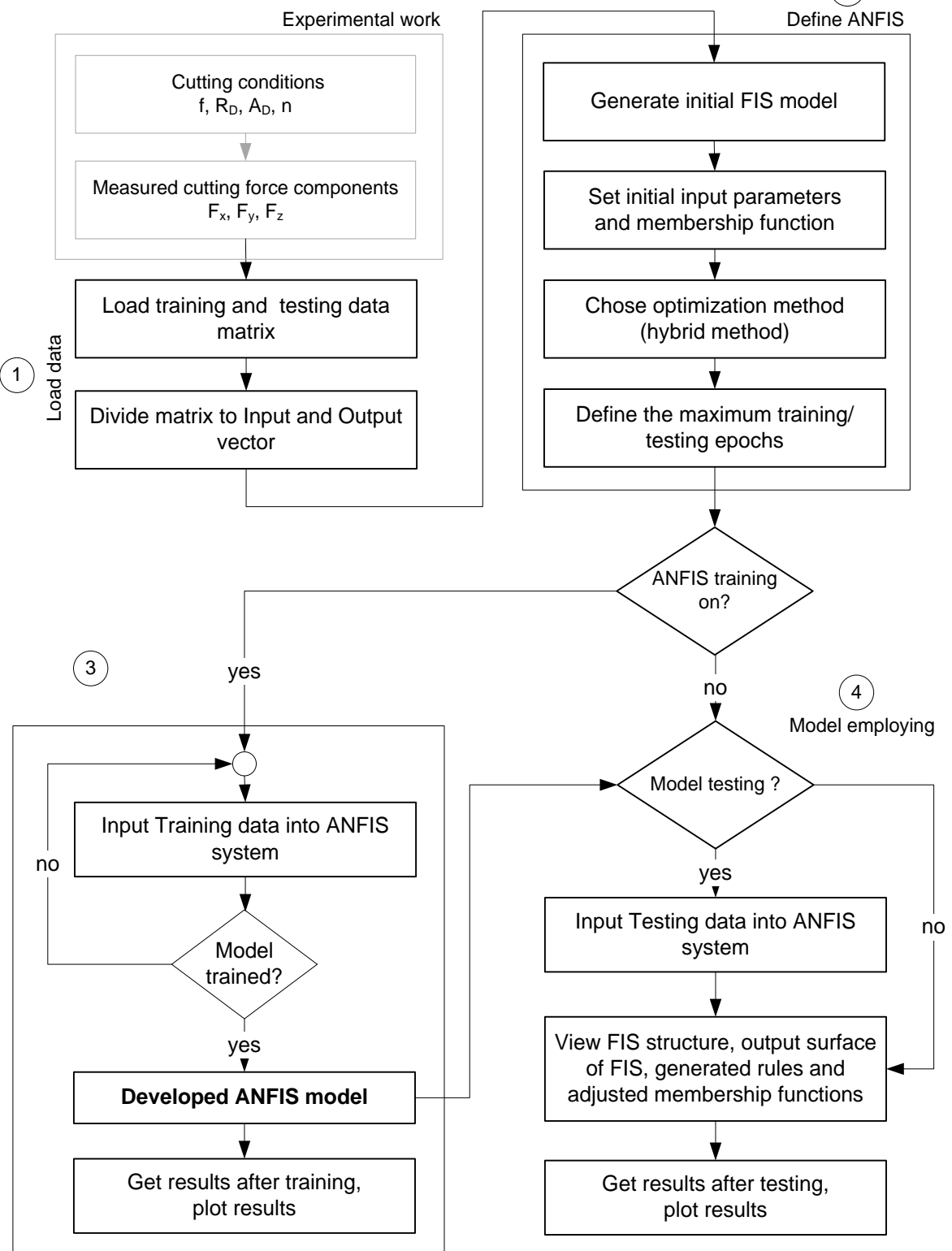

Figure 1. Algorithm for training and employing the cutting force model

Four steps are required to develop an ANFIS system. In step 1, the training and testing data are loaded to the system. The process variables are force sensor readings $(F)$, spindle speed $(n)$, feed rate $(f)$ and depth of cutting $\left(\mathrm{A}_{\mathrm{D}} / \mathrm{R}_{\mathrm{D}}\right)$. All the 
data were scaled. The whole data set is divided into the training and the testing set. 400 data points were used in this study. The training data set is used to find the initial premise parameters for the membership functions by equally spacing each of the membership functions. A threshold value for the error between the actual and desired output is determined.

The FIS architecture and training parameters were defined in step 2. The optimization method, the tolerance error, the maximal number of epoch, the number of membership functions and the membership functions types are defined. The ANFIS architecture is explained in detail in [8].

The fuzzy inference system under consideration has 4 inputs and one output. The inputs are the cutting conditions.

The output is cutting force sensor signal. In step 3, the training phase is accomplished. With the input-output data, the neuro-fuzzy algorithm is trained, and the unknown parameters are identified.

During the training stage, the ANFIS adjusts its internal structure to give correct output results according to the input features. The process is terminated when the error becomes less than the threshold value.

During training in ANFIS, 400 sets of experimental data are used to conduct 500 cycles of learning. Training of the ANFIS can be stopped by two methods. In the first method, ANFIS will be stopped to learn only when the testing error is less than the tolerance limit. This tolerance limit would be defined at the beginning of the training. It is obvious that the performance of a ANFIS that is trained with lower tolerance is greater than ANFIS that is trained with higher tolerance limit. In this method the learning time will change with the architecture of the ANFIS. The second method to stop the learning is to put constraint on the number of learning iterations. In our study, the ANFIS architecture is stopped to learn after 400 training iterations.

Finally, in the fourth step the trained ANFIS is used to predict cutting forces. After the training, the inference system could estimate cutting forces from selected cutting conditions in real time.

The developed ANFIS model can guide system or operator in tool change decisions making.

\section{Experimental set-up}

In order to develop the cutting force prediction model, experimental results were used. Experiments were performed on a CNC machining platform Heller with 
A Linguistic Model Based on if-then Rules for Cutting Force Predictions in End Milling

FAGOR CNC controller. Material $\mathrm{Ck} 45$ and $\mathrm{Ck} 45$ (XM) with improved machining properties were used for tests.

The solid end milling cutter (R216.24-16050 IAK32P) with four cutting edges, of $16 \mathrm{~mm}$ diameter and $10^{\circ}$ helix angle was selected for machining. The corner radius of the cutter is $4 \mathrm{~mm}$. The cutter is made of ultra-fine carbide grade coated with TiN/TiCN coating.

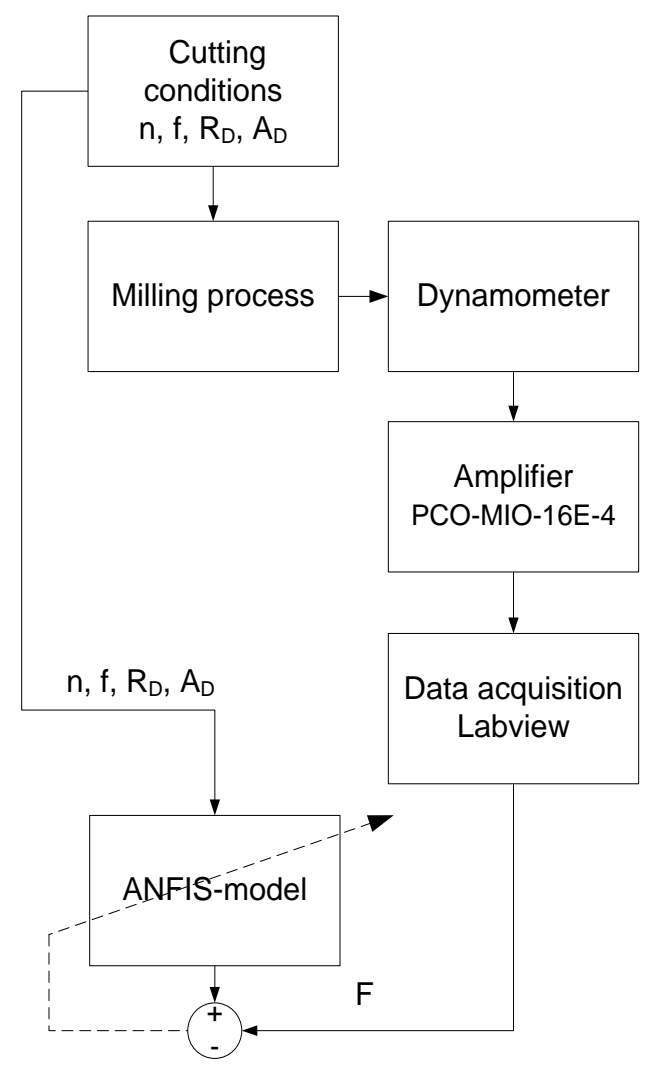

Figure 2. Experimental set-up for cutting force modelling

The coolant RENUS FFM was used for cooling. The cutting forces were measured with a piezoelectric dynamometer (Kistler 9255) mounted between the workpiece and the machining table. The force measurements were sampled at 20000 points/second, then digitally low-pass filtered at a cut-off frequency of $250 \mathrm{~Hz}$ to eliminate the high-frequency components resulting from the machine tool dynamics. These settings were limited by the available random access memory (RAM) of the computer. The digital data from the A/D board were then acquired and stored by the LabVIEW software into three files for the three force 
components. The data were also displayed on the computer monitor for inspection. The resultant cutting force was then determined.

The data acquisition package used was LabVIEW. The experimental set up can be seen in Fig. 2.

The experiments were carried out for all combinations of the chosen parameters, which are radial/axial depth of cut, feed rate, spindle speed and tool wear. Other parameters such as tool diameter, rake angle, etc. are kept constant. Three values for the radial/axial depth of cut have been selected for use in the experiments: $R_{D 1}$ $=1 \mathrm{~d}, R_{D_{2}}=0.5 \mathrm{~d}, R_{\mathrm{D} 3}=0.25 \mathrm{~d} ; \mathrm{A}_{\mathrm{D} 1}=2 \mathrm{~mm}, \mathrm{~A}_{\mathrm{D} 2}=4 \mathrm{~mm}, \mathrm{~A}_{\mathrm{D} 3}=8 \mathrm{~mm} ; \mathrm{d}-$ cutting parameter $(16 \mathrm{~mm})$. In the experiments the following values for feed rate and spindle speed were varied in the ranges from $0.05-0.6 \mathrm{~mm} /$ tooth and $125-350$ min-1, respectively. In this way two sets of data groups were generated, one for training and other for testing.

The cutting force signals were monitored by using a fast data acquisition card (National Instruments NI 9215 A) and software written with the National Instruments CVI programming package.

\section{$3 \quad$ Results and discussion}

This chapter presents the results of experiments and the comparison and analysis of results between the experimental and ANFIS model depending on the cutting parameters. The results and/or the values of cutting forces are graphically represented by means of diagrams depending on the machining time. A total of 300 sets of data were selected from the total of 400 sets obtained in the end milling experiments [3] for the purpose of training in ANFIS. The other 100 sets were then used for testing after the training was completed to verify the accuracy of the predicted values of cutting forces.

The best results were obtained when triangular membership functions were chosen for the neuro-fuzzy model. During training of the neuro-fuzzy algorithm the parameters of membership functions, the optimal rules and the output weights were determined.

Figure 3 shows the uniform falling of the value of testing error ETest with the number of iterations during the testing process for the ANFIS configuration with triangular membership function (Mf) and with Gaussian membership function (Mf).

The smallest error of testing (ETest) is reached at iteration 145 (triangular Mf) and at iteration 107 for Gaussian Mf. It can be seen in Fig. 3 that error converge not to 
A Linguistic Model Based on if-then Rules for Cutting Force Predictions in End Milling

zero but to $12 \%$ and $1.8 \%$. This is caused by the presence of some contradicting examples in the training and testing set.

By comparing the results predicted by ANFIS with the results of experiments the following was established: the values from prediction coincide well with the values from experiments and in addition, the process of the change of the cutting force with respect to the angle of rotation of the milling cutter and the amplitude agree well, with only slight differences in the peak and valley regions of $\mathrm{F}$.
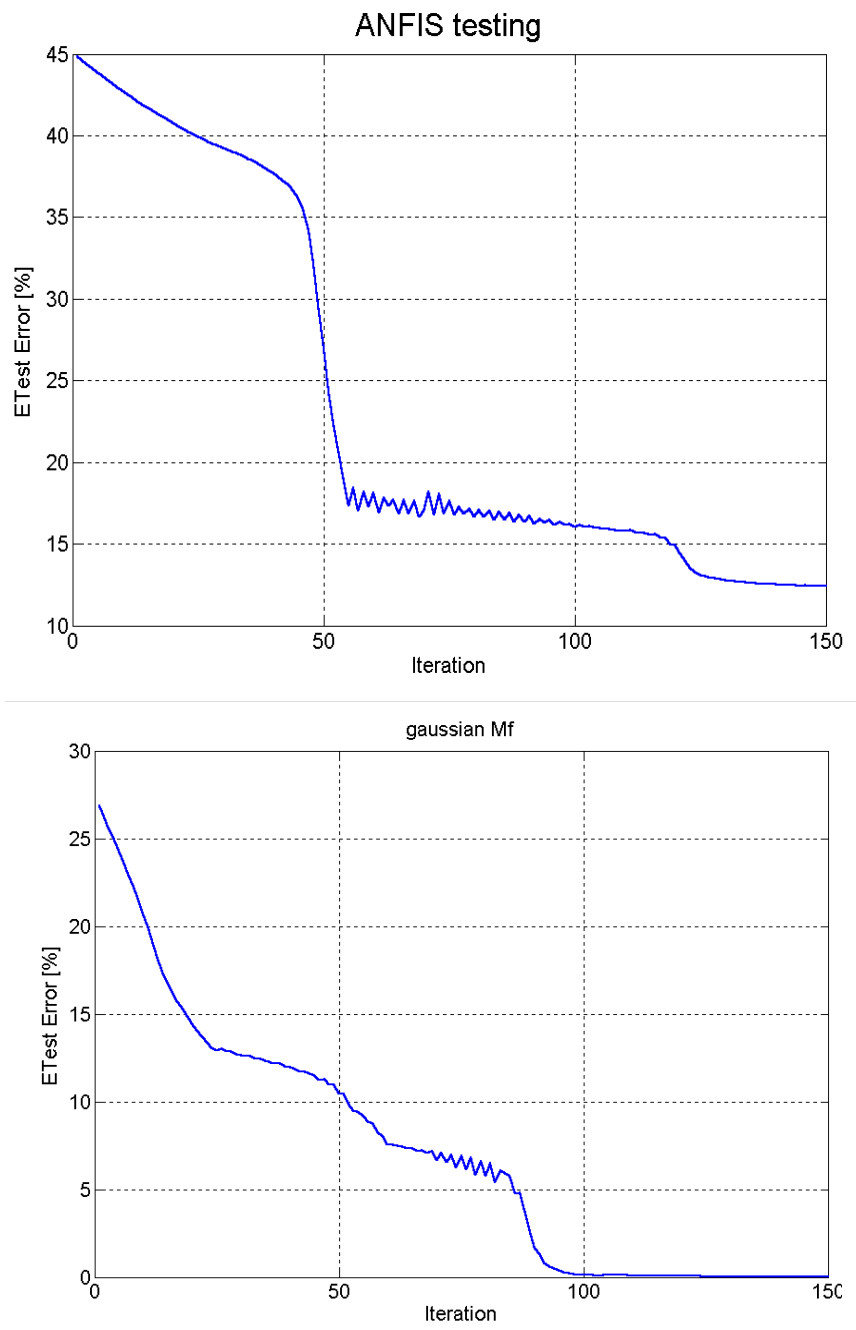

Figure 3. Testing error ETest 
Figure 4 shows the prediction accuracy of neuro-fuzzy system, when the triangular and combination of sigmoidal and Gaussian membership function were applied.

The average error of the prediction of cutting forces is around $1.8 \%$ when triangular membership function is used in ANFIS. The accuracy is as high as 98 $\%$.

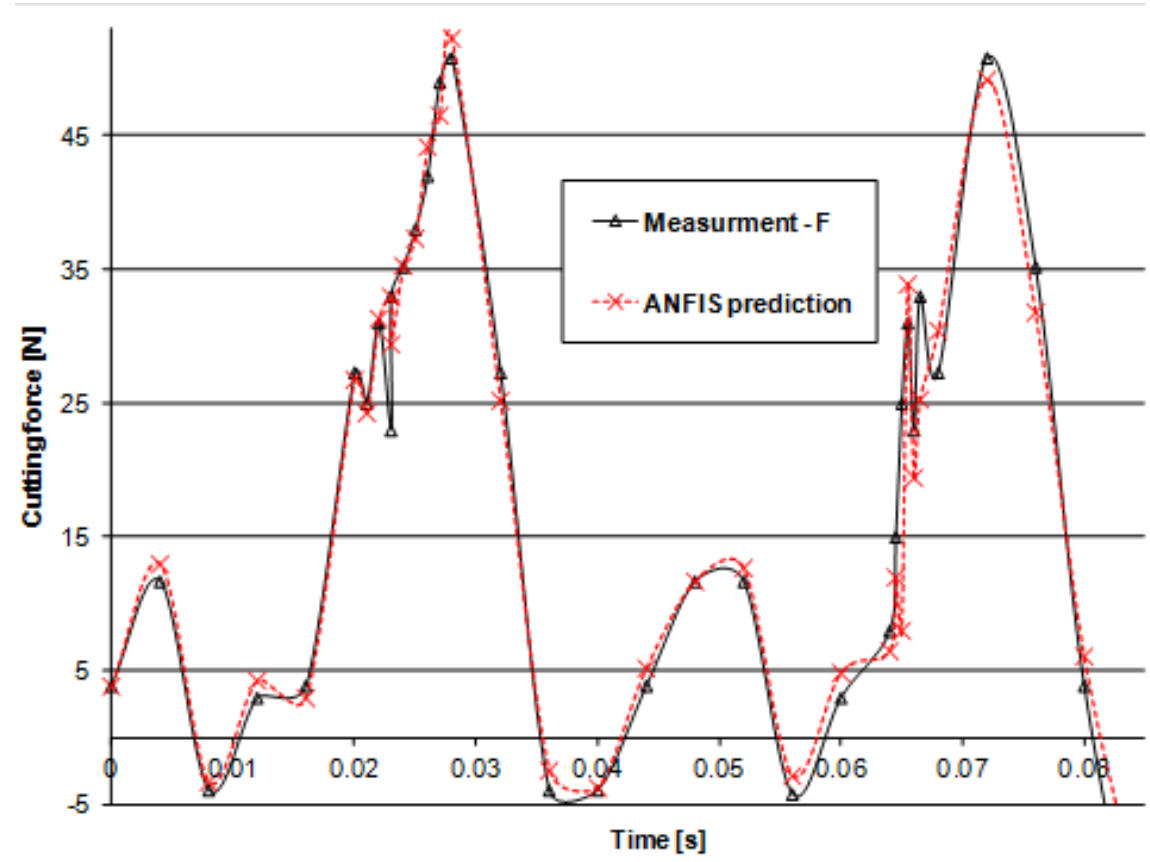

Figure 4. Representation of measured and predicted cutting forces. Ball-end milling cutter R216-16B20-040, cutting insert R216-16 03 M-M GC 4040, material $\mathrm{Ck} 45$, radial depth of cutting $R_{D}=4 \mathrm{~mm}$, axial depth of cutting $A_{D}=2$ $\mathrm{mm}$, feeding $f=0.05 \mathrm{~mm} / \mathrm{tooth}$ and cutting speed $v_{c}=12.5 \mathrm{~m} / \mathrm{min}$

The training was very fast, and the error reached a constant value after about 90 epochs. In this case, there were 36 rules in the fuzzy inference system. The prediction accuracy of ANFIS when the triangular membership function is used is higher than that when the trapezoidal membership function is used.

When the trapezoidal membership function is adopted the average error is around $2.7 \%$, with an accuracy of $96 \%$. Figure 4 shows the comparison of the predicted forces when triangular membership functions is used in ANFIS and the measured cutting forces. 
A Linguistic Model Based on if-then Rules for Cutting Force Predictions in End Milling

In other words, the predicted values are not far from the experimental measurement values.

The system with incorporated ANFIS model was capable of predicting the cutting forces in real time. The accuracy of the training data was $99.1 \%$, and the accuracy of the testing data was $98 \%$.

Wrong predictions accrued when the feed rate and rotational speed were low.

Based on the values of the experimental data, the cutting force components were also calculated according to analytical model [3]. The calculated cutting force components were then compared to the actual forces given in the testing data.

The predictive capability of using analytical and ANFIS approaches are compared using statistics, which showed that ANFIS predictions for cutting force were for $1.8 \%$ closer to the experimental measurements, compared to $11 \%$ using analytical method.

\section{$4 \quad$ Conclusions}

The correlation between cutting force and cutting conditions were determined via ANFIS modelling. The presented ANFIS model predicts cutting forces with $98 \%$ accuracy. This model is the main element of milling process simulator.

The trained ANFIS model is capable to predict cutting forces for various cutting conditions. The sensor signals and the measured cutting force was analyzed offline and applied to a neuro-fuzzy method to determine the membership functions and rules.

An effort is made to include only the most significant machining conditions that influence the cutting forces. Due to high speed of processing, low consumption of memory, great robustness, possibility of self-learning and simple incorporation into chips the approach ensures prediction of the cutting forces in real time.

Once the neuro-fuzzy algorithm was trained, the cutting conditioned could be interpreted to determine cutting force.

The training of ANFIS with the triangular membership function obtains a higher accuracy rate in the prediction of cutting force.

Comparison between the actual cutting forces and the simulated results from the neuro-fuzzy method showed good agreement. 
The trained model can be used to monitor milling operations and provide warnings to an operator.

\section{References}

[1] Ching, C.T., Kuang, H.F., Model for cutting forces in ball-end milling, International Journal of Machine Tools and Manufacturing 35 (1995), pp. 511-534.

[2] Lee, T.S., Lin, Y.J., A 3D Predictive cutting-force model for end milling of parts having sculptured surfaces, International Journal of Advanced Manufacturing Technology 16 (2000), pp. 773-783.

[3] Milfelner, M., Cus, F., Simulation of cutting forces in ball-end milling, Robotics and Computer Integrated Manufacturing 19 (2003), pp. 99-106.

[4] Milfelner, M., Kopac, J., Cus, F., Zuperl, U., Genetic equation for the cutting force in ball-end milling, Journal of Materials Processing Technology 164 (2005), pp. 15541560.

[5] Tandon, V., Mounayri, H.A., Novel artificial neural net-works force model for end milling, International Journal of Advanced Manufacturing Technology 18 (2001), pp. 693-700.

[6] Szecsi, T., Cutting force modeling using artificial neural networks, Journal of Materials Processing Technology 92 (1999), pp. 344-349.

[7] Hanafi, I., Khamlichi, A., Cabrera, F.M., López, P.J.N., Jabbouri, A., Fuzzy rule based predictive model for cutting force in turning of reinforced PEEK composite, Measurement 45 (6) (2012), pp. 1424-1435.

[8] Zuperl, U., Cus, F., Kiker, E., Adaptive network based inference system for estimation of flank wear in end-milling, Journal of Materials Processing Technology, 209, 3, 1 (2009), pp. 1504-1511. 
134 Advances in Production AND INDUSTRIAL ENGINEERING 


\title{
Chapter 9
}

\section{Design Guidelines in Developing a Prototype using Additive Manufacturing Methods}

\author{
OGEN TUTESKI \& ATANAS KochOV
}

\begin{abstract}
Todays advanced methods used in developing, designing and construction of new products are based on iterative analyses of all the parameters associated with the manufacturing process. Defining the specification of a new product nowadays is often followed by the construction of a functional prototype that has most of the crucial parameters that characterize the actual product. Additive manufacturing (3D printing) is a technology commonly used to produce physical prototypes and models for applications varying from mechanical and product design to archaeology and medicine. Apart from having to address limitations inherent to the printing process, getting the needed part clearance on the CAD model can be challenging as well. In this chapter, we'll go through the steps needed for converting 3D models into printable, functional, non-assembly models with an accent on 3D printed thread connections. The methods presented here were used effectively in developing a functional packaging prototypes for honey jars.
\end{abstract}

Keywords: - 3D printing $\cdot \mathrm{FDM} \cdot$ rapid prototyping $\bullet$ additive manufacturing $\bullet$ functional packaging

Correspondence Adress: Ognen Tuteski, Ph.D., Assistant, „Ss. Cyril and Methodius” University in Skopje, Faculty of Mechanical Engineering-Skopje, Rudger Boshkovikj bb, Skopje 1000, Republic of Macedonia, e-mail: ognen.tuteski@mf.edu.mk, Atanas Kochov, Ph.D., Full Professor, „Ss. Cyril and Methodius” University in Skopje, Faculty of Mechanical Engineering-Skopje, Rudger Boshkovikj bb, Skopje 1000, Republic of Macedonia, e-mail: atanas.kochov@mf.edu.mk.

https://doi.org/10.18690/978-961-286-028-8.9 ISBN 978-961-286-028-8

(C) 2017 University of Maribor Press

Available at: http://press.um.si. 
ADVANCES IN PRODUCTION AND INDUSTRIAL ENGINEERING

O. Tuteski \& A. Kochov: Chapter 9

Design Guidelines in Developing a Prototype using Additive Manufacturing

Methods

Todays advanced methods used in developing, designing and construction of new products are based on iterative analyses of all the parameters associated with the manufacturing process. Defining the specification of a new product nowadays is often followed by the construction of a functional prototype that has most of the crucial parameters that characterize the actual product.

Additive manufacturing (3D printing) is a technology commonly used to produce physical prototypes and models for applications varying from mechanical and product design to archaeology and medicine. Apart from having to address limitations inherent to the printing process, getting the needed part clearance on the CAD model can be challenging as well.

Rapid Prototyping (RP), refers to the layer-by-layer fabrication of threedimensional physical models directly from a computer-aided design (CAD) model. RP is the automatic construction of physical objects using additive fabrication. RP takes the virtual design from a CAD or some other 3D modelling software, transforms it into thin, horizontal cross-section layers and then by stacking those layers together in physical space, one after another until the physical model is completed.

The primary advantage of RP is its ability to create almost any shape or geometric features, even those complex shapes that would be virtually impossible to machine. With additive fabrication, the machine reads in data from a CAD model and lays down successive layers of different materials, and builds up the physical model from a series of layers. Those layers are joined together or fused automatically to create the final shape matching the CAD model.

3D printing is an additive manufacturing technology commonly used to produce physical prototypes and models for applications varying from mechanical and product design to archaeology and medicine.

While printing individual models that are directly supported by their own geometry is most common, it is also desirable to be able to print models with functional articulations, such as threads or joints. This can be done by printing the entire assembly at once without the need for manual connecting the separate components. If the models are too big or are meant to come off (ex. lids or covers), it is better if they are printed separately and are assembled afterwards.

\section{$2 \quad$ Basic guidelines in printing mechanical parts}

While printing 3D models meant for presentational purposes is a pretty straight forward task, when printing functional prototypes and mechanical parts there are a 
few limitations in the design that have to be taken into consideration. Every FDM $3 \mathrm{D}$ printer has a given accuracy and the printed parts can have a small deviation from their nominal dimensions. This is especially important when printing moving parts or parts that have to be assembled together afterwards.

\section{A. Material properties and limitations}

Different 3D printing materials and processes have very different material properties, limitations and strengths. The jar prototypes that are shown in this paper were printed on a FDM Dimension elite 3D printer using ABS plastic as the modelling material. Since ABS is an engineering-grade plastic it is suitable for lowvolume production as well as functional testing in harsher environments.

\section{B. Part orientation}

Orientation refers to the way in which your model is oriented inside the build area of the 3D printer. Once the machine gets the model in the proper format (.STL) it decides how to build it by calculating a build path (the movement pattern of the extrusion head). In most processes it also then calculates the support structures if needed.

Depending on the models orientation on the build platform the support structure and the strength of the printed part can vary by a large margin (Fig. 1). This stems from the additive nature of the printing process. Because the part is built in layers there is a pronounced anisotropy in its strength and in order to get an optimal prototype different orientations have to be taken into account.

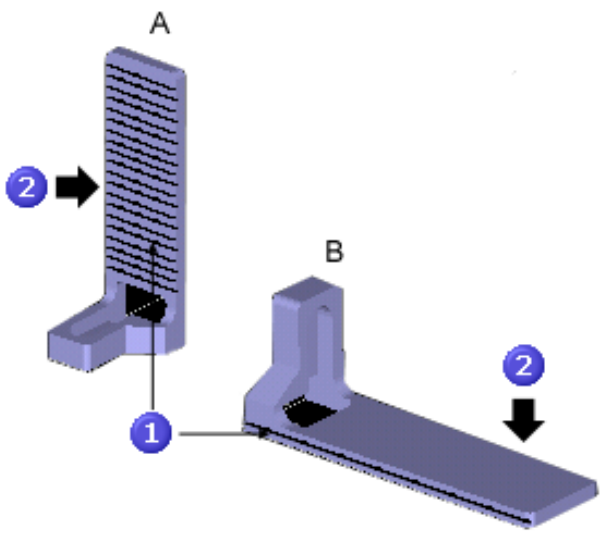

Figure 1. Different print orientation impacts the parts strength. Part " $B$ " has a more suitable layer orientation to withstand the given load -1) layer position, 2) load direction 


\section{Wall thickness}

The wall thickness of the part has to be large enough so that the machine can build it correctly and its strength is suitable its function. As a general guideline the part thickness for FDM 3D printing has to be at least $1 \mathrm{~mm}$. Any lower and there is a risk of breaking.

On the other side of the spectrum, very thick walls should be avoided because then the model is more susceptible to warping and also the printing cost is significantly larger on thicker parts.

\section{Clearance}

The standard tolerances for most additive manufacturing processes start at $+/-0.15$ $\mathrm{mm}$. That leads to certain deviation in the nominal dimensions that can cause problems when fitting in components together or mating up as intended. Typically, there should be at least $0.3-0.5 \mathrm{~mm}$ clearance between mating parts, which is different from what is required for traditional parts manufactured using injection molding.

\section{Determening the thread size}

When rapid prototyping a component, some of its designs finer details are often removed prior to printing. It is pretty common to print the threads onto tapped holes. The resolution of the printer is often limiting and leads to insurmountable issues when printing this geometry, thus creating a lower limit on the hole size that is feasible to print.

Taking the theoretical shape of a thread profile into consideration we can see that as the thread pitch increases so does the depth of the threads. For this reason thread pitch is the determining factor on whether a thread, internal or external, should be created through $3 \mathrm{D}$ printing or created as a post process to $3 \mathrm{D}$ printing.
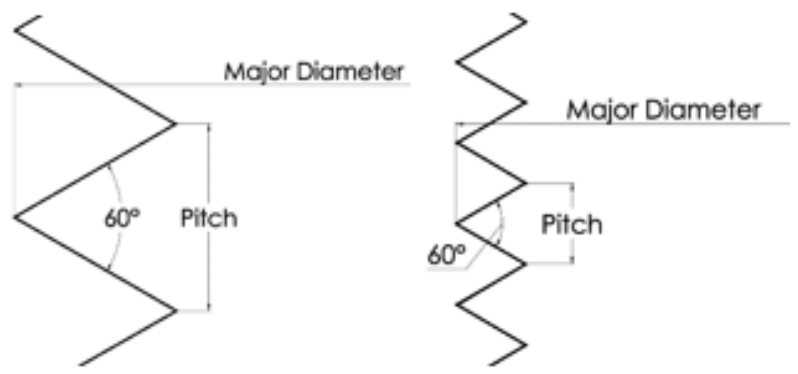
Figure 2. Theoretical cross sections of both a coarse thread and a fine thread [3]

The 3D printed geometry of a thread is not smooth as it would have been if it was machined. Its surface becomes gradually disjoint, creating a step geometry where the neighbouring layers are fused together.

Additionally there are machine accuracy issues that may also come into play. Even though on most FDM 3D printers the precision in the $\mathrm{X}$ and $\mathrm{Y}$ axis is not explicitly given, usually the accuracy is high enough not to cause major problems while $3 \mathrm{D}$ printing a thread. At this time accuracy studies on FDM machines report a 95\% confidence window for accuracy of $\pm 0.15 \mathrm{~mm}$ in the in-plane print directions (X and $\mathrm{Y}$ directions) with a negligible deviation in the printed thickness ( $\mathrm{Z}$ direction)[3]. The $\mathrm{Z}$ direction layer thickness, is usually defined as the printing resolution of the machine and can go as low as $0.1 \mathrm{~mm}$.

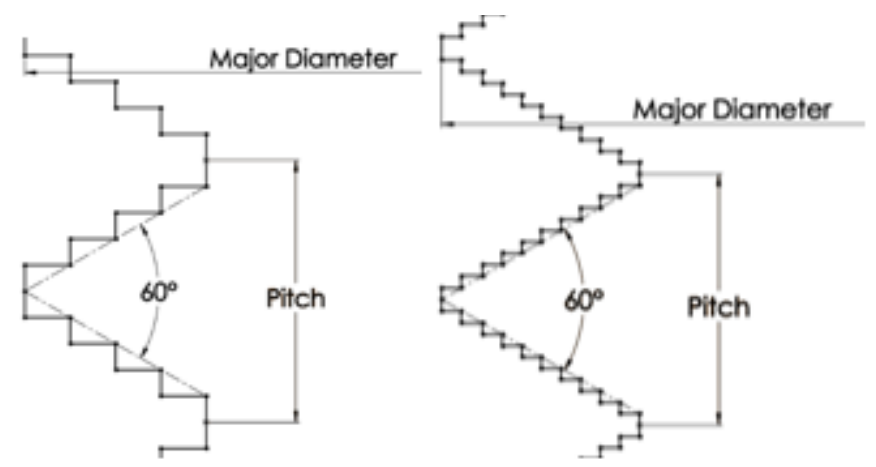

Figure 3. A 3D Printed cross sections of both a coarse thread and a fine thread [3]

As a result of machine limitations the cross section of a threaded hole will print similarly to the sections shown in Figure 3. The clear difference between these two examples is the number of layers used to define a full thread revolution. As with every model that requires finer detail, using more printed layers for each thread gives a significantly better representation of the threads geometry than using fewer layers. As a result, the primary concern for threads oriented in the Z-direction is the layer thickness and its relation to the pitch of the thread. The main issue is the minimum ratio of layers per thread that should be used when 3D printing threads.

Ultimately, a clear boundary must exist between the layers of the 3D printed thread. As the thread pitch is decreased the height of each thread approaches the height of each printed layer. It is clear that once the thread height reaches the value of the print thickness that the thread will be highly malformed and the actual prototype will not have a representation of a thread any longer. However, a printed 
thread will deviate from the desired theoretical thread long before these values match.

Threads printed in the "in-plane" directions of a 3D printer are not effected as heavily by the layer thickness itself as by the FDM machine precision. As mentioned previously, the X-direction and Y-direction print resolutions can be as low as $0.15 \mathrm{~mm}$. This lower limit will impact the quality of internal threads printed transverse to the printer extrusion direction, while the upper limit impacts the quality of externally printed threads.

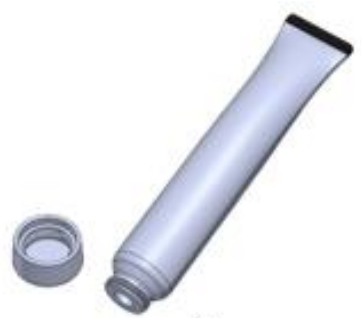

a)

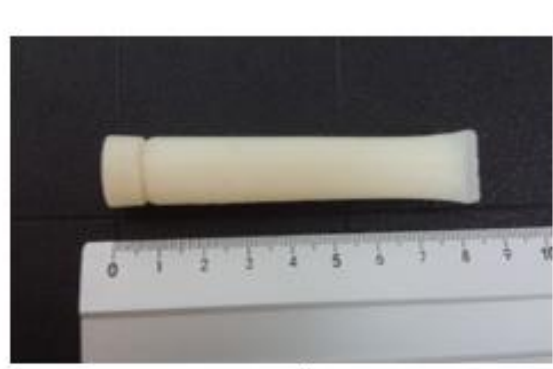

b)

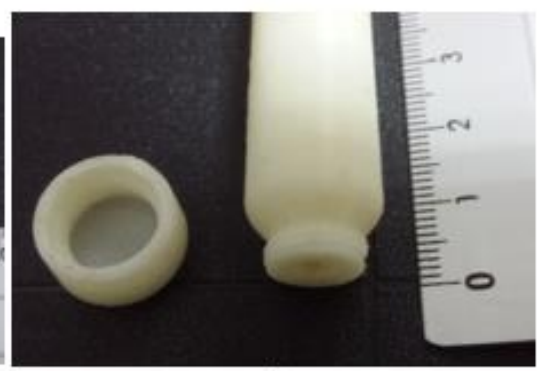

c)

Figure 4. Honey tube packaging prototype with thread connection between the cap and the head.

a) CAD model; b) $3 D$ printed parts - assembled; c) thread connection;

In order to get a thread with an acceptable quality, its pitch is recommended to be at least 8 times larger than the deviation in the print direction.

This means that when printing vertically oriented threads (along the $\mathrm{Z}$ axis) the pitch has to be at least 8 times larger than the layer thickness. On horizontally oriented threads however, the minimal pitch is defined by the accuracy in the $\mathrm{X}$ $\mathrm{Y}$ directions.

This is a pretty safe guideline but the lower limit actually depends on the machine used to print the given thread. The printed threads' pitch shown in Figure 4 is only $1 \mathrm{~mm}$. The 3D printer used to build the parts was the Dimension Elite and the 
printing resolution of the parts was $0.254 \mathrm{~mm}$. That makes the pitch size only 3.9 times the printing resolution which is almost half the value suggested in [3]. Printing threads with an even smaller pitch is also possible, but then there is a risk that the thread will not print as expected and it will be more susceptible to wear.

So in summary:

For vertical threads in the $Z$ direction:

PITCH SIZE $\geq 8 \times$ [Layer Thickness]

For horizontal threads in the in-plane directions ( $X$ and $Y$ ):

PITCH SIZE $\geq 8 \times$ [Machine Deviation]

Successful new product development is a critical cornerstone of firm success. Significant incentives exist for firms to continuously introduce viable new products to the markets they serve. The financial payoff from successful new product introductions can help many firms overcome the slowing growth and profitability of existing products and services that are approaching the maturity stages of their life cycles.

Unfortunately, new product development is an extremely challenging and complex process. Innovation is inherently risky, and firms may invest considerable time and money in new product ideas with no guarantee that they will ever become commercially viable. This is why investing in prototypes is essential to the development of a successful product. That way all the glitches and problems can be worked out early in the development cycle.

The models printed for this paper are packaging prototypes for honey jars. The initial design is shown on Figure 5. Since the jars had to have full functionality they had to be printed with correct threads. In order to have a good fit, the thread pitch had to be chosen according to the design guidelines presented before.

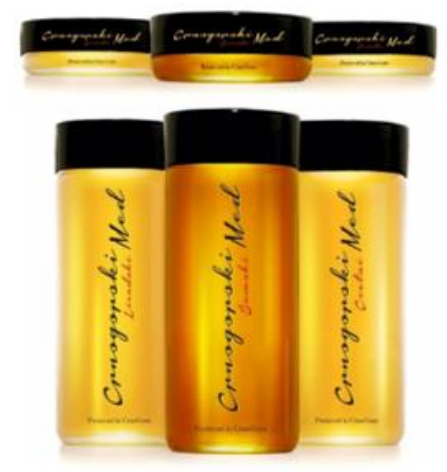


AdVANCES In PRoduction AND INDUSTRIAL ENGINEERING

O. Tuteski \& A. Kochov: Chapter 9

Design Guidelines in Developing a Prototype using Additive Manufacturing Methods

Figure 5. Conceptual honey jar design - $212 \mathrm{ml}$ and $730 \mathrm{ml}$

The print orientation of the jars and lids was as it's shown on Figure 6 so the tolerance needed to calculate the minimal thread was the $\mathrm{Z}$ direction layer thickness. Since the print resolution used was $0.254 \mathrm{~mm}$ for the minimal pitch we get:

$$
\mathrm{PITCH}_{\text {min }}=8 \times 0.254=2.032 \mathrm{~mm}
$$

Going from this calculation, the pitch on the jars and the lids is modelled accordingly. Its value is $4 \mathrm{~mm}$ and that is well above the lower limit of the machine.
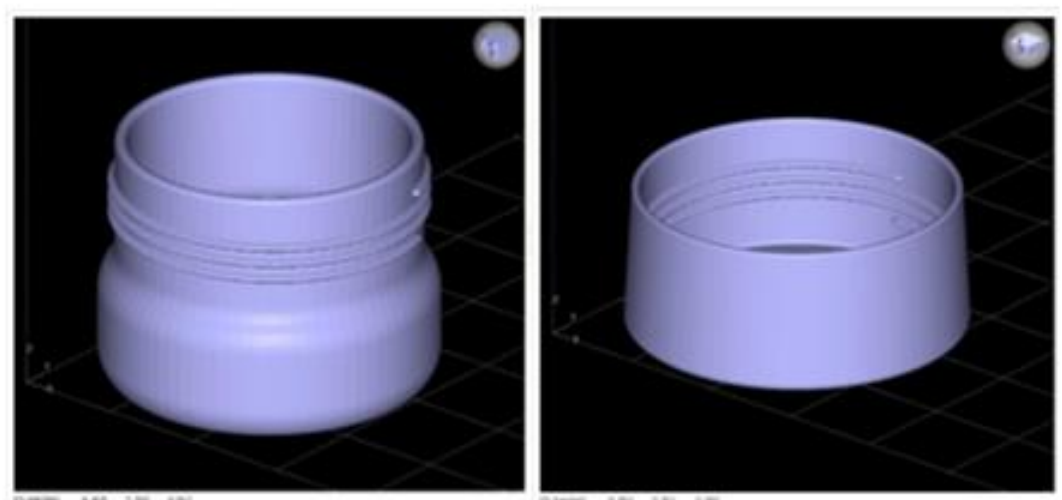

a)
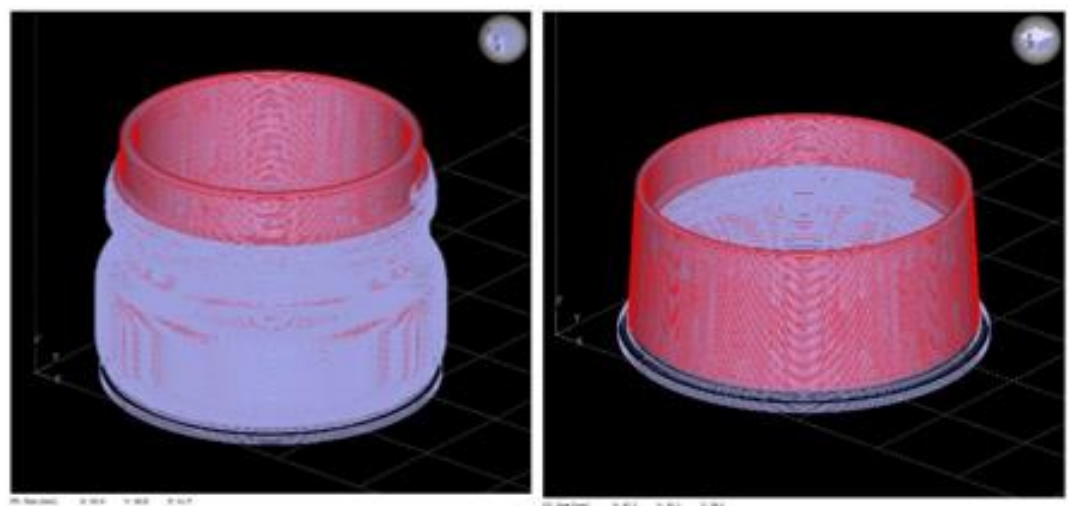

b)

Figure 6. Print orientation of the jars and lids before (a) and after the layer slicing $(b)$. The toolpaths for the modelling material are shown in red while the toolpaths for the supporting material are grey 
Tuteski \& A. Kochov: Chapter 9

Design Guidelines in Developing a Prototype using Additive

Manufacturing Methods

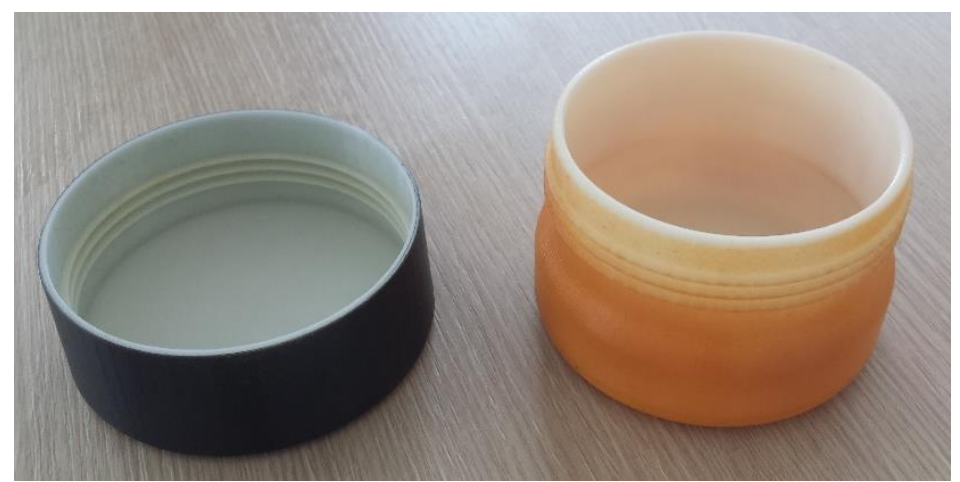

Figure 7. The final prototype after the post-processing and coloring

The modeling workflow can vary depending on the CAD software that is used but generally the thread profile is defined by a reference geometry in the form of a helix spiral (Figure 8a).

Another important factor is the clearance between the lid and the jar. As mentioned before it has to be at least $0.5 \mathrm{~mm}$. As shown on Figure $8 \mathrm{~b}$, the clearance between each corresponding turn of the thread helix on the mating components is about 0.7 $\mathrm{mm}$. Most CAD software have evaluation tools to check for the clearance between two parts. But these tools are mostly for verification only and the modelling has to be done with the design intent for 3D printing in mind in order to avoid the time consuming changes in the geometry.

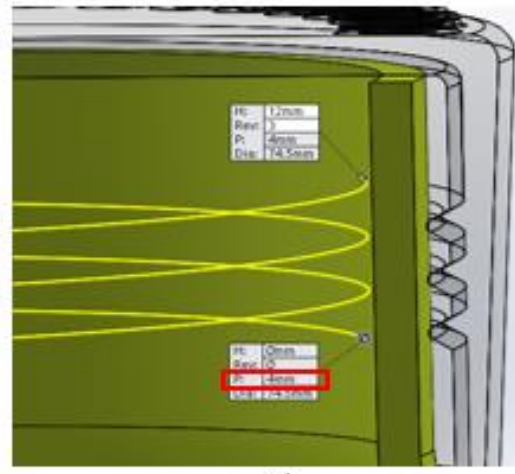

a)

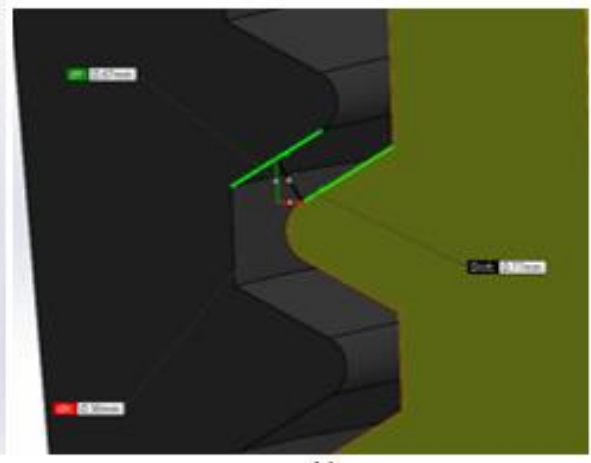

b)

Figure 7. a) Modelling the thread according to the minimal pitch limitation $(P=4 \mathrm{~mm})$;

b) Clearance between the jar and the lid so that the thread can maintain its functionality $(z=0,77 \mathrm{~mm})$; 
Design Guidelines in Developing a Prototype using Additive Manufacturing Methods

\section{Conclusion}

Prototypes are very important for realization of concepts in design, manufacturing and analysis. Prototyping is an essential part of product development and manufacturing cycles required for assessing the form, fit and functionality of a design before a significant investment is made [1]. The advantage of FDM as a rapid prototyping technology is that the material has good capacity to handle heat and other demanding product tests. It is a feasible option for both rapid prototyping and rapid manufacturing which means manufacturing using rapid prototyping and producing parts that are both accurate and durable [2]. The material selection encompasses options that are applicable to various industries, including aerospace, engineering, and manufacturing to name a few. The composition of the materials make them suitable options for end-use prototypes, greatly reducing the costs associated with product development.

While rapid prototyping using additive manufacturing methods is an incredible tool for new product development, there are still some constraints that need to be taken into consideration when designing the model. The design recommendations shown in this paper give an overview of the general workflow when modeling 3D printed thread connections that are supposed to withstand numerous working cycles and give a representation of the functionality of the final product. Taking into account the similarities between most rapid prototyping technologies these methods are applicable to other additive processes as well.

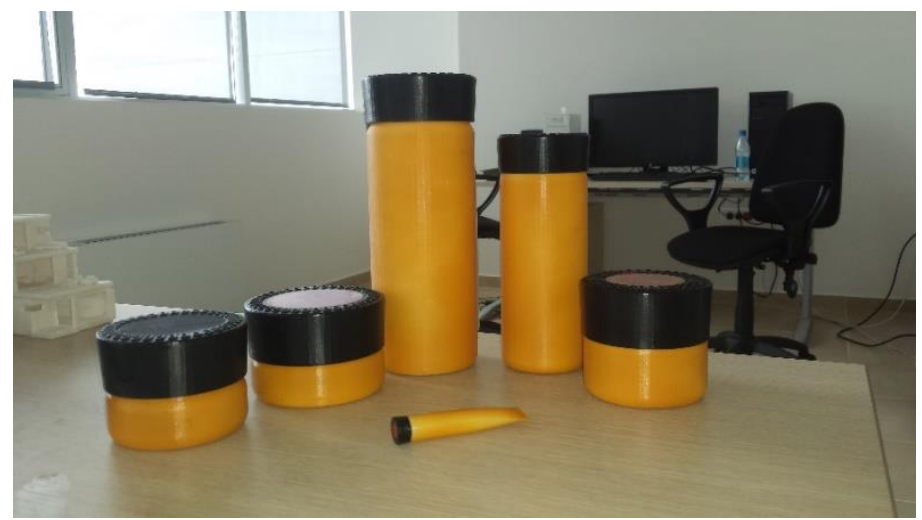

Figure 8. Family products of similar shapes can be easily designed using parametric design features 


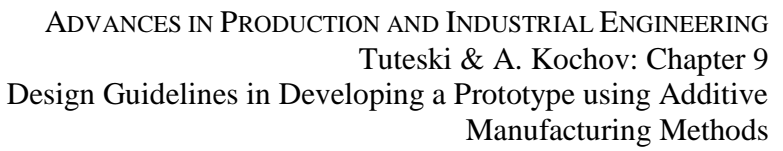

\section{References}

[1] Pham, D. T. and Gault, R. S. 1998. A comparison of rapid prototyping technologies. Machine Tools \& Manufacture, 38,.1257-87

[2] Gouldsen,C., Blake, P. 1998. Investment Casting Using FDM/ABS Rapid Prototype Patterns.

[3] Rapid Prototyping - Feasibility of Threaded Holes - GoEngineer

[4] Pranjal Jaina, A. M. Kutheb. 2013. Feasibility Study of manufacturing using rapid prototyping: FDM Approach. Procedia Engineering 63 (2013) 4 - 11.

[5] John R. Hauser and Ely Dahan. 2003. Product Management: New Product Development and Launching. Sage Press, (June), 179-222

[6] Andreas Gebhardt. 2011. Understanding Additive Manufacturing. Hanser Publications, Cincinnati 
146 Advances in PROduction AND INDUSTRIAL ENGINEERING 


\title{
Chapter 10
}

\section{Teaching-learning Based Optimization Algorithm for Cutting Force Maximization in end Milling Processes}

\author{
UROŠ ŽUPERL, FRANC ČUŠ \& TOMAŽ IRGOLIČ
}

\begin{abstract}
This chapter presents a multi-objective optimization of milling process by using ANFIS modelling and TBLO optimization algorithm. The ANFIS model is used to predict objective function and TLBO algorithm is used to obtain optimum spindle speed and feed rate for a typical case of milling found in industry. A set of 5 constraints were used during optimization. The paper presents mathematical fundamentals of TBLO optimization. The optimal cutting conditions obtained by TLBO have been verified through experiments. They have been conducted with optimal cutting parameters to verify the optimization results and effectiveness of the optimization approach.
\end{abstract}

Keywords: - end-milling - cutting parameters - optimization • TLBO $\bullet$ cutting force

Correspondence Adress: Uroš Župerl, Ph.D., Associate Professor, University of Maribor, Faculty of Mechanical Engineering, Smetanova ulica 17, 2000 Maribor, Slovenia, e-mail: uros.zuperl@um.si. Franc Čuš, Ph.D., Full Professor, University of Maribor, Faculty of Mechanical Engineering, Smetanova ulica 17, 2000 Maribor, Slovenia, e-mail: franc.cus@um.si. Tomaž Irgolič, Ph.D., Researcher, University of Maribor, Faculty of Mechanical Engineering, Smetanova ulica 17, 2000 Maribor, Slovenia, e-mail: tomaz.irgolic@um.si.

https://doi.org/10.18690/978-961-286-028-8.10 ISBN 978-961-286-028-8

(C) 2017 University of Maribor Press

Available at: http://press.um.si. 
Many researchers have studied the effects of optimal selection of machining parameters of end milling [1]. The proper selection of machining parameters is an important step towards increasing productivity, decreasing costs, and maintaining high product quality. This problem can be formulated and solved as a multiple objective optimization problem [2]. In practice, efficient selection of milling parameters requires the simultaneous consideration of multiple objectives, including maximum tool-life, desired roughness of the machined surface, target operation productivity, metal removal rate, etc [1]. In some instances, parameter settings that are optimal for one defined objective function may not be particularly suited for another objective function. Solving multi-objective problems with traditional optimization methods is difficult and the only way is to reduce the set of objectives into a single objective and handle it accordingly.

Therefore population based heuristic algorithms such as evolutionary algorithms (EA) and swarm intelligence (SI) are more convenient and usually utilized in multi-objective optimization problems. These methods are summarized by [3]. Some of the recognized evolutionary algorithms are: Genetic Algorithm (GA) [4], Evolution Strategy (ES), Evolution Programming (EP), Differential Evolution (DE), Bacteria Foraging Optimization (BFO), etc. Some of the well-known swarm intelligence based algorithms are: Particle Swarm Optimization (PSO) [5, 6], Ant Colony Optimization (ACO), Fire Fly (FF) algorithm, etc.

\section{Basic of teaching-learning based optimization}

TLBO is population based method and uses a population of solutions to obtain a global optimum. In TLBO a group of learners (students) is considered as population. TLBO is a teaching-learning process inspired algorithm based on the effect of influence of a teacher on the output of learners in a class. 
Teaching-learning Based Optimization Algorithm for Cutting Force

Maximization in end Milling Processes

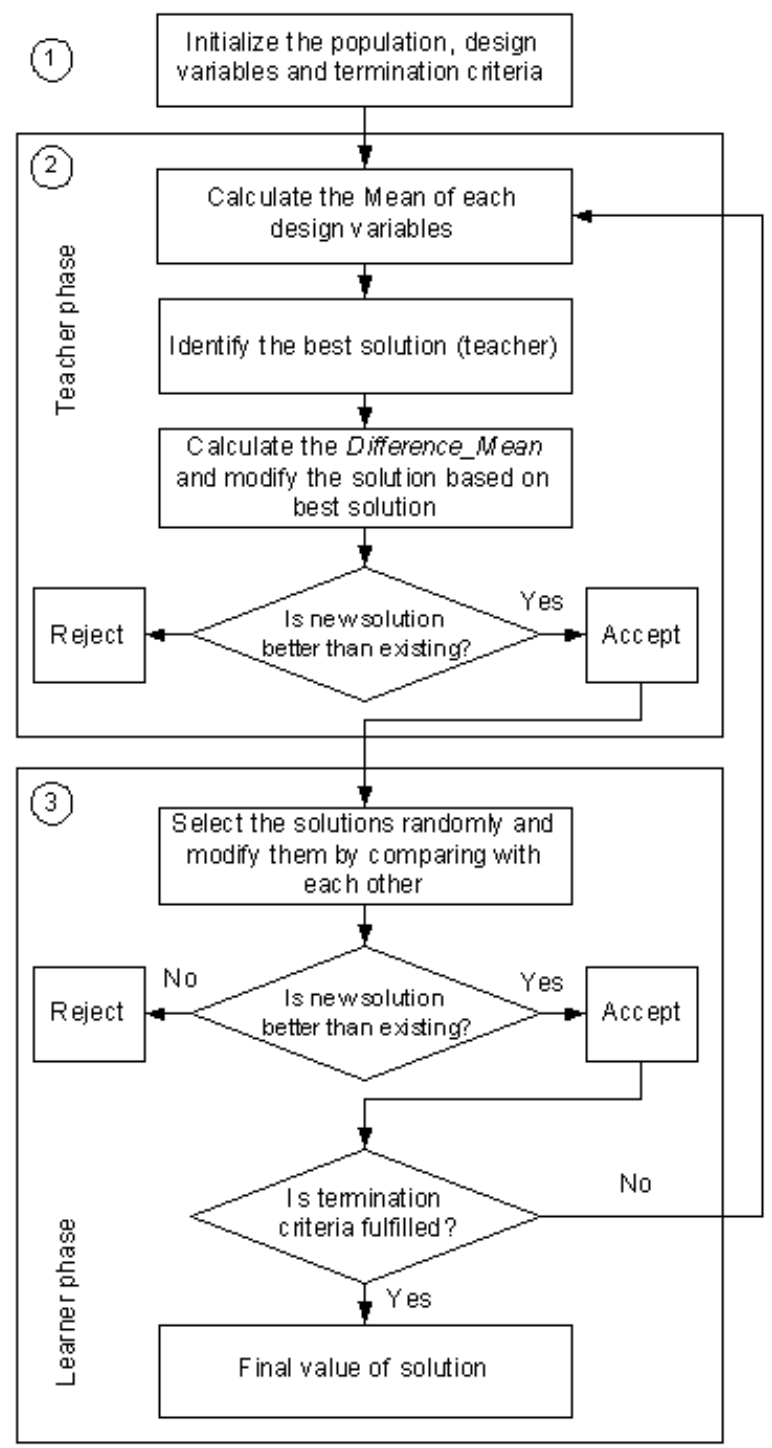

Figure 1. The flowchart of the TBLO algorithm

Teacher and learners are the two vital components of the algorithm and describes two basic modes of the learning, through teacher (known as teacher phase) and interacting with the other learners (known as learner phase). Moreover, learners also learn from the interaction among themselves which also helps in improving their results. 
The learners' result is analogous to the fitness value of the optimization problem. In the entire population the best solution is considered as the teacher. The output in TLBO algorithm is considered in terms of results or grades of the learners which depend on the quality of teacher.

The working of TLBO is divided into two phases, Teacher phase and Learner phase. Both phases are explained below.

\subsection{Teacher phase}

In this phase the learners learn through the teacher. A teacher conveys knowledge among the $\mathrm{n}$ students (population size, $\mathrm{k}=1,2, \ldots, \mathrm{n}$ ) and tries to increase the mean result of the class $\mathrm{M}$. At any teaching-learning iteration $\mathrm{i}, \mathrm{Mj}, \mathrm{i}$ is the mean result of the learners in a particular design variable $j(j=1,2, \ldots, m)$. $m$ is the number of subjects (i.e. design variables) offered to $\mathrm{n}$ number of learners. Xtotal-kbest,i is the result of the best student considering all the subjects, who is identified as a teacher for that iteration. The best identified student is considered as the teacher in the algorithm. The students will acquire knowledge according to the quality of teaching delivered and the quality of students in the class.

The difference between the result of the teacher and mean result of the students in each subject is expressed as:

$$
\text { Difference_Meanj,i }=\text { ri }(\mathrm{Xj}, \mathrm{kbest}, \mathrm{i}-\mathrm{TFMj}, \mathrm{i})
$$

where, $\mathrm{Xj}$,kbest, i is the result of the teacher (i.e. best learner) in subject $\mathrm{j}$. TF is the teaching factor which decides the value of mean to be changed, and ri is the random number in the range $[0,1]$. Value of TF can be either 1 or 2 . The value of TF is decided randomly using Eq. 2

$$
\mathrm{T}_{\mathrm{F}}=\text { round }[1+\mathrm{rand}(0,1)\{2-1\}]
$$

Based on the Difference_Meanj,k,i, the existing solution is updated in the teacher phase according to the following expression.

$$
X_{j, k, i}^{\prime}=X_{j, k, i}+\text { Difference_Mean }{ }_{j, k, i}
$$

where $X_{j, k, i}^{\prime}$ is the updated value of $X_{j, k, i}$. $X_{j, k, i}^{\prime}$ is accepted if it gives better function value. All the accepted function values at the end of the teacher phase are maintained and these values become the input to the learner phase. 


\subsection{Learner phase}

In this phase the learners increase their knowledge with the help of mutual interactions. The students can gain knowledge by discussing and interacting with the other students. The learning phenomenon of this phase is expressed below.

Every student has to interact with any other student. Randomly two learners $\mathrm{P}$ and $\mathrm{Q}$ are selected such that $\mathrm{X}_{\text {total-P,i }}^{\prime} \neq \mathrm{X}_{\text {total-Q,i, }} . \mathrm{X}_{\text {total-P,i }}^{\prime}$ and $\mathrm{X}_{\text {total-Q,i }}^{\prime}$ are the updated values at the end of teacher phase.

$$
\begin{aligned}
& X_{\mathrm{j}, \mathrm{P}, \mathrm{i}}^{\prime}=X_{\mathrm{j}, \mathrm{P}, \mathrm{i}}^{\prime}+\operatorname{ri}\left(\mathrm{X}_{\mathrm{j}, \mathrm{P}, \mathrm{i}}^{\prime}-X_{\mathrm{j}, \mathrm{Q}, \mathrm{i}}^{\prime}\right) \text {, If } X_{\text {total-P,i }}^{\prime}>X_{\text {total-Q,i }}^{\prime} \\
& X_{\mathrm{j}, \mathrm{P}, \mathrm{i}}^{\prime \prime}=X_{\mathrm{j}, \mathrm{P}, \mathrm{i}}^{\prime}+\mathrm{r}_{\mathrm{i}}\left(\mathrm{X}_{\mathrm{j}, \mathrm{Q}, \mathrm{i}}^{\prime}-X_{\mathrm{j}, \mathrm{P}, \mathrm{i}}^{\prime}\right) \text {, If } X_{\text {total-Q,i }}^{\prime}>X_{\text {total-P,i }}^{\prime}
\end{aligned}
$$

Above equations are for maximization problem, reverse is for minimization problem. X"j,P,i is accepted if it gives a better function value. Fig. 1 shows the flowchart of the TLBO algorithm [3].

\section{$3 \quad$ ANFIS based cutting force prediction model}

In his section an accurate and reliable model for predicting cutting forces during end milling process is outlined. The cutting force prediction model is built according to the ANFIS method. The ANFIS method seeks to provide a linguistic model for the prediction of cutting forces from the knowledge embedded in the trained neural network.

By given input/output data set, the ANFIS method constructs a fuzzy inference system (FIS) whose membership function parameters are tuned (adjusted) using a backpropagation algorithm. This allows fuzzy systems to learn from the data they are modeling.

FIS Structure is a network-type structure similar to that of a neural network, which maps inputs through input membership functions and associated parameters, and then through output membership functions and associated parameters to outputs.

Four steps are required to develop an ANFIS system. In step 1, the training and testing data are loaded to the system.

The process variables are force sensor readings $(F)$, spindle speed $(n)$, feed rate $(f)$ and depth of cutting (AD/RD).All the data were scaled. The whole data set is divided into the training and the testing set. 500 data points were used in this study. 
The training data set is used to find the initial premise parameters for the membership functions by equally spacing each of the membership functions.

A threshold value for the error between the actual and desired output is determined.

The FIS architecture and training parameters were defined in step 2. The optimization method, the tolerance error, the maximal number of epoch, the number of membership functions and the membership functions types are defined.

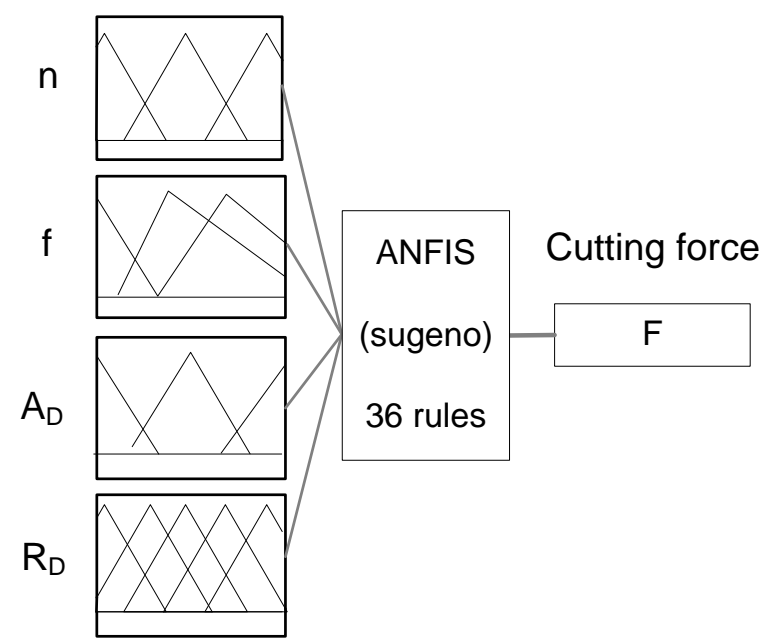

Figure 2. Architecture of ANFIS cutting force model

The fuzzy inference system under consideration has 4 inputs and one output. The inputs are the cutting conditions. The output is cutting force sensor signal.

In step 3, the training phase is accomplished. With the input-output data, the neuro-fuzzy algorithm is trained, and the unknown parameters are identified.

Fig. 2 shows the inputs, membership functions, and the fuzzy inference system for cutting force prediction.

During the training stage, the ANFIS adjusts its internal structure to give correct output results according to the input features. The process is terminated when the error becomes less than the threshold value.

During training in ANFIS, 50 sets of experimental data are used to conduct 500 cycles of learning.

Finally, in the fourth step the trained ANFIS is used to predict cutting forces.

\section{Adaptation of TBLO approach to milling optimization}


In order to find optimal cutting parameters, ANFIS model of cutting forces was integrated with TBLO algorithm. The optimization strategy is shown in Fig. 3.

ANFIS model is developed, and its output is fed into the TBLO algorithm where constraints are defined.

Table 1. Constraints and their expressions

\begin{tabular}{|c|c|c|}
\hline Constraints & Expression & Variables \\
\hline Feedrate & $f_{\min } \leq \frac{1000 \cdot z}{\pi \cdot D} v_{c} \cdot f_{z} \leq f_{\max }$ & $\begin{array}{l}z \text {-number of teeth, } \\
f_{z} \text {-feeding per tooth, } \\
D \text {-diameter of cutter }\end{array}$ \\
\hline Spindle speed & $n_{\min } \leq \frac{1000}{\pi \cdot D} v_{c} \leq n_{\max }$ & $\mathrm{v}_{\mathrm{c}}-$ cutting speed \\
\hline Radial depth of cut & $R_{D} \leq a e_{\max }$ & $\begin{array}{l}\text { ae } \max -\text { max. radial depth of } \\
\text { cutting }\end{array}$ \\
\hline Axial depth of cut & $A_{D} \leq a p_{\max }$ & $\begin{array}{l}\text { apmax }- \text { max. axial depth of } \\
\text { cutting }\end{array}$ \\
\hline Power of cutting & $\frac{M R R \cdot K c}{60} \leq P_{d o v}$ & $\begin{array}{l}\text { MRR - metal removal rate, } \\
\text { Kc -specific cutting force }\end{array}$ \\
\hline Cutting force & $F(f, n) \leq F_{r e f}$ & $\mathrm{~F}_{\text {ref }}$-desired cutting force \\
\hline Surface roughness & $R_{a} \leq R_{\text {a ref }}$ & $\begin{array}{l}R_{\text {a ref }} \text { - desired surface } \\
\text { roughness }\end{array}$ \\
\hline
\end{tabular}

TBLO algorithm is initiated with randomly generated answers in predefined population of students. The student's answers are optimum solution candidates. ANFIS model predicts cutting forces for each of the student.

Predicted maximal forces are used as an objective function which PSO tries to maximize.

The objective function serves as the only link between the optimization problem and the TBLO algorithm. 
ADVANCES IN PRODUCTION AND INDUSTRIAL ENGINEERING

U. Župerl, F. Čuš \& T. Irgolič: Chapter 10

Teaching-learning Based Optimization Algorithm for Cutting Force

Maximization in end Milling Processes

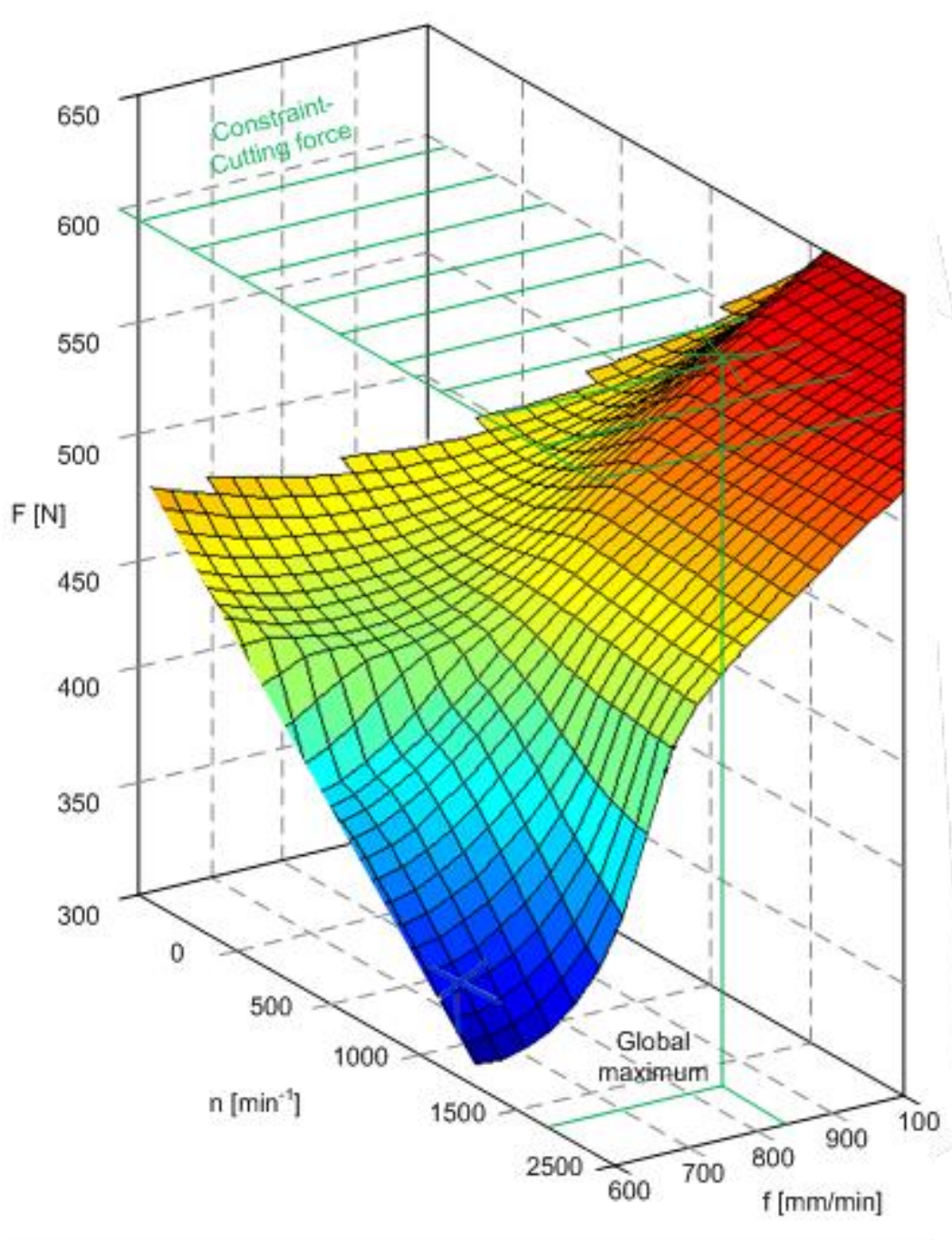

Figure 3. Optimal cutting conditions searching procedure

The optimization process executes in two phases. In first phase, the ANFIS model on the basis of recommended cutting conditions generates 3D surface of cutting forces, which represent the feasible solution space for the TBLO algorithm.

The cutting force surface is limited with planes which represent the constraints of cutting process. Seven constraints, which arise from technological specifications, can be considered during the optimization process. Those constraints are listed in Table 1. 
TBLO algorithm generates a population of students-learners during the second phase.

The learners learn through the teacher and at the end phase increase their knowledge by interaction among themselves to find the maximal cutting force.

The best answer of a student which has found the maximal but still allowable cutting force represents the optimal cutting conditions.

The optimization process is depicted by the following steps:

1. Define the optimization problem (maximization of cutting force surface) and initialize the optimization parameters: Population size ( $\mathrm{k}=8$ students), number of generations $(i=20)$, number of design variables $(j=2$ for $f$ and $n$ ) and limits of design variables $\left(\mathrm{f}_{\min }, \mathrm{f}_{\max }, \mathrm{n}_{\min }, \mathrm{n}_{\max }\right)$.

2. Generate a random population according to the population size and number of design variables $(\mathrm{j}=2)$.

3. Teacher phase; Calculate the mean of each design variable (f, $n$ ), evaluate of objective (cutting force surface) function for each student, identify the best solution (teacher), modify solution based on best solution.

4. Student phase; increase the knowledge of students with the help of their mutual interactions.

5. Termination criteria; Steps 3 and 4 are repeated until the generation number reaches a maximum generation number.

Fig. 3 shows simplified principle of optimization of cutting parameters by the use of TBLO. In this case, the group of students search for optimal feeding and spindle speed. Optimal feed rate is located at the cross-section of the following two planes: cutting force surface and the limit cutting force plane. The student's answer which is the nearest to mentioned cross-section represent the optimal feed rateand spindle speed.

A group of Matlab's m-files forms TLBO software for optimization. This software can be used for optimization of arbitrary non-linear system. The required input parameters required for executing TBLO algorithm are inserted in a software window.

The result of optimization (optimal cutting parameters) is presented to user in a tabular form. The progress of optimization process can be monitored on graph.

\section{TBLO optimization of cutting parameters-test case}

The repeatability of the TBLO optimization strategy is outlined with presented test case. The accuracy and repeatability of the proposed optimization strategy is first analyzed by simulations, then it is verified by experiments on a CNC machine tool 
Teaching-learning Based Optimization Algorithm for Cutting Force Maximization in end Milling Processes

HELLER BEA02 for 16MnCrSi5 XM steel workpieces [2]. The solid ball-end milling cutter with two cutting edges, of $16 \mathrm{~mm}$ diameter and $8^{\circ}$ helix angle was selected for experiments.

The following cutting parameters and constraints were used: milling width $R_{D}=2$ $\mathrm{mm}$, milling depth $A_{D}=3 \mathrm{~mm}, 500 \leq \mathrm{n} \leq 2500 \mathrm{~min}-1,10 \leq \mathrm{f} \leq 950 \mathrm{~mm} / \mathrm{min}, \mathrm{F}(\mathrm{f}$, n) $\leq$ Fref $=600 \mathrm{~N}$.

The objective function is generated by ANFIS cutting force model.

Table 2: Repeatability of results

\begin{tabular}{|c|c|c|c|c|}
\hline Test/Run & $n\left[\mathrm{~min}^{-1}\right]$ & $f[\mathrm{~mm} / \mathrm{min}]$ & $F[\mathrm{~N}]$ & Nr. of generations \\
\hline 1 & 1999 & 828.3 & 597 & 15 \\
\hline 2 & 1994 & 830.5 & 600 & 17 \\
\hline 3 & 1998 & 831.2 & 601 & 19 \\
\hline 4 & 1997 & 839.6 & 597 & 23 \\
\hline 5 & 2000 & 839.1 & 598 & 11 \\
\hline 6 & 1999 & 839.3 & 599 & 20 \\
\hline 7 & 2000 & 828.0 & 596 & 18 \\
\hline 8 & 1996 & 828.9 & 597 & 12 \\
\hline 9 & 1996 & 828.7 & 599 & 23 \\
\hline 10 & 1999 & 828.4 & 596 & 21 \\
\hline
\end{tabular}

The goal of this case is to maximize the objective function under given constraints. In TBLO, a population of 10 learners was used and learned continuously until global maximum is found within specified constraints.

The results are outlined in Table 2. Each run corresponds to each time the program is run to find the optimum machining parameters. Table 2 shows optimal cutting conditions along with the number of generations it took to reach that optimum.

This optimization strategy has higher convergence, unlike traditional methods and is always successful in finding the global optimum. The machining time is reduced by $27 \%$ as a result of optimizing the feed and speed.

Fig. 4 shows a typical student answers pattern toward the optimum solution. Generation 0 represents the random initialization of the student's answers coordinates in the solution space. In subsequent generations, the student`s answers are tracked with " $\mathrm{x}$ ". 
The best student in population is presented with "O". The solution space is marked by the rectangle. An acceptable solution has to be found within this twodimensional space.

The third constraint on force is also active and as such is not part of these illustrations. By simulations the efficiency of the optimization approach is demonstrated

\section{Conclusions}

In this research, teaching learning based optimization (TLBO) algorithm has been used for determining optimal cutting process parameters in ball- end milling processes where multiple conflicting objectives are present. First, dynamic cutting force components have been modeled using an adaptive neuro-fuzzy inference system (ANFIS) based on design of experiments and then TLBO algorithm is used to determine the objective function maximum (cutting force surface) by consideration of cutting constraints. Ball-end milling experiments have been performed according to the experimental plan. Analysis of the developed approach has been performed to test its validity. The results showed that integrated system of ANFIS and TLBO is an effective approach for solving multi-objective cutting conditions optimization problem in ball-end milling. 
U. Župerl, F. Čuš \& T. Irgolič: Chapter 10

Teaching-learning Based Optimization Algorithm for Cutting Force

Maximization in end Milling Processes
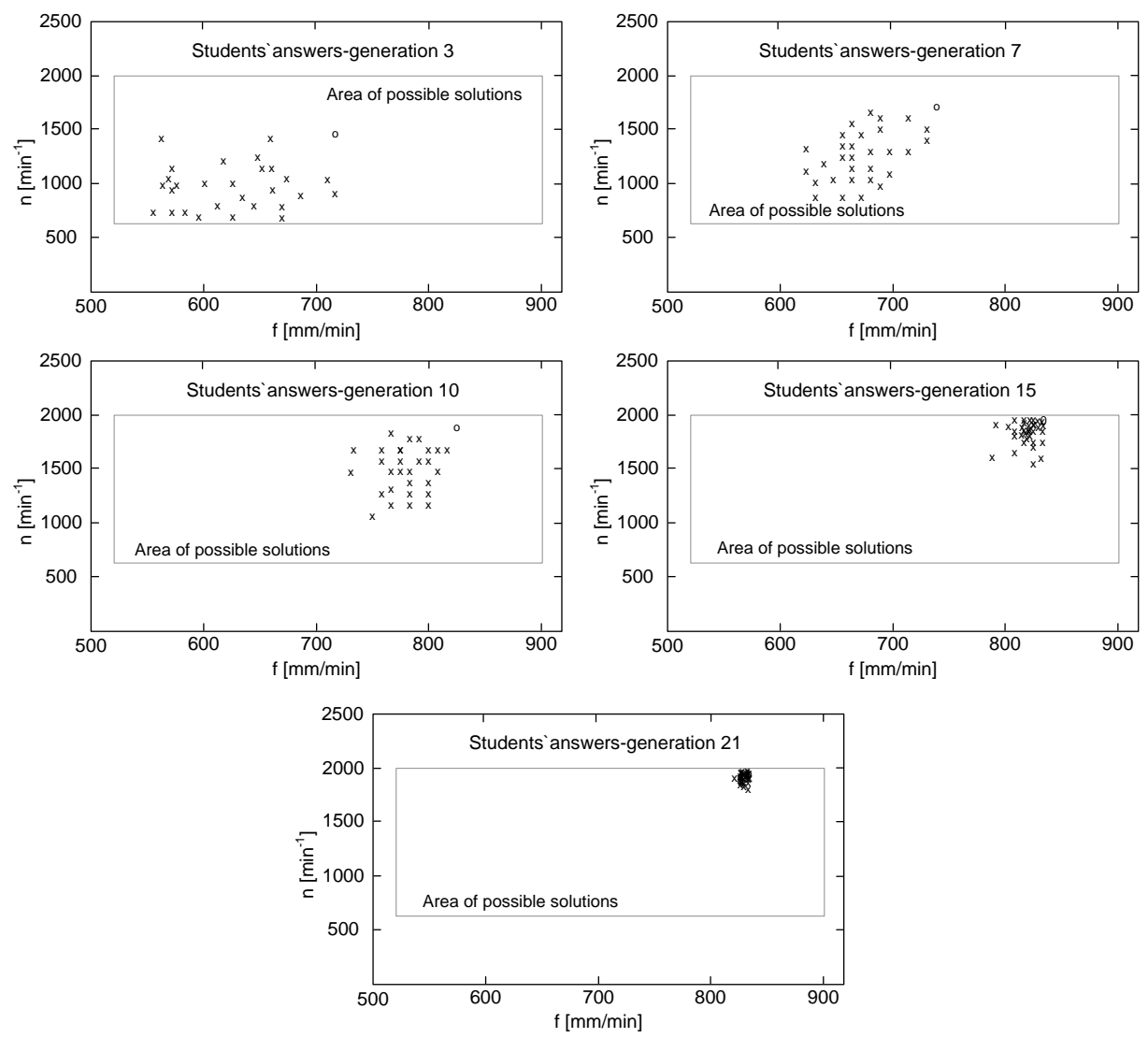

Figure 4. TBLO simulation

The high accuracy of results within a wide range of machining parameters indicates that the system can be practically applied in industry. The experimental results show that the MRR is improved by $19 \%$. Machining time reductions of up to $15 \%$ are observed.

\section{References}

[8] F. Cus, J. Balic, Selection of Cutting Conditions and Tool Flow in Flexible Manufacturing System, The International Journal for Manufacturing Science \& Technology, Vol.2, 2000, pp. 101-106.

[9] U. Župerl, F. Čuš, Optimization of cutting conditions during cutting by using neural networks, Robot. comput. integr. manuf., Vol. 19, 2003, pp. 189-199.

[10] R. V. Rao, V. J. Savsani, J. Balic, Teaching-learning-based optimizationalgorithm for unconstrained and constrained real-parameter optimization problems, Engineering Optimization, Vol. 44, No. 12, 2012, pp. 1447-1462. 
U. Župerl, F. Čuš \& T. Irgolič: Chapter 10

Teaching-learning Based Optimization Algorithm for Cutting Force

Maximization in end Milling Processes

[11] F. Čuš, J. Balič, Optimization of cutting process by GA approach, Robot. comput. integr. manuf., Vol. 19, 2003, pp. 113-121.

[12] Ozcan, E., C. Mohan (1998), Analysis of a simple Particle Swarm Optimization system, Intelligent Engineering Systems Through Artificial Neural Networks, 8(1998), pp. 253-258.

[13] R.C., Eberhart, Y. Shi, Comparison Between Genetic Algorithm and Particle Swarm Optimization, Proceedings of the 7th ICEC, 2003, pp. 611-616.

[14] Angeline, P.J. Evolutionary Optimization Versus Particle Swarm Optimizatio,8n: Philosophy and Performance Differences, in: Proceedings of the 7th ICEC, (1998), pp. 601-610.

[15] M.A. Abido, Optimal Power Flow Using Particle Swarm Optimization, International Journal of Electrical Power \& Energy Systems, Vol. 24, 2002, pp. 563-571. 
AdVANCES IN PRODUCTION AND INDUSTRIAL ENGINEERING

F. Čuš \& V. Gecevska

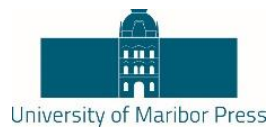

\section{Part IV - METHODS FOR SOCIAL AND ECONOMIC DEVELOPMENT}




\title{
Chapter 11
}

\section{Innovation Partners of Macedonian Companies}

\author{
BoJAn R. JOVANOVSKi, IVANA STANKOVSKa, RADMIL POLEANKOVIKJ \& \\ INES ŠUH
}

\begin{abstract}
In many industries, companies put great importance and potential on external sources, and their value depends on the size and depth of the available knowledge in the relevant industrial field. Along with the cost cutting, the open innovation significantly contributes to the reduction of time to market. The results presented in this chapter are based on the results of the CIS (Community Innovation Survey) conducted in Macedonia in 2013. The CIS was chosen as the empirical basis for this analyses because of its rich variable content and high response figures. This is a firm level survey, conducted every 4 years in all EU states and some non-EU countries using a harmonized questionnaire designed to give information on the innovativeness of different sectors and regions. It can be concluded that the collaboration between the private sector and the knowledge providers, primarily universities in Macedonia, should be further enhanced and intensified.
\end{abstract}

Keywords: • innovation $\bullet$ university $\bullet$ industry $\bullet$ cooperation $\bullet$ CIS survey

CORRESPONDENCE AdRESS: Bojan R. Jovanovski, Assistant, „Ss. Cyril and Methodius” University in Skopje, Faculty of Mechanical Engineering-Skopje, Rudger Boshkovikj bb, Skopje 1000, Republic of Macedonia, e-mail: bojan.r.jovanovski@mf.edu.mk, Ivana Stankovska, Ph.D., National Centre for Development of Innovation and Entrepreneurial Learning Skopje, Rudger Boskovic bb, 1000 Skopje, Republic of Macedonia, e-mail: ivana.stanovska@ncdiel.mk, Radmil Poleankovikj, Ph.D., Full Professor, ,,Ss. Cyril and Methodius" University in Skopje, Faculty of Mechanical Engineering-Skopje, Rudger Boshkovikj bb, Skopje 1000, Republic of Macedonia, e-mail: radmil.polenakovikj@mf.edu.mk, Ines Šuh, World University Service (WUS) Austria, Lichtenfelsgasse 21, 8036 Graz, Austria, e-mail: ines.suh@wus-asustria.org

https://doi.org/10.18690/978-961-286-028-8.11 ISBN 978-961-286-028-8

(C) 2017 University of Maribor Press

Available at: http://press.um.si. 
Innovation, especially open innovation is based on the ability of companies to identify and exploit ideas and knowledge within and outside of the organization. In many industries, companies put great importance and potential on external sources, and their value depends on the size and depth of the available knowledge in the relevant industrial field. Along with the cost cutting, the open innovation significantly contributes to the reduction of time to market. Universities play very important role in this system, especially in countries such as Macedonia where traditionally most of the research activities have been carried out at the universities or by their staff.

The characteristics of the knowledge environment depend on the knowledge derived from other companies and organizations, as well as the conditions and laws of intellectual property. The literature on open innovation focuses on knowledge that is exchanged between two or more companies, or the knowledge derived from the companies, while the literature on knowledge exchange examines the knowledge generated in educational, private and public institutions, universities, laboratories, research centres, etc.

The entire set of knowledge is not evenly distributed in the societies and in the businesses. For greater integration of this knowledge into new knowledge, innovation and products, companies provide various reward practices, measures and motivational work environment where employees use their knowledge and experience in practice. In the cases where further external knowledge is required, companies contract research partnerships.

The researchers who work at the universities use research findings, tools and techniques, experimental materials and highly educated personnel (Cohen et al. 2002). The university research is mostly at the basic level, but it gives an indication about the potential of the field, which allows industrial or applied research to be focused on the most promising research areas, and thus increase their productivity (David et al. 1992). Therefore, access to better knowledge base enables the researchers in the companies to search for new ideas and innovation. In certain scientific fields, such as high technology, pharmaceuticals, medical equipment, computers and semiconductors, university research is a crucial base for any industrial research. According to researchers (Belderbos et al., 2004), collaboration with universities is more used by industrial firms that carry out intensive research, have a quick technological development and production of new products. The knowledge that is produced by universities is not transferred to industry researchers automatically. The knowledge transfer is influenced by the established regime of rules of cooperation, the nature of knowledge and the competence of firms to identify and exploit this knowledge (Chesbrough 2003; Teece, 1986). The most common channel for distribution of the university research to the industry is the scientific literature and the open publications. In addition to 
the traditional channels, such as: conferences, consultations and informal interactions, the new interactive channels: social networks, blogs and forums are also important for efficient cooperation.

A technology as a generic term is defined by many scientists. The definition outlined by Rosenberg and Frischtak (1985) explains the concept through the conversion and accumulation of information about the production process and design. The technology transfer is tacit and cumulative phenomenon, which makes it more complex than the commercialization of products and processes. The interactive theory differentiates between two transfer processes: interorganisational process for exchange and adaptation, and process of learning new technologies (Keeble and Wilkinson 1999). The types of technology transfer can be classified in respect to several criteria (Kiper 2012). Depending on their relations and size, they can be: international (between firms or organizations in two or more countries), north-south (from developed to developing countries), private (between companies) and public-private (between university or public research lab and private company). Regarding the process of transferring the knowledge, the transfer can be direct, for instance: license agreements, mutual consultations, mutual ventures, etc., and indirect - the transfer that occurs during business trips, seminars and trainings. The absorption capacity determines whether the transfer is active or passive, as well as whether the transfer is horizontal or vertical. If the tacit knowledge is transferred, then the transfer is horizontal, otherwise the transfer is vertical. The technology transfer is influenced by the base of knowledge and by the national innovation systems. Therefore, it should not be discussed in isolation, but it should be examined in wider socio-economic context of the country where it occurs.

\section{University-industry cooperation in Macedonia}

The results presented in this paper will be based on the results of the CIS (Community Innovation Survey) conducted in Macedonia in 2013. The CIS was chosen as the empirical basis for our analyses because of its rich variable content and high response figures. This is a firm level survey, conducted every 4 years in all EU states and some non-EU countries using a harmonized questionnaire designed to give information on the innovativeness of different sectors and regions. The Macedonian sample is administered by the State Statistical Office of the Republic of Macedonia. The dataset used, CIS 2012, covered the years 2010 2012. The sample collected by CIS 2012 in Macedonia is consisted of 1130 surveyed companies. The surveyed firms are distributed across all major sectors of economic activity. Around $82 \%$ of the surveyed companies are small, $15 \%$ are medium and $3 \%$ are large corporations.

In order to examine the influence of high educational institutions on innovations in companies, the analysis was restricted to units with observable turnover coming from innovations. Given the original CIS 2012 database, the selection of subjects 
that have reported certain turnover coming from new or significantly improved products or services resulted in a dataset of 194 companies.

The observed companies have used variety of information sources in order to obtain information and knowledge necessary for carrying out the innovation processes. The comparison of the responses of information sources that are internal, that originate from the market or that are sources related to educational and research institutes, demonstrate that the most important informative sources are the internal ones. This comparison also showed that the sources related to educational and research institutes are the least important for the companies. However, if we analyse the number of companies that marked each of these information sources as important for the innovation processes, we can notice relatively high shares for each of these channels. Figure 1 presents the percentage of companies that have assessed each of the information channels from the educational and research institutes as significant for innovation. Conferences, fairs and exhibitions are important channels for information, used by $80 \%$ of the innovative companies. Also, scientific literature and technical journals are reported as significant sources for information by almost $78 \%$ of the companies.

Partnerships between industrial and high-educational sector are considered as crucial factor for boosting the innovativeness and increasing the commercialization of innovations. Therefore, this survey investigates the types of institutions that collaborate with the private sector for researching and developing innovations.

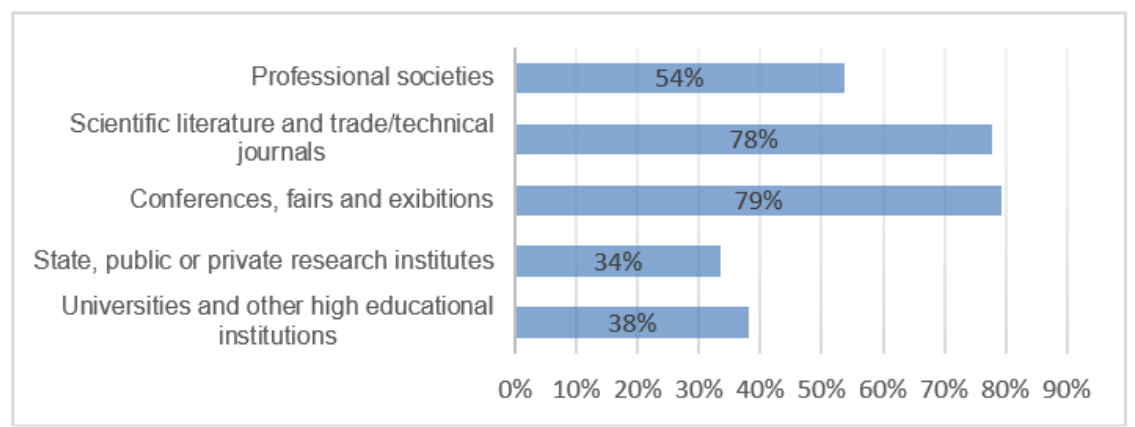

Figure 1. Information sources and collaboration for innovation

The respondents selected the most useful partnerships for innovation from the list of state, public and private units (Figure 2). The partnerships with the private sector (other firms, suppliers and clients) are pointed out as the most useful for innovation by the greatest percentage of the firms. The partnerships with universities or other high educational institutions are reported as the most useful for innovations by $3 \%$ of the companies. From the reported partnerships with high educational institutions, around 29 are with Macedonian universities (15\% of the surveyed companies), while 5 are with the universities based in other European countries (3\%), and additionally almost the same amount of respondents have 
reported cooperation with state, public or private research centres. As expected the main partners for open innovation are the suppliers of equipment, materials, components or software (28\% of surveyed companies have stated that they have cooperated with such partner from Macedonia and 18\% with such European partner) and clients or users from the private sector (25\% cooperated with Macedonian and 10\% with European partner) (Figure 3).

These results show that, most of the Macedonian companies that are part of a group of companies mainly rely on other companies in the group for development and introduction of innovation. Other companies are focused mainly on the support of the other entities in their supply chain.

On the other hand, the universities and other high educational institutions, although are very important for intensifying the innovation processes in the private sector in Macedonia, they still do not play important role in the innovation ecosystem. Both Macedonian society and the relevant governmental and private sector bodies responsible for the inter-sector collaboration should put more attention on promoting and stimulating the collaboration. In this way, mutual benefits for both sectors, as well as benefits for the national economy will be created.

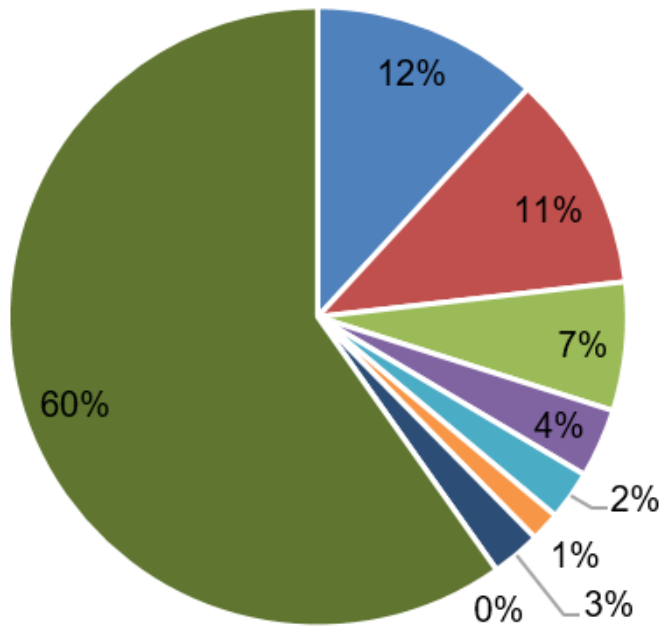

Figure 2. The most useful partnerships for innovation
- Other firms from your enterpsise groupation

- Suppliers of equipment, materials, components or software

Clients or users from the private sector

- Clients or users from the public sector

- Competition or other firms from your area

- Consultants or commercial labs

- Univerisities or other high educational institutions

- State, public or private research centres

- Have not responded 


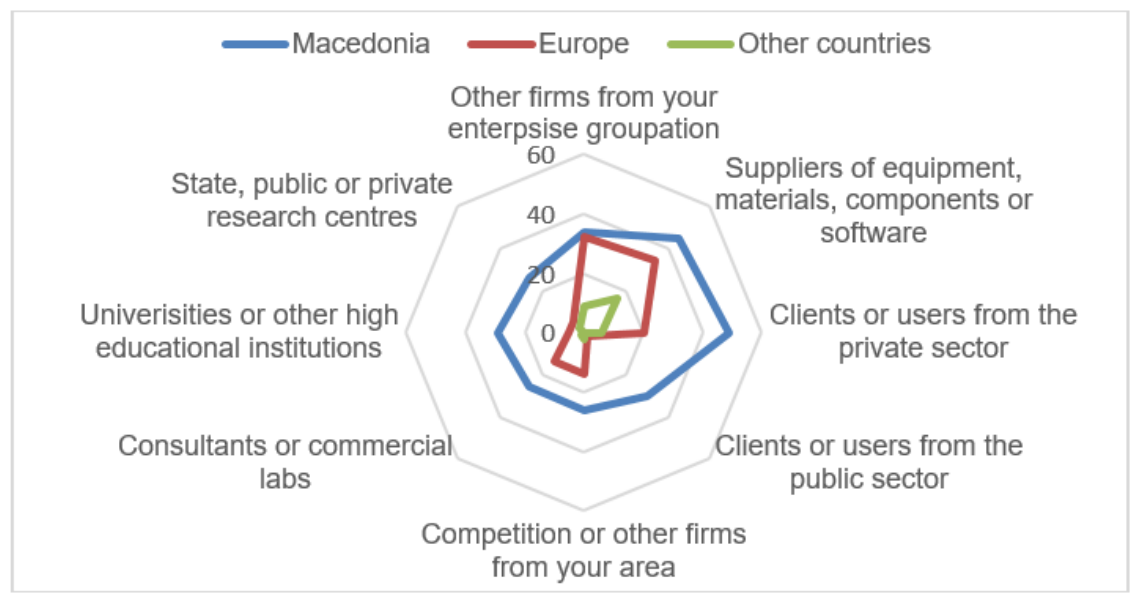

Figure 3. Cooperation partners by countries

The importance of innovation for the growth of the private sector is widely acknowledged. However, private sector, consisting mainly of small and medium enterprises, does not have sufficient resources to carry out research and development of innovation by itself. Instead, private entities should be focused on collaboration and partnering for innovation among themselves and with other organisations from the innovation ecosystems. In addition, the innovative and knowledge-intensive activities are essential not only for the private sector, but also for the overall development of modern, knowledge-based economies.

The survey CIS 2012 conducted in Macedonia indicated that Macedonian universities still have marginalised role in the innovation ecosystem. The information and knowledge sources that originate from universities are less popular than the internal and market channels. Also, the partnerships with private sector are assessed more useful for innovation than the partnerships with the universities. With respect to the contribution that universities can provide through the public-private partnerships, the governmental and private-sector bodies in charge should put more effort to stimulate the collaboration between the public and private sector.

According to the findings of this paper, it can be concluded that the collaboration between the private sector and the knowledge providers, primarily universities in Macedonia, should be further enhanced and intensified. For this to be achieved the engagement of the stakeholders, the private sector (directly and through business associations) and the universities is not enough. The government support through cooperation infrastructure and funds is crucial for rebuilding the bridges between these actors. This collaboration is expected to influence the enhancement of the 
innovation capacities and increase the development of innovation and their commercialization.

\section{References}

[1] Cohen, W.M, Nelson, R.R., Walsh, J.P. (2002), "Links and Impacts: The Influence of Public Research on Industrial R\&D”, Management Science, 48(1):1-23.

[2] David, P.A., Mowery, D., Steinmueller, W.E. (1992), "Analysing the Economic Payoffs from Basic Research", Economics of Innovation and New Technology, 2:7390.

[3] Belderbos, R., Carree, M., Lokshin, B. (2004), "Cooperative R\&D and Firm Performance", Research Policy, 33(10):1477-1492.

[4] Chesbrough, H.W. (2003), Open innovation: The new imperative for creating and profiting from technology, Boston: Harvard Business School Press.

[5] Teece, D.J. (1986), "Profiting from technological innovation: Implications for integration, collaboration, licensing and public policy", Research Policy, 15:285-305.

[6] Rosenberg, N. and Frischtak, C. (1985) International technology transfer: concepts, measures, and comparisons. Praeger Special Studies.

[7] Keeble and Wilkinson 1999 Collective Learning and Knowledge Development in the Evolution of Regional Clusters of High Technology SMEs in Europe. Regional Studies, 33(4): 295-303.

[8] Kiper, M. (2012), “Technology Transfer and the Knowledge Economy”, In: Yulek, M.A., Taylor, T.K. (eds.), Designing Public Procurement Policy in Developing Countries, Springer, pp: 91-110. 


\title{
Chapter 12
}

\section{Assessment of Alternatives for Natural Gas Supply in Macedonia versus Technical Indicators}

\author{
DANIEla MladenOVSKa \& Atanas Kochov
}

\begin{abstract}
The biggest part of consumption is in the industry, while residential sector is facing a lot of obstacles in providing natural gas connection. One of the reasons is the availability, due to the fact that only two municipalities have distribution network. Having in consideration this fragile situation regarding gas infrastructure and gas consumption, as well as the fact that Macedonia hasn't domestic natural gas production, experts and decision makers in the country are aware for the need of urgent action. The main task of this chapter is to define relevant technical indicators significant for creating policies in natural gas supply chains in Macedonia, calculation of their weights and perform ranking of the supply options versus each of indicators.
\end{abstract}

Keywords: • natural gas $・$ supply chain $・$ policy $・$ technical indicators $\bullet$ Macedonia

Correspondence Adress: Daniela Mladenovska, Ph.D., JSC Macedonian Power Plants, Branch Energetika, 16 Makedonska brigada 18, 1000 Skopje, Republic of Macedonia, email: daniela.mladenovksa@elem.com.mkm. Atanas Kochov, Ph.D., Full Professor, „Ss. Cyril and Methodius" University in Skopje, Faculty of Mechanical Engineering-Skopje, Rudger Boshkovikj bb, Skopje 1000, Republic of Macedonia, e-mail: atanas.kochov@mf.edu.mk.

https://doi.org/10.18690/978-961-286-028-8.12 ISBN 978-961-286-028-8

(C) 2017 University of Maribor Press

Available at: http://press.um.si. 
Since 1997, when Macedonia started to use natural gas, the progress in developing of gas infrastructure and increasing the consumption is negligible. The biggest part of consumption is in the industry, while residential sector is facing a lot of obstacles in providing natural gas connection. One of the reasons is the availability, due to the fact that only two municipalities have distribution network. Having in consideration this fragile situation regarding gas infrastructure and gas consumption, as well as the fact that Macedonia hasn't domestic natural gas production (gas supply is fully sourced from Russia), both experts and decision makers in the country are aware for the need of urgent action Developing a concept for diversification in natural gas supply in the country is among the highest priorities among the decision makers and policy makers. Several potential supply options or possibilities are described into this paper, with corresponding technical indicators for assessment [1]. Security and diversification of natural gas supply became even more important due to the three established objectives of the European Union (EU)'s energy policy - security, sustainability and competitiveness. In line with these efforts of the EU, in July 2015 in Dubrovnik, is signed a memorandum of understanding on a joint approach to address the natural gas diversification as a part of the Central and South-Eastern European Gas Connectivity (CESEC) initiative. Macedonia participated in this initiative, whose main objective is commitment of the parties (countries) for providing gas supply from at least three independent sources [2]. The main task of this paper is to define relevant technical indicators significant for creating policies in natural gas supply chains in Macedonia, calculation of their weights and perform ranking of the supply options versus each of indicators.

\section{Problem definition and hierarchy}

The basic dimension of energy supply sustainability in general considers environmental, social and economic aspects. But, there are studies found in the literature that includes technical aspects in sustainable energy planning. Hence, in this paper the focus is exactly on technical indicators. As it was mentioned before, there are numerous such examples in sustainable energy resources management literature. Wang et al. (2006) [3], and. Afgan et al. (2007) [4], use this classification for evaluating the potential of natural gas usage in the energy sector. Demirtas (2013) [5], uses technical indicators in evaluating the best renewable technology for sustainable energy planning. Defined technical indicators relevant for Macedonian case, which are subject of this analysis are presented on Fig.1. Identified technical indicators are divided into two main groups: security of supply and supply possibilities [1].

Security of supply has significant importance for several specific markets. Usually these are markets for food, water and energy. There are several reasons justifying the importance of security of supply for natural gas markets. This question has been 
elaborated in the literature (Bielecki (2002) [6] and Salameh (2003) [7]. Among the main issues that amplify the importance of natural gas security of supply are the following: natural gas supply is more vulnerable compared to supply with other commodities, and the consequences from supply interruptions are more serious. In general, energy security concept has been elaborated in different aspects, but the truth is that there is no universal definition. On Fig. 1 are presented six options supply possibilities, actually presenting in the same time alternatives into the created model for multi-criteria decision making (MCDM).

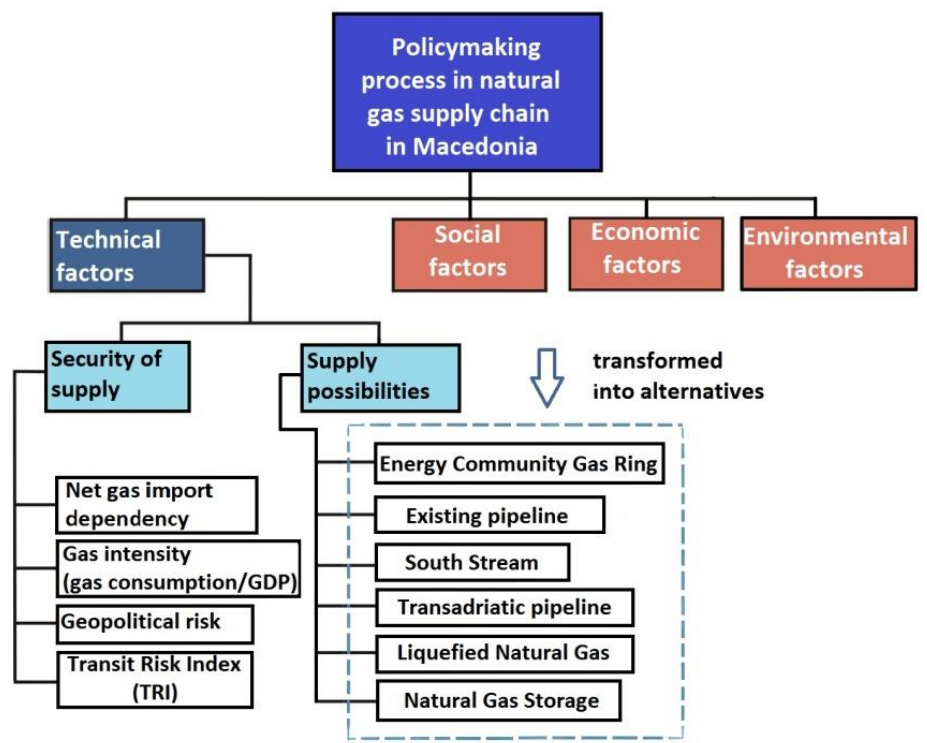

Figure 1.Problem hierarchy

Geopolitical risk as an indicator was elaborated by Cabalu and Alfonso (2010) [8], while Transit Risk Index (TRI) is introduced by Le Coq and Paltseva (2011) [9],. Thomaidis (2007) [10], uses MCDM for selection of optimal gas pipeline routes which are of interests for South Eastern Europe.

\section{Description of used methodology}

MCDM is a process for evaluating real world situations, based on various qualitative or quantitative criteria in different environments to suggest a suitable course of choice or policy among the available options [11]. As a key elements in MCDM process appear indicators and alternatives. There are different MCDM techniques. Analytical Hierarchy Process (AHP) is one of them, which is used in this survey. 


\section{A. Indicators Definition}

Indicators basically are defined as information tools. Indicators summarize the data for complex and often conflicting problems, with objective to determine the actual condition, as well as to create a forecast for future trends. In the context of the policy making processes, indicators represent key signals for necessary legislation improvements. [12].

\section{B. Alternatives Definition}

The alternatives represent the decision maker's possible choices. When the alternatives are to be constructed, the starting point is usually a small number of ideas from the (pool_of) decision maker(s). These ideas must then be enriched to arrive at a respectable choice set. This enrichment is twofold: firstly, the choice must be enlarged, and secondly each alternative must be clothed with information [13].

\section{Analytical Hierarchy Process (AHP)}

Analytic Hierarchy Process (AHP) is a technique utilized by the MCDM methodology based on priority theory. It deals with complex problems which involve consideration of multiple criteria and alternatives simultaneously. The methodology is convenient for breaking down a complex, unstructured situation into its component parts, then arranging these parts into a hierarchic order (criteria, subcriteria, indicators) and assigning numerical values from 1 to 9 to subjective judgments on the relative importance of each criterion/indicator using pair-wise comparison [11]. Saaty suggests that hierarchies are to be limited to six levels and nine items per level. This is based on the psychological result that people can consider 7+/-2 items simultaneously (Miller, 1956) [14].

To retrieve the resulting weights of the criteria (indicators), the normalized principle eigenvector is computed. It corresponds to the vector of weights. In addition, AHP provides a measure of the evaluator's inconsistency. It is based on the fact that the participants perform pair-wise comparisons in a circle. They compare criterion A with B, B with C, but also C with A. Building on this information, Saaty (1980) [15], uses the largest eigenvalue $\lambda_{\max }$, to define a consistency index CI defined by the following expression:

$$
C I=\frac{\lambda_{\max }-N}{N-1}
$$

where $\mathrm{N}$ is the number of criteria. The consistency index is divided by the random index of the order of the matrix considered to compute the final inconsistency 
measure referred to as consistency ratio. A consistency ratio of 0.1 or less is considered acceptable [16].

\section{Survey elaboration, results and discussion}

\section{Weights Calculation}

For determining corresponding weights for the selected set of indicators, (pool of) experts and stakeholders is selected and questionnaire is distributed among them. Total number of consulted experts and stakeholders is 34. As it was already explained, the AHP is utilised to calculate weights. A decision making software was utilized to calculate indicators' weights per participant, and to aggregate weights from all participants. Inconsistency check has been performed to exclude or correct inconsistent answers obtained by the experts. [17]. The values of indicator's weights are presented on Fig. 2.

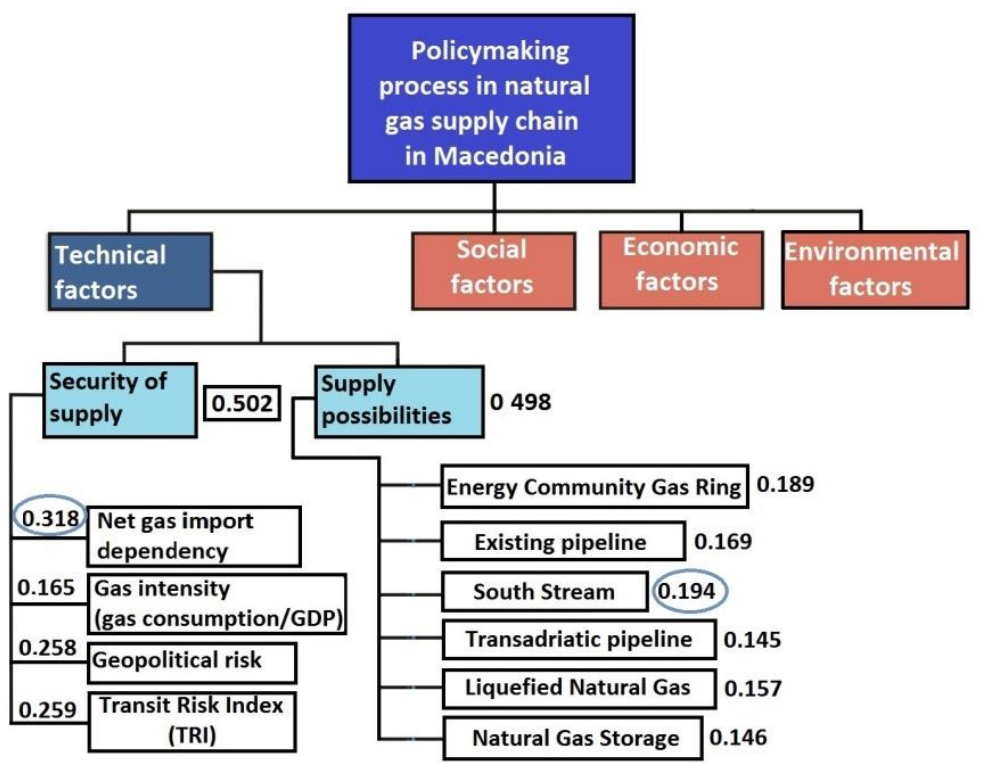

Figure 2. Values of calculated indicators weights

\section{E. Selection of the Alternatives (Supply Options)}

The objective mapping from the attribute set, in particular the category "supply possibilities", into the alternatives set results in defining the alternatives relevant for this case study [18].Considering the geographic location, geostrategic position, capacities and availability of existing and potential natural gas projects in the 
region, herein the following supply options are identified as relevant alternatives [19], [20].

- A1: Existing pipeline (business as usual (BaU) scenario);

- A2: South Stream (concerning Turkish stream as its alternative);

- A3: Transadriatic pipeline (TAP);

- A4: Energy Community (EC) Gas Ring;

- A5: Liquiefied Natural Gas (LNG); and

- A6: Natural Gas storage.

Hence, after the selection of alternatives, remains only 4 indicators grouped into "security of supply" set. (Fig.1 and Fig 2.)

\section{F. Assessment and Ranking of the Alternatives}

A decision making software was utilized to calculate final ranking of the selected alternatives versus the 4 analyzed indicators describing security of supply (Fig.1 and Fig.2), in accordance to data in relevant literature. Following ratings were used: 3 for low, 7 for medium and 10 for best rank. The results from the assessment are presented in Table 1.

Table 1. Assessment of the Alternatives versus Security of Supply Indicator|
\begin{tabular}{|l|l|l|l|l|l|l|}
\hline Indicators & \multicolumn{7}{|c|}{ Alternatives } \\
\cline { 2 - 8 } & $\mathbf{A 1}$ & $\mathbf{A 2}$ & $\mathbf{A 3}$ & $\mathbf{A 4}$ & $\mathbf{A 5}$ & $\mathbf{A 6}$ \\
\hline $\begin{array}{l}\text { 1.Net gas import } \\
\text { dependency }\end{array}$ & 3 & 3 & 3 & 3 & 3 & 3 \\
\hline 2.Gas intensity & 3 & 3 & 3 & 3 & 3 & 3 \\
\hline 3.Geopolitical risk & 3 & 3 & 7 & 7 & 10 & 7 \\
\hline $\begin{array}{l}\text { 4.Transit Risk } \\
\text { index (TRI) }\end{array}$ & 3 & 3 & 7 & 10 & 10 & 7 \\
\hline
\end{tabular}

Regarding Net gas import dependency (indicator 1) all option are ranked low, because Macedonia is 100\% importer of gas and none of the alternatives contributes to changing this status. With respect to Gas intensity (indicator 2) all alternatives are ranked low, because consumption of natural gas in the country is low, and there are other mainly economic indicators that will contributes in Gas intensity increasing In terms of Geopolitical risk (indicator 3) LNG is ranked best because it offers numerous possibilities for diversification [21]. From the TRI point of view, EC Gas Ring and LNG are ranked high, while South Stream and $\mathrm{BaU}$ have low rating due to the numerous transiting countries and their geopolitics [9]. Finally, the ranking of the alternatives as a result of assessment versus security of supply indicators, is presented on Fig.3. 


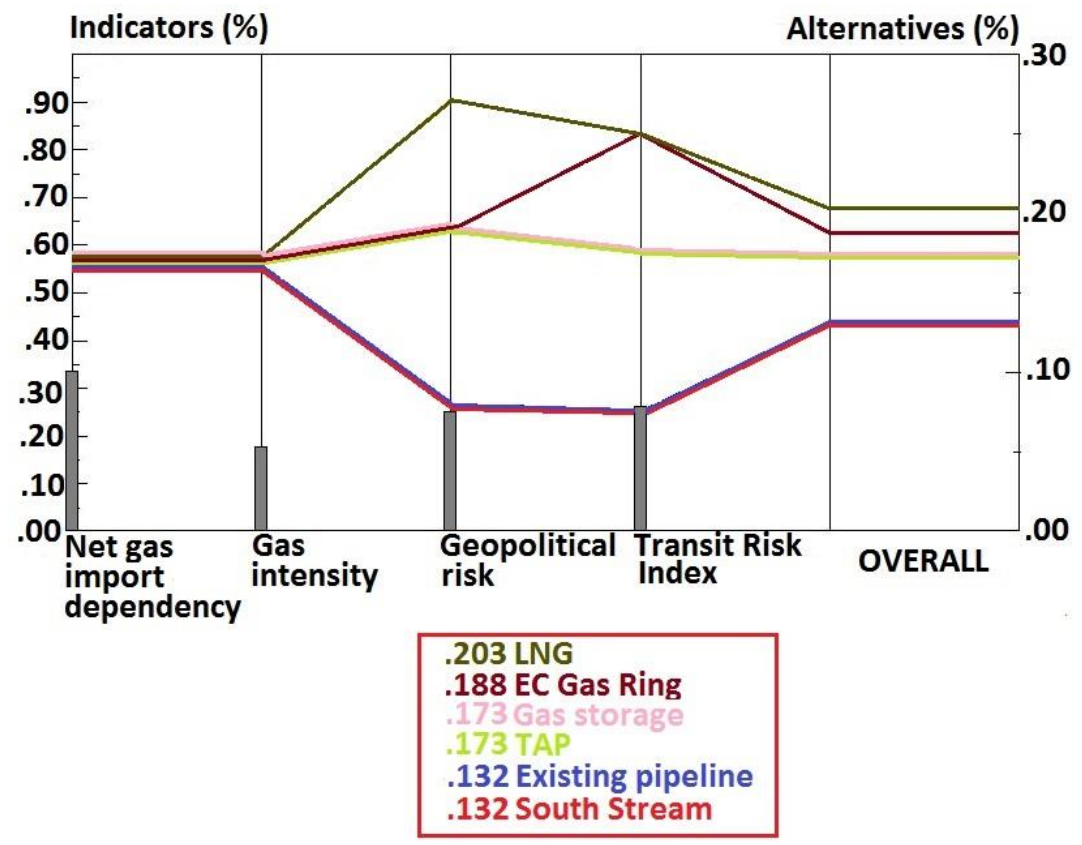

Figure 3. Ranking of the alternatives versus corresponding weighted indicators

\section{G Discussion of the Results}

The results presented on Fig.2, indicates that security of supply prevails over supply possibilities set of indicators, although the difference is almost negligible. Net gas import dependency is more important indicator in terms of security of supply. It is expected, mostly due to the fact that Macedonia is fully supplied by import (100\%). Geopolitical risk and TRI have almost the same values. The both indicators are influenced by many transiting countries and their geopolitics. In terms of Gas intensity which has the lowest weighting factor value, it can be emphasized that Macedonian industry is quite energy intensive, but has low value for gas intensity.

The results from the supply possibilities options preferences, obtained by pool of experts using a pairwise comparison questionnaire, at first, point out that South Stream is the best option. EC Gas Ring is ranked as second. Both concepts are totally different in terms of providing diversification. While EC Gas Ring as a regional project will include wider diversification and will improve supply security, South Stream not contributes at all for diversification. BaU i.e Existing pipeline is on the third place, which implies that "status-quo" option is a choice for significant number of participants in the survey. TAP is the last ranked option, despite the fact that it offers diversification and shorter transit route compared to 
South Stream and Existing pipeline. One of the reasons for the highest ranking of South Stream might be Government commitment for participation in this project by signing an agreement with the Russian Federation [22], as well as intense coverage of this project in the national media. That situation for sure affects public and experts opinion.

Regarding the second part of the survey, i.e assessment of alternatives versus security of supply (technical) indicators, the ranking clearly shows that advantage is given to the more flexible options and to options providing diversification of natural gas supply. LNG is first ranked, and has the highest importance in terms of geopolitical risk. EC Gas Ring is on a second place, as project that holds a potential to cause serious regional impact and, as well, could enable significant price-competition due to diversification of supply. LNG has the best ranking versus TRI, assuming that the regional cooperation will prevail over the barriers and obstacles. TAP prevails over the South Stream project, also due to the advantage of geopolitical risk. It is important to emphasize that TAP facilitates decreasing the country's $100 \%$ dependency on Russian gas. South Stream and Existing pipeline have the equal lowest ranking, mostly due to the lowest assessment versus geopolitical risk and TRI. In the both cases it is a question of increased dependency from one source of supply (Russian gas), and long pipelines crossing several countries, thus affecting TRI and geopolitical risk.

\section{$5 \quad$ Conclusion}

The herein presented paper offers an interesting point of view with respect to identify and assessed a technical group of indicators for natural gas supply chain policy making in Macedonia, and a set of scenarios (alternatives) for natural gas supply in the country. The paper describe two cases of alternatives assessment: firstly based on the stakeholders' preferences and opinions trough simple pairwise comparison of the alternatives, and second by their assessment versus technical indicators (4 security of supply indicators). The analyses of the results shows certain similarities but also some major discrepancies.

With respect to overall ranking in both cases, as per the herein conducted analysis, EC Gas Ring project was ranked second. The biggest discrepancy shows South Stream option. While it is first ranked due to the expert preferences among the alternatives, it finished last in the ranking versus the security of supply indicators. It is interesting to note that decision makers in Macedonia actually decided to engage in the South Stream project - at least at the time when it still represented a realistic option - while, no initiative existed to engage in the TAP project (last ranked due to the survey results). Similarly, for the time being, top level policy makers in Macedonia do not consider LNG as a serious option. It is ranked in the fourth place due to the expert preferences, while it is first ranked versus the 
security of supply indicators. Further analysis shall be necessary to investigate the reasons for these discrepancies.

Such results further indicate that in order to contribute towards higher objectivity and transparency when delivering decisions regarding energy advancements in a country, especially when gas supply and infrastructure are at stake, a thorough and multi-criteria approach is a solid base that facilitates preventing subjectivity among all concerned parties.

\section{LIST OF ABBREVIATIONS, ACRONYMS AND SYMBOLS}

$\begin{array}{ll}\text { AHP } & \text { Analytical Hierarchy process } \\ \text { EU } & \text { European Union } \\ \text { CESEC } & \text { Central and South }- \text { Eastern European Gas Connectivity } \\ \text { MCDM } & \text { Multi }- \text { criteria Decision Making } \\ \text { CI } & \text { Consistency Index } \\ \text { TRI } & \text { Transit Risk index } \\ \text { BaU } & \text { Business as Usual } \\ \text { TAP } & \text { Transadriatic pipeline } \\ \text { EC } & \text { Energy Community } \\ \text { LNG } & \text { Liquified Natural Gas }\end{array}$

\section{References}

[1] Mladenovska, D., Kochov, A. (2015). Identification of technical indicators for creating natural gas supply policies - Macedonian case, Proceedings of the Conference for International Energy and Environmental Protection in South Eastern Europe (IEPP).

[2] CESEC. (2015): https://ec.europa.eu/energy/sites/ener/files/documents/CESEC

[3] Wang, T-C., Liang, L-J., Ho. Ch-Y. (2006). Multi - criteria decision analysis by using fuzzy VIKOR, Proceedings of the International Conference on Service Systems and Service Management, vol. 2, pp. 901-906.

[4] Afgan, N. M., Pilavachi, P. A., Carvalho, M. G. (2007). Multicriteria Evaluation of Natural Gas Resources, Energy Policy, vol. 35, pp. 704-713.

[5] Demirtas, O. (2013). Evaluating the Best Renewable Energy Technology for Sustainable Energy Planning, International Journal of energy Economics and Policy, vol. 3, pp. 23-33.

[6] Bielecki, J. (2002). Energy Security:Is the wolf at the door?, The Quarterly Review of Economic and Finance, 42 (2).

[7] Salameh M. G. (2003). The New Frontiers of the United States Energy Security in the 21st century, Applied Energy, vol. 76 (1), pp. 135-144.

[8] Cabalu, H., Alfonso, C. (2010). Energy security in Asia: the Case of Natural Gas, Springer Verlag Berlin Heidelberg.

[9] Le Coq, C., Paltseva, E. (2011). Assessing Gas Transit Risks: Russia vs. the EU, Stockholm Institute of Transition Economics. 
Assessment of Alternatives for Natural Gas Supply in Macedonia versus Technical Indicators

[10] Thomaidis, F. (2007). Method for Route Selection of Transcontinental Gas Pipelines, PhD. thesis (in engish), National and Kapodistrian University of Athens.

[11] Kumar, D. N., Raju, R. K. (2010). Multicriterion Analysis in Engineering and Management, PHI Learning New Delhi.

[12] Birkmann, J. (2006). Measuring Vulnerability to Natural Hazards: Towards Disaster Resilent Societies, United Nation University Press.

[13] Pomerol, J. Ch., S.B. Romero, S. B. (2000). Multicriterion Decision in Management: Principles and Practice, Kluwer Academic Publishers.

[14] Miller, G. (1956). The magical number seven plus or minus two: some limitations on our capacity for processing information, The psychological review, vol. 68, pp. 81-97.

[15] Saaty, L. T. (1980). The Analytic Hierarchy Process, New York, McGraw-Hill.

[16] C. Sutter, C. (2003). Sustainability Check-up for CDM projects, How to assess the sustainability of international projects under the Kyoto Protocol, Swiss Federal institute of Technology

[17] Mladenovska, D., Lazarevska, A. M. (2015). Decision making concept for creating policies for natural gas supply chain in Macedonia, (accepted for publishing in the Proceedings of the Conference for Sustainable Development of Energy, Water and Environment Systems (SDEWES)).

[18] Mladenovska, D., Lazarevska, A. M. (2015). Multi-Criteria Assessment of Natural Gas Supply Options - the Macedonian Case, (accepted for publishing in the Proceedings of the Conference REMOO (Regional Energy Mix and Outlook Options).

[19] Macedonian Academy of Sciences and Arts (2010): Strategy for Energy Development in the Republic of Macedonia until 2030, Ministry of economy, Skopje, original in Macedonian language.

[20] Energosistem, Prostor, Gastek, Petrol, Hrvoje Požar (2010): Feasibility study for the gas distribution system in the Republic of Macedonia with a Preliminary project, Ministry for transport and communications, Skopje, original in Macedonian language.

[21] Van Der Linde C., al. (2004). Study on Energy Supply Security and Geopolitics, Final report, Clingendael Int. Energy Programme, The Hague, p.65.

[22] http://www.finance.gov.mk/en/node/3641. 


\title{
Chapter 13
}

\section{Nursing in Support to Maintain the Health of Machine Tool Operator}

\author{
PETRA KLANJŠEK \& JADRANKA STRIČEVIĆ
}

\begin{abstract}
It is important to ensure the correct posture and movement of an operator at CNC machine tool. The ourpose of this research is to present the commercial ergonomic assessment tools, physical consequences of the existing non-ergonomic wok environment on machine tool and machine tool operator posture. A systematic review was conducted. The milling machine operator during his work was observed. Systematic review indicate seven ergonomics tools for assessment of MSDs risks. The consequences of the operator standing position are: fatigue, pain, loses of energy, oedema, tissue hypoxia, lower labour productivity, increasing number of errors or accidents and permanent disability. With the principals of ergonomic, with the help of combined workplace and accessories we ensure the operator the correct posture in the sitting and standing position. By regular assessment of MSDs risks with ergonomics assessment of workplace and with ergonomics activities could provide the healthier and safer workplace.
\end{abstract}

Keywords: - combined working environment $-\mathrm{CNC}$ milling machine $\bullet$ operator posture/movement $\bullet$ assessment tools $\bullet$ health care

CORRESPONDENCE AdRess: Petra Klanjšek, Assistant, University of Maribor, Faculty of Health Sciences, Žitna ulica 15, 2000 Maribor, Slovenia, e-mail: petra.klanjsek@um.si. Jadranka Stričević, Ph.D., Associate Professor, University of Maribor, Faculty of Health Sciences, Žitna ulica 15, 2000 Maribor, Slovenia, e-mail: jadranka.stricevic@um.si.

https://doi.org/10.18690/978-961-286-028-8.13 ISBN 978-961-286-028-8

(C) 2017 University of Maribor Press

Available at: http://press.um.si. 
The purpose of this section is to present an ergonomic assessment tool, physical results of existent non-ergonomic working environment and the posture of worker which operate $\mathrm{CNC}$ tool machine. Further, the aim is to propose nursing support interventions on this kind of machines in order to reduce the level of risk of muscular-skeleton disorders (MSDs) for worker operating machine tool.

MSDs are injuries or dysfunctions affecting muscles, bones, nerves, tendons, ligaments, joints, cartilages, and spinal discs. MSDs include sprains, strains, tears, soreness, pain, carpal tunnel syndrome, hernias, and connective tissue injuries of the structures previously mentioned [1].

Reducing the prevalence of MSDs in machining today represents the main goal in developed countries [2]. According to international estimates $40 \%$ of all health care costs of working injuries are associated with MSDs. Spain pain represents the most common complication and the most expensive treatment [3]. Some European countries estimated the costs associated with back pain treatment in the amount of $1 \%$ of gross domestic product [4]. Punnett, Prüss-Ütün [5] reported that many of the factors that are important in MSDs aetiology are associated with the workplace and as much as $30 \%$ of all MSDs can be attributed to occupational exposures. The occupational physical ergonomic exposures associated with MSDs risk include awkward back postures [6], physical effort, including manual exertion related to handling objects or people [7] and exposure to whole body vibration [8].

The greatest burden of machine tool operator represent the lifting, carrying, lowering, pushing, pulling, positioning on fixture or machine tool table, clamping and unclamping the workpieces. The burden also represents the lifting, carrying, lowering, pushing, positioning, assembling, disassembling cutting tools on tool measuring machine, automatic tool store and tool magazine on machine tool. [9]. The above mentioned loads and corresponding movements perform machine tool operator most of his working time. It is noted that the planning of workstations in modern production systems are focused on quality of machined workpiece and not on the field of health [10] and safety Karwowski [11].

\section{$2 \quad$ Methods}

We conducted a systematic literature review of Ergonomic Assessment Tools and ergonomic right poise and movement of a worker operating the CNC milling machine tool. We have observed the milling machine operator during his work for 8 hours. Examination and analysis of the literature using the ScienceDirect and ProQuest Dissertation \& Theses, Scopus, Wiley Online Library and Google scholar databases was carried out. Search terms included key words for "Ergonomic Assessment Tools", "ergonomic right poise", "CNC lathe", "grinding machine", "milling machine" and "muscular skeletal disorders" and their 
equivalent to the Boolean operators AND and OR. Inclusion criteria for the selection of literature were: ergonomic right poise and movement of a milling machine operator and ergonomics assessment tools. The search was limited to articles, books and web pages, in the English language.

\section{$3 \quad$ Results}

The systematic review produced the following results.

\subsection{Contemporary environment}

Ergonomics assessment tools enable the assessment of occurrence risk for of the MSDs.

The Ergonomics assessment tools are used for:

- to identify the ergonomics risk factors for MSDs,

- $\quad$ to implement the measurable improvements in the workplace, ensuring that jobs and tasks are within workers' capabilities and limitations.

It is recommended that the ergonomics assessment of workplace is an on-going process of risk identification and reduction based on objective, scientific analysis of workplace [12].

The important Ergonomics assessment tools are:

NIOSH Lifting Equation; WISHA Lifting Calculator; Rapid Entire Body Assessment (REBA); Liberty Mutual Manual Material Handling Tables (Snook Tables); Rapid Upper Limb Assessment (RULA); Washington State Ergonomic and MSD Risk Assessment Checklist; [12] and software Ovako Working posture Assessment System (OWAS) [13].

\subsection{Physiological consequences of non-ergonomic working environment and machine tool operator posture}

It is found that the milling machine operator most of his working time (7.5 hours) work in standing posture. It is noticeable that during process of machining are present operator postures which causing fatigue [14]. It is also noticed the pain in legs and the lower part of the spine due to the ergonomic design disadvantages of milling machine and non-ergonomics operator work postures. At the same time at the standing posture the efficiency of mental work decreases. This consequently causes the tool operator loss of energy, low work productivity, increasing the number of errors and increasing the risk of accidents (eg. sprains) and permanent disability. [14, 15]. 
At standing post the machine tool operator performs many bends (the inclination angle of the spine $>15^{\circ}$ ), back flexion/extensions, back and head twisting, caring the weight on one leg, occasionally stretched hand posture, hands away from the body or lifting hands, holding the upper or lower limbs in an no physiological posture (performs activities at an inappropriate work surface height).
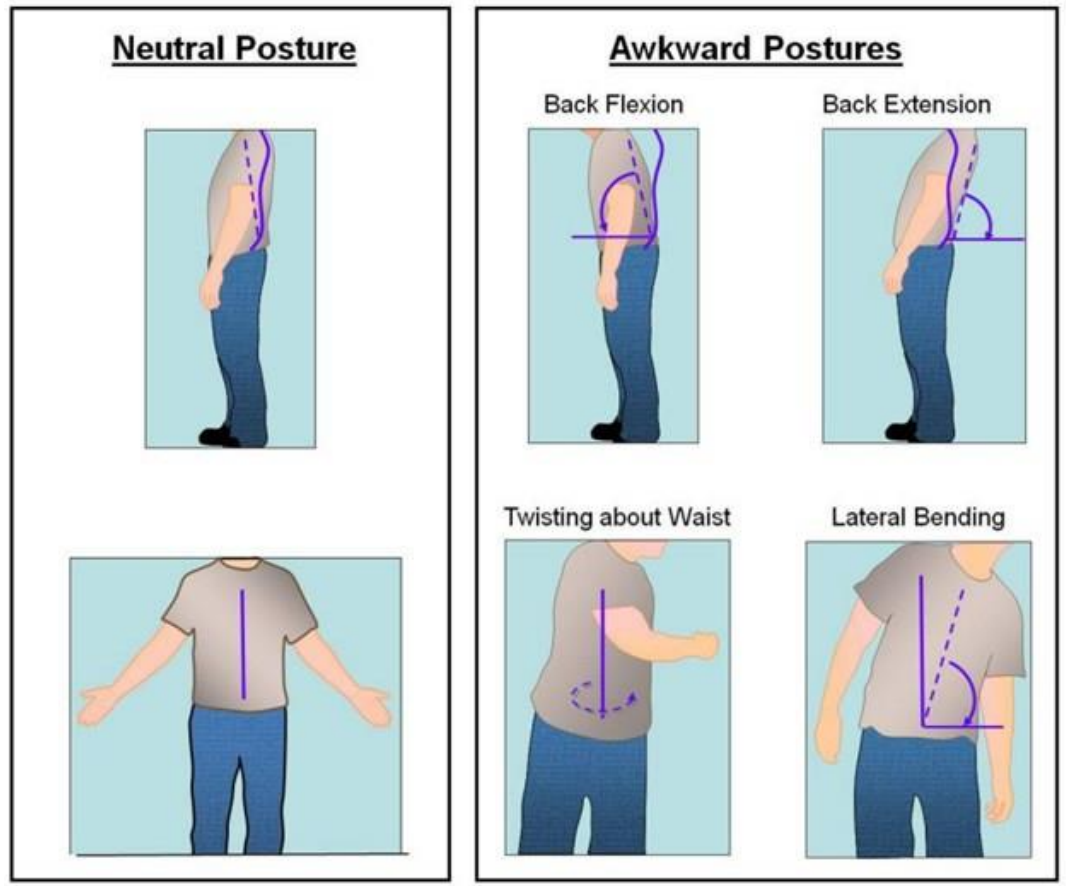

Figure 1. Neutral and awkward postures of the machine tool operator [16]

Head movement occurs simultaneously with movements of other parts of the body, such as the movements of legs, feet and hip, knee, ankle movements.

Repeatable inappropriate movements result in impairment of body structures such as tendons, muscles, joints, ligaments or nerves $[17,18]$.

The work in standing posture at the $\mathrm{CNC}$ milling machine is not appropriate when an operator changes a working posture dou to working operations (controlling machine tool, monitoring machining process, positioning/clamping workpiece in a fixture, etc.)

Due to distances between the control elements on control panels, the operator often performs inappropriate movements which cause him additional burdens. The results are overload, fatigue, impaired concentration and small number of high quality of manufactured workpieces. 
On the operator working posture influences the height of work surface (control panel of machine tool). Due to the improper height of control and monitoring surfaces, the operator performs operations in a bent posture. These are the reason for unnecessary and improper movements which lead to MSDs [14]. Therefore, it is necessary for milling machine operator that restricts or replaces the unnecessary and improper movements with correct and effective ones. Maldonado-Macias, Ramírez [19] in their study with REBA method found that machine tool operators have frequent and moderate pain in the shoulders and lower back and the unbearable pain in the area of the central part of the back, hands and arms. These are the consequences of incorrect movements of the elbow (figure 2) and the shoulder (figure 3) [16].

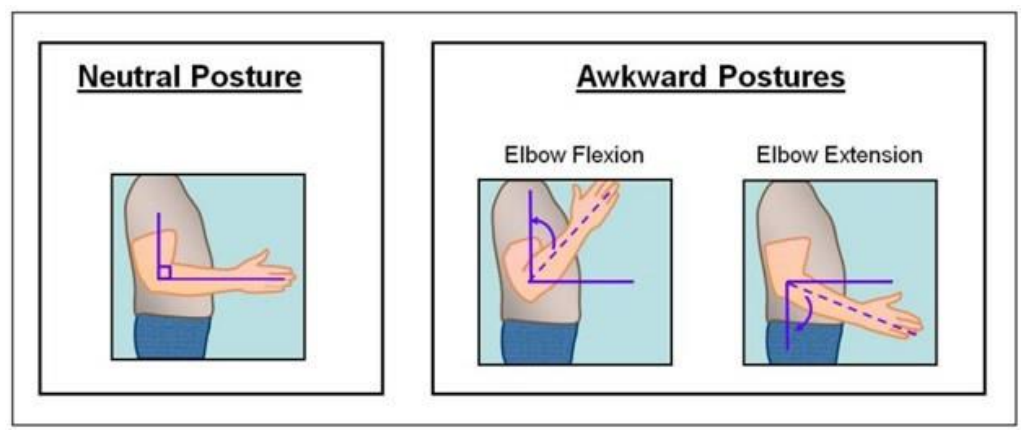

Figure 2. Neutral and awkward elbow postures beside the machine tool [16]

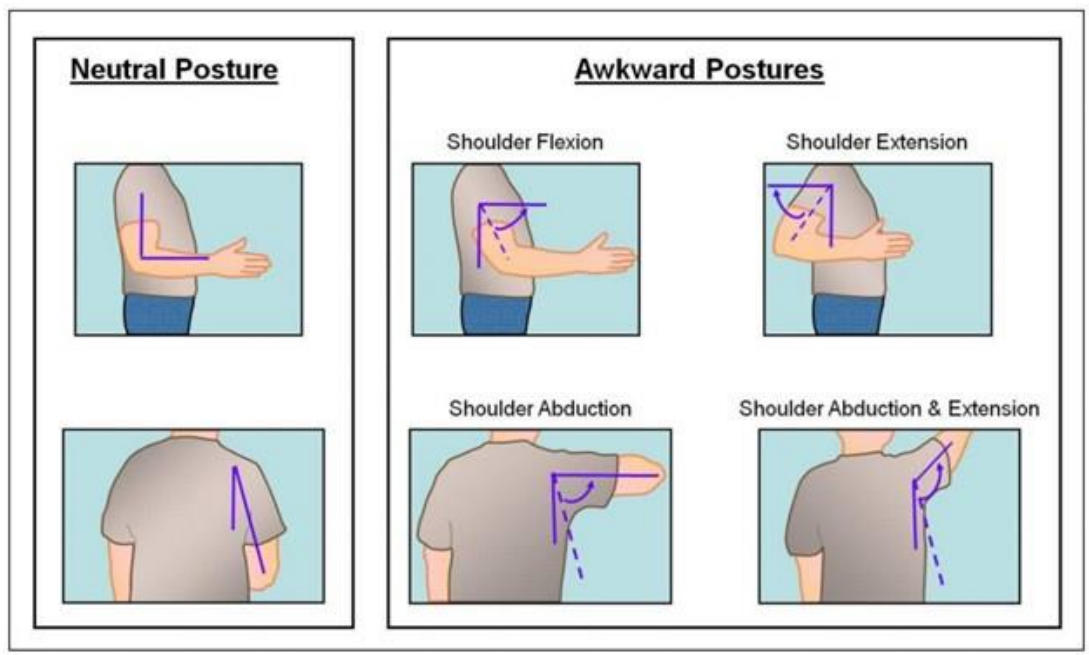

Figure 3. Neutral and awkward shoulder postures [16]

These pain was also identified by Maldonado-Macias, Ramírez [19] when observing machine tool operator during his work. 
Vieira and Kumar [20] reported that milling machine operator feels pain in the lower part of the back. Also, rigid posture impedes muscle pump function in the lower extremities [18]. This results in oedema of the ankles and local tissue hypoxia [17]. Abdillah [9] in his paper states that there is $52 \%$ of MSDs injuries during lifting, $13 \%$ during pushing or pulling, $10 \%$ during carrying loads and 13 $\%$ during repeated body movements.

Poor ergonomics of the work environments leads the operator in mental and physical fatigue, consequently he does not perform his work efficiently and safe (operator does not clamped the workpiece correctly, it does not identify excessive toll wear or tool brakeage).

Ergonomics activities will not only improve the workplace but also creates safer and healthier working environment. As result, the operator's productivity is increased from $60 \%$ to $86 \%$. Quality of work increases for $40 \%$ and decreases absenteeism for $50-70 \%$ [21, 22].

\subsection{Workplace design recommendations}

In designing the workplace the attention is devoting to the safe worker movement (See, figure 6). By effective ergonomically designed accessories, appropriate protection equipment and instructions the number of accidents or injuries at work is successfully reduced.

All of these ensure safe work on machine tool and movement in its surroundings [16].

From psychological point of view is suggested that machine tool operator can chose between standing and seating working posture (combined working environment). The working position should contain both seating and standing position.

The operator should maintain proper posture so that the work is carried out as close as working surface, maintain the physiological curvature of the spine at the correct leg movements. In this way, the worker reduces pressure on ligaments, joint muscles and intervertebral disks in the spine.

Maldonado-Macias, Ramírez [19] recommended that the control panel should have an extension and should be adjustable in height. Thus the operator does not need to perform unnecessary and improper turning of torso and lifting hands.

Under the measuring machine table should be enough space for non-crossed knee. We must provide sufficient space for the feet (at least $20 \mathrm{~cm}$ in hight and $15 \mathrm{~cm}$ in length) so that the operator should stand at the machine. 
Under the foot it is advisable to install Anti-fatique Mats (Element 3 In Figure 5). Anti-fatique Mats reduces burden and fatigue at the lower part of the foot area, pain in the claves, legs and spinal muscle fatigue [23].

It is necessary to provide the backrest for the foot for the operator, who most of the time works in standing position (Element 2, Figure 5).

Back rest of the foot enables the operator to reduce pressure on the lower back and change the position and occasional movements that changing the pressure in legs and the back $[16,24]$.

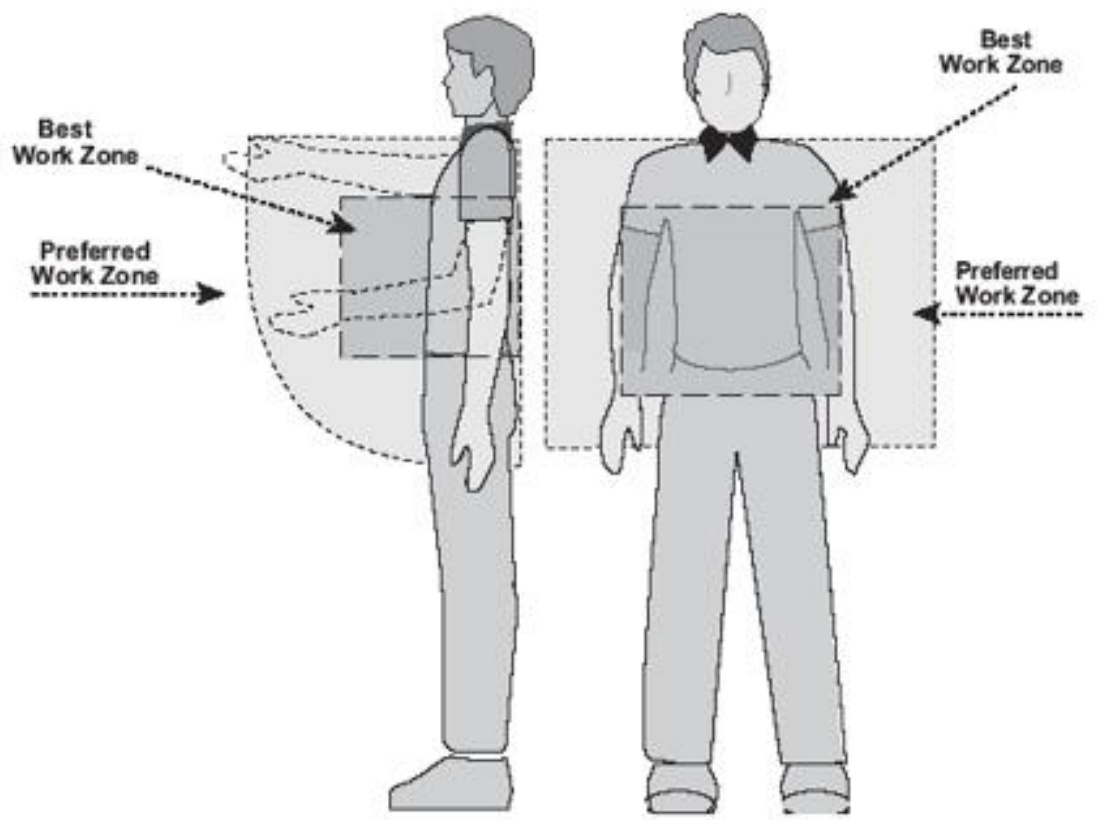

Figure 4. Hands below the shoulders [25]

When it is possible, the manual handling of loads (workpieces and cutting tools) should be replaced by mechanical accessories (lifts, mini loader) (Element 7 , Figure 5). Operator controlling tje machine tool should have arms below the shoulder level (Figure 5). 
Nursing in Support to Maintain the Health of Machine Tool Operator
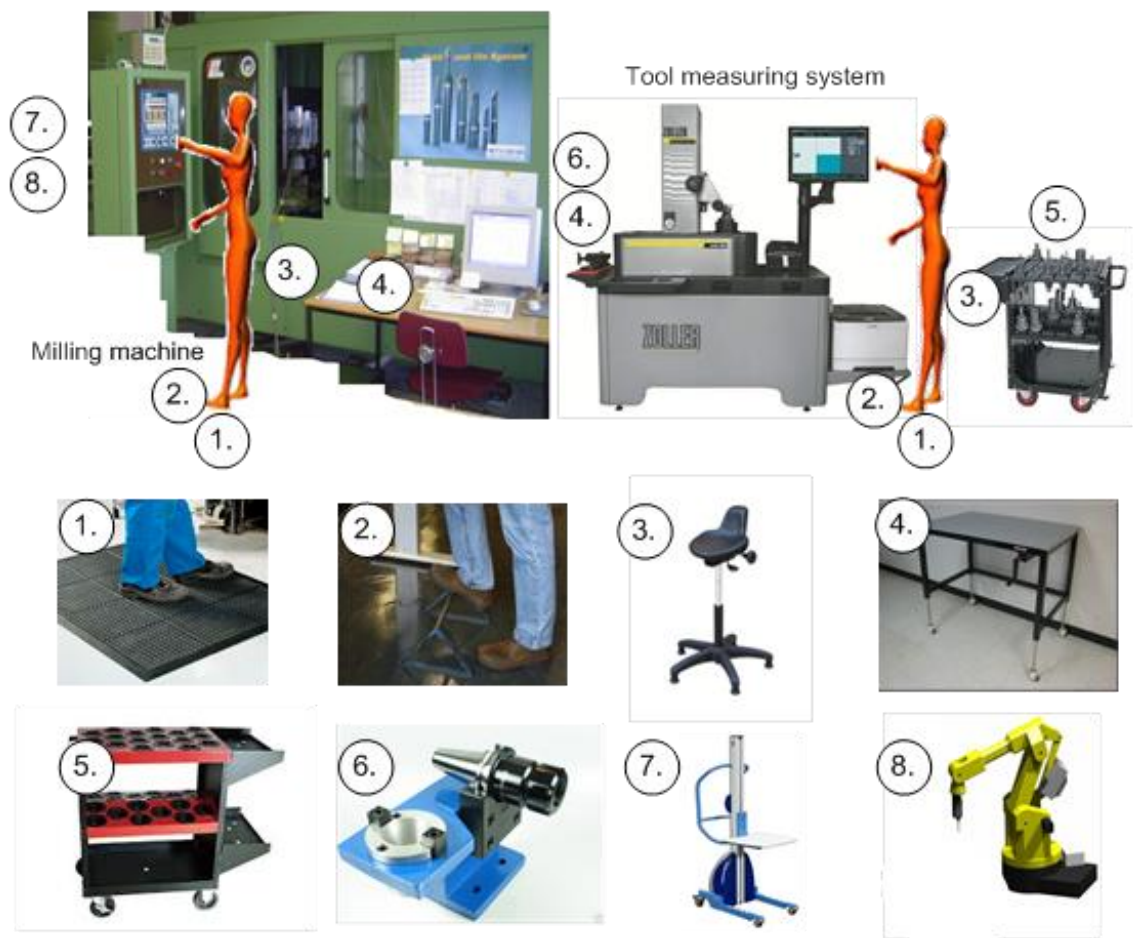

Figure 5. Ergonomic combined position of the operator and the new layout of accessories on milling and measuring machine

The work under the shoulder level must be time limited, additional breaks are needed. The combined work place should be designed in a such way, tha the work surfaces height are adjusted to the sitting and standing position posture.

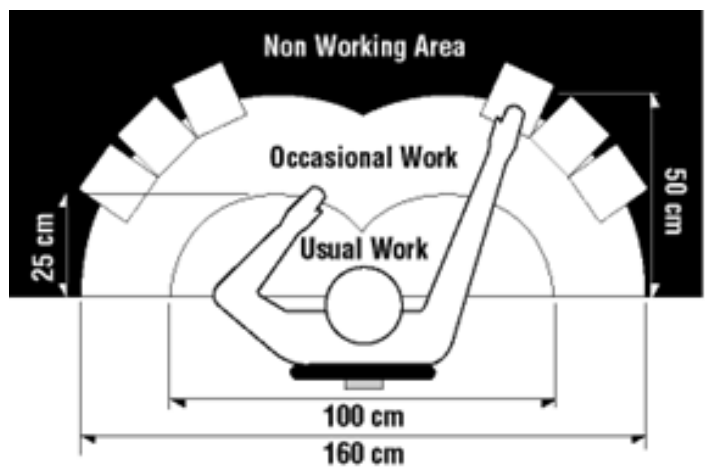

Figure 6. Working surface and positioning objects within easy reach [26]

The working operations should be designed so that the majority of work should be performed in sitting posture. 
If this is not possible, the worker should be allowed to sit occasionally. In sitting position the operator should perform operations which do not require large forces and long movements of hands. In sitting posture the energetic consumption is lower, the hydrostatic pressure is easier to handle, more suitable for precise work with hands in comparison with standing posture.

The worker in combined working environment can change poster positions and therefore prevents static loads. It is recommended to use a chair which allows a sitting-standing posture. Such a chair must be properly ergonomicaly designed and dimensioned according to the size of machine. It should promote changing posture of operator (Element 3, Figure 6). The seat height from the ground should be a little smaller than the popliteal height, the seat angle should have inclination. it is recommended the height adjustable chair with a back rest which allows the worker to lean against and thus relive the leg.

In combined workplace the working objects should be located so that the worker can reach them without significant straining (Figure 6) [26].

In case, when operator needs additional accessories (tools, measuring equipment, documentation, clamping/positioning elements, etc.) it is necessary to insure additional work surface, which is adjustable in height. This surface has to be in reach of hands and should be on wheels (Element 4 and 5, Figure 6). Bilban [27] states, that the working surface is the height of product (assembled tool or workpiece clamped on fixture) and not the height of table. Therefore the height of the table is accordingly lower. Distance of working objects or accessories on the working surface should be such that worker should see them without head and body movements. The working accessories should be placed in the form of half circle and within field of view of 800 in all directions (Figure 6). Thus the worker will not unnecessarily burden hands, shoulders and back and consequently worker fatigue will be reduced and the work will be done with greater precision.

\section{Discussion}

Literature review indicate the following ergonomics tools: NIOSH Lifting Equation; WISHA Lifting Calculator; Rapid Entire Body Assessment (REBA); Liberty Mutual Manual Material Handling Tables (Snook Tables); Rapid Upper Limb Assessment (RULA); Washington State Ergonomic and MSD Risk Assessment Checklist; and OWAS [12, 13].

We recommend that those tools should be used frequently to assess the risk of MSD on machine tool operator work stations. Thus the timely ergonomics improvements of work place should be implemented and thus the MSD should be prevented. The consequences of improper postures, unnecessary and incorrect body movements and stresses of worker, who operate machine tools, are presented. 
The consequences of the operator standing position are: the mental and physical fatigue [14], pain in the lower spine, the decline in efficiency of mental work, loss of energy [15], oedema of the ankles, tissue hypoxia [17], lower labour productivity, increasing number of errors, a greater possibility of occurrence of accidents and permanent disability [15]. The standing posture on milling machine is not appropriate when the worker often changes working posture due to working operations.

We have found that with the principals of ergonomic (replace incorrect and necessary movement with the correct and effective ones), with the help of combined workplace (by using ergonomics chair) and accessories (anti-fatigue mats, height adjustable worktables, the backrest legs, mini loader) we ensure the operator the correct posture in the sitting and standing position.

\section{Conclusion}

By regular assessment of MSDs risks with ergonomics assessment of workplace and with nursing support activities (adaptation of machine tool operator posture) does not only enable improvement of workplace but create a safer and healthier working environment.

\section{References}

[1] B.R. da Costa, E.R. Vieira: Risk factors for work-related musculoskeletal disorders: a systematic review of recent longitudinal studies, American journal of industrial medicine. Vol. 53(3), pp. 285-323, 2010.

[2] T. Jafry, D.H. O'Neill: The application of ergonomics in rural development: a review, Applied ergonomics, Vol. 31(3), pp. 263-268, 2000

[3] W.C. Whiting, F. Ronald, R.F. Zernicke: Biomechanics of Musculoskeletal Injury ( $2^{\text {nd }}$ ed.). Champaign: Human Kinetics; 2008.

[4] E.K. Hansson, T.H. Hansson: The costs for persons sick-listed more than one month because of low back or neck problems. A two-year prospective study of Swedish patients. European spine journal, Vol. 14(4), pp. 337-345, 2005.

[5] L. Punnett, A. Prüss-Ütün, D.I. Nelson, M.A. Fingerhut, J. Leigh, S. Tak, et al.: Estimating the global burden of low back pain attributable to combined occupational exposures, American journal of industrial medicine, Vol. 48(6), pp. 459-469, 2005.

[6] J. Jansen, H. Morgenstern, A. Burdorf: Dose-response relations between occupational exposures to physical and psychosocial factors and the risk of low back pain, Occupational and Environmental Medicine, Vol. 61(12), pp. 972-979, 2004.

[7] Y. Bing Yip: A study of work stress, patient handling activities and the risk of low back pain among nurses in Hong Kong, Journal of advanced nursing, Vol. 36(6), pp. 794-804, 2001.

[8] O.O. Okunribido, M. Magnusson, M.H. Pope: The role of whole body vibration, posture and manual materials handling as risk factors for low back pain in occupational drivers, Ergonomics, Vol. Vol. 51(3), pp. 308-329, 2008. 
[9] F. Abdillah: Analisis Postur Kerja dengan Metode Rapid Upper Limb Assesment (RULA) pada Pekerja Kuli Angkut Buah di “Agen Ridho Illahi” Pasar Johar Kota Semarang (in Indonesian), Jurnal Kesehatan Masyarakat, Vol. 2(01), pp. 1-10, 2013.

[10] A. Palese, A. Zabalegui Yárnoz, A. K. Sigurđardóttir, M. Bergin, B. Dobrowolska, C. Gasser, M. Pajnkihar, C. Jackson: Bologna process, more or less: nursing education in the European economic area: a discussion paper, International journal of nursing education scholarship, Vol. 11(1), pp. 1-10, 2014.

[11] W. Karwowski: Ergonomics and human factors: the paradigms for science, engineering, design, technology and management of human-compatible systems, Ergonomics, Vol. 48(5), pp. 436-63, 2005.

[12] M. Middlesworth: Recommended Ergonomic Assessment Tools, 2016, Available from: http://ergo-plus.com/ergonomic-assessment-tools/ [Accessed 20 September 2016].

[13] P. Kivi, M. Mattila: Analysis and improvement of work postures in the building industry: application of the computerised OWAS method, Applied ergonomics, Vol. 22(1), pp. 43-48, 1991.

[14] Workplace safety toolkit: Fact sheet: Ergonomics, 2008, Available from: https://nonprofitrisk.org/tools/workplace-safety/nonprofit/c5/ergonomics.htm [Accessed 20 September 2016].

[15] A.M. McEwan, P. Sackett: The human factor in CIM systems: worker empowerment and control within a high-volume production environment, Computers in Industry, Vol. 36(1), pp. 39-47, 1998.

[16] S.M. Moore, J. Torma-Krajewski, L.J. Steiner: Practical Demonstrations of Ergonomic Principles, 2011, Available from: http://www.cdc.gov/niosh/mining/ UserFiles/works/ pdfs/2011-191.pdf [Accessed 20 October 2016].

[17] European Agency for Safety and Health at Work: E-Fact 45 Checklist for preventing bad working postures - Checklist for preventing bad working postures, 2008, Available from: https://osha.europa.eu/en/tools-and-publications/publications [Accessed 20 October 2016].

[18] L. Punnett, D.H. Wegman: Work-related musculoskeletal disorders, the epidemiologic evidence and the debate, Journal of electromyography and kinesiology, Vol. 14(1), pp. 13-23, 2004.

[19] A. Maldonado-Macias, M.G. Ramírez, J.L. García, J.J. Díaz, S. Noriega: Ergonomic evaluation of work stations related with the operation of advanced manufacturing technology equipment: two cases of study, XV Congreso Internacional de ergonomia SEMAC, 2009.

[20] E. Vieira, S. Kumar: Occupational risks factors identified and interventions suggested by welders and computer numeric control workers to control low back disorders in two steel companies, International journal of industrial ergonomics, Vol. 37(6), pp. 553-561, 2007

[21] Washington State Department of Labor \& Industries: Examples of costs and benefits of ergonomics, 2016, Available from: http://www.pshfes.org/Resources/ Documents/Ergonomics_cost_benefit_case_study_collection.pdf [Accessed 21 October 2016].

[22] M. Middlesworth: 5 Proven Benefits of Ergonomics in the Workplace, 2016, Available from: http://ergo-plus.com/workplace-ergonomics-benefits/ [Accessed 21 October 2016].

[23] J. Jose: Musculetal problems in sitting \& standing, 2016, Available from: http://www.slideshare.net/geomichael/musculoskeletal-problems-in-sitting-standing [Accessed 20 October 2016]. 
[24] M. Husić: Ergonomija in varstvo pri delu. Ljubljana: Zavod IRC; 2010.

[25] United States Department of Labor: Storewide Ergonomic Solutions, 2016, Available from: https://www.osha.gov/ergonomics/guidelines/retailgrocery/grocerysolutions-insert.pdf [Accessed 21 October 2016].

[26] Canadian Centre for Occupational Health \& Safety: Working in a Standing Position - Basic Information, 2016, Available from: https://www.ccohs.ca/oshanswers/ ergonomics/standing/standing_basic.html [Accessed 22 October 2016].

[27] M. Bilban. Medicina dela za zdravnike družinske medicine. Ljubljana: ZZD; 2002. 
AdVANCES IN PRODUCTION AND INDUSTRIAL ENGINEERING

F. Čuš \& V. Gecevska

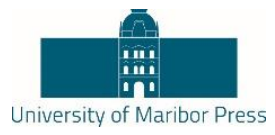

\section{Part V - EDUCATION IN SOCIAL AND ECONOMIC DEVELOPMENT}





\title{
Chapter 14
}

\section{The Educational Model for Occupational Safety Expert}

\author{
JASMINA CALOSKA \& TRAJCE VELKOVSKI
}

\begin{abstract}
The educational model for the occupational safety expert is developed on a basis of the research of the relevant formal educational institutions in Republic of Macedonia. Occupational safety expert is employed by the employer designee for performing professional tasks related to safety. The employers are responsible for the choice of occupational safety experts who need to implement and maintain system for OSH (Occupation, Safety Health) in their companies. In this research, the authors, by analyzing the current situation of educational models in $\mathrm{OSH}$ in Macedonia, have addressed the situation in the labor market and recommendations for further activities to improve. The analysis has shown that It is necessary serious systematic approach to education system that needs to produce engineers capable for dealing with all the challenges of modern business, and stuff that will be recognized in the labor market as a necessity to improve the working conditions.
\end{abstract}

Keywords: • occupation and safety • OHS System • working conditions $\bullet$ educational model $\bullet$ Macedonia

Correspondence Adress: Jasmina Caloska, Ph.D., Full Professor, „Ss. Cyril and Methodius" University in Skopje, Faculty of Mechanical Engineering-Skopje, Rudger Boshkovikj bb, Skopje 1000, Republic of Macedonia, e-mail: jasmina.chaloska@mf.edu.mk. Trajce Velkovski, M.S., Assistant, „Ss. Cyril and Methodius" University in Skopje, Faculty of Mechanical Engineering-Skopje, Rudger Boshkovikj bb, Skopje 1000, Republic of Macedonia, e-mail: trajce.velkovski@mf.edu.mk. 


\section{Introduction}

The educational model for the occupational safety expert is developed on a basis of the research of the relevant formal educational institutions in Republic of Macedonia. Occupational safety expert is employed by the employer designee for performing professional tasks related to safety. Despite the mandatory liability of employers for the appointment of an occupational safety expert, they must determine the number, type and level of education of professionals depending on the organization, the nature and scope of the employment process, the number of employees, number of shifts or number of separate work units.

Overall, employers are responsible for the choice of occupational safety experts who need to implement and maintain system for OSH in their companies. Nevertheless, is there any company depending on the activity, respectively person who can meet the challenges of such a complex system? What should be his/her education, experience, organizational skills, ability to work in teams? Do we have capacity to build a profile of a professional person who professionally meet the need for safe operation?

\section{$2 \quad$ Statical data}

In this research, the authors by analyzing the current situation of educational models in OSH in Macedonia have addressed the situation in the labor market and recommendations for further activities to improve.

The situation in the field of education in occupational safety and health in each country is linked to the situation in the economy, working conditions and employment.

According to the State Statistical Office, in the first quarter of 2016 the labor force in the Republic of Macedonia numbered 945821 persons, of which 714435 employed, and 231386 people were unemployed.

The activity rate in this period is 56.4 , the employment rate was 42.6 , while the unemployment rate is 24.5 .

Table 1 shows the situation in the past three years of data on the proportion of active business entities by number of employees. 
Table 1. The condition for the participation of active business entities by number of employees

\begin{tabular}{|l|l|l|l|}
\hline Entities & $\mathbf{2 0 1 3}$ & $\mathbf{2 0 1 4}$ & $\mathbf{2 0 1 5}$ \\
\hline Number of active business entities & 71.290 & 70.659 & 70.139 \\
\hline Businesses with 1-9 employees & $85 \%$ & $85.2 \%$ & $80.2 \%$ \\
\hline Businesses without employees & $6.2 \%$ & $5.6 \%$ & $10.4 \%$ \\
\hline Enterprises with 10-19 employees & $4.2 \%$ & $4.4 \%$ & $4.3 \%$ \\
\hline Enterprises with 20-49 & $2.5 \%$ & $2.6 \%$ & $2.8 \%$ \\
\hline Enterprises with 50-249 employees & $1.8 \%$ & $1.8 \%$ & $1.9 \%$ \\
\hline $\begin{array}{l}\text { Enterprises with over 250 } \\
\text { employees }\end{array}$ & $0.3 \%$ & $0.3 \%$ & $0.3 \%$ \\
\hline
\end{tabular}

Source: State Statistical Office of the Republic of Macedonia

From the data presented it can be concluded that the structure of active business entities most common are micro and small enterprises.

In the past Republic of Macedonia conducted a series of reforms aimed at better and more efficient development of SMEs and the reduction of the unemployment rate.

In table 2 the structure of active population by gender and educational attainment is shown. 
Table 2. Active population by educational attainment

\begin{tabular}{|l|c|c|c|c|c|c|}
\hline \multirow{2}{*}{$\begin{array}{l}\text { Educational } \\
\text { attainment }\end{array}$} & \multicolumn{2}{|c|}{ Labour force } & \multicolumn{3}{|c|}{ Employed } & \multicolumn{2}{|c|}{ Unemployed } \\
\cline { 2 - 7 } & $2015 / \mathrm{I}$ & $2016 / \mathrm{I}$ & $2015 / \mathrm{I}$ & $2016 / \mathrm{I}$ & $2015 / \mathrm{I}$ & $2016 / \mathrm{I}$ \\
\hline Total & $\mathbf{9 5 9 3 8 8}$ & $\mathbf{9 4 5 ~ 8 2 1}$ & $\mathbf{6 9 7 ~ 2 4 8}$ & $\mathbf{7 1 4 ~ 4 3 5}$ & $\mathbf{2 6 2 ~ 1 4 0}$ & $\mathbf{2 3 1 ~ 3 8 6}$ \\
\hline $\begin{array}{l}\text { Without } \\
\text { education }\end{array}$ & $(3399)$ & $(4972)$ & $(1721)$ & $(3064)$ & $(1678)$ & $(1908)$ \\
\hline $\begin{array}{l}\text { Incomplete } \\
\text { primary } \\
\text { education }\end{array}$ & 28497 & 18752 & 18500 & 14894 & 9997 & $(3859)$ \\
\hline $\begin{array}{l}\text { Primary } \\
\text { education }\end{array}$ & 194230 & 186569 & 133504 & 128706 & 60726 & 57862 \\
\hline $\begin{array}{l}3 \text { years of } \\
\text { secondary } \\
\text { education }\end{array}$ & 79771 & 69694 & 55393 & 53901 & 24378 & 15793 \\
\hline $\begin{array}{l}4 \text { years of } \\
\text { secondary } \\
\text { education }\end{array}$ & 434285 & 421961 & 314973 & 315229 & 119312 & 106732 \\
\hline $\begin{array}{l}\text { Professional } \\
\text { education }\end{array}$ & 23025 & 18590 & 18445 & 16314 & $(4580)$ & $(2276)$ \\
\hline $\begin{array}{l}\text { High (faculty) } \\
\text { education }\end{array}$ & 196182 & 225283 & 154713 & 182327 & 41469 & 42956 \\
\hline
\end{tabular}

Source: State Statistical Office of the Republic of Macedonia

Of the active population according to education, most unemployed are with primary and secondary education, pointing to the existence of a large number of unskilled workers.

In addition, people that are waiting for employment too long are excluded from the labor market, which makes them unaware of the occupational risks in the workplace in terms of safety and health. It is therefore necessary to implement measures for occupational safety and health in order to emphases the training of the workers in terms of developing a culture for prevention.

However, the strategic commitment of Macedonia for EU integration clearly requires taking a more aggressive policy on occupational safety and health in order to improve working conditions and reduce injuries and occupational diseases.

Occupational safety and health strategy must provide activities aimed at improving legislation, instructional cooperation, capacity building of occupational safety experts and support for consistent implementation of all measures for safe operation. 
Educational programs that involve the occupational safety and health are basis for development of the area. In the Republic of Macedonia, there are higher educational institutions with study programs in the field of safety and health at all levels.

The first interdisciplinary studies in the field of occupational safety are established in 1989 at the Faculty of Mechanical Engineering of the "Ss. Cyril and Methodius" University in Skopje, with the total number of 349 students, of whom 132 engineers graduated in occupational safety.

In table 3 the current situation of the educational models in the Universities in Macedonia conducting study programs OSH are shown. 
Table 3. Situation of the of the educational models in the Universities in Macedonia conducting study programs $\mathrm{OSH}$

\begin{tabular}{|c|c|c|c|c|c|c|c|}
\hline 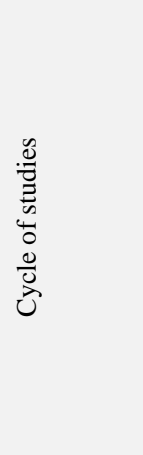 & 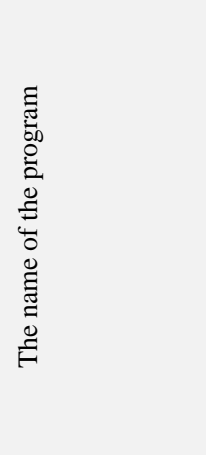 & 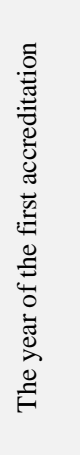 & 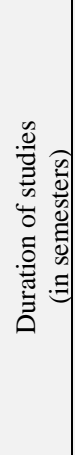 & 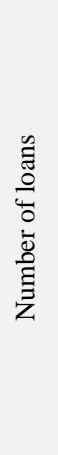 & 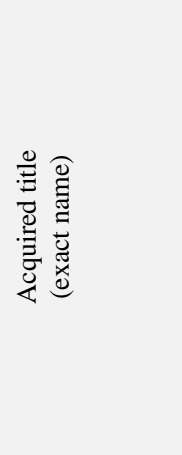 & 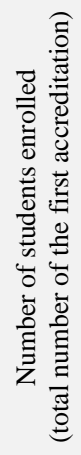 & 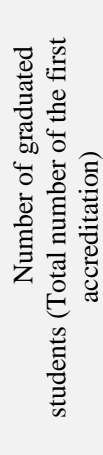 \\
\hline \multicolumn{8}{|c|}{ University: „Ss Cyril and Methodius,, in Skopje } \\
\hline \multicolumn{8}{|c|}{$\begin{array}{l}\text { Faculty: Mechanical Engineering, Skopje; } \\
\text { Address: Karpos II post code } 4641000 \text { Skopje }\end{array}$} \\
\hline $\begin{array}{l}\text { I } \\
\text { Cycle } \\
\text { Studies }\end{array}$ & $\mathrm{OSH}$ & 1989 & 8 & & $\begin{array}{l}\text { Occupational } \\
\text { Engineer }\end{array}$ & 349 & 132 \\
\hline $\begin{array}{l}\text { II } \\
\text { Cycle } \\
\text { Studies }\end{array}$ & $\begin{array}{l}\text { Management } \\
\text { Systems for } \\
\text { safety and health } \\
\text { at work }\end{array}$ & 2012 & 4 & 120 & $\begin{array}{l}\text { Master of } \\
\text { Science in } \\
\text { Safety at Work }\end{array}$ & 43 & 10 \\
\hline $\begin{array}{l}\text { III Cycle } \\
\text { Studies }\end{array}$ & Doctoral School & 2012 & 6 & & $\begin{array}{l}\text { Doctor of } \\
\text { Technical } \\
\text { Sciences }\end{array}$ & 2 & \\
\hline \multicolumn{8}{|c|}{ University: International Slavic University "Gavrilo Romanovich Derzavin" } \\
\hline \multicolumn{8}{|c|}{$\begin{array}{l}\text { Faculty: Faculty of safety engineering; } \\
\text { Address St . „Marshal Tito“ } 772220 \text {, Sveti Nikole }\end{array}$} \\
\hline $\begin{array}{l}\text { I } \\
\text { Cycle } \\
\text { studies }\end{array}$ & Safety at work & $\begin{array}{l}2012 / \\
2013\end{array}$ & 6 & 180 & $\begin{array}{l}\text { Graduated } \\
\text { engineer for } \\
\text { safety at work }\end{array}$ & 240 & 54 \\
\hline $\begin{array}{l}\text { II } \\
\text { Cycle of } \\
\text { studies }\end{array}$ & Safety at work & $\begin{array}{l}2012 / \\
2013\end{array}$ & 4 & 120 & $\begin{array}{l}\text { Master of } \\
\text { Safety at work }\end{array}$ & 114 & 25 \\
\hline $\begin{array}{l}\text { III Cycle } \\
\text { of studies }\end{array}$ & & & & & & & \\
\hline \multicolumn{8}{|c|}{ University: University „Goce Delcev” Stip } \\
\hline
\end{tabular}




\begin{tabular}{|c|c|c|c|c|c|c|c|}
\hline 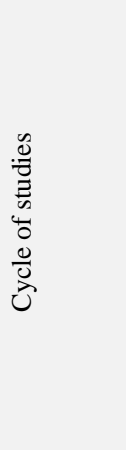 & 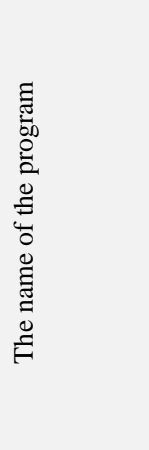 & 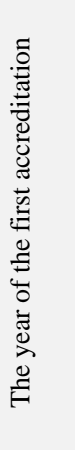 & 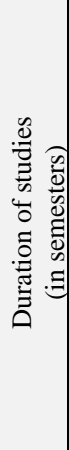 & 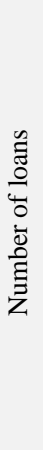 & 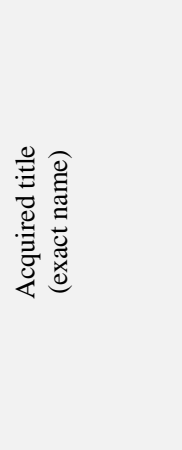 & 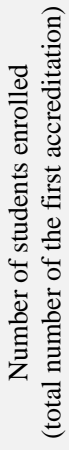 & 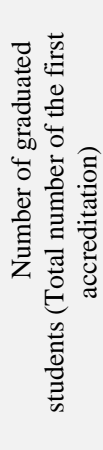 \\
\hline $\begin{array}{l}\text { I } \\
\text { Cycle } \\
\text { studies }\end{array}$ & & & & & & & \\
\hline $\begin{array}{l}\text { II } \\
\text { Cycle } \\
\text { studies }\end{array}$ & $\begin{array}{l}\text { Engineering } \\
\text { work } \\
\text { environment }\end{array}$ & 2011 & 2 & 60 & $\begin{array}{l}\text { MA in } \\
\text { technical } \\
\text { sciences }\end{array}$ & 21 & 2 \\
\hline $\begin{array}{l}\text { III Cycle } \\
\text { studies }\end{array}$ & & & & & & & \\
\hline
\end{tabular}

The curricula of the study program have been developed for all three cycles of education: undergraduate, graduate and doctoral studies.

Due to exceptional multidisciplinary field of study, programs include knowledge from different fields, building a profile of the most professional engineer who can meet the challenges of modern business.

However evident is the need to include a larger number of students in these study guidelines with regard to the needs of the labor market.

Paradoxically, now all completed occupational safety engineers are unable to work as occupational safety professionals because of restrictive requirement of work experience of 5 years for taking the professional exam. In this way, academic studies are undervalued in relation to the exam for $\mathrm{OSH}$, and young highly educated personnel are prevented from working in the field that they are educated.

Besides producing quality, engineering personnel, because of the complexity of the area, of particular concern is the enlargement specialists in the field of occupational medicine. In recent years, the Department of Occupational Health at the Faculty of Medicine enrolled 18 trainees in the field of occupational medicine. Otherwise, in the Republic of Macedonia, 70 specialists in occupational medicine are actively involved in OSH systems. 
Because of increasing of the awareness in the youngest population about the importance of their own health and safety, this field has to be represented in the programs of primary and secondary education. Thus, students will be aware of the risks at work, which may face from an early age to recognize the necessity of developing a culture of safe operation (work).

For this purpose it is necessary the area of occupational safety and health at work to be included in the educational programs provided by the Law on Primary Education and Law on Secondary Education.

By the Law on Safety and Health at work, The Republic of Macedonia provided continuous education of professionals for safety at work. Thus, professionals enlarge their knowledge in the area, adding new value to systems, implementing OSH in their companies. The implementation of the trainings and the criteria for trainers and trainees are now regulated by the Law on OSH.

An important part of informal education should emphasize the role of associations for safety in Macedonia that their programs continuously conduct education of occupational safety experts, aimed at sustainable development of occupational safety and health systems in our companies. In the past year 34 trainings are held, on topics of mining, construction, mobbing and stress, personal protective equipment, methodologies for risk assessment under varying operating (work) conditions, chemical hazards, ionizing radiation, ergonomic working conditions, outdoor work.

\section{$4 \quad$ Profile of an occupational safety expert}

If the employer in accordance with the legal obligations to provide measures for OSH must appoint one or more experts for safety, it is his/her responsibility for choosing them. However, is there any company depending on the activity, respectively person who can meet challenges of such a complex system? What should be his/her education, experience, organizational skills, ability for teamwork? Do we have the capacity to build a profile of an expert professional who will address the needs for safe operation (work)?

The answer of these above-mentioned questions, certainly we can find if we look into the system of selection and appointment of the occupational safety expert. Studies shows that the expert is usually randomly selected person to whom obligations for occupational safety is granted function despite all other work tasks. It is clear, how much professionally this additional task can be carried out, for implementing measures for prevention and reduction of risks at work place! In this situation, we can speak only for necessary implementation, and not for prevention and maintenance!

When an employer have a choice of highly trained and professional staff, it is easy to choose the most appropriate for its activity. However, how to find the way 
to build professionally competent person with the necessary knowledge and skills? Of course, the answer of this problem we should look at the most responsible persons for education and training, higher educational institutions with study programs in the field of occupational safety and health.

Figure 1 shows the current system for appointing occupational safety expert in the country, in the Republic of Macedonia.

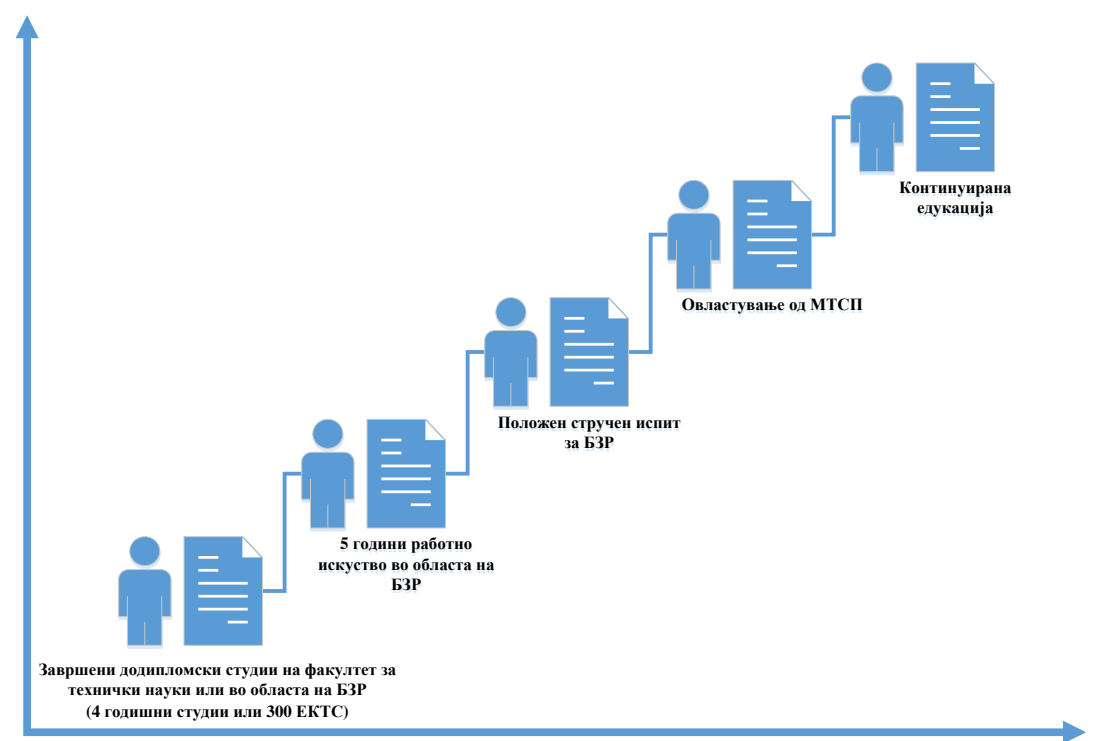

Figure 1. Current system for appointing occupational safety expert in the Republic of Macedonia.

Namely, according the Low on OSH in the Republic of Macedonia, an occupational safety expert can be a person who has a university degree in occupational safety, technical or other department for 4 years or 300 ECTS and passed exam for occupational safety at the Ministry of Labor and Social Policy. The condition for conducting the occupational safety exam is that the candidate must have at least 5 years experience in the field of applying. This requirement excludes the graduated engineers and masters for occupational safety to conduct the occupational safety exam and to work as occupational safety experts. On the other hand, MLSP approves this requirement for the other candidates only with provided statement by the employer of the employees work experience. This situation discriminates the people who dedicated their entire education to this specific area. In the current situation, the occupational safety exam, which consists electronic database of questions and case studies (divided into theoretical and practical part) is above the several years of academic education in the specific occupational safety program. 
Table 3 shows that in the Republic of Macedonia there is already a specialized staff in the area of safety and health at work, that can respond to all challenges in complex systems for OSH. Staff completing studies in OSH acquire general competencies:

- Ability to work in interdisciplinary teams

- Ability to analyze problems and design and synthesis solutions

- A recognition of the need for, and an ability to engage in life-long learning

- Ability to apply knowledge in practice

- Capacity for generating new ideas and solutions through the application of research methods

- Ability of critical thinking

- Ability to generate innovative approaches

- Ability to make decisions in real time (in time)

Besides the general, the candidates have developed specific competences, such as:

- Research and anticipating the needs of companies in the area of OSH

- Expert knowledge of the areas studied by the study programs

- Ability to connect theoretical knowledge with their practical application

- Ability to use the techniques, skills, and modern engineering tools

- OSH Management System through preventive approach and aimed at sustainable development

- Manage the data through an integrated information system

- Perform consulting services related to the implementation, management and maintenance of systems for OSH

\section{$5 \quad$ Recommendations}

Given the presented situation, it is necessary to establish a system of education of occupational safety experts. If the structure of active business entities by number of employees (table 1), is that over $80 \%$ of businesses are with 1-9 employees, it is clear that the profile of an occupational safety expert in the authorized bodies must have a broader knowledge system in various OSH activities. To this end, higher education institutions will have to pay particular attention to the profiling of the engineering staff to work on implementation and maintenance of systems of OSH. A profile of an occupational safety expert can be build through:

- Accredited academic and professional study programs as well as specialized professional studies,

- Within the period of: undergraduate 3-4 years (180-240 ECTS) graduate and specialized studies 1-2 years (60-120 ECTS),

- Acquired title: Graduate engineer in the field of safety or Master in the field of safety, a specialist in the field of safety, 
- Authorization of state institution, and

- Continuous education and training.

The introduction of the occupational safety expert in the National Classification of Occupation will help to facilitate the recognition of the profile at the labor market. This is an issue that requires an urgent update of the National Classification of Occupation since the educators and the peoples that are profiling the occupational safety experts are recognized, such as: Professor for occupational safety, Trainer for occupational safety, Teaching assistant for occupational safety, even Inspector and Director for occupational safety, but yet not occupational safety expert.

\section{Conclusion}

Occupational safety expert has a very complex executive and advisory functions expressed in OSH systems through a number of tasks and responsibilities. In the pyramid of systems for OSH, the occupational safety expert found its base.

Therefore, certainly the educational model is very important for profiling the professional person in terms of knowledge, abilities and skills to implement and maintain the system for OSH. Since his/her selection and appointment, as well as continuous education depends on how successfully will implement the planned measures to prevent and reduce occupational risks. We must not allow the occupational safety expert to be randomly selected person with given additional function and activities in order to fulfil the legal obligation.

For the professional profile of the person the most responsible and professional actors are the centers for education and continuous education. It is therefore necessary serious systematic approach to education system that needs to produce engineers capable for dealing with all the challenges of modern business, and stuff that will be recognized in the labor market as a necessity to improve the working conditions.

\section{References}

[1] OSHA (2004) Work and health in the EU - A statistical portrait, Office for Official Publications of the European Communities, 2004. https://osha.europa.eu/fop/latvia/en/news/news_archive/work_health_eu.pdf, 18.03.2015.

[2] Chua, D., K., H., Goh Y., M. (2004) Incident Causation Model for Improving Feedback of Safety Knowledge, JOURNAL OF CONSTRUCTION ENGINEERING AND MANAGEMENT ASCE /JULY/AUGUST, pp. 542-551

[3] Conte, J., C., Rubio, E., García, A., I., Cano, F. (2011) Occupational accidents model based on risk-injury affinity groups, Safety Science, 49, pp. 306-314

[4] Bellamy, L., J., Ale, B., J., M., Geyer, T., A., W., Goossens, L., H., J., Hale, A., R., Oh, J., Mud, M., Bloemhof, A., Papazoglou, I., A., Whiston, J., Y. (2007) 
Storybuilder-A tool for the analysis of accident reports, Reliability Engineering and System Safety, 92, pp. 735-744

[5] Hughes, P., Ferrett, E. (2007) Introduction to Health and Safety at Work, Elsevier ISO (2009), ISO 31000:2009, "Risk Management — Principles and Guidelines

[6] Republic of Macedonia State statistic Office, Macedonia in Figures 2013 Skopje , Republic of Macedonia State Statistic Office ,2014 (ISSN 1857 - 6761)

[7] Law for Safety and Health at Work (Official Gazette No 92/07 )

[8] Law on Pension and Disability ( Official Gazette of RM No .80/93)

[9] Rulebook on the preparation of safety statement, its content, and the data on which should be based on risk assessment (Official Gazette of RM No.02/09)

[10] Rulebook of the state for running evidence in the field for safety and health at work (Official Gazette of RM No.20/04)

[11] Prof. Ph.D Ljuben Dudeski, Prof. Ph.D Jasmina Caloska, Ass. MSc Trajce Velkovski, "Current Situation and Trends in the Field of OSH in R.Macedonia". Ohrid, R.Macedonia, 10-12.05.2013 


\title{
Chapter 15
}

\section{Status - quo of Macedonian Entrepreneurship Education System in 2016}

\author{
LILJANA POLENAKOVIKJ \& RADMIL POLENAKOVIKJ
}

\begin{abstract}
Entrepreneurship Education is on the top of the research agenda among Entrepreneurship, Small Business Management and Innovation Management researches. Its goal is to promote creativity, innovation and self-employment. Results from several 2016 published world reports related to entrepreneurship, small business development and entrepreneurship education are presented in the next few paragraphs. Macedonian performances are measured on number of dimensions, while specific focus in this chapter is placed on the comparison of the level of entrepreneurship education between Macedonia and other countries.
\end{abstract}

Keywords: - entrepreneurship education - innovation • selfemployment $\bullet$ Education System $\bullet$ Macedonia

CorResPondence Adress: Liljana Polenakovikj, M.Sc., Adviser, Bureau for Development in Education, Skopje 1000, Republic of Macedonia. Radmil Poleankovikj, Ph.D., Full Professor, „Ss. Cyril and Methodius" University in Skopje, Faculty of Mechanical Engineering-Skopje, Rudger Boshkovikj bb, Skopje 1000, Republic of Macedonia, e-mail: radmil.polenakovikj@mf.edu.mk.

https://doi.org/10.18690/978-961-286-028-8.15 ISBN 978-961-286-028-8

(C) 2017 University of Maribor Press

Available at: http://press.um.si. 
Entrepreneurship education is essential not only to shape the mind-sets of young people but also to provide the skills, knowledge and attitudes that are central to developing an entrepreneurial culture. This paper analyzes latest (2016) rankings of the Republic of Macedonia related to entrepreneurship education and entrepreneurial learning. Results and Macedonian standing from Global Entrepreneurship Monitor 2015-2016, Small Business Act for Western Balkan countries and Turkey (2016) and Entrepreneurship Education in Schools in Europe 2016 were presented. This paper elaborates main developments in the area of entrepreneurship education in formal sector in the country in the last 10 years. Paper ends with the recommendations for next steps for improvement of the entrepreneurship education in the country.

\section{Entrepreneurship education}

Entrepreneurship Education is on the top of the research agenda among Entrepreneurship, Small Business Management and Innovation Management researches in the last 5-10 years. Entrepreneurship is more complex process than it can be described in different educational curricula, because different situations based on the industry, market, country culture and other will require different approaches in practicing entrepreneurship. Jack and Anderson [1] argue that teaching entrepreneurship involve both "arts" where creativity and innovative thinking is highlighted and "science" where the focus is on financial models, marketing, business functions, management functions and so on. The science part of teaching entrepreneurship is the teachable and can be used structured training materials that will provide technical and personal skills for "would be" entrepreneurs. On the other side the "art" part can't be teachable in the same way as "science" part because it is much more subjective and will depend on many external conditions.

In order to understand better the meaning of entrepreneurship education we are presenting the research on different definition from different experts (organizations) in this filed:

- All activities aiming to foster entrepreneurial mindsets, attitudes and skills and covering a range of aspects such as idea generation, start-up, growth and innovation [2].

- Entrepreneurial education is a dynamic process of awareness, reflection, association and application that involves transforming experience and knowledge into functional learning outcomes [3].

- Entrepreneurship education refers to activities aimed at developing enterprising or entrepreneurial people and increasing their understanding and knowledge about entrepreneurship and enterprise [4]. 
It is obvious that there are many different approaches towards definition of entrepreneurship education. Mainly from one side is the education that will prepare students for their business venture (to start and run business), and from other side is the approach where students will learn and develop broad level of skills (creativity, sense of initiative, risk-taking, autonomy, self-confidence, leadership, team spirit, etc.) that will allow him/her to have entrepreneurial mindset, innovative thinking and behavior.

In Macedonia, we are more in favor of second option, while the definition provided by the European Commission is accepted and implemented in our strategic documents.

Entrepreneurship education should not be confused with general business and economic studies; its goal is to promote creativity, innovation and selfemployment, and may include the following elements:

- developing personal attributes and skills that form the basis of an entrepreneurial mindset and behaviour (creativity, sense of initiative, risk-taking, autonomy, self-confidence, leadership, team spirit, etc.),

- raising the awareness of students about self-employment and entrepreneurship as possible career options,

- working on concrete enterprise projects and activities,

- providing specific business skills and knowledge of how to start a company and run it successfully [5]

In the last 10 years there is significant push towards implementation of entrepreneurship education on all educational levels, and both - in formal and non(in-)formal education in the country. Chapter 2 presents where is Macedonian ranking on several top level research investigations in the area of entrepreneurship education. Chapter 3 presents main activities conducted in the last decade towards strengthening the entrepreneurship education in the Republic of Macedonia (but only in formal sector).

\section{Republic of Macedonia in the international rankings for entrepreneurship education in 2016}

Results from several 2016 published world reports related to entrepreneurship, small business development and entrepreneurship education are presented in the next few paragraphs. Macedonian performances are measured on number of dimensions, while specific focus in this paper is placed on the comparison of the level of entrepreneurship education between Macedonia and other countries. 


\subsection{Global Entrepreneurship Monitor 2015-2016}

GEM stands for Global Entrepreneurship Monitor. GEM is the world's foremost study of entrepreneurship. Through a vast, centrally coordinated, internationally executed data collection effort, GEM is able to provide high quality information, comprehensive reports and interesting stories, which greatly enhance the understanding of the entrepreneurial phenomenon. GEM has tracked rates of entrepreneurship across multiple phases and assessed the characteristics, motivations and ambitions of entrepreneurs, and the attitudes societies have toward this activity. In each economy, GEM looks at two elements:

- The entrepreneurial behaviour and attitudes of individuals,

- The national context and how that impacts entrepreneurship.

GEM2015/2016 report covers results based on 60 economies completing the Adult Population Survey ( 2000 candidates per country) and 62 economies completing the National Expert Survey ( 40 experts from all fields related to eco-system for entrepreneurship support). An analysis carried out by the GEM shows a strong correlation between perceived entrepreneurial capabilities (skills) and the total early stage entrepreneurial activity, which indicates how important education is in developing entrepreneurial competences.

Figure 1 presents the ranking of the main Macedonian indicators in comparison of 62 countries. It can be noticed that Macedonia is performing best in the areas of Internal market dynamics (15/62) and Government policies 4.61 (16/62). For the interest of this paper, we are mentioning that Macedonia is relatively good placed with the indicators Entrepreneurship education at school stage 3.56 (22/62), Entrepreneurship education at post school stage $4.85(22 / 62)$, where Macedonia is on the 22 place of 62 countries. It can be noticed that Macedonia is performing better than the overall GEM average on these two dimensions. 


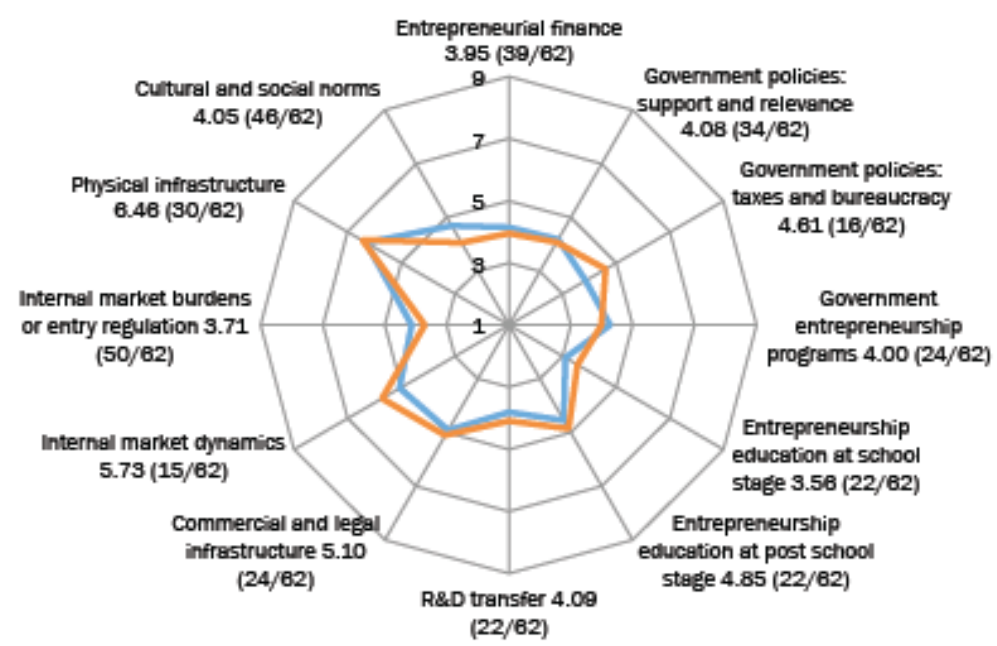

Figure 1. Rankings of main Macedonian indicators in the GEM 2015/2016 Report [6]

\subsection{Small Business Act for Western Balkan countries and Turkey}

The SME Policy Index: Western Balkans and Turkey 2016 - Assessing the Implementation of the Small Business Act for Europe offers policy makers and other stakeholders in the EU enlargement region a framework to assess progress in designing and implementing effective SME policies. The SME Policy Index assesses both quantitative and qualitative policy indicators and is structured around the ten principles of the Small Business Act for Europe. For this paper of main interest is the first part of first dimension: Entrepreneurial learning (EL) and women's entrepreneurship. Macedonia did significant improvement on this dimension in comparison to 2012, and also in comparison to other countries (Table 1). It can be noticed that on average level only Croatia is little higher than Macedonia, while Macedonia is almost on a same level like Turkey. The strongest mark for Macedonia is for the policy level, where on the sub-indicator - Policy partnership we have mark 4, and for Policy development process we have mark 3.5. These high marks are the result of National Strategy for EL 2014-2020 (adopted by the government in November 2014), and because of activities of the interagency board that is responsible for monitoring of the implementation of the strategy. However, many marks 2 or 2.5 for several sub-dimensions, showed that still a lot should be done in order Macedonia to perform better. 
Table 1. Comparison of the marks for Dimension 1 in SME Policy Index for Western Balkan and Turkey [7]

\begin{tabular}{|c|c|c|c|c|c|c|c|c|}
\hline & & \multicolumn{7}{|c|}{ Scores ( 1 - lowest, 5 - highest mark) } \\
\hline & & ALB & BIH & $\begin{array}{l}\text { KO } \\
\text { S }\end{array}$ & $\begin{array}{l}\text { MK } \\
\text { D }\end{array}$ & $\begin{array}{l}\text { MN } \\
\mathbf{E}\end{array}$ & SRB & $\begin{array}{l}\text { TR } \\
\mathbf{K}\end{array}$ \\
\hline 1 & \multicolumn{8}{|c|}{ Entrepreneurial learning and women's entrepreneurship } \\
\hline 1.1 & $\begin{array}{l}\text { Policy framework for } \\
\text { entrepreneurial learning }\end{array}$ & & & & & & & \\
\hline 1.1 & Policy partnership & 2 & 3.5 & 2 & 4 & 4 & 3 & 4 \\
\hline 1.2 & Policy development process & 3 & 4 & 3 & 3.5 & 4 & 3.5 & 3 \\
\hline 1.3 & Monitoring and evaluation & 2 & 2 & 2 & 2 & 3 & 3 & 2 \\
\hline 1.4 & Non-formal learning & 2 & 2.5 & 2 & 2.5 & 2.5 & 2.5 & 2.5 \\
\hline 1.5 & Good practice exchange & 3 & 3 & 3 & 3 & 3 & 3 & 3 \\
\hline 1.6 & $\begin{array}{l}\text { Entrepreneurial learning in lower } \\
\text { secondary education: schools }\end{array}$ & 2 & 2 & 2 & 2.5 & 3 & 2 & 2 \\
\hline 1.7 & $\begin{array}{l}\text { Entrepreneurial learning in lower } \\
\text { secondary education: teachers }\end{array}$ & 2 & 2 & 2 & 2 & 2.5 & 2 & 2 \\
\hline 1.8 & $\begin{array}{l}\text { Entrepreneurial learning in lower } \\
\text { secondary education: students }\end{array}$ & 2.5 & 2.5 & 2.5 & 3.5 & 3.5 & 3 & 2.5 \\
\hline 1.9 & $\begin{array}{l}\text { Entrepreneurial learning in upper } \\
\text { secondary education: schools }\end{array}$ & 2 & 3 & 2 & 2.5 & 2.5 & 2.5 & 2 \\
\hline $\begin{array}{l}1.1 \\
0\end{array}$ & $\begin{array}{l}\text { Entrepreneurial learning in upper } \\
\text { secondary education: teachers }\end{array}$ & 2 & 2 & 2 & 2 & 2 & 2 & 2 \\
\hline $\begin{array}{l}1.1 \\
1\end{array}$ & $\begin{array}{l}\text { Entrepreneurial learning in upper } \\
\text { secondary education: students }\end{array}$ & 2.5 & 3 & 3 & 3.5 & 3 & 3 & 3 \\
\hline $\begin{array}{l}1.1 \\
2\end{array}$ & $\begin{array}{l}\text { Entrepreneurial experience for } \\
\text { young people in upper secondary } \\
\text { education }\end{array}$ & 2 & 2.5 & 2 & 2 & 3 & 3 & 2.5 \\
\hline $\begin{array}{l}1.1 \\
3\end{array}$ & $\begin{array}{l}\text { Entrepreneurship promotion in } \\
\text { vocational education and training }\end{array}$ & 1.5 & 1.5 & 1.5 & 2.5 & 2.5 & 1.5 & 3 \\
\hline $\begin{array}{ll}1.1 \\
4\end{array}$ & $\begin{array}{l}\text { Entrepreneurial learning in } \\
\text { higher education }\end{array}$ & 2 & 2 & 2 & 2.5 & 2 & 2 & 2.5 \\
\hline $\begin{array}{l}1.1 \\
5\end{array}$ & $\begin{array}{l}\text { Higher education co-operation } \\
\text { with the world of business }\end{array}$ & 2.5 & 3 & 3 & 3 & 3 & 3 & 3.5 \\
\hline $\begin{array}{l}1.1 \\
6\end{array}$ & $\begin{array}{l}\text { Good practice in entrepreneurial } \\
\text { learning in higher education }\end{array}$ & 2 & 2 & 2 & 2.5 & 2 & 2 & 2 \\
\hline 1.2 & Women's entrepreneurship & 2.5 & 1.5 & 2.5 & 2 & 2.5 & 3 & 3 \\
\hline Ave & rage Dimension 1: 2016 & 2.18 & 2.46 & 2.24 & 2.70 & 2.80 & 2.56 & 2.72 \\
\hline$\overline{\text { Ave }}$ & rage Dimension 1: 2012 & 2.54 & 1.79 & 1.81 & 2.4 & 2.54 & 2.35 & 2.52 \\
\hline
\end{tabular}

\subsection{Entrepreneurship Education in Schools in Europe 2016}

Recently, the latest EU report for Entrepreneurship Education was published including data for Macedonia (European Commission 2016). The Report start with the statement that "there is a growing awareness of the potential of young people 
to launch and develop their own commercial or social ventures thereby becoming innovators in the areas in which they live and work. Entrepreneurship education is essential not only to shape the mind-sets of young people but also to provide the skills, knowledge and attitudes that are central to developing an entrepreneurial culture." In the Report Macedonia is positively mentioned as one of the rare countries that have its EL strategy (fig. 2)

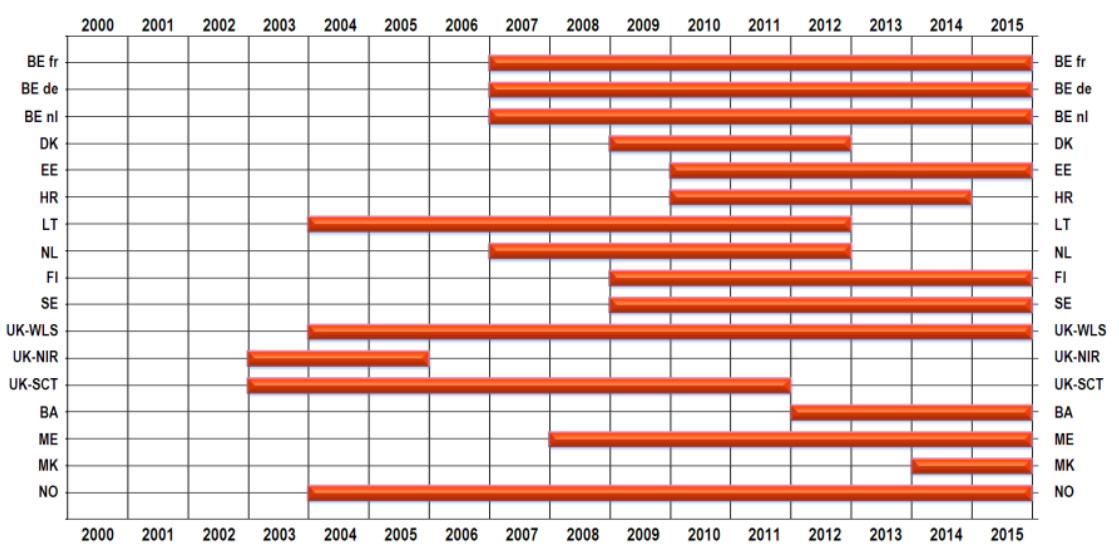

Figure 2. Implementation of specific central level entrepreneurship education strategies [8]

On figure 3 it can be noticed that Macedonia have among most comprehensive strategies in the Europe. Only Estonia, Finland and Montenegro have fulfilled all dimensions of the entrepreneurial learning strategy. Macedonia is missing only more serious career guidance.

Figure 4 shows that Macedonia fully integrated in its national entrepreneurial learning strategy: active citizenship, social entrepreneurship, venture creation and employability.

In addition to curricular approaches and guidelines for teaching and learning methods, another important factor in assessing how well entrepreneurship education is embedded in the curriculum is whether there are also explicitly defined learning outcomes related to entrepreneurial skills. Only Macedonia and Lithuania among all European countries meet following criteria [9]:

- whether there is either a cross-curricular approach and/or compulsory subjects integrating entrepreneurship education in the curriculum of at least three education levels (primary, lower secondary, general upper secondary, school-based IVET);

- whether specific central guidelines on teaching and learning methods in entrepreneurship education exist for at least three education levels. 


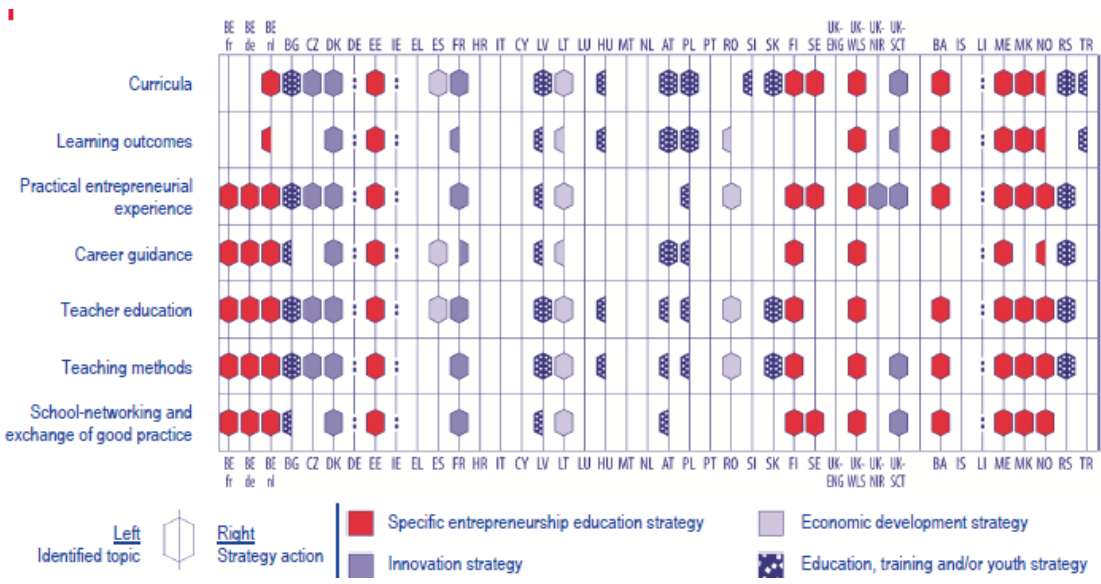

Figure 3. Strategy topics and corresponding actions linked to entrepreneurship education [10]

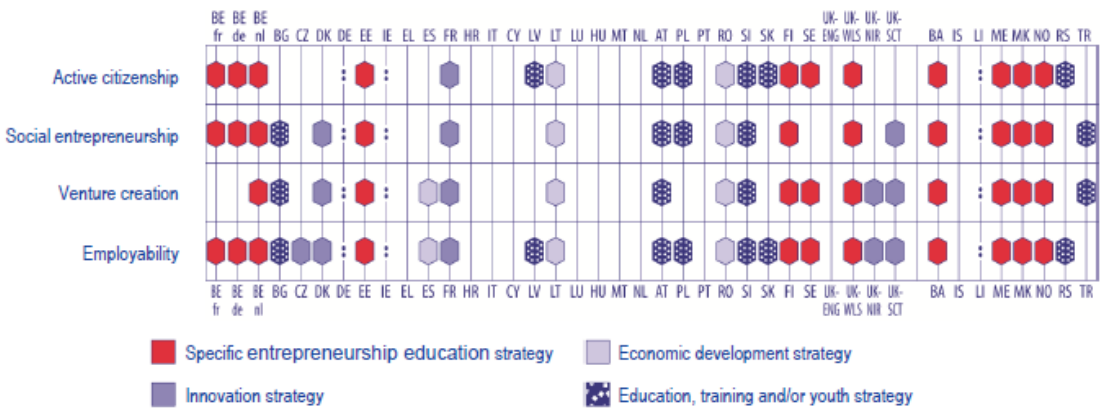

Figure 4. Overview of wider strategy objectives linked to entrepreneurship education [11]

So, what are the reasons for having Macedonian entrepreneurship education so high on the different international rankings?

\section{$4 \quad$ Entrepreneurship education in the Republic of Macedonia}

In the Republic of Macedonia there are number of initiatives that are directly or indirectly linked with entrepreneurship education. Desk research, on-site visits and authors' previous experience can be summarized into following list of main activities that are in line with entrepreneurship education in the Republic of Macedonia (here will be presented only activities related to in formal education:

- On the University level, course Entrepreneurship and Small Business was introduced in 1997 at the Faculty of Mechanical Engineering, Ss. Cyril and Methodius University (UKIM). In the last decade of XX century only on Economic Faculty, UKIM was course Entrepreneurship, only on two majors. 
- The subject (course) "Business and Entrepreneurship" was introduced as compulsory subject in high (secondary) school (2007/2008). Updated curriculum and textbook was introduced from September 2012.

- The subject "Innovation and Entrepreneurship" was introduced as a project activity in $1^{\text {st }}, 2^{\text {nd }}$ and $3^{\text {rd }}$ year of secondary school from September 2012. For better preparation of teachers Bureau for Development of education in the period May - September 2012 organized 2-day training for 1300 professors.

- From September 2013 different contents from the area "Innovation and Entrepreneurship" are introduced in six subjects in $9^{\text {th }}$ grade of primary school (mathematics, art, informatics, chemistry, biology and physics). This activity was also followed by extensive training of teachers that covers above mentioned courses.

- In April 2014, a new program and curriculum for course "Innovation" for IX grade of primary school (obligatory course with one hour per week) was officially introduced. This course started with teaching in all Macedonian schools form September 2014.

- Two days training of 600 teachers that are teaching course "Innovation" in IX grade of primary school was conducted (September - October 2014).

- In the period February April 2015, redesign of 5 curriculums for courses (1) "Innovation" for IX grade of primary school, $(2,3,4)$ "Innovation and Entrepreneurship" in $1^{\text {st }}, 2^{\text {nd }}$ and $3^{\text {rd }}$ year in secondary schools and (5) "Business and Entrepreneurship" in the $4^{\text {th }}$ year of secondary schools was conducted. New textbooks are in the process of development.

- In the period December 2012 - June 2014 with support from European Training Foundation (ETF) expert group worked on the development of National Strategy for Entrepreneurial learning 2014 - 2020 with action plan. This strategic Document was adopted by the Government of the Republic of Macedonia in November 2014. The high priority areas for Macedonian EL strategy are located in five main pillars: Primary education; Secondary education; Higher Education; Informal and non-formal education; Young entrepreneurs. Five pillars are the central part of the entrepreneurial learning ecosystem in the country. They are the basic foundation that will directly frame the implementation of EL activities and EL strategy vision - to ensure sustainable economic development and prosperity of the country and Macedonia to become a country with highly developed entrepreneurial culture and spirit that inspires everyone.

\section{Conclusion}

The activities implemented yielded significant results in boosting the innovation and entrepreneurial learning in the country. There are numerous direct outcomes from these initiatives like: well-trained teachers who are highly capable to deliver the novel content for the innovation and entrepreneurship to the students; the teaching materials have constantly been moderated and corrected; the action plan of the National strategy for entrepreneurial learning $2014-2020$ is 
recently updated for 2016-2017. The importance of these achievements for the overall economic development of the country is widely acknowledged by the international experts and European Commission.

However, more should be done in order Macedonia to continue its entrepreneurial learning journey towards leading positions in the Europe. Here are some of the propositions:

- Continuous teachers career guidance and trainings (not only on the topic of entrepreneurship and innovation), but also on new teaching methods and techniques;

- Strengthening links between schools and its environment (local selfgovernment, industry and public administration;

- Development of "entrepreneurial schools";

- Increasing mobility of professors, teachers and students, but also administrative staff;

- Development of monitoring scheme for teachers/professors development;

- Increasing the use of information techologies in day-to-day teaching activities;

- Encouraging teachers and professors to realize "entrepreneurial projects",

- Shearing domestic and international "good practices", etc.

\section{References}

[1] Jack, S.L., \& Anderson, A.R. (1999) Entrepreneurship education within the enterprise culture. Producing reflective practitioners. International Journal of Entrepreneurship Behavior \& Research, Vol. 5, (No. 3), 1999, 110-125

[2] Alain Fayolle (2009). Entrepreneurship education in Europe: Trends and Challenges (accessed on September 15, 2015 on http://www.oecd.org/cfe/leed/43202553.pdf)

[3] Heinonen, J., \& Akola, E. (2007). Entrepreneurship Training and Entrepreneurial Learning in Europe: Results from the Entlearn Project. TSE Entre, Turku School of Economics.

[4] Heinonen, J and Poikkijoki, S (2005) An entrepreneurial-directed approach to entrepreneurship education: mission impossible? Journal of Management Development, Vol. 25

[5] European Commission - Entrepreneurship in higher education, especially within nonbusiness studies - Final Report of the Expert Group, March 2008

[6] GEM - 2015/2016, Global Entrepreneurship Monitor - Global Report, p. 89

[7] SME Policy Index - Western Balkans and Turkey 2016 (Assessing the Implementation of the Small Business, p. 33

[8] European Commission/EACEA/Eurydice, 2016. Entrepreneurship Education at School in Europe. Eurydice Report. Luxembourg: Publications Office of the European Union, p. 38 
[9] European Commission/EACEA/Eurydice, 2016. Entrepreneurship Education at School in Europe. Eurydice Report. Luxembourg: Publications Office of the European Union, p. 109

[10] European Commission/EACEA/Eurydice, 2016. Entrepreneurship Education at School in Europe. Eurydice Report. Luxembourg: Publications Office of the European Union, p. 46

European Commission/EACEA/Eurydice, 2016. Entrepreneurship Education at School in Europe. Eurydice Report. Luxembourg: Publications Office of the European Union, p. 49 
ADVANCES IN PRODUCTION AND INDUSTRIAL ENGINEERING

F. Čuš \& V. Gecevska

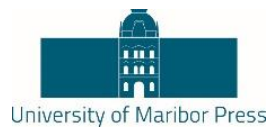

\section{Part VI - OTHER TECHNIQUES FOR INDUSTRY DEVELOPMENT}





\title{
Chapter 16
}

\section{Modeling of Liquid Nitrogen Thermal Influence of Inconel 718}

\author{
MATIJA HRIBERŠEK, FRANCI PUŠAVEC \& JANEZ KOPAČ
}

\begin{abstract}
For predicting surface integrity after cryogenic machining, it is necessary to know liquified nitrogen properties when it us delivered to different locations on the cutting tool and/or workpiece. One of the key properties of liquified nitrogen that is still not known is its surface heat transfer coefficient, which defines the depth of the thermal affected layer of workpiece material and indirectly influence the characteristics of the machined surface integrity (residual stresses, hardness, etc.). In order to define the surface heat transfer coefficent, the numerical simulation has been designed and validated with performed temperature measuring experiments on Inconel 718, as workpiece material. For cutting force predicition, during cryogenic machining (orthogonal turning), the experimets have been conducted and teoretically also correlated with the FEM results of cryogenic machining model.
\end{abstract}

Keywords: • liquified nitrogen $\bullet$ cryogenic machining $\bullet$ surface heat transfer coefficient $\bullet$ finite element modeling $\bullet$ Inconel 718

CORRESPONDENCE AdRESS: Matija Hriberšek, Assistant, University of Ljubljana, Faculty of Mechanical Engineering, Aškerčeva 6, 1000 Ljubljana, Slovenia, e-mail: matija.hribersek@fs.uni-lj.si. Franci Pušavec, Ph.D., Associate Professor, University of Ljubljana, Faculty of Mechanical Engineering, Aškerčeva 6, 1000 Ljubljana, Slovenia, email: franci.pusavec@fs.uni-lj.si. Janez Kopač, Ph.D., Full Professor, University of Ljubljana, Faculty of Mechanical Engineering, Aškerčeva 6, 1000 Ljubljana, Slovenia, email: janez.kopac@fs.uni-lj.si.

https://doi.org/10.18690/978-961-286-028-8.16 ISBN 978-961-286-028-8

(C) 2017 University of Maribor Press

Available at: http://press.um.si. 
Materials such as high temperature alloys (nickel, titanium, etc.) are usually employed in manufacturing processes of high added valued products, especially in space, aircraft and military industry [1]. Such materials have excellent mechanical and thermal properties, which are maintained even when the materials are exposed to high temperatures. Additionally, such materials have low thermal conductivity and get plastically hardened at high temperatures [2].

Nickel-based alloy Inconel 718, which is subject of research in this paper is a hightemperature alloy. It is a corrosion (oxidation) resistant material that can be used at high temperatures, while maintaining hardness characteristics. This is due to its good tensile strength, fatigue life, creep properties and rupture strength. However, due to these specific material characteristics, this alloy is generally difficult to machine [3].

According to the mentioned facts, it can be suitable to machine those materials by the usage of a cooling lubrication fluids, such as high pressure jet and liquified nitrogen, etc. The development of industry, in the field of machining processes, has been striving to improve level of productivity and environmental acceptance. This includes minimization of the use of cooling lubrication fluids based on oils, and increasing cutting speeds (increasing productivity). The use of ecologically impeccable cooling lubrication fluids that do not harm people's health and are environment-friendly has been promoted. Thus, it is absolutely necessary to use an environmentally acceptable coolant in manufacturing industry.

For this purpose, liquified nitrogen as a cryogenic coolant has been explored since the 1950s in metal cutting industry [4]. The main characteric of this technology is the use of a cryogenic fluid (liquified nitrogen) as a cooling fluid during cutting processes, at very low temperatures $\left(-196^{\circ} \mathrm{C}\right)$.

Based on the researches of the temperature in the cutting zone, Ding has explained that the use of liquified nitrogen increases tool-life and achieves better material machining performance (shorter chips, etc.), compared to conventional processes [5]. Courbon has proven reduction of friction coefficient and consequently lower cutting forces in cryogenic machining, in comparision to dry machining [6]. Kaynak has proven that the surface quality after cryogenic machining can be better (lower roughness), compared to the machining dry processes [7]. Pu has conducted experiments to prove that compressive residual stresses in a material after cryogenic machining are favorable since they prevent cracks on the surface [8]. Researches of the difference between the influence of the liquid and gaseous phase of nitrogen have proven that the phase has significant impact on cooling layer in Inconel 718 workpiece. This simulates the temperature distribution in the cutting zone during machining, what indirectly influences the tool wear, the surface 
integrity of the workpiece, and the functionality of a final component/product, etc. [9].

First part of the paper presents the protocol of defining the surface heat transfer coeffcient (design of the numerical simulation and validation with experiment), as a function of temperature difference between coolant (liquified nitrogen) and the workpiece surface (Inconel 718 plate). Coeffcient values can not be found in the past publications. In the second part of the paper, the comparision between experimental and simulation cutting forces during cryogenic cutting is conducted. The new acquired values for heat transfer coeficient were put in the FEM model of cryogenic machining.

\section{Theoretical backround}

\subsection{The Surface Heat Transfer Coeffcient}

The most important characteristics affecting the cooling and lubrication performances are: temperature $\mathrm{T}$, heat capacity $\mathrm{Cp}$ and viscosity $v$ [1]. Temperature and heat capacity, determine the cooling capability. Being close to the evaporation point, gas and liquid nitrogen would not really have drastically difference in temperature. However, there is a significant difference between them, concerning specific heat and viscosity, when the phase is changed from liquid to gas $[10,11]$.

Physical properties for both phases are the following: density ( $\rho_{\text {liquid }}=803.6 \mathrm{~kg} / \mathrm{m}^{3}$, $\left.\rho_{\text {gas }}=1.165 \mathrm{~kg} / \mathrm{m}^{3}\right)$, specific heat $\left(C_{\mathrm{p} \text { (liquid) }}=2100 \mathrm{~J} / \mathrm{kgK}, C_{\mathrm{p}(\text { gas })}=1100 \mathrm{~J} / \mathrm{kgK}\right)$, viscosity $\left(v_{\text {fluid }}=1.463 \cdot 10-4\right.$ Pas, $v_{\text {gas }}=0.5 \cdot 10-4$ Pas $)$ and thermal conductivity $\left(\lambda_{\text {liquid }}=0.125 \mathrm{~W} / \mathrm{mK}, \lambda_{\text {gas }}=0.04 \mathrm{~W} / \mathrm{mK}\right)[1]$.

The function of liquified nitrogen delivery to the cutting zone is cooling local area and consequently decreasing tool wear and cutting forces. Thus, it is a cooling process, where a cold flow of the fluid comes to the surface of a warmer body and creates a boundary gas nitrogen film between warm surface and cold liquid nitrogen flow [12]. Heat flux, accepted by the body, is defined by equation 1 :

$$
q=h\left(T_{\text {body }}-T_{\text {fluid }}\right)
$$

where $h[\mathrm{~W} / \mathrm{m} 2 \mathrm{~K}]$ is a surface heat transfer coefficient, $q$ is a heat flux [W/m2], $T_{\text {body }}\left[{ }^{\circ} \mathrm{C}\right]$ is the temperature of the workpiece, and $T_{\text {fluid }}\left[{ }^{\circ} \mathrm{C}\right]$ represents coolant temperature.

\subsection{Cryogenic Machining FEM Model}

Past studies have shown that combining of the Lagrangian and the Eulerian methods (ALE - Arbitrary Lagrangian Eulerian formulation) gives best results for 
prediction of machining process output variables (temperature, cutting forces, stresses, etc.), as numerical simulation of machining processes [13]. The combined ALE method combines strain and the flow of material through the mesh (figure 1). The Lagrangian method most precisely explains the flow of a chip and cutting conditions, but due to the time-consuming numerical simulations, it is more suitable to use the ALE method [14].

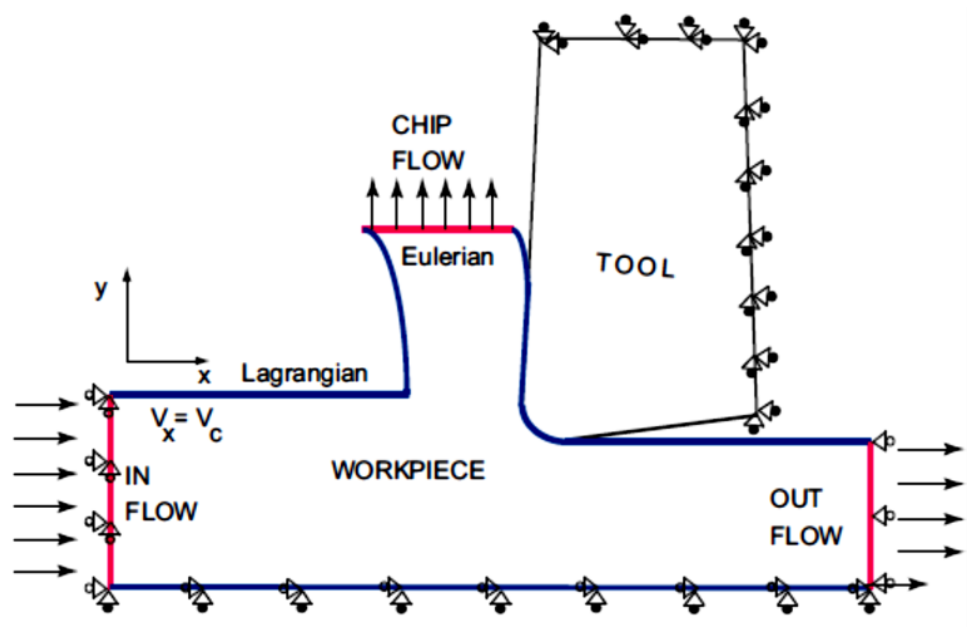

Figure 1. Boundary conditions for the ALE method

For workpiece stress model in a workpiece material, the Johnson-Cook model was used. This model is a mechanism for analysing thermo-visco-plastic behaviour, which consists of three parts: strain hardening, strain and the softening of material due to temperature. The Johnson-Cook model is defined with the equation 2:

$$
\sigma_{e q}=\left[A+B\left(\varepsilon_{p}\right)^{n}\right]\left[1+C \cdot \ln \left(\frac{\varepsilon_{p}}{\varepsilon_{0}}\right)\right]\left[1-\frac{T-T_{0}}{T_{f}-T_{0}}\right]
$$

Past researches have shown that Kobayashi parameters are best to be used for the chosen model because there is minimum deviation between experimental and calculated cutting forces during cryogenic machining [15]. Thus, also in this research, this model will apply for modeling with FEM. Values for Johnson-Cook parameters are: $A=980 \mathrm{MPa}, B=1370 \mathrm{MPa}, C=0.02, n=0.164, m=1.3, \varepsilon_{0}=1$, $T_{\mathrm{m}}=1300{ }^{\circ} \mathrm{C}, T_{0}=20^{\circ} \mathrm{C}[15]$.

\section{$3 \quad$ Experimental Work}

3.1 Measuring of the temperature (the surface heat transfer coeffcient) 
The experiments of measuring temperature in material have been performed, with the aim to define the temperatures (cooling) profiles, while moving the liquified nitrogen jet across the Inconel 718 plate. The surface heat transfer coeffcient has been defined by fitting experimentally measured temperature-time $T_{\exp }(t)$, in Inconel 718, with calculated temperature-time distribution $T_{\text {sim }}(t)$, and with back calculation define the heat transfer coefficient values.

The object, whereto the nitrogen is jetted, was a plate of Inconel 718 (150 x $246 \mathrm{x}$ $2.5 \mathrm{~mm}$ ) polished at $R_{\mathrm{a}}<0.3 \mathrm{um}$ (on the upper side), where the flow of liquified nitrogen was applied (figure 2). On the bottom side of the plate, 3 sets of 5 holes within the distance of $5 \mathrm{~mm}$ were manufactured by EDM machining (center, 2 on the left and 2 on the right of the flow).

System for delivering liquified nitrogen

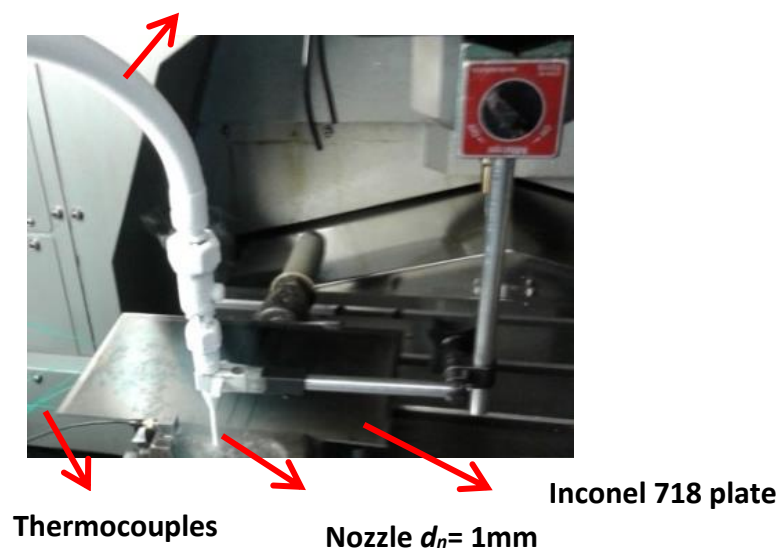

5x NiCr-Ni (K)

Figure 2. The schematic concept of the experiment

The nozzle (diamater $d_{\mathrm{n}}=1 \mathrm{~mm}$ ) was clamped in magnetic holder on the spindle of the CNC machine and moved across the middle of the plate, right above the middle hole, on the polished surface of the plate. Thus, the middle sensor senses the approaching of liquid nitrogen flow, while the side ones sense the distribution of the heat across the plate.

The thermocouples were fixed to the holes, on the back side of the plate. To assure the contact of thermocouple with the workpiece, the thermopaste based on silicon oil with metal oxides was used. The liquified nitrogen has been delivered through the nozzle under pressure of $p=1.8 \cdot 10^{5} \mathrm{~Pa}$. For data acquisition, a NI acquisition card was used. Input parameters were the movement speed of the nozzle $v=(5$, $15,25) \mathrm{m} / \mathrm{min}$, measuring temperature depth $d=(0.1,0.5,1) \mathrm{mm}$ and distance from the center of the plate $x=(0,5,10) \mathrm{mm}$. Output parameter was temperature $T\left[{ }^{\circ} \mathrm{C}\right]$. 
According to the results obtained by measuring the temperature of the material, input parameters for performing simulation have been selected. The reference experiment was chosen to be with the following input parameters: $v=5 \mathrm{~m} / \mathrm{min}, d$ $=0.5 \mathrm{~mm}$ and $x=0 \mathrm{~mm}$. Table 1 presents maximum temperature difference for each thermocouple in dependance of input parameters. One set consists of 5 holes in distance 5 and $10 \mathrm{~mm}$ from the center (thermocouple $\mathrm{T} 3, x=0 \mathrm{~mm}$ ) to each side of the plate.

Table 1. Temperature difference in material at nozzle speed $v=5 \mathrm{~m} / \mathrm{min}$ and depth $d=0.5 \mathrm{~mm}$

\begin{tabular}{|l|c|c|c|c|c|}
\hline Thermocouple $T\left[{ }^{\circ} \mathrm{C}\right]$ & $T 1$ & $T 2$ & $T 3$ & $T 4$ & $T 5$ \\
\hline$x[\mathrm{~mm}]$ & 10 & 5 & 0 & 5 & 10 \\
\hline$\Delta T[\mathrm{~K}]$ & 1.6 & 2.5 & 5.4 & 2.6 & 1.4 \\
\hline
\end{tabular}

The process of moving the nozzle across the plate took $1.8 \mathrm{~s}$. However, the difference to $2.4 \mathrm{~s}$ was predicted for balancing a heat flux in the system. The results show that the change of the temperature in the material is the biggest in the middle of the plate (that corresoinds to the position of the jet nozzle), and it is reached after the nozzle crosses the thermocouple $\mathrm{T} 3(\Delta T=5.4 \mathrm{~K})$.

The reason for this phenomenon can be described with the formation of a gaseous nitrogen film, which causes convective cooling of the material surface. While the nozzle was moving across the plate, it gradually pounded the convective insulated film, which prevented higher cooling rate of the material.

\section{Orthogonal Cryogenic Turning of Inconel 718}

In second part of the experimental evaluation, the operations of orthogonal turning were conducted at CNC Machine Mori Seiki SL-153. The cutting insert was coated with TiAlN (Sandvik Coromant: TCGT 1103 01-UM 1125). The workpiece material was aged Inconel 718 in bars. The method of orthogonal turning was used to simplify the problem for numerical modeling purpose because the process can be simplified to be 2D in nature, what makes numerical modeling easier. For the application of liquified nitrogen (cryogenic cutting), the computercontrolled system (figure 3) SUSCRYMAC has been used. Liquified nitrogen has been applied between the rake face of the tool and chip face. 


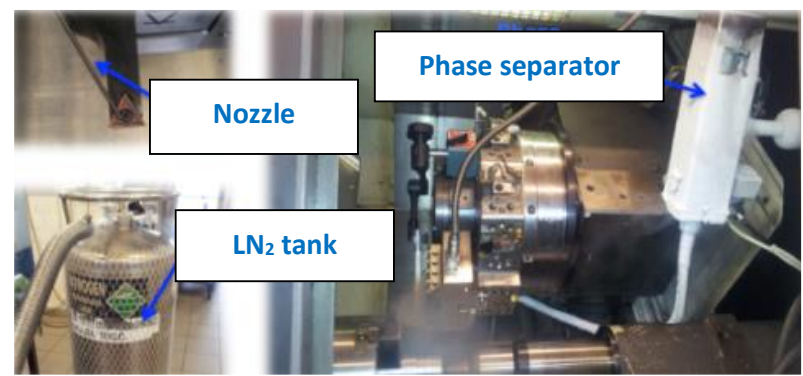

Figure 3. Scheme of the nitrogen delivery device

\subsection{Measuring of the temperature (the surface heat transfer coeffcient)}

In the current case, the numerical simulation was designed in Abaqus/Explicit 6.10., to correlate the model with experiemtnal observaions. For simulating heat transfer through the material there was used the Eulerian formulation [13]. The Eulerian specification of the flow field is a way of looking at fluid motion that focuses on specific locations in the space through which the fluid flows as time passes $[16,17]$. For the gaseous phase of nitrogen, there was designed thin film. The input parameters were: Eulerian formulation, tetrahedral mesh, the nozzle moving speed: $\mathrm{v}=5 \mathrm{~m} / \mathrm{min}$, measuring point at depth $\mathrm{d}=0.5 \mathrm{~mm}$, distance $\mathrm{x}=0$ $\mathrm{mm}$, material mechanical and thermal properties data, as well as the initial and boundary conditions. The output parameter was the temperature. Mechanical and thermal properties of the materials were adapted from literature $[13,6,18,19]$.

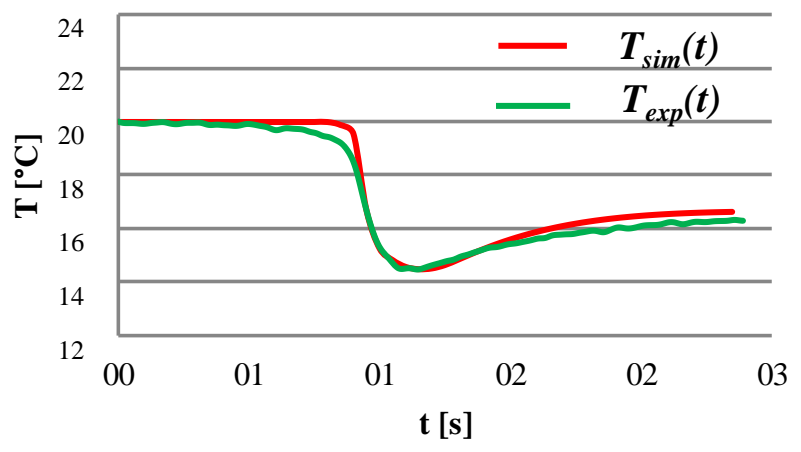

Figure 4. The comparision between experimental $T_{\text {exp }}(t)$ and calculated curve $T_{\text {sim }}(t)$ (temperature measured at depth: $0.5 \mathrm{~mm}$, nozzle speed $v=5 \mathrm{~m} / \mathrm{min}$, distance $x=0 \mathrm{~mm}$ )

Figure 4 present calculated curve, in relation to experimental curve, based on determining surface heat transfer coefficient between the liquified nitrogen and 
the workpiece Inconel 718 surface. The result of determined surface heat transfer coefficent is shown on the table 2 .

Table 2. The surface heat transfer coeffcient in depend on temperature difference between liquified nitrogen and surface workpiece (Inconel 718)

\begin{tabular}{|c|c|c|c|c|c|c|c|}
\hline$\left.\Delta T{ }^{\circ} \mathrm{C}\right]$ & 196 & 172 & 149 & 110 & 60 & 20 & 0 \\
\hline$h\left[\mathrm{~W} / \mathrm{m}^{2} \mathrm{~K}\right]$ & 75000 & 34000 & 16000 & 5800 & 2150 & 1500 & 1500 \\
\hline
\end{tabular}

\subsection{The comparison between experimental and calculated cutting forces during orthogonal cryogenic machining}

In cryogenic orthogonal turning, the flow of liquified nitrogen was directed from the nozzle to the rake face of the cutting tool. Table 3 shows the cutting forces obtained by numerical simulations and experiments. The table presents that experimentally obtained forces slightly differ from the numerical simulation. The reason is simplified in that, that model is only a simplified approximation of real conditions. With the choice of Kobayashi parameters for the Johnson-Cook model (aged Inconel 718), the numerical simulation have in good agreement simulate the experimental results.

\begin{tabular}{|c|c|c|c|c|c|c|}
\hline \multicolumn{3}{|c|}{ Cutting parameters } & \multicolumn{2}{c|}{ Experiment } & \multicolumn{2}{c|}{$\begin{array}{c}\text { Numerical } \\
\text { simulation }\end{array}$} \\
\hline$v_{c}[\mathrm{~m} / \mathrm{min}]$ & $f[\mathrm{~mm} / \mathrm{vrt}]$ & $a_{p}[\mathrm{~mm}]$ & $F_{c}[\mathrm{~N}]$ & $F_{f}[\mathrm{~N}]$ & $F_{c}[\mathrm{~N}]$ & $F_{f}[\mathrm{~N}]$ \\
\hline 25 & 0.04 & 1 & 145 & 120 & 200 & 120 \\
\hline 25 & 0.06 & 1 & 180 & 140 & 220 & 130 \\
\hline 35 & 0.01 & 1 & 355 & 200 & 310 & 130 \\
\hline 35 & 0.01 & 2 & 645 & 510 & 670 & 260 \\
\hline 35 & 0.01 & 3 & 1020 & 680 & 960 & 380 \\
\hline 35 & 0.15 & 1 & 420 & 230 & 450 & 240 \\
\hline 35 & 0.15 & 2 & 990 & 570 & 980 & 380 \\
\hline 50 & 0.1 & 2 & 620 & 330 & 660 & 330 \\
\hline 50 & 0.1 & 3 & 960 & 530 & 1020 & 490 \\
\hline
\end{tabular}

5 Cocnclusion

The focus of the paper is in the determination of the values for surface heat transfer coefficient between liquified nitrogen and Inconel 718 workpiece surface in relation to temperature difference. Additionally, the purpose of this study was to improve FEM model for cryogenic machining. Obtained experimental and calculated cutting forces from numerical simulation are presented. Based on results, the following conclusions can be made: 
- Conducted experiments, of the temperature measurements, when cooling with liquified nitrogen present delayed process because of the formed gaseous nitrogen film (low thermal conductivity $\lambda=0.04 \mathrm{~W} / \mathrm{mK}$ ) on the Inconel 718 workpiece surface.

- Gaseous nitrogen film on the workpiece surface has been removed by jet of liquified nitrogen but gaseous phase has quite great impact because at nozzle speed $\mathrm{v}=5 \mathrm{~m} / \mathrm{min}$ the temperature drop in material is only $\Delta T=$ $5.5 \mathrm{~K}$.

- In the numerical simulation, a gasous film was designed, which escribes boiling nature of the nitrogen on the warm workpiece surface.

- The surface heat transfer coefficient decreases with decreasing temperature difference between the coolant and workpiece surface because nitrogen is losing its cooling ability (bubble boiling and formation of insulating layer on the workpiece surface).

- The comparison between experimental and calculated cutting forces showed good agreement and confirm that Johnson-Cook parameters are good approximation of material behaviour.

\section{References}

[1] Pusavec F, Courbon C, Rech J, Kopač J, Jawahir IS. Importance of the Nitrogen Phase on the Cryogenic Machining Performance ASME 2014; DOI: 10.1115/MSEC2014-3992.

[2] Pušavec F, Hamdi H, Kopač J, Jawahir IS. Surface Integrity in Cryogenic Machining of Nickel- based Alloy - Inconel 718. Journal of Material Processing Technology, 2011, vol. 211, p. 773-783.

[3] Pušavec F, Deshpande A, Yang S, M'Saoubi R, Kopac J, Dillon OW Jr, Jawahir IS. Sustainable machining of high temperature Nickel alloy -Inconel 718: part 1-predictive performance models. Journal of Cleaner Production, 2014, vol. 81, p. 255-269.

[4] Yildiz Y, Nalbant M. A Review of Cryogenic Cooling in Machining Processes. International Journal of Machine Tools \& Manafacture, 2008, vol. 48, p. 947-964.

[5] Ding Y, Hong SY. A study of the cutting temperatures in machining processes cooled by liquid nitrogen. Socety of Mechanical Engineering MR, 1995, p. 95-113.

[6] Courbon C, Pušavec F, Dumont F, Rech J, Kopač J. Tribological behaviours of TiAl4V and Inconel 718 under dry and cryogenic conditions - Application to the context of machining with carbide tools, Tribology International, 2013, p. 72-82.

[7] Kaynak Y, Karaca HE, Jawahir IS. Surface integrity characteristics of NiTi shape memory alloys resulting from dry and cryogenic machining. Procedia CIRP, 2014, vol. 13, p. 393-398. 
[8] Pu Z, Outeiro J, Batista AC, Dillon OW Jr, Puleo DA, Jawahir IS. Surface Integrity in Dry and Cryogenic Machining of AZ31B Mg Alloy with Varying Cutting Edge Radius Tools. 1st CIRP Conference on Surface Integrity Procedia Engineering, 2011, vol. 19, p. 282-287.

[9] Ambrosy F, Zanger F, Schulze V, Jawahir IS. An Experimental Study of Cryogenic Machining on Nanocrystalline Surface Layer Generation. 2 CIRP Conference on Surface Integrity, 2014, p. 169-174.

[10] Bryson WE. Cryogenics, Hanser Gardner Publications, Cincinnati, 1999.

[11] Weisend JG. The Handbook of Cryogenic Engineering, Taylor \& Francis, Philadelphia, 1998.

[12] Leinhard JH IV, Lienhard JH V. A Heat Transfer Textbook $3^{\text {rd }}$ Edition. Phlogiston Press Camridge Massachusetts, USA, 2008.

[13] Arrazola PJ, Özel T. Investigations on the Effects of Friction Modeling in Finite Element Simulation of Machining. International Journal of Mechanical Sciences, 2010, vol. 52, p. 31-42.

[14] Arrazola PJ, Özel T, Umbrello D, Davies M, Jawahir IS. Recent Advances in Modeling of Metal Machining Processes. CIRP Annals - Manufacturing Technology, 2013, vol. 62, issue 2, p. 698-715.

[15] Kobayashi T, Simons JW, Brown CS, Shockey DA. Plastic flow behaviour of Inconel 718 under dynamic shear loads, International Journal of Impact Engineering, 2008, vol. 35, p. 389-396.

[16] Batchelor GK. An Introduction to Fluid Dynamics, Cambridge University Press, United Kingdom, 1973.

[17] Lamb H. Hydrodynamics (6th ed.), Cambridge University Press, United Kingdom, 1994.

[18] Courbon C, Šajn V, Kramar D, Rech J, Kosel F, Kopač J. Investigation of Machining Performance in High Pressure Jet Assisted Turning of Inconel 718: A Numerical model. Journal of Material Processing Technology, 2011, vol. 211, issue 11, p. 1834-1851.

[19] ELPRO, from http://www.elpro.si/, accessed on 2015-10-9. 


\title{
Chapter 17
}

\section{Optimization of Single Pass Welding of High Carbon Bainitic Steel}

\author{
PETER KIRBIŠ, TOMAŽ VuHERER, TOMAŽ IRGOLIČ \& IVAN ANŽEL
}

\begin{abstract}
Welding of high carbon steels presents a technological challenge, as such alloys are prone to cold cracking, due to formation of brittle high carbon martensite. A possible solution can be found in the formation of a carbide free lower bainitic microstructure, which introduces only a fraction of distortions, commonly encountered with martensite. The formation of bainite is however associated with an excessively long heat treatment. A group of newly developed steels, which exhibit exceptionally fast kinetics of bainite formation at temperatures below $250^{\circ} \mathrm{C}$, are termed KAB (Kinetically Activated Bainite) steels. When such steels are welded, using suitable parameters, bainite is formed instead of martensite, enabling the obtainment of a uniform hardness profile throughout the weld and heat affected zone. As low heat inputs are have proven favorable, single pass welding using the activated TIG method was deemed suitable and is the subject of the current work.
\end{abstract}

Keywords: KAB-Kinetically activated bainite $\cdot$ welding of high carbon steel $\bullet$ A-TIG welding $\bullet$ carbide free lower bainite $\bullet$ welding of ultra high strength steel

CORRESPONDENCE ADRESS: Peter Kirbiš, University of Maribor, Faculty of Mechanical Engineering, Smetanova ulica 17, 2000 Maribor, Slovenia, e-mail: peter.kirbis@um.si. Tomaž Vuherer, Ph.D., Assistant Professor, University of Maribor, Faculty of Mechanical Engineering, Smetanova ulica 17, 2000 Maribor, Slovenia, e-mail: tomaz.vuherer@um.si. Tomaž Irgolič, Ph.D., Researcher, University of Maribor, Faculty of Mechanical Engineering, Smetanova ulica 17, 2000 Maribor, Slovenia, e-mail: tomaz.irgolic@um.si. Ivan Anžel, Ph.D., Full Professor, University of Maribor, Faculty of Mechanical Engineering, Smetanova ulica 17, 2000 Maribor, Slovenia, e-mail: ivan.anzel@um.si.

https://doi.org/10.18690/978-961-286-028-8.17 ISBN 978-961-286-028-8

(C) 2017 University of Maribor Press

Available at: http://press.um.si. 


\section{Introduction}

Low temperature carbide free bainitic steels are known for their superior combination of mechanical properties, they are capable of achieving tensile strengths up to $2500 \mathrm{MPa}$, while maintaining reasonable values of ductility and fracture toughness [1], [2]. Their mechanical properties are derived from the very fine scale of bainitic ferrite plates embedded within a matrix of retained austenite. The latter undergoes a stress/strain induced transformation into martensite and gives rise to work hardening, known as the TRIP (transformation induced plasticity) effect [3]. In order to obtain fine bainitic ferrite subunits with a thickness of only 20-50 nm requires low transformation temperatures between 200 and $300^{\circ} \mathrm{C}$. These unfortunately coincide with prolonged isothermal holding times, which depending on the steels composition may last from 8 hours or as long as 10 days [4]. The bainite reaction is thought to be of a displacive character, therefore the rate limiting factor is the formation of bainite nuclei [5]. This requires the paraequilibrium partitioning of carbon [6] and consequently the kinetics are slowed down exponentially with decreasing temperatures [7]. To ensure the low transformation temperatures and a carbide free bainitic microstructure substantial quantities of carbon and about $1.5 \% \mathrm{Si}$ are present in the steels compositions [8]. The amount of carbon is rarely below $0.8 \mathrm{w} \%$, resulting in high carbon equivalents.

When such steels are welded they are susceptible to cold cracking [9] due to the formation brittle martensite within the weld and reaustenitized heat affected zone (HAZ). Therefore they need to be preheated, to a temperature which usually is close to the designated temperature of bainite formation. Prolonged isothermal holding times are then applied to regenerate the bainitic microstructure within the weld and reaustenitized region [10]. As this treatments can last from several hours to days, they are performed at a slightly higher temperature, then the initial austempering. The application of rotary impacted trailed welding is also known to accelerate the regeneration [11]. It has been shown that the strength of the weld can be comparable to that of the base material as welds with tensile strengths of up to $2100 \mathrm{MPa}$ (92\% of the strength of base materials), have been obtained [12]. On the other hand the reaustenitized region is somewhat more prone to failure due to grain growth. It is known that larger grains form smaller fractions of bainite [13], thus requiring the heat inputs to be tightly controlled [14].

A new grade of low temperature bainitic steels with exceptionally rapid transformation kinetics at temperatures below $200^{\circ} \mathrm{C}$, has been recently developed. The mechanism through which this has been achieved is by the introduction of numerous Nano scale precipitates. This precipitates develop carbon depleted zones, which upon cooling act as potential nucleation sites for the bainitic ferrite subunits. With such an approach kinetically suitable conditions for the bainite reaction are obtained at a high temperature and it thus proceeds rapidly 
upon cooling below Bs. By virtue of their specific trait this newly developed alloys have hence been named kinetically activated bainite (KAB) steels. In these steels fully bainitic microstructures can be easily obtained during air cooling, without the need for any isothermal holding procedures. The weldability of the new steel was subject to previous investigations, and it has been observed that the bainitic microstructure regenerates within the weld.

For certain applications the steel needs to be soft annealed and machined if the final parts are to be then welded it is preferable to perform welding prior to final austempering. The whole welded part can then be heat treated and a uniform hardness obtained throughout the whole section. The aim of this paper is to optimize the welding parameters during single pass welding of soft annealed steel plates, and to investigate their effect upon the microstructure. The latter is of interest as the precipitates which promote the formation of bainite might have coarsened during the soft annealing process.

\section{$2 \quad$ Materials and methods}

The alloy was produced using master alloys and pure components, induction melted in vacuum and mold cast under a protective atmosphere of pure argon. The alloys chemical composition can be seen in table 1 .

Table 1: Steel composition (in $w \%$ )

\begin{tabular}{|c|c|c|c|c|c|c|c|c|c|c|c|c|c|c|}
\hline $\mathrm{C}$ & $\mathrm{Si}$ & $\mathrm{Mn}$ & $\mathrm{Mo}$ & $\mathrm{Cr}$ & $\mathrm{V}$ & $\mathrm{Cu}$ & $\mathrm{Al}$ & $\mathrm{Mg}$ & $\mathrm{N}$ & $\mathrm{Ni}$ & $\mathrm{Ti}$ & $\mathrm{Zr}$ & $\mathrm{P}$ & $\mathrm{S}$ \\
\hline 0.8 & \multicolumn{10}{c|}{ SUM $8.2 \%$} \\
\hline
\end{tabular}

Certain elements have been introduced from the master alloys used or are present as unavoidable impurities. The ingot was then homogenized at $1200^{\circ} \mathrm{C}$ for 2 days, followed by hot rolling at $1050{ }^{\circ} \mathrm{C}$. During the latter the thickness was reduced from the initial $18 \mathrm{~mm}$ to a final thickness of $6 \mathrm{~mm}$, followed by air cooling. Upon cooling to room temperature the newly developed steel forms a fully bainitic microstructure, comprised of fine bainitic ferrite sheaves, separated by fine blocks of retained austenite, as shown in Fig. 1. 


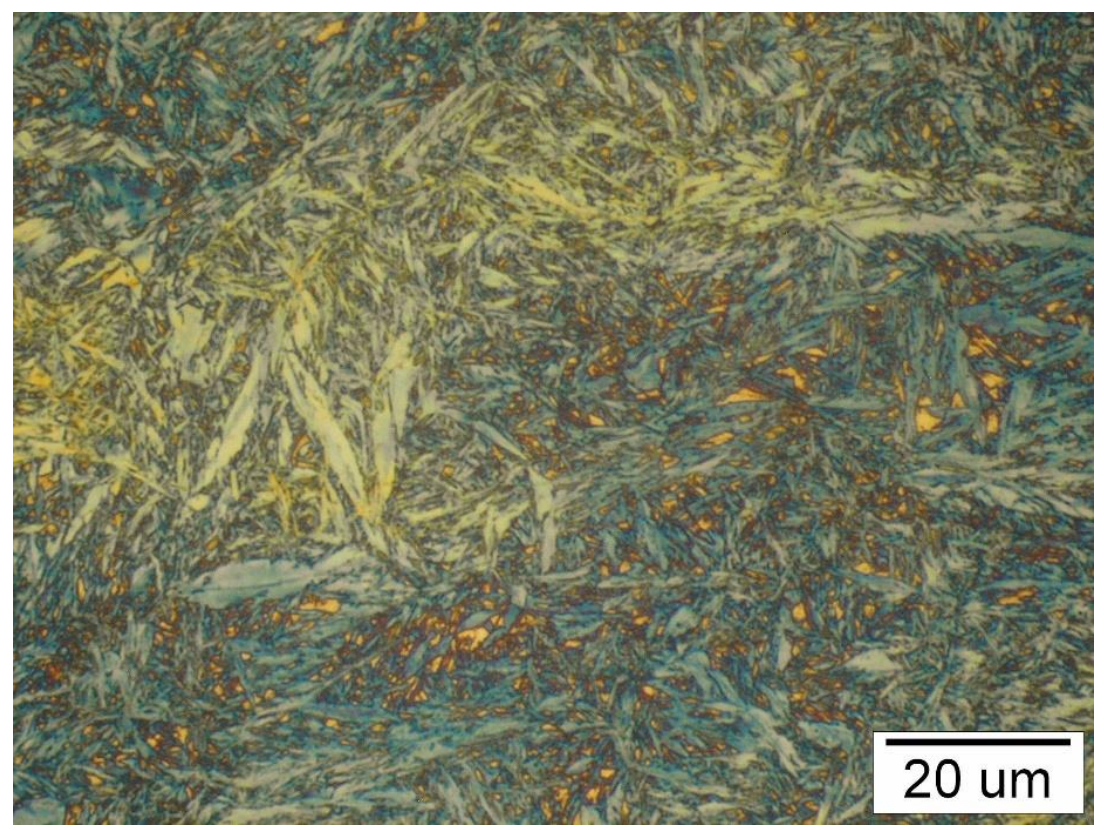

Figure 1: Initial carbide free bainitic microstructure obtained after air cooling

(etched with $7 \% \mathrm{Na}_{2} \mathrm{~S}_{2} \mathrm{O}_{5}$ )

The microstructure is revealed by tint etching with $7 \%$ aqueous sodiummetabysulfite (Na2S2O5). This etchant is known to respond by coloring bainitic regions blue and martensite brown, whereas retained austenite etches white or in a slight purple [18]. In the hot rolled and air cooled condition, the steel has a high hardness of $660 \mathrm{HV} 1$. And exhibits a yield strength of $1800 \mathrm{MPa}$. The retained austenite within the microstructure introduces a TRIP effect resulting in about 6 $\%$ of homogeneous elongation, the steel continuously work hardens during straining to an ultimate tensile strength of $2800 \mathrm{MPa}$.

Prior to welding the steel was soft annealed by applying a rapid spheroidization treatment [15], with the use of the divorced pearlite reaction. The latter is very easily obtained in the new steel due to the high coherency between ferrite and cementite, which is known to promote this perlite morphology. After spheroidizing, we obtain a low hardness of 225HV1. This enabled the steel to be then milled and the final thickness reduced to $3 \mathrm{~mm}$. The microstructure in the soft annealed state is shown in Fig. 2. 
P. Kirbiš, T. Vuherer, T. Irgolič, U. Župerl \& I. Anžel:

Chapter 17 Optimization of Single Pass Welding of High Carbon Bainitic

Steel

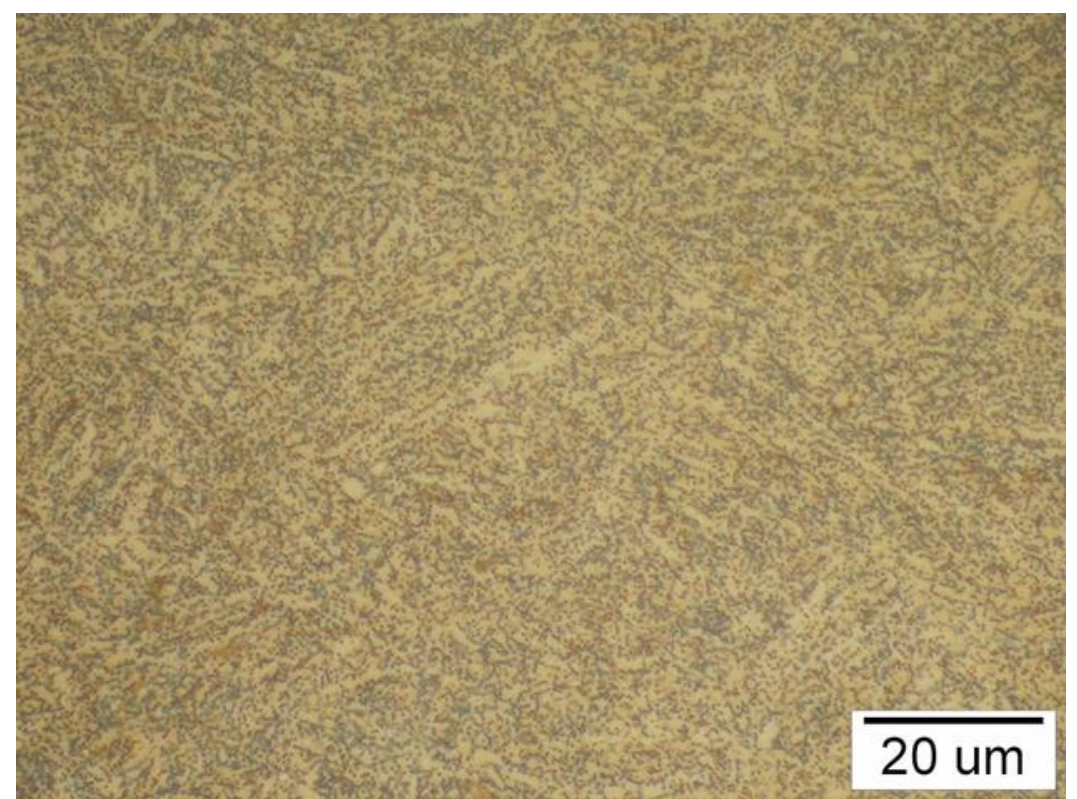

Figure 2: Microstructure after spheroidization annealing, visible are numerous spherical cementite particles and prior bainite lath boundaries. (Etched with Viella)

Critical thermodynamic temperatures such as Bs, Ms, as well as the temperatures of onset and completion of austenite formation Ac1 and Ac3 respectively, are summarized in table 2. The methods used in the calculations can be found in [16], [17].

Table 2: Calculated critical thermodynamic temperatures of the newly developed $K A B$ steel $\left(\right.$ in $\left.^{\circ} \mathrm{C}\right)$

\begin{tabular}{|c|c|c|c|}
\hline $\mathrm{Ac}_{1}$ & $\mathrm{Ac}_{3}$ & $\mathrm{Bs}$ & $\mathrm{Ms}$ \\
\hline 703 & 879 & 240 & 51 \\
\hline
\end{tabular}

Welding was performed with single pass welds of too adjacent plates on a steel backing, without the use of preheating. Prior to welding an active flux was applied to increase the penetration depth. Different welding speeds were tested and the results are summarized in table 3 . The heat input was consequently varied as described by equation 1 in accordance with the standard EN 1011-1:

$$
Q=\frac{U \cdot I \cdot 60}{V \cdot 1000} \cdot \mathrm{k}\left[\frac{\mathrm{kJ}}{\mathrm{mm}}\right]
$$


Where $U, I$ and $V$ are the welding voltage [A], current $[\mathrm{V}]$ and speed $[\mathrm{mm} / \mathrm{min}]$ respectively. The efficiency of the welding process needs to be accounted for as well and in the case of TIG welding the above standard recommends the value of $\mathrm{k}$ as 0.6 .

Table 3: Welding parameters

\begin{tabular}{|c|c|c|c|c|c|}
\hline Weld & $\begin{array}{c}\text { Heat input } \\
{[\mathrm{J} / \mathrm{cm}]}\end{array}$ & $\begin{array}{c}\text { Amp. } \\
{[\mathrm{A}]}\end{array}$ & $\begin{array}{c}\text { Voltage } \\
{[\mathrm{V}]}\end{array}$ & $\begin{array}{c}\text { Speed } \\
{[\mathrm{cm} / \mathrm{min}]}\end{array}$ & $\begin{array}{c}\text { Penetration } \\
\text { depth }[\mathrm{mm}]\end{array}$ \\
\hline $\mathbf{1}$ & 13.630 & 142 & 16 & 6 & 3 \\
\hline $\mathbf{2}$ & 10.220 & 142 & 16 & 8 & 3 \\
\hline $\mathbf{3}$ & 8.172 & 142 & 16 & 10 & 2,7 \\
\hline
\end{tabular}

\section{$3 \quad$ Results}

Samples for metallographic investigation were EDM cut, and hot mounted in resin. Preparation proceeded by grinding using SiC papers from P220 to P4000, followed by polishing using $1 \mu \mathrm{m}$ diamond suspension, the final step was polishing with $0.05 \mu \mathrm{m}$ colloidal alumina. Hardness measurements were performed using a Vickers hardness tester with a $1 \mathrm{~kg}$ load and a spacing of $10 \mathrm{~d}$ $(0.6 \mathrm{~mm})$. Metallographic observations of the etched samples were performed with an optical microscope using polarized light. The microstructure of the weld and reaustenitized region produced by a high heat input is shown in Fig. 3. It can be seen that due to the high heat input appreciable grain growth occurs within the reaustenitized region, where the grains have coarsened up to a size of about 200 $\mu \mathrm{m}$. Grain growth is accompanied with the segregation of alloying elements towards the grain boundaries, and the retention of austenite in the adjacent area upon cooling. The microstructures were revealed by tint etching with $7 \%$ aqueous sodium-metabysulfite. Coloration using the latter strongly suggests a predominantly bainitic microstructure with some martensite formed throughout the weld and in the heat affected zone. As this phenomena are thought to originate from excessive heating, we attempt to mitigate them by reducing heat input, by means of a faster welding speed. 
P. Kirbiš, T. Vuherer, T. Irgolič, U. Župerl \& I. Anžel: Chapter 17 Optimization of Single Pass Welding of High Carbon Bainitic Steel

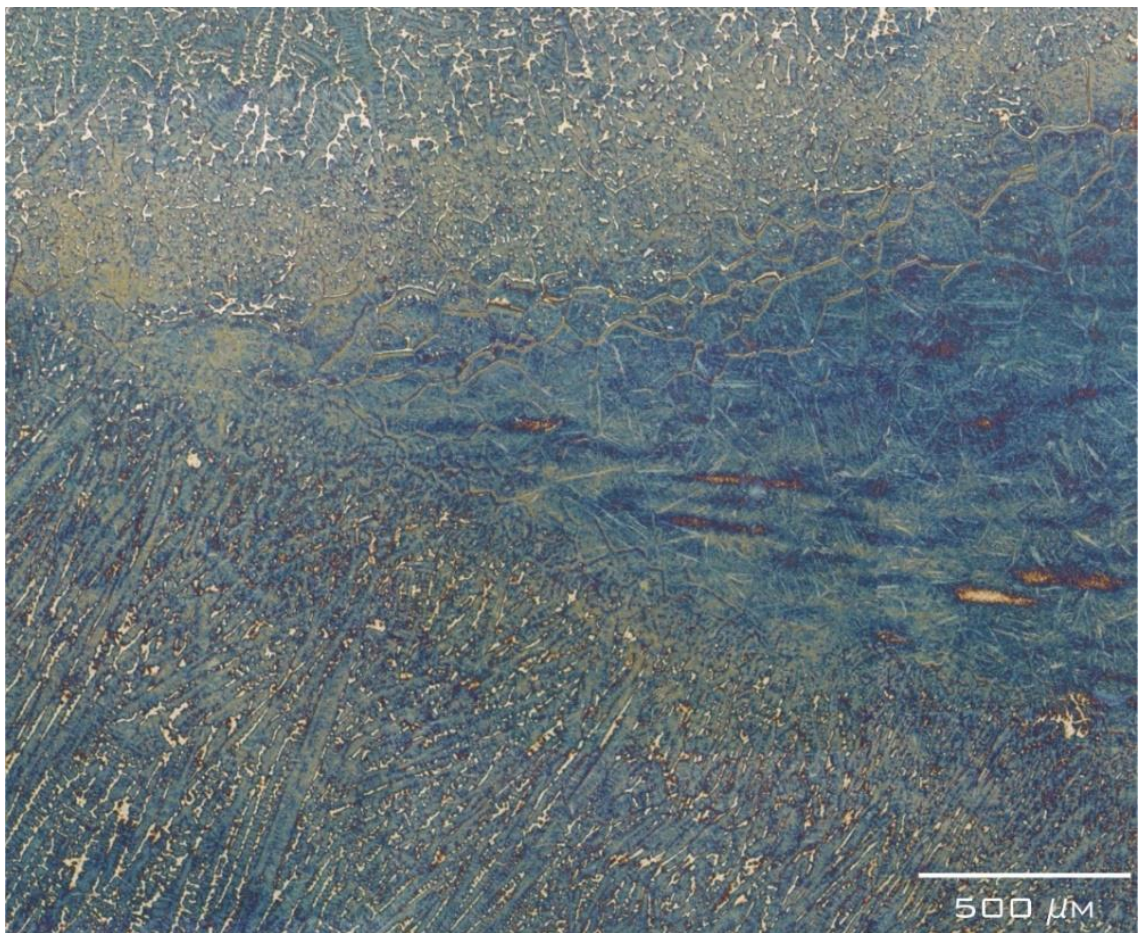

Figure 3: Weld microstructure formed with a high heat input, visible are radially oriented dendrites and severe grain growth (etched with $7 \% \mathrm{Na}_{2} \mathrm{~S}_{2} \mathrm{O}_{5}$ )

An example of a weld produced using a low heat input can be seen in Fig. 4, the dotted line indicates the position of the welded plates.

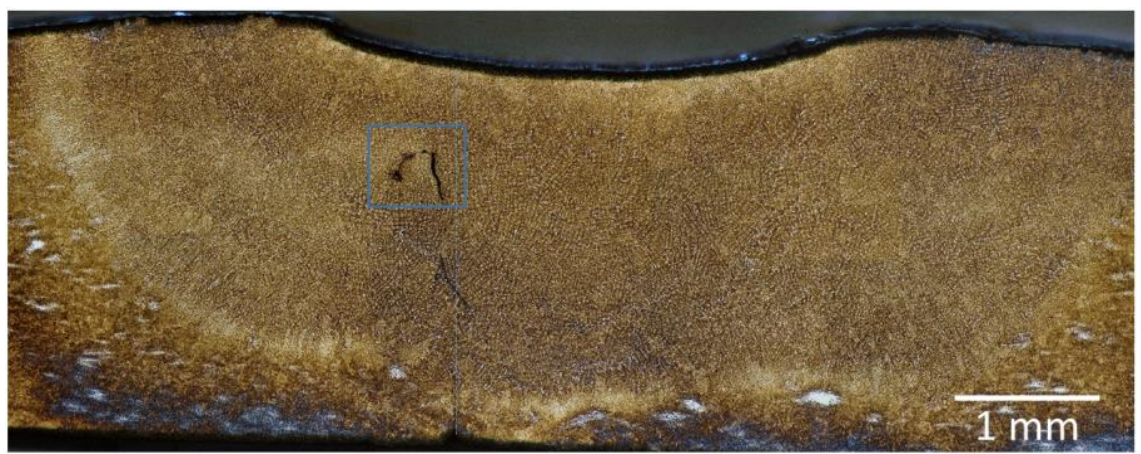

Figure 4: Microstructure of Weld 3, showing the weld bead, HAZ and centerline porosity due to insufficient fusion (etched with Viella) 
A more detailed view of the weld is provided in Fig. 5. In contrast a low heat input will result in a finer weld microstructure and reduce the amount of grain growth in Heat Affected Zone (HAZ), the latter is further reduced by the use of single pass welding, as previous studies have shown the weld intersections to be somewhat heterogeneous with respect to hardness.

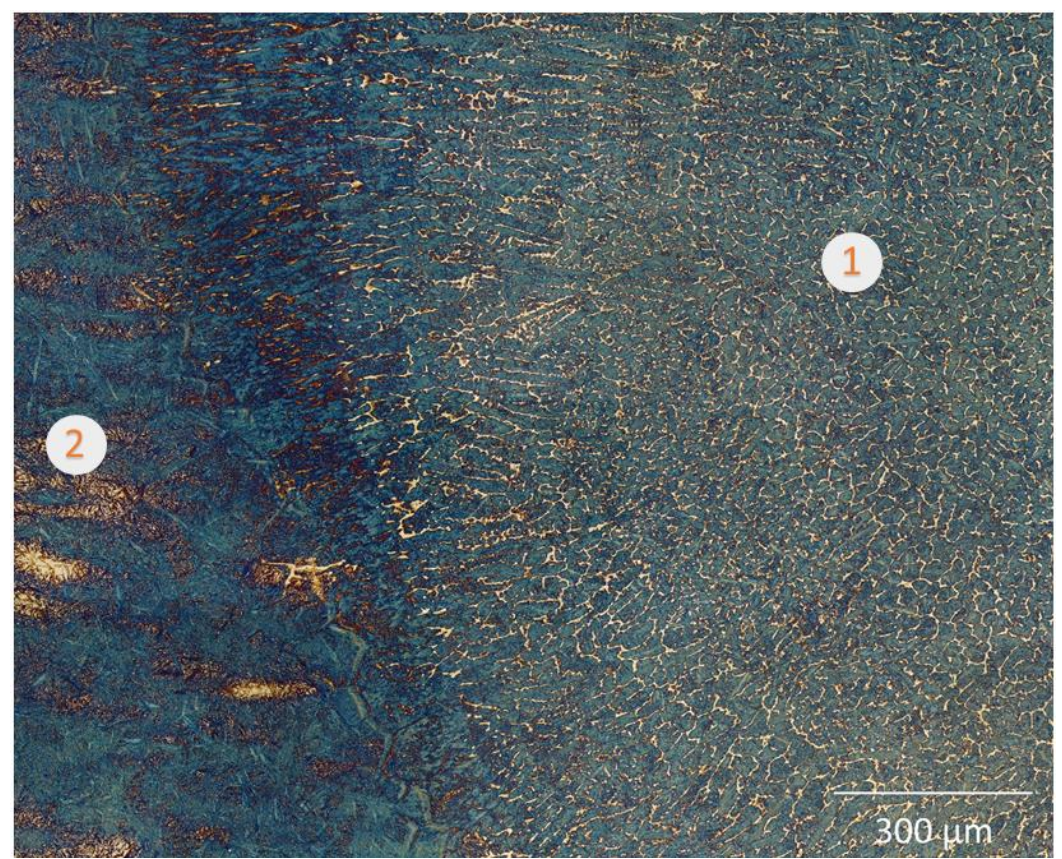

Figure 5: Weld microstructure of weld 3, due to a lower heat input the solidification morphology changes towards equiaxed dendrites. Grain growth and coarse retained austenite are still present but to a lesser extent (etched with $7 \% \mathrm{Na}_{2} \mathrm{~S}_{2} \mathrm{O}_{5}$ )

The sites of interest are the martensite islands in the HAZ, and the dendritic microstructure of the weld. After single pass welding with the adjusted parameters all of the welds exhibit a uniform hardness of $640 \mathrm{HV} 1$ throughout the entire weld as shown in table 4. From the micrograph in Fig. 6-B it can be seen that appreciable segregations within the heat affected zone are still visible, but to a lesser extent. The morphology of the weld microstructure changes from radially orientated dendrites, towards more equiaxed dendrites with a slight radial character adjacent to the HAZ as can be seen in Fig. 5. 


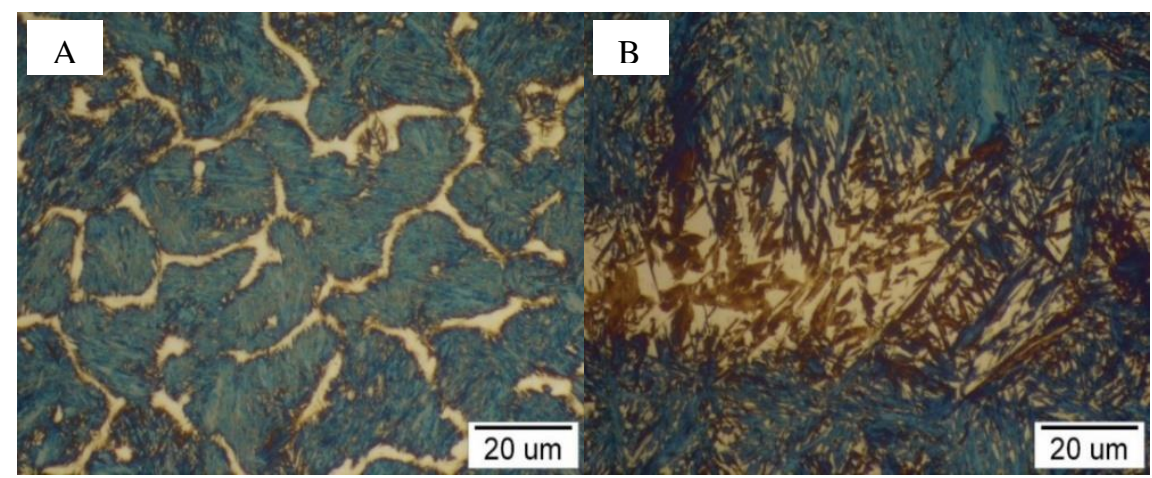

Figure 6: A.) Detail 1, showing equiaxed dendrites formed within weld 3. B.) Detail 2, showing the localized formation of martensite and coarse retained austenite blocks (etched with $7 \% \mathrm{Na}_{2} \mathrm{~S}_{2} \mathrm{O}_{5}$ )

From the measurements in table 4, it can be seen that the highest hardness is attained within the weld, as the remaining material remains spheroidized, therefore we observe a sharp decline in hardness as we enter the HAZ.

Table 4: Properties of different welds

\begin{tabular}{|c|c|c|c|}
\hline Weld & Weld y [V\%] & $\begin{array}{c}\text { Width of reaustenitized zone } \\
{[\mathrm{mm}]}\end{array}$ & $\begin{array}{c}\text { Hardness } \\
{[\mathrm{HVI}]}\end{array}$ \\
\hline 1 & 12.0 & 2.1 & 640 \\
\hline 2 & 10.2 & 1.6 & 640 \\
\hline 3 & 9.7 & 1.2 & 642 \\
\hline
\end{tabular}

\section{Discussion}

During single pass welding the hardness of the different welds is uniform throughout the weld, and almost constant between the different welds. The heat input however greatly influences the width of the reaustenitized region, and the penetration depth. The latter has proven too shallow only in the case of weld 3 . Weld 3 is also notably different as it solidified as equiaxed dendrites. The solidification morphology also exerts a certain influence on the total amount of retained austenite measured in the normal cross section, as can be seen in table 4 . The metallographic analysis conclusively show that the bainitic microstructure was able to regenerate during the cooling of the weld. This offers new possibilities for application of KAB steels, where the as welded properties of the weld are not as important as the final properties after reheating to $1100^{\circ} \mathrm{C}$ followed by air cooling. The latter does however not eliminate banding, which needs to be mitigated beforehand. 
The welds produced at higher welding speeds have a preferable microstructure from the point of view of toughness, however they have shown to be prone to centerline porosity as marked by the square in Fig. 4, which occurs due to the somewhat poor liquidity of the molten metal. The latter can be traced back to its high aluminum content, which is known to exert this effect. We observe substantial localized formation of martensite or even retention of coarse retained austenite. These have been discussed in previous works, but suffice to say they are the cause of embrittlement in such microstructures [18]. Manganese is known to promote banding and localized formation of martensite in high strength steels [19] and even softer grades like dual phase steels [20], where the latter commonly contain about $2 \%$ of Mn. Its elimination is possible by optimization of the hot rolling treatment. Manganese is commonly present in low temperature bainitic steels, due to the high hardenability requirements to form such microstructures [21], [22], and has been shown as beneficial in improving the toughness [23]. Therefore it is not viable to completely remove it from the steels composition. The hardness of the welds is highly homogeneous and shows no appreciable variations across the three welds studied. This might be explained by the fact that all welds were produced from an initially spheroidized microstructure, as generally speaking the hardness tends to vary as a function of the heat input.

\section{$5 \quad$ Conclusions}

It has been shown that the concept of KAB steels can be applied during welding of the steel from the spheroidized condition. Significant segregations which result in the formation of coarse retained austenite regions within the reaustenitized zone remain present even after appreciable reductions in the heat input. The latter is however favorable as it reduces the total amount of retained austenite. Therefore it seems that the weld integrity can only be further improved by alterations of the chemical composition. In particularly the Mn content is thought to be the cause of the observed banding, and will either have to be regulated or the hot rolling treatment optimized. Lower heat inputs result in improved weld solidification microstructures, but provide pure fusion properties. Due to porosity being present at lower heat inputs the use of an additive material is thought to be favorable, and should be subject to further studies. The additive material should be designed with the aim to minimize interdendritic austenite, or to produce it with very high stability to provide sufficient toughness at low temperatures.

\section{References}

[1] F. G. Caballero and H. K. D. H. Bhadeshia, "Very strong bainite," Curr. Opin. Solid State Mater. Sci., vol. 8, no. 3-4, pp. 251-257, 2004.

[2] H. K. D. H. Bhadeshia, "The first bulk nanostructured metal," Sci. Technol. Adv. Mater., vol. 14, no. 1, pp. 1-7, 2013. 
[3] B. C. De Cooman, "Structure-properties relationship in TRIP steels containing carbide-free bainite," Curr. Opin. Solid State Mater. Sci., vol. 8, no. 3-4, pp. 285303, 2004.

[4] F. G. Caballero and H. K. D. H. Bhadeshia, "Acceleration of Low-temperature Bainite," vol. 43, no. 11, pp. 1821-1825, 2003.

[5] M. J. Santofimia, F. G. Caballero, C. Capdevila, C. García-Mateo, and C. G. De Andrés, "New Model for the Overall Transformation Kinetics of Bainite. Part 1: the Model," Mater. Trans., vol. 47, no. 10, pp. 2465-2472, 2006.

[6] Z. G. Yang and H. S. Fang, "An overview on bainite formation in steels," Curr. Opin. Solid State Mater. Sci., vol. 9, no. 6, pp. 277-286, 2005.

[7] H. K. D. H. Bhadeshia, "Very Short and Very Long Heat Treatments in the Processing of Steel," Mater. Manuf. Process., vol. 25, no. 1-3, pp. 1-6, 2010.

[8] H. K. D. H. Bhadeshia, "Nanostructured bainite," Proc. R. Soc. A Math. Phys. Eng. Sci., vol. 466, no. 2113, pp. 3-18, 2010.

[9] W. Savage, E. Nippes, and E. Szekeres, "Hydrogen induced cold cracking in a low alloy steel," Weld. Journal, Res. ..., 1976.

[10] K. Fang, J. G. Yang, X. S. Liu, K. J. Song, H. Y. Fang, and H. K. D. H. Bhadeshia, "Regeneration technique for welding nanostructured bainite," Mater. Des., vol. 50, pp. 38-43, 2013.

[11] K. Fang, J. G. G. Yang, K. J. J. Song, X. S. S. Liu, and H. Y. Y. Fang, “Acceleration of regeneration treatment for nanostructured bainitic steel by rotary impacting trailed welding," J. Mater. Process. Tech., no. August 2015, 2014.

[12] K. Fang, J. G. Yang, K. J. Song, X. S. Liu, Z. B. Dong, and H. Y. Fang, "Microstructure and mechanical properties of nanostructured bainite weld with regeneration," Met. Mater. Int., vol. 20, no. 5, pp. 923-928, 2014.

[13] S. J. Lee, J. S. Park, and Y. K. Lee, "Effect of austenite grain size on the transformation kinetics of upper and lower bainite in a low-alloy steel," Scr. Mater., vol. 59, no. 1, pp. 87-90, 2008.

[14] K. Fang, J. G. Yang, K. J. Song, X. S. Liu, J. J. Wang, and H. Y. Fang, "Study on tempered zone in nanostructured bainitic steel welded joints with regeneration," Sci. Technol. Weld. Join., vol. 19, no. 7, pp. 572-577, 2014.

[15] a. S. Pandit and H. K. D. H. Bhadeshia, "Divorced pearlite in steels," Proc. R. Soc. A Math. Phys. Eng. Sci., vol. 468, no. 2145, pp. 2767-2778, 2012.

[16] H. K. D. H. Bhadeshia, "Thermodynamic analysis of isothermal transformation diagrams," Met. Sci., vol. 16, no. March, pp. 159-165, 1982.

[17] O. G. Kasatkin, B. B. Vinokur, and V. L. Pilyushenko, "Calculation models for determining the critical points of steel," Met. Sci. Heat Treat., vol. 26, no. 1, pp. 2731, 1984.

[18] C. García-Mateo and F. G. Caballero, "The Role of Retained Austenite on Tensile Properties of Steels with Bainitic Microstructures," Mater. Trans., vol. 46, no. 8, pp. 1839-1846, 2005.

[19] S. a. Khan and H. K. D. H. Bhadeshia, "The bainite transformation in chemically heterogeneous 300M high-strength steel," Metall. Trans. A, vol. 21, no. 3, pp. 859$875,1990$.

[20] F. G. Caballero, A. García-Junceda, C. Capdevila, and C. García de Andrés, "Evolution of Microstructural Banding during the Manufacturing Process of Dual Phase Steels," Mater. Trans., vol. 47, no. 9, pp. 2269-2276, 2006. 
Steel

[21] M. N. Yoozbashi, S. Yazdani, and T. S. Wang, "Design of a new nanostructured, high-Si bainitic steel with lower cost production," Mater. Des., vol. 32, no. 6, pp. 3248-3253, 2011.

[22] C. Garcia-Mateo, F. G. Caballero, T. Sourmail, J. Cornide, V. Smanio, and R. Elvira, "Composition design of nanocrystalline bainitic steels by diffusionless solid reaction," Met. Mater. Int., vol. 20, no. 3, pp. 405-415, 2014.

[23] F. G. Caballero, J. Chao, J. Cornide, C. García-Mateo, M. J. Santofimia, and C. Capdevila, "Toughness deterioration in advanced high strength bainitic steels," Mater. Sci. Eng. A, vol. 525, no. 1-2, pp. 87-95, 2009. 


\title{
Chapter 18
}

\section{Microstructure and Properties of Kinetically Activated Bainite (KAB) Steels}

\author{
PETER KIRBIŠ, IVAN ANŽEL, TOMAŽ IRGOLIČ \& MIHAEL BRUNČKO
}

\begin{abstract}
Within the current literature there exists a vast amount of data, derived from numerous observations confirming a sluggish bainite formation at low temperatures. This feature is so predominant it is considered an inherent property of the bainite transformation, and has been known as far back as the very first mention of bainite, where the steel was transformed at $200^{\circ} \mathrm{C}$ in excess of 10 hours. The new methodology and alloy design concept of KAB (Kinetically activated bainite) steels enables the formation of carbide free nanostructured bainite in a matter of seconds. The bainite formed within the new grade is very fine and exhibits a hardness between $660 \mathrm{HV} 1$ upon air cooling, which corresponds to tensile strengths of up to $2800 \mathrm{MPa}$, with predominantly uniform elongations due a pronounced TRIP effect.
\end{abstract}

Keywords: - bulk nanostructured steel - phase transformations in steels $\bullet$ ultra high strength steels $\bullet$ transformation induced plasticity steels $\bullet$ rapid bainite formation at low temperatures

CORRESPONDENCE ADRESS: Peter Kirbiš, University of Maribor, Faculty of Mechanical Engineering, Smetanova ulica 17, 2000 Maribor, Slovenia, e-mail: peter.kirbis@um.si. Ivan Anžel, Ph.D., Full Professor, University of Maribor, Faculty of Mechanical Engineering, Smetanova ulica 17, 2000 Maribor, Slovenia, e-mail: ivan.anzel@um.si. Tomaž Irgolič, Ph.D., Researcher, University of Maribor, Faculty of Mechanical Engineering, Smetanova ulica 17, 2000 Maribor, Slovenia, e-mail: tomaz.irgolic@um.si. Mihael Brunčko, Ph.D., Assistant Professor, University of Maribor, Faculty of Mechanical Engineering, Smetanova ulica 17, 2000 Maribor, Slovenia, e-mail: mihael.brunčko@um.si.

https://doi.org/10.18690/978-961-286-028-8.18 ISBN 978-961-286-028-8

(C) 2017 University of Maribor Press

Available at: http://press.um.si. 
Ever since its discovery by Davenport and Bain in 1933, bainite has been subject to certain controversy, as the shape of bainitic plates suggest a displacive transformation and jet the transformation kinetics resemble those of a diffusion controlled process. Due to this bainitic microstructures were often defined as a non-lamellar aggregate of ferrite and cementite or as an intermediate product between the pearlite and martensite. Later the terminology was adjusted as different types of bainite have been observed in non-ferrous alloy systems like Ti$\mathrm{Cr}, \mathrm{Cu}-\mathrm{Zn}$ and it is thus defined as.

Within steels different morphologies of bainite can be formed, (i) lath like upper bainite where cementite particles are precipitated at the ferrite lath boundaries, (ii) Plate like lower bainite, which forms in steels with a carbon content above $0.4 \%$ whereby particles of epsilon carbide precipitate within the bainitic ferrite plates (iii) carbide free plate like lower bainite, whereby the precipitation of cementite is suppressed by additions of about $1,5 \% \mathrm{Al}$ and $\mathrm{Si}$, either separate or in combination, alternatively $\mathrm{P}$ can be used in lower strength grades [1], causing the carbon to partition into the adjacent austenite stabilizing it down to room temperature. The latter is of particular interest as the interaction between the plates of bainitic ferrite and the thin films of retained austenite can provide additional ductility as it promotes alternative mechanisms of strain hardening. Depending on its stability, the metastable austenite undergoes a stress/strain induced transformation to martensite, which provides additional local microstructural hardening.

If this retained austenite is present in sufficient quantity (about $30 \%$ ) the resulting transformation induced plasticity effect (TRIP), can delay or even prevent the onset of plastic instability (necking). Carbide free bainitic steels have thus been successfully applied in the automotive industry due to their higher strength combined with sufficiently high formability, and in the production of rails and gears where the retained austenite substantially improve rolling fatigue properties. The formation of this particular morphology is however more time consuming when compared to conventional lower bainite [2], especially when the transformation temperatures are decreased to about $200{ }^{\circ} \mathrm{C}$. Low transformation temperatures of about $200^{\circ} \mathrm{C}$, are however desirable, as they have shown to result in the formation very thin and slender plates of bainite which approach the nanoscale. Nanostructured bainitic steels transformed at $200^{\circ} \mathrm{C}$ for 10 days can achieve tensile strengths of $2500 \mathrm{MPa}$, while maintaining a predominantly uniform elongation of about $10 \%$ [3]. The exceptional combination of tensile properties originates from the very fine scale of the carbide free bainitic microstructure. Such a level of refinement where the bainitic ferrite subunits are only about $20-50 \mathrm{~nm}$ thick is only obtainable by specific alloy design and by transforming at a low temperature. There is in principle no lower limit to the temperatures at which bainite can be formed. But a further decrease, and therefore additional 
microstructural refinement, has to date been vastly impractical as the required annealing times scale exponentially [4].

A useful approach of rationalizing the formation of bainite in steels is by means of physical modeling. To date several models have been proposed, the majority of which attribute certain common features to the nature of carbide free bainite. To the most widely accepted belongs: (i) the formation of bainite is nucleation controlled, (ii) the nucleation occurs via paraequilibrium partitioning of carbon, (iii) once the first plates have formed the reaction proceeds by means of autocatalysis, (iv) the reaction is incomplete at a given transformation temperature as the carbon partitions from the newly formed bainitic ferrite into the adjacent austenite, (v) lastly due to their comparably slow kinetics, bainitic microstructures tend to be formed using isothermal heat treatments, as summarized Table 1.

Table 1: Different models describing the formation of bainite in steels

\begin{tabular}{|c|c|c|c|c|}
\hline MODEL & REF. & $\begin{array}{c}\text { CONTROLLIN } \\
\text { G PROCESS }\end{array}$ & $\begin{array}{c}\text { HEAT } \\
\text { TREATME } \\
\text { NT }\end{array}$ & FEATURES \\
\hline $\begin{array}{c}\text { H. Matsuda et } \\
\text { al. }\end{array}$ & {$[5]$} & $\begin{array}{c}\text { Nucleation } \\
\text { controlled }\end{array}$ & $\begin{array}{c}\text { Isothermal/ } \\
\text { continuous }\end{array}$ & $\begin{array}{c}\text { Autocatalytic nucleation, } \\
\text { incomplete reaction }\end{array}$ \\
\hline M. Azuma et al. & {$[6]$} & $\begin{array}{c}\text { Nucleation } \\
\text { controlled }\end{array}$ & Isothermal & $\begin{array}{c}\text { Autocatalytic nucleation, } \\
\text { incomplete reaction }\end{array}$ \\
\hline $\begin{array}{c}\text { M. J. } \\
\text { Santofimia et } \\
\text { al. }\end{array}$ & {$[7]$} & $\begin{array}{c}\text { Nucleation } \\
\text { controlled }\end{array}$ & Isothermal & $\begin{array}{c}\text { Autocatalytic nucleation, } \\
\text { incomplete reaction }\end{array}$ \\
\hline $\begin{array}{c}\text { S. M.C. Van } \\
\text { Bohemen et al. }\end{array}$ & {$[8]$} & $\begin{array}{c}\text { Nucleation } \\
\text { controlled }\end{array}$ & Isothermal & Autocatalytic nucleation, \\
\hline $\begin{array}{c}\text { G. Sidhu et al. } \\
\text { Ducleation } \\
\text { controlled }\end{array}$ & {$[9]$} & Isothermal & $\begin{array}{c}\text { Autocatalytic nucleation, } \\
\text { incomplete reaction }\end{array}$ \\
\hline Fugarolas et al. & {$[10]$} & $\begin{array}{c}\text { Nucleation } \\
\text { controlled }\end{array}$ & Isothermal & $\begin{array}{c}\text { Autocatalytic nucleation, } \\
\text { incomplete reaction }\end{array}$ \\
\hline
\end{tabular}

Since the formation of bainite nuclei involves the paraequilibrium partitioning of carbon, the rate of nucleation becomes exceedingly sluggish with decreasing temperature. Therefore, nucleation sites would be readily formed at higher temperatures where diffusion of carbon is substantially faster. The essence of the $\mathrm{KAB}$ concept lies in the separation of the nucleation and growth stages in the bainite reaction.

The potential nucleation sites are formed at higher temperatures in the vicinity of precipitates and upon further cooling below the Bs temperature the carbide free bainitic plates start to grow instantly. In such a way, the rapid formation of carbide free lower bainite is obtained at temperatures which are considered staggeringly low. 

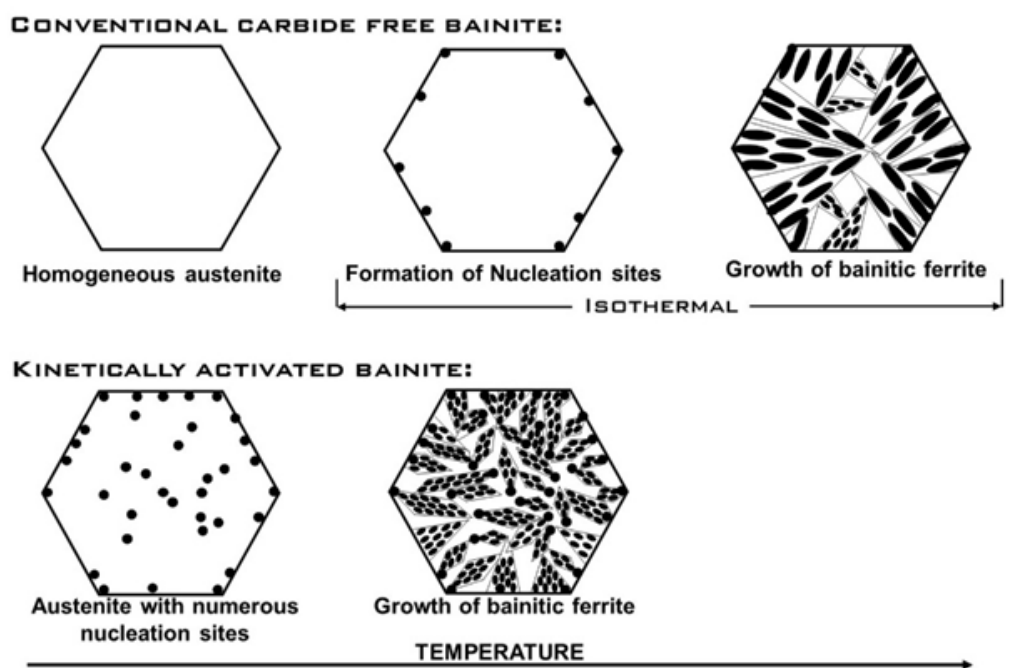

Figure 1: Schematic representation of the concept of bainite formation in kinetically activated bainite $(K A B)$ steels

\section{$2 \quad$ Materials and methods}

The steels compositions were determined with the following considerations; $\mathrm{C}$, $\mathrm{Cr}, \mathrm{Mn}, \mathrm{Mo}, \mathrm{V}$ and $\mathrm{Ni}$ control the transformation temperatures and provide hardenability. Additions were made to the steel KAB 1 as to retard the bainite reaction as little as possible, whereas the formation of martensite was promoted in the second experimental steel by partially suppressing bainite via additions of $\mathrm{Mn}$ [11] and has thus been named KAB Hi-Mn. A sufficiently high total amount of Si and $\mathrm{Al}$ suppresses the precipitation of cementite in both steel $[12,13,1]$, and ensures that carbide free bainite is formed even at a slow cooling rate. A small addition of Mo prevents temper embrittlement in combination with sufficient $\mathrm{C}$ $[14,15]$. $\mathrm{Zr}$ provides better control over the shape of inclusions, and functions together with $\mathrm{V}, \mathrm{Ti}$ and $\mathrm{Al}$ as a grain refining agent [16].

Certain elements have been introduced from the master alloys used or are present as unavoidable impurities. The alloys chemical composition can be seen in Table 1. Critical thermodynamic temperatures such as Bs, Ms $\alpha$ and Ms $\varepsilon$ as well as the temperatures of onset and completion of austenite formation Ac1 and Ac3 respectively, are summarized in Table 2, using equations proposed in $[17,18]$. The Bs and Ms temperatures were calculated using the software mucg83 [19].

Table 2: Steel compositions (in $w \%$ )

\begin{tabular}{|c|c|c|c|c|c|c|c|c|c|c|c|c|c|}
\hline & $\mathrm{C}$ & $\mathrm{Si}$ & $\mathrm{Mn}$ & $\mathrm{Mo}$ & $\mathrm{Cr}$ & $\mathrm{V}$ & $\mathrm{Al}$ & $\mathrm{Ni}$ & $\mathrm{Ti}$ & $\mathrm{Zr}$ & $\mathrm{P}$ & $\mathrm{S}$ & $\mathrm{N}$ \\
\hline KAB 1 & 0.82 & 1.2 & 2.5 & 0.6 & 1.8 & 0.22 & 1.5 & 1 & 0.05 & 0.05 & 0.02 & 0.013 & 0.002 \\
\hline
\end{tabular}


P. Kirbiš, T. Vuherer, T. Irgolič, U. Župerl \& I. Anžel: Chapter 17 Optimization of Single Pass Welding of High Carbon Bainitic

Steel

Table 3: Calculated critical thermodynamic temperatures of the newly developed

\begin{tabular}{|c|c|c|c|c|}
\multicolumn{5}{|c|}{ steels $\left(\right.$ in ${ }^{\circ} \mathrm{C}$ ) } \\
\hline & $\mathrm{Ac}_{1}$ & $\mathrm{Ac}_{3}$ & $\mathrm{Bs}$ & $\mathrm{Ms}$ \\
\hline $\mathrm{KAB} 1$ & 703 & 879 & 240 & 48 \\
\hline
\end{tabular}

The steels were produced using master alloys and pure components, induction melted in vacuum and mold cast under a protective atmosphere of pure argon. The ingots were then homogenized at $1200{ }^{\circ} \mathrm{C}$ for 2 days. After homogenization heat treatment the $\mathrm{KAB}$ steel was hot rolled at $1050{ }^{\circ} \mathrm{C}$ and reduced from $18 \mathrm{~mm}$ to a final thickness of $6 \mathrm{~mm}$, followed by air cooling. Samples were then taken and soft annealed using the slow divorced pearlite reaction heat treatment [20,21].

\section{$2 \quad$ Results and discussion}

The microstructure of the steel after homogenization annealing and hot rolling can be seen in Fig. $1 \mathrm{a}$ and $\mathrm{b}$ respectively. Although the scale of the sheaves is significantly refined via the hot rolling, it can be deduced from the etching response (blue) that bainite is the only phase that has formed, there is also a significant amount of retained austenite present which etches white.

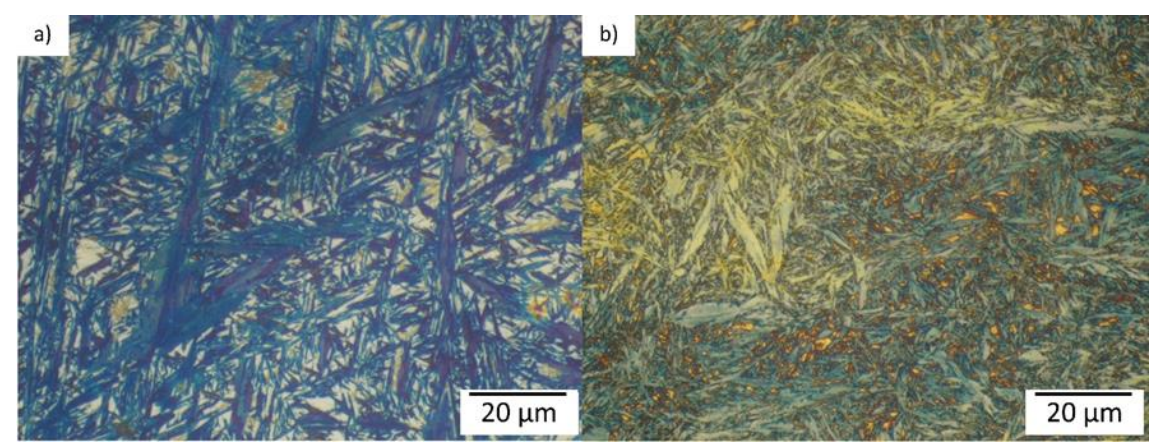

Figure 2: Optical micrographs of the microstructures formed in KAB steels with different grain sizes; a: coarse-grained KAB steel after air cooling showing bainite (blue) and retained austenite (white). $b$ : KAB steel after hot rolling at $1050^{\circ} \mathrm{C}$ and air cooling, bainite (blue) and retained austenite (white)

As can be seen from the higher magnification image in Fig. 3 the sheaves in the hot rolled sample of KAB steel are very fine and reach even submicron sizes, consequently the individual subunits are very short. The microstructure of this rapidly formed continuously cooled bainite is therefore in sharp contrast with isothermally formed low temperature bainite. The microstructure of the latter is characterized by very long and thin individual subunits [22]. The rapid nucleation rate of the sheaves during continuous cooling favors the formation of new sheaves, rather than the growth of existing ones. Sheave lengthening is favored during 
isothermal heat treatments, and proceeds via autocatalytic nucleation of individual subunits.

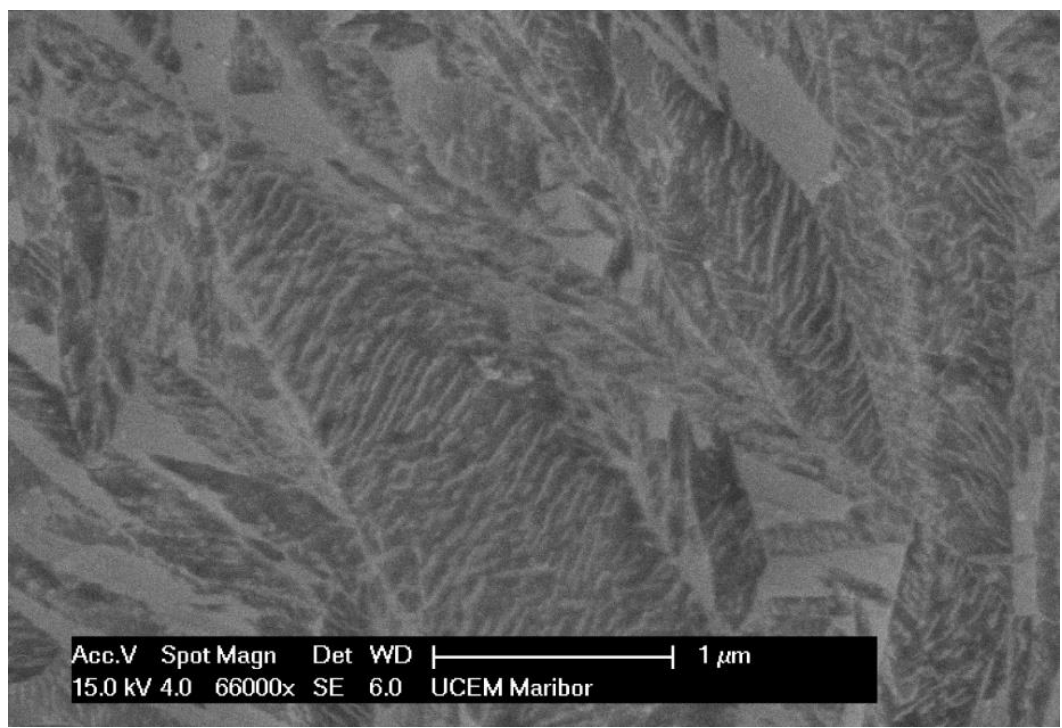

Figure 3: FESEM micrograph of steel KAB 1 after hot rolling

The bainitic ferrite subunits in the newly developed steel are very fine, the coarsest being about $50 \mathrm{~nm}$ thick. From the HRTEM micrograph in Fig.4 a tendency for coagulation of the individual plates can be clearly seen. This is commonly observed when the transformation proceeds with high driving forces [23], aluminum additions also tend to promote this effect. Noteworthy even the thin films of avstenite which were the first to form decomposed into an austenite/ferrite mixture at a lower temperature. 


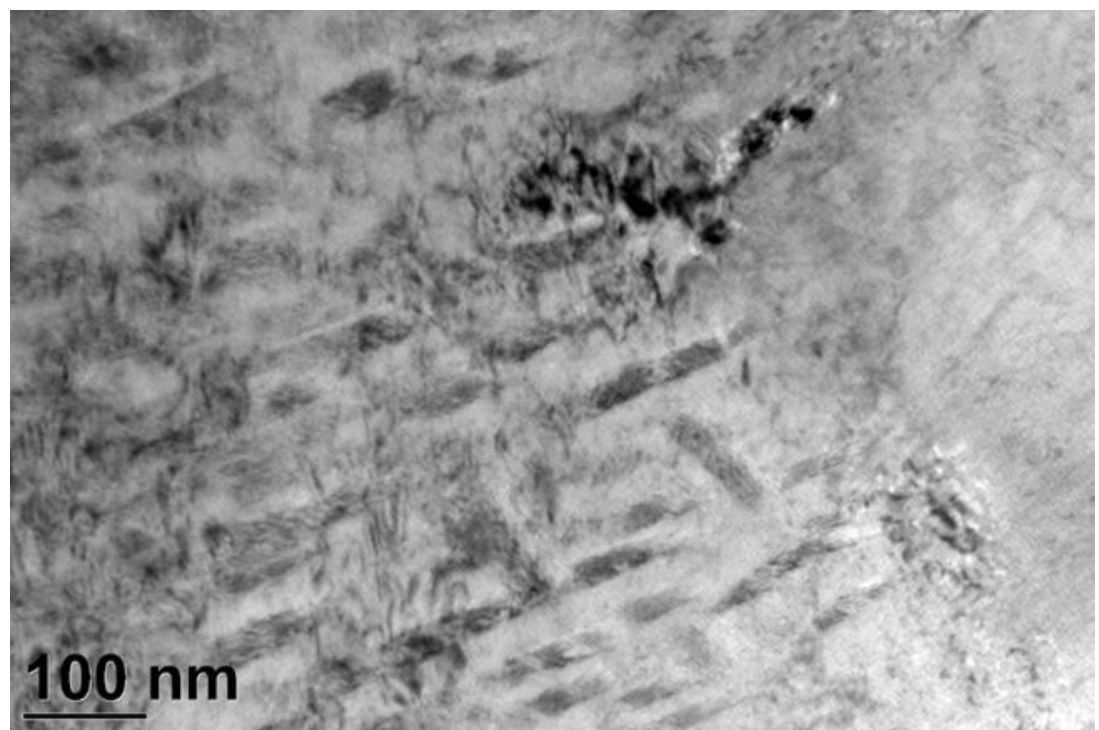

Figure 1: TEM micrograph of steel KAB 1 after hot rolling and air cooling, ferrite is observed dark, austenite light

Non isothermal heat treatments achieve improvements through a greater geometrical division of the retained austenite, caused by the bimodal size distribution of plates. It is reasonable to assume that an increased number of isothermal holding steps would amplify this effect. A continuous cooling transformation can be thought of as a superposition of several short isothermal steps. The formation of bainite during air cooling therefore introduces a similar effect. In the newly developed steel bainite forms very rapidly at staggeringly low temperatures, which makes it highly unlikely that carbon would have time to partition into the adjacent austenite after or during the initial formation of bainitic ferrite. The growth rate is known to be significantly slower compared to martensite [24], and some studies suggest the diffusion of carbon occurs during growth of bainitic ferrite plates [25-27]. The latter seems unlikely when bulk diffusion is considered, which strongly supports the view that the bainite forms via a displacive mechanism.

From the tensile curve in Fig. 5, continuous yielding and a predominantly uniform elongation are clearly visible. This indicates a pronounced TRIP effect that enables the steel to retain its work hardening capacity even at such high strength levels. The latter is indicative that the retained austenite has a sufficiently high stability, which originates mostly from its fine size. Analogous to other low temperature bainitic steel grades the strength arises from the very fine microstructure, but there is also thought to be a contribution from the fine scale of the sheaves themselves. 


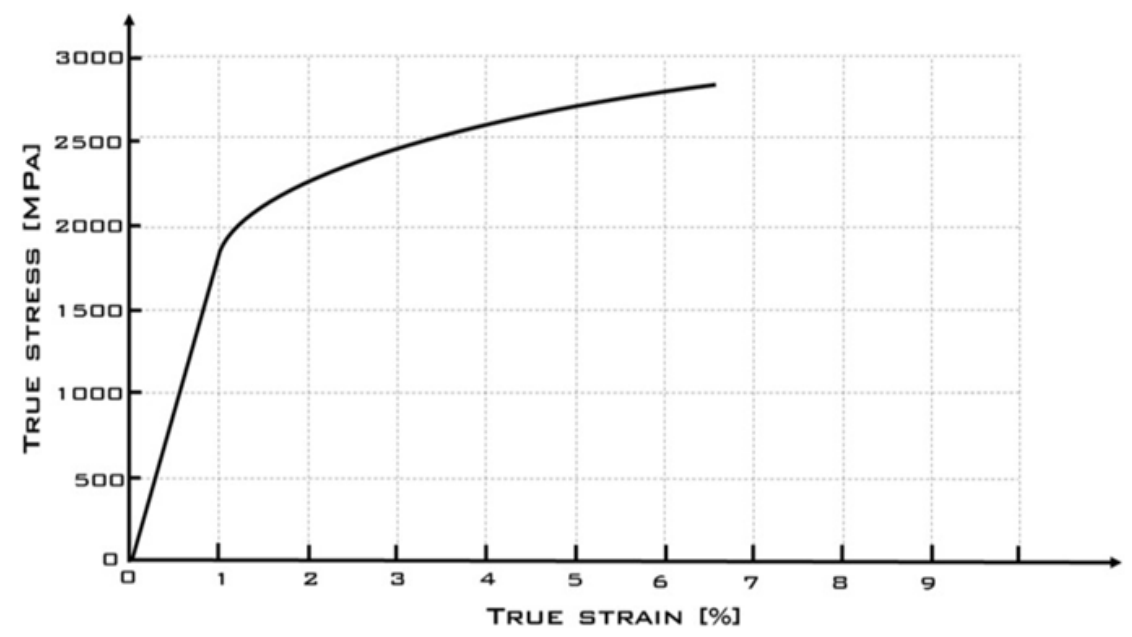

Figure 5: True stress/true strain curve of KAB steel after hot rolling

\section{$4 \quad$ Conclusion}

The concept of kinetic activation of the bainite reaction - KAB, was successfully applied to the design of an experimental high carbon steel. The microstructure was characterized using different methods which have conclusively confirmed carbide free bainite upon air cooling, with no detectable martensite or carbide precipitation. Observations using HRTEM have shown a very fine scale of the bainitic ferrite plates, which correspond well with the low calculated transformation temperatures. The measured tensile properties are slightly higher when compared to similar steels from the literature, which is most likely due to the continuous character of the transformation, whereby a larger amount of retained austenite has decomposed. Further work should be aimed towards the characterization of deformed microstructures and a detailed analysis of the deformation mechanism of the retained austenite phase. Additionally larger ingots should be casted to assert the repeatability of the current mechanism in an industrial environment.

\section{References}

[1] B.C. De Cooman, Structure-properties relationship in TRIP steels containing carbidefree bainite, Curr. Opin. Solid State Mater. Sci. 8 (2004) 285-303.

[2] S. Khare, K. Lee, H.K.D.H. Bhadeshia, Carbide-free bainite: Compromise between rate of transformation and properties, Metall. Mater. Trans. A Phys. Metall. Mater. Sci. 41 (2010) 922-928.

[3] C. Garcia-Mateo, F.G. Caballero, H.K.D.H. Bhadeshia, Development of Hard Bainite, ISIJ Int. 43 (2003) 1238-1243. doi:10.2355/isijinternational.43.1238. 
[4] H.K.D.H. Bhadeshia, Very Short and Very Long Heat Treatments in the Processing of Steel, Mater. Manuf. Process. 25 (2010) 1-6.

[5] H. Matsuda, H.K.D.H. Bhadeshia, Kinetics of the bainite transformation, Proc. R. Soc. A Math. Phys. Eng. Sci. 460 (2004) 1707-1722. doi:10.1098/rspa.2003.1225.

[6] M. Azuma, N. Fujita, M. Takahashi, T. Iung, Modelling Upper and Lower Bainite Transformation in Steels, Mater. Sci. Forum. 426-432 (2003) 1405-1412.

[7] M.J. Santofimia, F.G. Caballero, C. Capdevila, C. García-Mateo, C.G. De Andrés, New Model for the Overall Transformation Kinetics of Bainite. Part 1: the Model, Mater. Trans. 47 (2006) 2465-2472.

[8] J.S. S. M. C. van Bohemen, Modeling of isothermal bainiteformation based on the nucleation kinetics, Int. J. Mat. Res. 99 7. (2008).

[9] G. Sidhu, S.D. Bhole, D.L. Chen, E. Essadiqi, An improved model for bainite formation at isothermal temperatures, Scr. Mater. 65 (2011) 373-375.

[10] D. Gaude-Fugarolas, P.J. Jacques, A New Physical Model for the Kinetics of the Bainite Transformation, ISIJ Int. $46 \quad$ (2006) 712-717. doi:10.2355/isijinternational.46.712.

[11] T. Sourmail, V. Smanio, Low temperature kinetics of bainite formation in high carbon steels, Acta Mater. 61 (2013) 2639-2648.

[12] E. Kozeschnik, H.K.D.H. Bhadeshia, Influence of silicon on cementite precipitation in steels, Mater. Sci. Technol. 24 (2008) 343-347.

[13] J. Slycken, P. Verleysen, J. Degrieck, J. Bouquerel, B.C. Cooman, The effect of silicon, aluminium and phosphor on the dynamic behavior and phenomenological modelling of multiphase TRIP steels, Met. Mater. Int. 13 (2007) 93-101.

[14] A.I. Kovalev, T.K. Sergeeva, D.A. Litvinenko, Segregation of impurities, temper brittleness, and hydrogen embrittlement of steeL 30KHnma with different concentrations of molybdenum, Met. Sci. Heat Treat. 37 (1996) 196-199.

[15] V. V. Zabil'skii, Temper embrittlement of structural alloy steels (review), Met. Sci. Heat Treat. Volume 29 (1987) 24-32.

[16] T.N. Baker, Processes, microstructure and properties of vanadium microalloyed steels, 25 (2009) 1083-1107.

[17] O.G. Kasatkin, B.B. Vinokur, V.L. Pilyushenko, Calculation models for determining the critical points of steel, Met. Sci. Heat Treat. 26 (1984) 27-31.

[18] H.S. Yang, J.H. Jang, H.K.D.H. Bhadeshia, D.W. Suh, Critical assessment: Martensite-start temperature for the $\gamma \rightarrow \varepsilon$ transformation, Calphad Comput. Coupling Phase Diagrams Thermochem. 36 (2012) 16-22.

[19] H.K.D.H. Bhadeshia, Thermodynamic analysis of isothermal transformation diagrams, Met. Sci. 16 (1982) 159-165.

[20] D. Luo, M.J. Peet, S.W. Ooi, P. Yan, Z. Yin, H.K.D.H. Bhadeshia, Spheroidisation of hypereutectoid state of nanostructured bainitic steel, Mater. Sci. Technol. 30 (2014) 1282-1286.

[21] a. S. Pandit, H.K.D.H. Bhadeshia, Divorced pearlite in steels, Proc. R. Soc. A Math. Phys. Eng. Sci. 468 (2012) 2767-2778.

[22] H.K.D.H. Bhadeshia, Nanostructured bainite, Proc. R. Soc. A Math. Phys. Eng. Sci. 466 (2010) 3-18.

[23] H.K.D.H.B. Chang L. C., Microstructure of lower bainite formed at large undercoolings below bainite start temperature, Mater. Sci. Technol. 12 (1996) 233236.

[24] M. Kang, M.X. Zhang, M. Zhu, In situ observation of bainite growth during isothermal holding, Acta Mater. 54 (2006) 2121-2129. 
[25] M. Hillert, Diffusion in growth of bainite, Metall. Mater. Trans. A. 25 (1994) 19571966.

[26] G.J. Shiflet, R.E. Hackenberg, Partitioning and the growth of bainite, Scr. Mater. 47 (2002) 163-167.

[27] A.B.M.H.J. Ågren, Metallographic evidence of carbon diffusion in the growth of bainite, Acta Mater. Volume 57 (2009). 


\section{Editorial review}

\section{Editors:}

\section{Prof. Franc CUS̆, PhD}

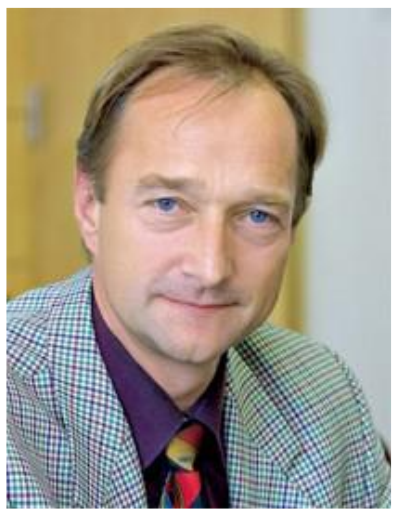

Prof. CUS has studied mechanical engineering and economics at University of Maribor. Since the year 2000, he became full professor and head of the Production Engineering Institute at the Faculty of mechanical engineering, University Maribor. He is the author of over 140 original scientific papers and over 220 papers in peer reviewed international scientific conferences covering production technology, intelligent manufacturing and advanced cutting technologies. He has been invited lecturer in several international scientific conferences and at foreign universities.

Trainings: Specialization at the Technical University in Graz, Darmstadt, Vienna, Torino, postgraduate study TU Darmstadt and at the International Cooperation Agency in Tokyo, in the area of the Japanese industrial policy. He is the president of the Commission for Quality Assurance, University Maribor and member of the Council of Slovenian Quality Assurance Agency for Higher Education (Slovenian Ministry of Science and Technology). He was General Secretary and Vice rector at the University of Maribor, founder and head of Styrian Technology Park Maribor. He founded Maribor Development Agency. 


\section{Prof. Valentina GECEVSKA, PhD}

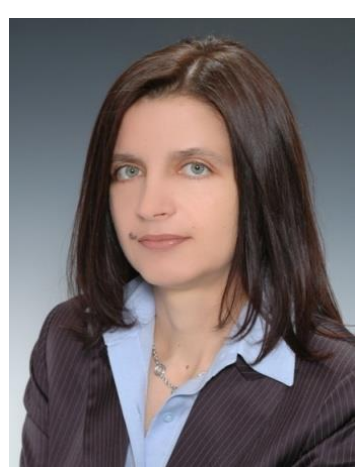

Prof. GECEVSKA is a professor at Institute of Production Engineering and Management, at the Faculty of Mechanical Engineering in frame of Ss. Cyril and Methodius University in Skopje, Republic of Macedonia. She is founder and head of Product Lifecycle Management Center, WEBLAB e-Learning Training Center and CIM Laboratory. Her academic and scientific fields of interest are in production engineering, industrial engineering and management engineering. She is author of over 80 original scientific papers and over 180 papers published in peer reviewed international scientific conferences. She has been visiting professor at several foreign universities and invited lecturer at several international scientific conferences.

Trainings: specializations at the technical universities in Portland, Maribor, Vienna, Bochum, Florence, postdoctoral studies at Technical University in Turin, production management at International Cooperation Agency of Japan in Tokyo, Sapporo, Kyoto. Team member for development of regional R\&D Innovation strategy and industrial policy. Leader or team member of over than 50 international research and educational projects supported by different programmes: FP7, Tempus, EAR, WB, CEI, ADA, CEEPUS, Erasmus. 